$$
\begin{gathered}
\text { UNIVERSIDADE DE SÃO PAULO } \\
\text { INSTITUTO DE QUÍMICA DE SÃO CARLOS } \\
\text { PROGRAMA DE PÓS-GRADUAÇÃO EM QUÍMICA }
\end{gathered}
$$

\title{
AVALIAÇÃO DO DESEMPENHO DE CATALISADORES OBTIDOS DE HIDROTALCITAS NA REFORMA SECA DO METANO
}

DÉBORA MORAIS BEZERRA 


\section{AVALIAÇÃO DO DESEMPENHO DE CATALISADORES OBTIDOS DE HIDROTALCITAS NA REFORMA SECA DO METANO}

Tese apresentada ao Programa de Pós Graduação em Química do Instituto de Química de São Carlos da Universidade de São Paulo - Brasil como parte dos requisitos para obtenção do título de Doutor em Ciências.

Área de concentração: Físico-Química

Orientadora: Prof ${ }^{\mathrm{a}}$. Dr ${ }^{\mathrm{a}}$. Elisabete Moreira Assaf 
Autorizo a reprodução e divulgação total ou parcial deste trabalho, por qualquer meio convencional ou eletrônico para fins de estudo e pesquisa, desde que citada a fonte.

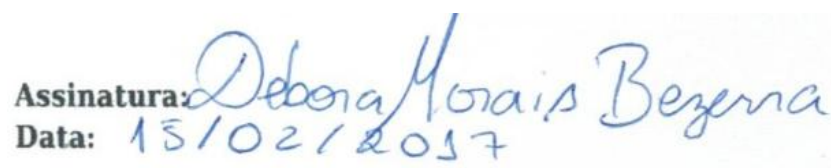

\section{Bezerra, Débora Morais}

Avaliaçào do desempenho de catalisadores obtidos de hidrotalcitas na reforma seca do metano / Débora Morais Bezerra. - São Carlos. 2017. $152 \mathrm{f}$.

Tese (Doutorado em Físico-Química) - Instituto de Química de Sào Carlos I Universidade de São Paulo, 2017.

Ediçăo revisada

Orientadora: Profa. Dra. Elisabete Moreira Assaf

1. Catálise. t. Título. 


\section{AGRADECIMENTOS}

Gostaria de agradecer a Deus por todos os momentos maravilhosos que tenho tido em minha vida e oportunidade de estar aqui.

Ao Instituto de Química de São Carlos-USP, pela oportunidade de realização do curso de doutorado em Físico-Química.

À Coordenação de Aperfeiçoamento de Pessoal de Nível Superior (CAPES), pela concessão da bolsa de doutorado e pelo apoio financeiro para a realização desta pesquisa.

Aos meus amados pais, Francisco De Paula e Maria José, pela educação, pelo grande incentivo aos estudos e por estarem sempre dispostos a me proporcionar os melhores caminhos.

Ao meu João Elias pelo carinho, companheirismo, amizade e, por todo esse tempo estarmos juntos firmes e fortes nessa batalha.

Aos meus queridos irmãos, Paulo e Flank, pela amizade, carinho e por estarem sempre ajudando quando preciso.

A Profa. Dr Elisabete Moreira Assaf, pelas sugestões que sempre foram muito válidas e pela a orientação ao longo dessa pesquisa, contribuindo para meu crescimento científico e intelectual.

Aos membros do laboratório de catálise heterogênea, Alessandra, Ana Maria, Aline, Fernando Geogeti, Francielle, Gabriela, Guilherme, Kariny, Luciano, Thaisa e Vivian.

Ao técnico do IQSC, Aldimar Tadeu Jesuino Constante pelas medidas de infravermelho e pelas conversas sempre agradáveis.

À todos vocês, muito obrigada por tudo. 
Se choro, quando choro, e minha lágrima cai

É pra regar o capim que alimenta a vida

Chorando eu refaço as nascentes que você secou Se desejo, o meu desejo faz subir marés de sal e sortilégio Vivo de cara pra o vento na chuva, e quero me molhar O terço de Fátima e o cordão de Gandhi cruzam o meu peito Sou como a haste fina, que qualquer brisa verga, mas nenhuma espada corta Não mexe comigo, que eu não ando só

Eu não ando só, que eu não ando só

Não mexe não!

Trecho da Música Carta de amor, Letra de Maria Bethânia.

Descansem o meu leito solitário; Na floresta dos homens esquecida, Á sombra de uma cruz, e escrevam nela: -Foi poeta-sonhou- e amou a vida.

Sombras do vale, noites da montanha, Que minha alma cantou e amava tanto,

Protegei o meu corpo abandonado, E no silêncio derramai-lhe canto!

\section{Trecho da Poesia Lembrança de Morrer,}

Álvares de Azevedo.

"O tempo é uma das razões nobre do homem; saber preenchê-lo é saber conquistado"

\section{De Paula}




\section{RESUMO}

Catalisadores ativos e estáveis, preparados a partir dos hidróxidos duplos lamelares (HDLs) contendo os cátions $\mathrm{Ni}^{2+}, \mathrm{Zn}^{2+}, \mathrm{Al}^{3+}$ e $\mathrm{Zr}^{4+}(\mathrm{NiZn}-\mathrm{Al}$, NiZn-AlZr e NiZn-Zr), foram avaliados na reação de reforma seca do metano. Os precursores foram caracterizados por difração de raios $\mathrm{X}$, confirmando a formação das fases para as amostras de NiZn-Al e NiZn-AlZr. As espectroscopias no infravermelho/Raman elucidaram a ocorrência dos ânions $\left(\mathrm{CO}_{3}{ }^{2-}\right)$ e das moléculas de água na intercamada. A Fisissorção de nitrogênio ( método de BET) determinou a presença de poros e a área superficial específica. As formas das isotermas foram do tipo IV, de acordo com a IUPAC, e representa uma estrutura mesoporosa. A análise termogravimétrica foi utilizada para determinar a temperatura de calcinação dos precursores para obtenção dos catalisadores e as temperaturas utilizadas foram $550{ }^{\circ} \mathrm{C}, 650{ }^{\circ} \mathrm{C}$ e $750{ }^{\circ} \mathrm{C}$. Os resultados de difração de raios $\mathrm{X}$ dos catalisadores apresentaram uma mistura de óxidos binários $(\mathrm{NiO}$, $\mathrm{ZnO}, \mathrm{ZrO}_{2}$ e $\left.\mathrm{Al}_{2} \mathrm{O}_{3}\right)$ e óxidos ternários $\left(\mathrm{NiAl}_{2} \mathrm{O}_{4}\right.$ e $\left.\mathrm{ZnAl}_{2} \mathrm{O}_{4}\right)$. As fases de espinélios foram observadas nos catalisadores obtidos a $650^{\circ} \mathrm{C}\left(\mathrm{Ni} / \mathrm{ZnAl}-6\right.$ e Ni/ZnAlZr-6) e $750^{\circ} \mathrm{C}(\mathrm{Ni} / \mathrm{ZnAl}-$ 7 e Ni/ZnAlZr-7). A redução a temperatura programada de hidrogênio $\left(\mathrm{TPR}-\mathrm{H}_{2}\right)$ forneceu informações sobre a redução do catalisador. Os resultados exibiram interações entre a fase ativa com as outras fases presentes no intervalo entre $350-800{ }^{\circ} \mathrm{C}$, enquanto que a dessorçãoàtemperatura programada de $\mathrm{CO}_{2}\left(\mathrm{DTP}-\mathrm{CO}_{2}\right)$ mostrou que os catalisadores possuem sítios básicos fracos. Ademais, os catalisadores foram caracterizados por fisissorção de nitrogênio, microscopia eletrônica de varredura (MEV), espectroscopia Raman e basicidade usando um indicador de Hammett. O desempenho dos catalisadores foi avaliado na reação de reforma seca do metano utilizando uma razão molar de alimentação de $\mathrm{CH}_{4}: \mathrm{CO}_{2}=1,5: 1,0$; a fim de simular a composição do biogás. Os resultados mostraram uma maior conversão para o $\mathrm{CO}_{2}$ em todos os catalisadores investigados, o que pode ser atribuído ao maior teor de $\mathrm{CH}_{4}$ alimentado. Além disso, é importante ressaltar a contribuição dos sítios básicos presentes nas amostras, o que pode também contribuir para a conversão do $\mathrm{CO}_{2}$. A maior conversão de $\mathrm{CH}_{4}$ foi observada para os catalisadores tratados a $750{ }^{\circ} \mathrm{C}$. Após as reações, foi observada a formação de carbono grafite sobre todos os catalisadores, com menor percentual para a amostra $\mathrm{Ni} / \mathrm{ZnAl}$, calcinadas a $550{ }^{\circ} \mathrm{C}$ e $650{ }^{\circ} \mathrm{C}$, e Ni/ZnZr-7, calcinada a $750{ }^{\circ} \mathrm{C}$. Finalmente, os catalisadores calcinados a $650{ }^{\circ} \mathrm{C}$ e $750{ }^{\circ} \mathrm{C}$ também foram ativados na temperatura de $750^{\circ} \mathrm{C}$ e os resultados reacionais mostraram que essa temperatura favoreceu o processo de aglomeração e, portanto, promoveu baixas conversões para o $\mathrm{CH}_{4}$ e $\mathrm{CO}_{2}$. 


\begin{abstract}
Active and stable catalysts, prepared from the lamellar double hydroxides (HDLs) containing the cations $\mathrm{Ni}^{2+} \mathrm{Zn}^{2+}, \mathrm{Al}^{3+}$ and $\mathrm{Zr}^{4+}(\mathrm{NiZn}-\mathrm{Al}, \mathrm{NiZn}-\mathrm{AlZr}$ and $\mathrm{NiZn}-\mathrm{Zr})$ were evaluated in the dry reforming reaction of methane. The precursors were characterized by X-ray diffraction method, confirming the formation of phases for NiZn-Al and NiZn-AlZr samples. Infrared / Raman spectroscopies elucidated the occurrence of anions $\left(\mathrm{CO}_{3}{ }^{2-}\right)$ and water molecules in the interlayer. Nitrogen physisorption (BET method) determined the presence of pores and the specific surface area. The shape of the isotherms were type IV, according to the IUPAC, representing a mesoporous structure. The thermogravimetric analysis was used to determine the calcination temperature of the precursors to obtain the catalysts and the temperatures used were $550{ }^{\circ} \mathrm{C}, 650^{\circ} \mathrm{C}$ and $750{ }^{\circ} \mathrm{C}$. The X-ray diffraction results of the catalysts showed a mixture of binary oxides $\left(\mathrm{NiO}, \mathrm{ZnO}, \mathrm{ZrO}_{2}\right.$ and $\left.\mathrm{Al}_{2} \mathrm{O}_{3}\right)$ and ternary oxides $\left(\mathrm{NiAl}_{2} \mathrm{O}_{4}\right.$ and $\left.\mathrm{ZnAl}_{2} \mathrm{O}_{4}\right)$. The spinel phases were observed in the catalysts obtained at $650{ }^{\circ} \mathrm{C}(\mathrm{Ni} / \mathrm{ZnAl}-6$ and $\mathrm{Ni} / \mathrm{ZnAlZr}-6)$ and $750^{\circ} \mathrm{C}(\mathrm{Ni} / \mathrm{ZnAl}-7$ and Ni/ZnAlZr-7) Temperature- programmed reduction with hydrogen $\left(\mathrm{H}_{2}-\mathrm{TPR}\right)$ provided information on catalyst reduction. The results showed interactions between the active phase and the other phases present in the range of 350 $-800{ }^{\circ} \mathrm{C}$, while temperature- programmed desorption of $\mathrm{CO}_{2}\left(\mathrm{CO}_{2}\right.$-TPD) showed that the catalysts have weak basic sites. In addition, the catalysts were characterized by Nitrogen physisorption, scanning electron microscopy (SEM), Raman spectroscopy and basicity using a Hammett indicator. The performance of the catalysts was evaluated in the dry reforming reaction of the methane using a $\mathrm{CH}_{4}: \mathrm{CO}_{2}$ molar feed ratio $=1.5: 1.0$; In order to simulate the biogas composition. The results showed a higher conversion to $\mathrm{CO}_{2}$ in all the catalysts investigated, which can be attributed to the higher content of $\mathrm{CH}_{4}$ fed. In addition, it is important to restate the contribution of the basic sites present in the samples, which may also contribute to the conversion of $\mathrm{CO} 2$. The higher conversion of $\mathrm{CH}_{4}$ was observed for the catalysts treated at $750{ }^{\circ} \mathrm{C}$. After the reactions, the formation of graphite carbon was observed on all the catalysts, with a lower percentage for $\mathrm{Ni} / \mathrm{ZnAl}$ samples, calcined at $550^{\circ} \mathrm{C}$ and $650^{\circ} \mathrm{C}$, and $\mathrm{Ni}$ / ZnZr-7, calcined at $750^{\circ} \mathrm{C}$. Finally, the catalysts calcined at $650^{\circ} \mathrm{C}$ and $750^{\circ} \mathrm{C}$ were also activated at the temperature of $750{ }^{\circ} \mathrm{C}$. and the reaction results showed that this temperature favored the agglomeration process and, therefore, promoted low conversions for $\mathrm{CH}_{4}$ and $\mathrm{CO}_{2}$.
\end{abstract}




\section{LISTA DE FIGURAS}

Figura 1 - Representação da formação do filamento de carbono.

Figura 2 - (a) Histograma de artigos publicados e indexados por ano pela Scopus; (b) Distribuição em porcentgem (\%) dos primeiros doze países que mais publicaram na temática reforma seca do metano, onde mostramos a participação do Brasil com $\sim 4,31 \%$. Na pesquisa, as expressões 'dry reforming of the methane' foram utilizadas.

Figura 3 - Representação esquemática da estrutura dos hidóxidos duplos lamelares ( HDL's).

Figura 4 - Representação do efeito memória que ocorre nos hidróxidos duplos lamelares (HDL's).

Figura 5 - Esquema do aparato experimental para uma preparação por coprecipitação a pH constante.

Figura 6 - Diagrama de preparação dos precursores tipo hidrotalcitas e catalisadores pelo método de co-precipitação química, onde se ilustra cada etapa do processo: Precipitação (1. ${ }^{\circ}$ PASSO); Decantação (2. PASSO); Filtração (3. ${ }^{\circ}$ PASSO); Lavagem (4. ${ }^{\circ}$ PASSO); Secagem (5. ${ }^{\circ}$ PASSO); Maceração ( $6 .^{\circ}$ PASSO) e Tratamento térmico para obtenção dos catalisadores (7. $\left.{ }^{\circ} \mathrm{PASSO}\right)$.

Figura 7 - Metodologia utilizada para a realização do teste de efeito memória na presença da solução de $\mathrm{Na}_{2} \mathrm{CO}_{3}$.

Figura 8 - (a) Esquema geral de um tubo de raios $X$ (b) Espectros de raios $X$ contínuo e característico.

Figura 9 - Representação da propagação de feixes de raios X em camadas de átomos como planos de reflexão.

Figura 10 - Ilustração esquemática dos componentes de um difratômetro de raios X............44

Figura 11 - Modelo do ajuste dos picos usando Fityk com a função Pseudo Voig.

Figura 12 - Espalhamento da luz: (I) espalhamento elástico (Rayleigh); (II) espalhamento inelástico (região Stokes) (III) e espalhamento inelástico ( região anti-stokes).

Figura 13 - Banda Rayleigh, banda Raman-Stokes e banda Raman-antiStokes. 48

Figura 14 - Diagrama ilustrando o sistema de espectroscopia Raman.

Figura 15 - Curvas de TG e DTG do precursor de Zinco obtido pelo método de coprecipitação.

Figura 16 - Esquema dos componentes do TG.

Figura 17 - Perfil de RTP- $\mathrm{H}_{2}$ do padrão utilizado de $\mathrm{Ag}_{2} \mathrm{O}$ para a quantificação do consumo de $\mathrm{H}_{2}$ nas análises dos catalisadores 
Figura 18 - Sistema utilizado para determinação da basicidade pelo método de titulação. ...57

Figura 19 - (a) Representação de um feixe de elétrons ao colidir com a superfície da amostra desencadeando uma série de processos; (b) Canhão eletrônico tradicional com filamento de tungstênio.

Figura 20 - Esquema do sistema catalítico. Os números destacados em amarelo correspondem os componentes da linha: (1) Linha de gás; (2) Controlador com as válvulas dos gases utilizados na redução $\left(\mathrm{H}_{2}\right)$ e reação $\left(\mathrm{N}_{2}, \mathrm{CH}_{4}\right.$ e $\left.\mathrm{CO}_{2}\right)$.; (3) Forno (4) Condensador; (5) Cromatógrafo e (6) Computador.

Figura 21 - Padrões de difração de raios X dos precursores NiZn-AlZr, NiZn-Al e NiZn-Zr. $O$ detalhe da figura ilustra a estrutura em camadas típicas de HDL's. O segundo detalhe traz o deslocamento referente ao pico (012).

Figura 22 - Padrões de difração de raios X dos precursores de NiZn-Zr, Zinco, Níquel e Zircônio.

Figura 23 - Polítipos para as estruturas HDL's: (a) politipo romboédrico 3R e (b) politipo hexagonal $2 \mathrm{H}$. No caso romboédrico, $\mathrm{c}=3 \mathrm{~d}_{(003)}$. Por outro lado, $\mathrm{c}=2 \mathrm{~d}_{(003)}$ para o polítipo hexagonal.

Figura 24 - Espectros de infravermelho por transformada de Fourier dos precursores (a) NiZn-Al, (b) NiZn-AlZr e (c) NiZn-Zr coletados à temperatura no modo de absorbância. No detalhe, as decomposições por funções Gaussianas foram conduzidas visando à obtenção dos centros das bandas pertinentes às vibrações das hidroxilas.

Figura 25 - Espectros Raman à temperatura ambiente dos precursores NiZn-Al, NiZn-AlZr e NiZn-Zr. Número no top de cada banda indica a posição aproximada de seu centro 70

Figura 26 - Isotermas de adsorção para os precursores (NiZn-Al, NiZn-AlZr e NiZn-Zr ), onde (I) representa adsorção (condensação dos líquidos nos poros) e II a dessorção (evaporação dos líquidos nos poros) partir das quais foram determinado os valores das áreas superficiais específicas pelo método de BET. Detalhe: distribuição de tamanho dos poros (BJH, ramo dessorção de isotérmica).

Figura 27 - (a) Imagem representativa da microscopia eletrônica de varredura do precursor $\mathrm{NiZn-Al;} \mathrm{(b)} \mathrm{Distribuição} \mathrm{das} \mathrm{partículas} \mathrm{utilizando} \mathrm{o} \mathrm{image} \mathrm{J.}$

Figura 28 - (a) Imagem representativa da microscopia eletrônica de varredura do precursor NiZn-AlZr; (b) Distribuição das partículas utilizando o image J

Figura 29 - (a) Imagem representativa da microscopia eletrônica de varredura do precursor NiZn-Zr; (b) Distribuição das partículas utilizando o image J.

Figura 30 - Imagens representativas da microscopia eletrônica de transmissão dos precursores NiZn-Al, NiZn-AlZr and NiZn-Zr. As setas indicam a formação das plaquetas hexagonais presentes nas amostras

Figura 31 - Perfis de perda de massa (TG) e sua derivada (DTG) para os precursores de NiZn-Al. A quantificação porcentual da perda e sua respectiva atribuição seguem sumarizadas na Tabela 13 
Figura 32 - Perfis de perda de massa (TG) e sua derivada (DTG) para os precursores de NiZn-AlZr. A quantificação porcentual da perda e sua respectiva atribuição seguem sumarizadas na Tabela 13 ....

Figura 33 - Perfis de perda de massa (TG) e sua derivada (DTG) para os precursores de NiZn-Zr. A quantificação porcentual da perda e sua respectiva atribuição seguem sumarizadas na Tabela 13.

Figura 34 - Padrões de difração de raios $\mathrm{X}$ do precursor NiZn-Al; do pó resultante da desintegração deste precursor a $500{ }^{\circ} \mathrm{C}$; dos precursores submetidos ao efeito memória em diferentes concentrações de carbonato de sódio, (I) 0,5 M; (II) 1M e (III) $2 \mathrm{M}$. Os símbolos $\alpha \mathrm{e}$ $\beta$ denotam a ocorrência das fases de $\mathrm{ZnO}$ e $\mathrm{NiO}$ nos catalisadores.

Figura 35 - Padrões de difração de raios X do precursor NiZn-AlZr; do pó resultante da desintegração deste precursor a $500{ }^{\circ} \mathrm{C}$; dos precursores submetidos ao efeito memória em diferentes concentrações de carbonato de sódio, a saber, (I) 0,5 M; (II) $1 \mathrm{M}$ e (III) $2 \mathrm{M}$. Os símbolos $\alpha$ e $\beta$ denotam a ocorrência das fases de $\mathrm{ZnO}$ e $\mathrm{NiO}$ nas amostras. 80

Figura 36 - Padrões de difração de raios $\mathrm{X}$ do precursor NiZn-Zr; do pó resultante da desintegração deste precursor a $500{ }^{\circ} \mathrm{C}$; dos precursores submetidos ao efeito memória em diferentes concentrações de carbonato de sódio, a saber, (I) 0,5 M; (II) $1 \mathrm{M}$ e (III) $2 \mathrm{M}$. Os símbolos $\alpha$ e $\beta$ denotam a ocorrência das fases de $\mathrm{ZnO}$ e $\mathrm{NiO}$ nas amostras.

Figura 37 - Padrões de difração de raios $X$ dos catalisadores Ni/ZnAl-5 (I), Ni/ZnAlZr-5 (II) e Ni/ZnZr-5(III), além dos óxidos binários $\mathrm{ZnO}, \mathrm{NiO}$ e $\mathrm{ZrO}_{2}$. Os símbolos $\alpha, \beta$ e $\lambda$ denotam a ocorrência das fases de $\mathrm{ZnO}, \mathrm{NiO}$ e $\mathrm{ZrO}_{2}$ nos catalisadores, respectivamente. . .84

Figura 38 - Padrões de difração de raios $X$ dos catalisadores Ni/ZnAl-6 (I), Ni/ZnAlZr-6 (II) e Ni/ZnZr-6 (III), além dos óxidos binários $\mathrm{ZnO}, \mathrm{NiO} \mathrm{Al}_{2} \mathrm{O}$ e $\mathrm{ZrO}_{2}$. Os símbolos $\alpha, \beta, \lambda$, $\phi$ e $\gamma$ denotam a ocorrência das fases de $\mathrm{ZnO}, \mathrm{NiO}, \mathrm{ZrO}_{2}, \mathrm{Al}_{2} \mathrm{O}_{3}$ e $\mathrm{ZnAl}_{2} \mathrm{O}_{4}$ nos catalisadores, respectivamente.

Figura 39 - Padrões de difração de raios $X$ dos catalisadores Ni/ZnAl-7 (I), Ni/ZnAlZr-7 (II) e Ni/ZnZr-7 (III), além dos óxidos binários $\mathrm{ZnO}, \mathrm{NiO}, \mathrm{Al}_{2} \mathrm{O}_{3}$ e $\mathrm{ZrO}_{2}$. Os símbolos $\alpha, \beta, \lambda$, $\phi$, $\delta$ e $\gamma$ denotam a ocorrência das fases de $\mathrm{ZnO}, \mathrm{NiO}, \mathrm{ZrO}_{2}, \mathrm{Al}_{2} \mathrm{O}_{3}, \mathrm{NiAl}_{2} \mathrm{O}_{4}$ e $\mathrm{ZnAl}_{2} \mathrm{O}_{4}$ nos catalisadores, respectivamente. $\mathrm{O}$ detalhe na figura ilustra a distribuição de picos no intervalo $2 \theta$ de $27^{\circ}$ a $39^{\circ}$, no qual as setas de cor preta evidenciam a ocorrência das fases $\mathrm{Al}_{2} \mathrm{NiO}_{4} \mathrm{e}$ $\mathrm{Al}_{2} \mathrm{ZnO}_{4}$ no catalisador $\mathrm{Ni} / \mathrm{ZnAlZr}-7$.

Figura 40 - Perfis de redução dos catalisadores tratados termicamente a $550^{\circ} \mathrm{C}$ por $15 \mathrm{~h}$. Os pontos representa os dados experimentais e a linha vermelha o ajuste da curva por uma soma de funções gaussiana. $\mathrm{O}$ número sobre cada pico indica a temperatura aproximada de redução.

Figura 41 - (a) Perfis de redução dos catalisadores tratados termicamente a $650^{\circ} \mathrm{C}$ por $15 \mathrm{~h}$. Os pontos representam os dados experimentais e a linha vermelha o ajuste da curva por uma soma de funções gaussiana. O número sobre cada pico indica a temperatura aproximada de redução.

Figura 42 - Perfis de redução dos catalisadores tratados termicamente a $750^{\circ} \mathrm{C}$ por $15 \mathrm{~h}$. Os pontos representam os dados experimentais e a linha vermelha o ajuste da curva por uma 
soma de funções gaussiana. O número sobre cada pico indica a temperatura aproximada de redução.

Figura 43 - Isotermas de adsorção para os catalisadores tratados termicamente a $550{ }^{\circ} \mathrm{C}$ por $15 \mathrm{~h}$, a partir das quais foram determinados os valores das áreas superficiais específicas pelo método de BET (a) e a distribuição do tamanho de poro (b).

Figura 44 - Isotermas de adsorção para os catalisadores tratados termicamente a $650{ }^{\circ} \mathrm{C}$ por $15 \mathrm{~h}$, a partir das quais foram determinados os valores das áreas superficiais específicas pelo método de BET (a) e a distribuição do tamanho de poro (b).

Figura 45 - Isotermas de adsorção para os catalisadores tratados termicamente a $750{ }^{\circ} \mathrm{C}$ por $15 \mathrm{~h}$, a partir das quais foram determinados os valores das áreas superficiais específicas pelo método de BET (a) e a distribuição do tamanho de poro (b).

Figura 46 - Sítios ácidos e básicos do $\mathrm{Al}_{2} \mathrm{O}_{3}$.

Figura 47- Mecanismo da mudança de coloração do indicador fenolftaleína ao ser desprotonada na presença de sítios básicos. 102

Figura 48 - Perfis de TPD- $\mathrm{CO}_{2}$ dos catalisadores tratados termicamente a $550^{\circ} \mathrm{C}$ 103

Figura 49 - Interações entre os sítios básicos presentes na superfície do $\mathrm{ZrO}_{2}$ com a molécula de $\mathrm{CO}_{2}$. 103

Figura 50 - Perfis de TPD- $\mathrm{CO}_{2}$ dos catalisadores tratados termicamente a $650^{\circ} \mathrm{C}$ 104

Figura 51 - Perfis de TPD- $\mathrm{CO}_{2}$ dos catalisadores tratados termicamente a $750{ }^{\circ} \mathrm{C}$ 105

Figura 52 - Resultados dos testes catalíticos na reação de reforma seca do metano utilizando os catalisadores tratados termicamente $550^{\circ} \mathrm{C}$. 107

Figura 53 - Resultados dos testes catalíticos na reação de reforma seca do metano utilizando os catalisadores tratados termicamente $650^{\circ} \mathrm{C}$. 109

Figura 54 - (a) Padrões de difração de raios $X$ in situ da etapa de redução para o catalisador $\mathrm{Ni} / \mathrm{ZnAl}-6$, onde verifica-se a ocorrência das fases de $\mathrm{ZnO}(\alpha), \mathrm{NiO}(\beta), \mathrm{NiAl}_{2} \mathrm{O}_{4}(\delta), \mathrm{ZnAl}_{2} \mathrm{O}_{4}$ $(\gamma)$ e Ni metálico; (b) Representação do mapa de contorno bidimensional para os difratogramas de raios $\mathrm{X}$ das amostras em função do tempo de redução.

Figura 55 - Difratograma in situ das reações catalíticas referentes ao catalisador Ni/ZnAl-6. Os símbolos $\alpha, \beta, \delta, \gamma, \mathrm{Ni}^{0}$, e $\mathrm{C}$ denotam a ocorrência das fases de $\mathrm{ZnO}, \mathrm{NiO}, \mathrm{Al}_{2} \mathrm{NiO}_{4}$, $\mathrm{Al}_{2} \mathrm{ZnO}_{4}$, Ni metálico e carbono nos catalisadores, respectivamente. 111

Figura 56 - (a) Padrões de difração de raios $X$ in situ da etapa de redução para o catalisador $\mathrm{Ni} / \mathrm{ZnAlZr}-6$, onde verifica-se a ocorrência das fases de $\mathrm{ZnO}(\alpha), \mathrm{NiO}(\beta), \mathrm{ZrO}_{2}(\lambda), \mathrm{NiAl}_{2} \mathrm{O}_{4}$ $(\delta), \mathrm{ZnAl}_{2} \mathrm{O}_{4}(\gamma)$ e Ni metálico; (b) Representação do mapa de contorno bidimensional para os difratogramas de raios $\mathrm{X}$ das amostras em função do tempo de redução. 112

Figura 57 - Difratograma in situ das reações catalíticas realizadas com o catalisador $\mathrm{Ni} / \mathrm{ZnAlZr}-6$. Os símbolos $\alpha, \beta, \lambda_{(\mathrm{M}, \mathrm{T})}, \delta, \gamma, \mathrm{Ni}^{0}$, e $\mathrm{C}$ denotam a ocorrência das fases de $\mathrm{ZnO}$, $\mathrm{NiO}, \mathrm{ZrO}_{2}, \mathrm{Al}_{2} \mathrm{NiO}_{4}, \mathrm{Al}_{2} \mathrm{ZnO}_{4}$, Ni metálico e carbono nos catalisadores, respectivamente...113 
Figura 58 - (a Difratograma in situ das reações catalíticas referentes ao catalisador Ni/ZnZr6 , onde verificou-se a ocorrência das fases de $\mathrm{ZnO}(\alpha), \mathrm{NiO}(\beta), \mathrm{ZrO}_{2}(\lambda)$ e Ni metálico; (b) Representação do mapa de contorno bidimensional para os difratogramas de raios $\mathrm{X}$ das amostras em função do tempo de redução.

Figura 59 - Difratograma in situ das reações catalíticas referentes ao catalisador Ni/ZnAl-6. Os símbolos $\alpha, \beta, \delta, \gamma, \mathrm{Ni}^{0}$, e $\mathrm{C}$ denotam a ocorrência das fases de $\mathrm{ZnO}, \mathrm{NiO}, \mathrm{Al}_{2} \mathrm{NiO}_{4}$, $\mathrm{Al}_{2} \mathrm{ZnO}_{4}$, Ni metálico e carbono nos catalisadores, respectivamente.

Figura 60 - Resultados dos testes catalíticos na reação de reforma seca do metano utilizando os catalisadores tratados termicamente $750{ }^{\circ} \mathrm{C}$.

Figura 61 - Padrão de difração de raios $\mathrm{X}$ in situ do catalisador Ni/ZnAl-7 durante a atividade catalítica. Os símbolos $\alpha, \beta, \lambda, \delta, \gamma, \mathrm{o}, \mathrm{Ni}^{0}$ e $\mathrm{C}$ denotam a ocorrência das fases de $\mathrm{ZnO}, \mathrm{NiO}$, $\mathrm{ZrO}_{2}, \mathrm{Al}_{2} \mathrm{NiO}_{4}, \mathrm{Al}_{2} \mathrm{ZnO}_{4}$, fase óxida contendo $\mathrm{Ni}$ e $\mathrm{Zn}$, $\mathrm{Ni}$ metálico e carbono nos catalisadores, respectivamente.

Figura 62 - Mapa das intensidades dos padrões difração de raios X in situ durante o processo catalítico referente ao $\mathrm{Ni} / \mathrm{ZnAl}-7$.

Figura 63 - Padrão de difração de raios $\mathrm{X}$ in situ do catalisador Ni/ZnAlZr-7 durante a atividade catalítica. Os símbolos $\alpha, \beta, \lambda, \delta, \gamma, \mathrm{Ni}^{0}$ e $\mathrm{C}$ denotam a ocorrência das fases de $\mathrm{ZnO}$, $\mathrm{NiO}, \mathrm{ZrO}_{2}, \mathrm{Al}_{2} \mathrm{NiO}_{4}, \mathrm{Al}_{2} \mathrm{ZnO}_{4}$, Ni metálico e carbono nos catalisadores, respectivamente...120

Figura 64 - Mapa das intensidades dos padrões difração de raios X in situ durante o processo catalítico referente ao $\mathrm{Ni} / \mathrm{ZnAlZr}-7$.

Figura 65 - Padrões de difração de raios $\mathrm{X}$ in situ do catalisador Ni/ZnZr-7 durante a atividade catalítica. Os símbolos $\alpha, \beta, \lambda, \mathrm{Ni}^{0}$ e $\mathrm{C}$ denotam a ocorrência das fases de $\mathrm{ZnO}, \mathrm{NiO}$, $\mathrm{ZrO}_{2}$, Ni metálico e carbono nos catalisadores, respectivamente.

Figura 66 - Mapa das intensidades dos padrões difração de raios X in situ durante o processo catalítico referente ao $\mathrm{Ni} / \mathrm{ZnZr}-7$.

Figura 67 - (a) Difração de raios $X$ dos catalisadores tratados a $550^{\circ} \mathrm{C}$ ( $\mathrm{Ni} / \mathrm{ZnAl}-5$, Ni/ZnAlZr-5 e Ni/ZnZr-5) após a reação; (b) Espectros Raman dos catalisadores (Ni/ZnAl-5, Ni/ZnAlZr-5 e Ni/ZnZr-5) após a reação.

Figura 68 - (a) Difração de raios $X$ dos catalisadores tratados a $650^{\circ} \mathrm{C}(\mathrm{Ni} / \mathrm{ZnAl}-6$, Ni/ZnAlZr-6 e Ni/ZnZr-6) após a reação; (b) Espectros Raman dos catalisadores (Ni/ZnAl-6, $\mathrm{Ni} / \mathrm{ZnAlZr-6}$ e Ni/ZnZr-6) após a reação. 125

Figura 69 - (a) Difração de raios $X$ dos catalisadores tratados a $750^{\circ} \mathrm{C}(\mathrm{Ni} / \mathrm{ZnAl}-7$, $\mathrm{Ni} / \mathrm{ZnAlZr-7} \mathrm{e} \mathrm{Ni/ZnZr-7)} \mathrm{após} \mathrm{a} \mathrm{reação;} \mathrm{(b)} \mathrm{Espectros} \mathrm{Raman} \mathrm{dos} \mathrm{catalisadores} \mathrm{(Ni/ZnAl-7,}$ $\mathrm{Ni} / Z n A l Z r-7$ e Ni/ZnZr-7) após a reação.

Figura 70 - Microscopia eletrônica de varredura dos catalisadores calcinados a $550^{\circ} \mathrm{C}$ (a) Ni/ZnAl-5 (b) Ni/ZnAlZr-5 and (c) Ni/ZnZr-5. Além dos catalisadores após a reação de reforma seca do metano (d) Ni/ZnAl-5 (e) Ni/ZnAlZr-5 e (f) Ni/ZnZr-5. 
Figura 71 - Microscopia eletrônica de varredura dos catalisadores calcinados a $650^{\circ} \mathrm{C}$ (a) Ni/ZnAl-6 (b) Ni/ZnAlZr-6 e (c) Ni/ZnZr-5. Além dos catalisadores após a reação de reforma seca do metano (d) Ni/ZnAl-6 (e) Ni/ZnAlZr-6 e (f) Ni/ZnZr-6. 128

Figura 72 - Microscopia eletrônica de varredura dos catalisadores calcinados a $750^{\circ} \mathrm{C}$ (a) Ni/ZnAl-7 (b) Ni/ZnAlZr-7 e (c) Ni/ZnZr-7. Além dos catalisadores após a reação de reforma seca do metano (d) Ni/ZnAl-7 (e) Ni/ZnAlZr-7 e (f) Ni/ZnZr-7. 129

Figura 73 - Reações realizadas com os catalisadores calcinados a $650^{\circ} \mathrm{C}$ e reduzidos a $750^{\circ} \mathrm{C}$.

Figura 74 - Reação dos catalisadores calcinados a $750^{\circ} \mathrm{C}$ e reduzidos a $750^{\circ} \mathrm{C}$

Figura 75 - Sinterização da fase ativa através da migração dos átomos e cluster para formar partículas maiores : (1) representa a etapa de sinterização e (2) etapa de crescimento da partícula. 132

Figura 76 - (a) Difração de raios $X$ dos catalisadores tratados a $650^{\circ} \mathrm{C}$ ( $\mathrm{Ni} / \mathrm{ZnAl}-7$, $\mathrm{Ni} / \mathrm{ZnAlZr-7} \mathrm{e} \mathrm{Ni/ZnZr-7)} \mathrm{após} \mathrm{a} \mathrm{reação;} \mathrm{(b)} \mathrm{Espectros} \mathrm{Raman} \mathrm{dos} \mathrm{catalisadores} \mathrm{(} \mathrm{Ni/ZnAl-7,}$ $\mathrm{Ni} / \mathrm{ZnAlZr-7} \mathrm{e} \mathrm{Ni/ZnZr-7)} \mathrm{após} \mathrm{a} \mathrm{reação.}$

Figura 77 - (a) Difração de raios $X$ dos catalisadores tratados a $750^{\circ} \mathrm{C}$ ( $\mathrm{Ni} / \mathrm{ZnAl}-7$, $\mathrm{Ni} / Z n A l Z r-7$ e Ni/ZnZr-7) após a reação; (b) Espectros Raman dos catalisadores ( Ni/ZnAl-7, $\mathrm{Ni} / Z n A l Z r-7$ e Ni/ZnZr-7) após a reação. 


\section{LISTA DE TABELAS}

Tabela 1- Composição percentual de compostos resultantes da degradação anaeróbica ( Biogás)

Tabela 2 - Exemplo de hidróxidos duplos lamelares (HDL's) com suas respectivas fórmulas químicas e sistema cristalinos (3R, romboédrico; $2 \mathrm{H}$, hexagonal)......................................33

Tabela 3 - Fatores que influenciam a síntese de argilas aniônicas. .........................................36

Tabela 4 - Reagentes químicos utilizados na síntese dos precursores com as respectivas fórmulas, valores de massa molecular, teor e as marcas dos regentes.

Tabela 5 - Quantidade molar dos cátions $\mathrm{Ni}^{2+}, \mathrm{Zn}^{2+}, \mathrm{Al}^{3+}$ e $\mathrm{Zr}^{4+}$ presentes nos precursores tipo hidrotalcita.

Tabela 6 - Nomenclatura dos catalisadores obtidos nas temperaturas de $550^{\circ} \mathrm{C}, 650^{\circ} \mathrm{C}$ e $750^{\circ} \mathrm{C}$

Tabela 7- Temperaturas utilizadas na obtenção, redução e reação dos catalisadores estudados ( $\mathrm{T}^{*}=$ Temperatura).

Tabela 8 - Porcentagem teórica e experimental em massa dos metais presentes nos precursores.

Tabela 9 - Índices hkl de cada pico de difração de raios X do precursor NiZn-Al, com seus respectivos centros e espaçamentos interplanares determinados pela Lei de Bragg. A partir desses dados, os parâmetros de rede foram determinados pela Equação 8, ver texto. O espaçamento interplanar teórico é obtido através da aplicação dos parâmetros recémcalculados novamente na Equação 8, fornecendo informação sobre a qualidade do processo de cálculo. [* experimental (exp ) \# téorico (teor)].

Tabela 10 - Índices hkl de cada pico de difração de raios X do precursor NiZn-AlZr, com seus respectivos centros e espaçamentos interplanares determinados pela Lei de Bragg. A partir desses dados, os parâmetros de rede foram determinados pela Equação 8, ver texto. O espaçamento interplanar teórico é obtido através da aplicação dos parâmetros recémcalculados novamente na Equação 8, fornecendo informação sobre a qualidade do processo de cálculo. [* experimental (exp ) \# téorico (teor)]

Tabela 11- Basicidade total e perda por rubro dos precursores NiZn-Al, NiZn-AlZr e NiZn$\mathrm{Zr}$ a $100^{\circ} \mathrm{C}$ por $15 \mathrm{~h}$

Tabela 12 - Valores das perdas porcentuais obtidos pelos perfis de perda de massa de cada precursor nos seus respectivos intervalos de ocorrência.

Tabela 13 - Índices hkl de cada pico de difração de raios X do precursor NiZn-Al (III), com seus respectivos centros e espaçamentos interplanares determinados pela Lei de Bragg. A partir desses dados, os parâmetros de rede foram determinados pela Equação 8 ver texto. $\mathrm{O}$ espaçamento interplanar teórico é obtido através da aplicação dos parâmetros recémcalculados novamente na Equação 8, fornecendo informação sobre a qualidade do processo de cálculo. 
Tabela 14 - Índces hkl de cada pico de difração de raios X do precursor NiZn-Zr reconstituído via efeito memória, com seus respectivos centros e espaçamentos interplanares determinados pela Lei de Bragg. A partir desses dados, os parâmetros de rede foram determinados pela Equação 8, ver texto. O espaçamento interplanar teórico é obtido através da aplicação dos parâmetros recém-calculados novamente na Equação 8, fornecendo

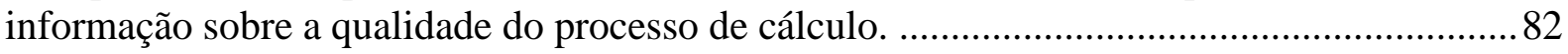

Tabela 15 - Tabela contendo o consumo teórico e real dos catalisadores estudados..............92

Tabela 16 - Valores das áreas superficiais específicas para os catalisadores Ni/ZnAl,

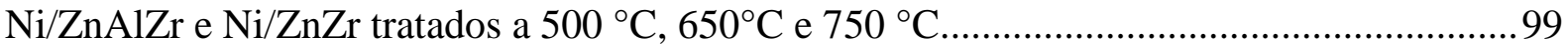

Tabela 17 - Valores obtidos para a basicidade dos catalisadores tratados termicamente a 550 ${ }^{\circ}, 650^{\circ}$ e $750{ }^{\circ} \mathrm{C}$ por $15 \mathrm{~h}$. Em cada linha, a massa pesada, o volume gasto na titulação e o aspecto final do catalisador na presença do indicador podem ser visualizados. ....................101

Tabela 18 - Taxa de formação do carbono Rc (gc/gcat h) obtida para os catalisadores a 550 ${ }^{\circ} \mathrm{C}, 650^{\circ} \mathrm{C}$ e $750{ }^{\circ} \mathrm{C}$ através da análise termogravimétrica. 


\section{REAÇÕES APRESENTADAS}

$$
\begin{aligned}
& \mathrm{CH}_{4}+\mathrm{H}_{2} \mathrm{O} \rightleftarrows \mathrm{CO}+3 \mathrm{H}_{2} \\
& \mathrm{CO}+\mathrm{H}_{2} \mathrm{O} \rightleftarrows \mathrm{CO}_{2}+\mathrm{H}_{2} \\
& \mathrm{CH}_{4}+1 / 2 \mathrm{O}_{2} \rightarrow \mathrm{CO}+2 \mathrm{H}_{2} \\
& \mathrm{CH}_{4}+2 \mathrm{O}_{2} \rightarrow \mathrm{CO}_{2}+2 \mathrm{H}_{2} \mathrm{O} \\
& \mathrm{CH}_{4}+\mathrm{CO}_{2} \rightleftharpoons 2 \mathrm{CO}+2 \mathrm{H}_{2} \\
& \mathrm{CO}_{2}+\mathrm{H}_{2} \rightleftharpoons \mathrm{CO}+\mathrm{H}_{2} \mathrm{O} \\
& \mathrm{CH}_{4} \rightleftharpoons 2 \mathrm{H}_{2}+\mathrm{C} \\
& 2 \mathrm{CO} \rightleftharpoons \mathrm{CO}_{2}+\mathrm{C}(\mathrm{s}) \\
& \mathrm{CO}+\mathrm{H}_{2} \rightleftharpoons \mathrm{H}_{2} \mathrm{O}+\mathrm{C}_{(\mathrm{s})} \\
& \mathrm{CH}_{4}+2 \mathrm{M} \rightleftharpoons \mathrm{CH}_{3}-\mathrm{M}+\mathrm{H}-\mathrm{M} \\
& \mathrm{CH}_{3}-\mathrm{M}+2 \mathrm{M} \rightleftharpoons \mathrm{CH}_{2}-\mathrm{M}+\mathrm{H}-\mathrm{M} \\
& \mathrm{CH}_{2}-\mathrm{M}+2 \mathrm{M} \rightleftharpoons \mathrm{CH}-\mathrm{M}+\mathrm{H}-\mathrm{M} \\
& \mathrm{CH}-\mathrm{M}+2 \mathrm{M} \rightleftharpoons \mathrm{C}-\mathrm{M}+\mathrm{H}-\mathrm{M} \\
& 2 \mathrm{H}-\mathrm{M} \rightleftharpoons \mathrm{H}_{2}-2 \mathrm{M} \\
& \mathrm{CO}_{2} \rightleftharpoons \mathrm{CO}_{2}-\mathrm{M} \\
& \mathrm{CO}_{2}-\mathrm{M} \rightleftharpoons \mathrm{CO}-\mathrm{M}+\mathrm{O}-\mathrm{M} \\
& \mathrm{CO}-\mathrm{M} \rightleftharpoons \mathrm{CO}-\mathrm{M} \\
& \mathrm{CO}_{2} \rightleftharpoons \mathrm{CO}_{2}-\mathrm{S} \\
& \mathrm{CO}_{2}-\mathrm{S}+\mathrm{O}^{2-} \rightleftharpoons \mathrm{CO}_{2}-\mathrm{S}
\end{aligned}
$$




$$
\begin{aligned}
& 2 \mathrm{H}-\mathrm{M} \rightleftharpoons 2 \mathrm{H}-\mathrm{S} \\
& \mathrm{CO}_{3}^{2-}-\mathrm{S}+2 \mathrm{H}-\mathrm{S} \rightleftharpoons \mathrm{HCO}_{2}^{-}-\mathrm{S}+\mathrm{OH}^{-}-\mathrm{S} \\
& \mathrm{CO}-\mathrm{S} \rightleftharpoons \mathrm{CO} \\
& (1-\mathrm{x}) \mathrm{M}^{\mathrm{II}}\left(\mathrm{X}^{-}\right)_{2}+\mathrm{x} \mathrm{M}^{\mathrm{III}}\left(\mathrm{X}^{-}\right)_{3}+2 \mathrm{M}^{\mathrm{I}} \mathrm{OH}+(\mathrm{x} / \mathrm{m}) \mathrm{M}_{\mathrm{m}}^{\mathrm{I}}\left(\mathrm{A}^{\mathrm{m}-}\right) \rightarrow \\
& \mathrm{M}_{1-\mathrm{x}}^{\mathrm{II}} \mathrm{MIII}_{\mathrm{x}}(\mathrm{OH})_{2}\left(\mathrm{~A}_{\mathrm{x} / \mathrm{n}}^{\mathrm{m}-}\right) \mathrm{nH}_{2} \mathrm{O}+(2+\mathrm{x}) \mathrm{M}^{\mathrm{I}} \mathrm{X} . \\
& \mathrm{MO}_{(\mathrm{s})}+\mathrm{H}_{2(g)} \rightarrow \mathrm{M}_{(\mathrm{s})}+\mathrm{H}_{2} \mathrm{O}_{(\mathrm{g})} \\
& \mathrm{Ag}_{2} \mathrm{O}+\mathrm{H}_{2} \rightarrow 2 \mathrm{Ag}^{0}+\mathrm{H}_{2} \mathrm{O} \\
& \mathrm{Ni}^{2+}+\mathrm{H}_{2} \rightarrow \mathrm{Ni}^{0}+2 \mathrm{H}^{+}
\end{aligned}
$$

Reação 20

Reação 21

Reação 22

Reação 23

Reação 24

Reação 25

Reação 26 


\section{LISTA DE ABREVIATURAS E SIGLAS}

$\begin{array}{ll}\mathrm{CO} & \text { Monóxido de carbono } \\ \mathrm{CO}_{2} & \text { Dióxido de carbono } \\ \mathrm{CH}_{4} & \text { Metano } \\ \mathrm{N}_{2} & \text { Nitrogênio } \\ \mathrm{H}_{2} & \text { Hidrogênio } \\ \text { DRX } & \text { Difração de Raios X } \\ \text { EDS } & \text { Energia dispersiva de raios X } \\ \text { TPR } & \text { Redução à temperatura programada } \\ \text { JCPDS } & \text { Centro Internacional para dados de Difração } \\ \text { ICSD } & \text { Inorganic Crystal Structure Database } \\ \text { BET } & \text { Brunauer, Emmett, Teller } \\ \text { TGA } & \text { Análise Termogravimétrica } \\ \text { FTIR } & \text { Espectroscopia no Infravermelho com transformada de Fourier } \\ \text { IUPAC } & \text { International Union of Pure and Applied Chemistry } \\ \text { MEV } & \text { Microscopia eletrônica de varredura } \\ \text { MET } & \text { Microscopia eletrônica de transmissão }\end{array}$




\section{SUMÁRIO}

1 INTRODUÇÃO....................................................................................................................21

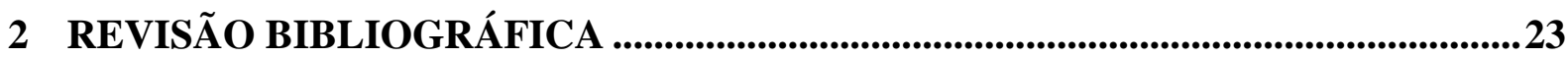

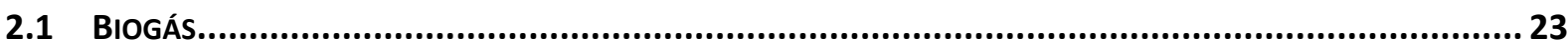

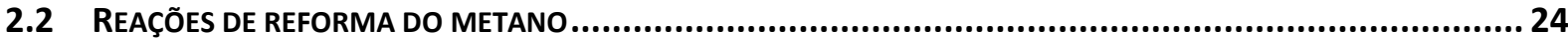

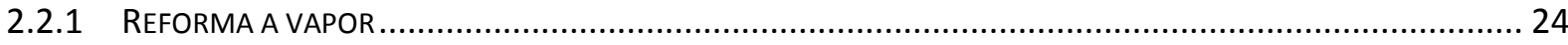

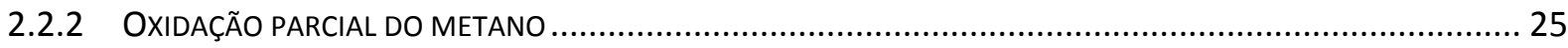

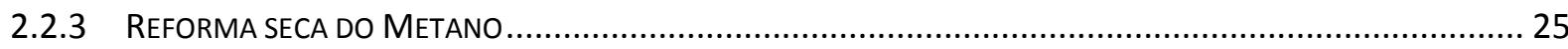

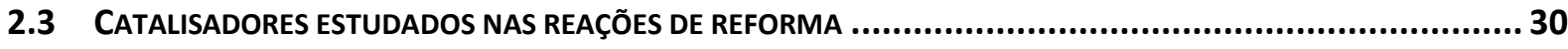

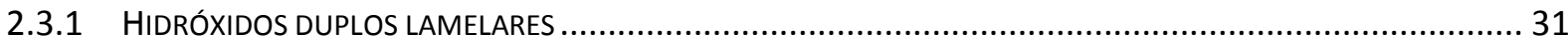

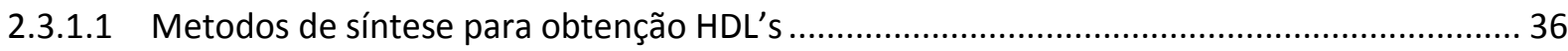

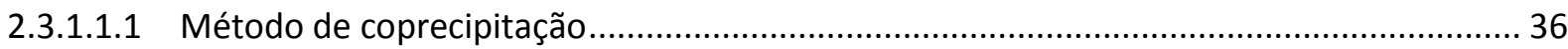

3 OBJETIVO

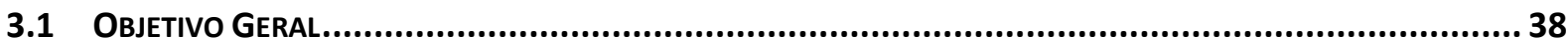

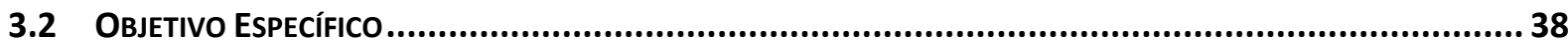

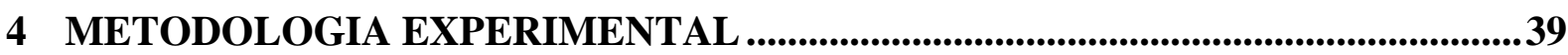

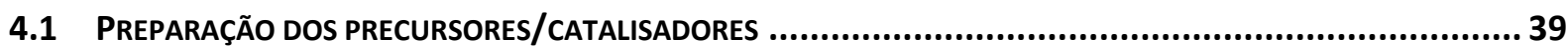

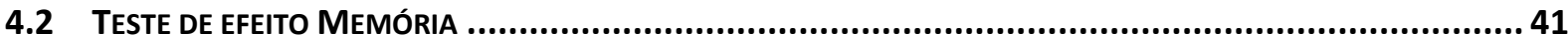

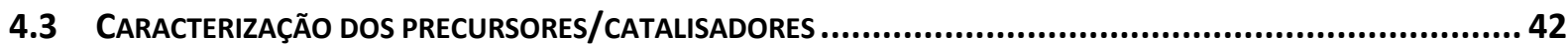

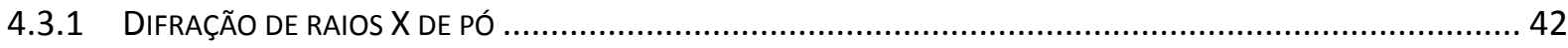

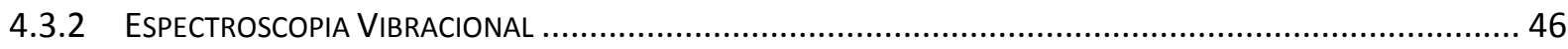

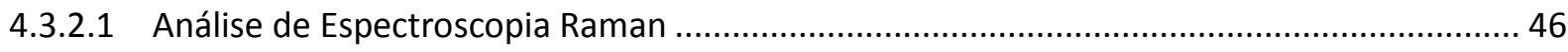

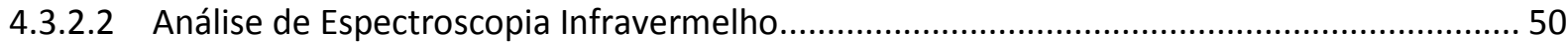

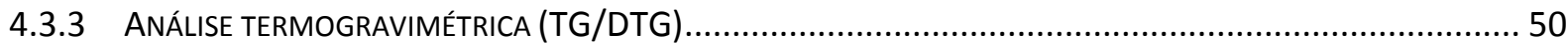

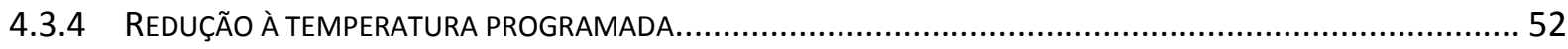

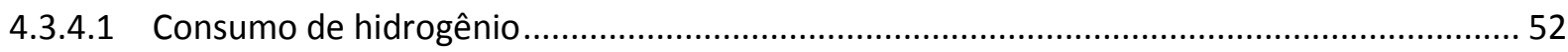

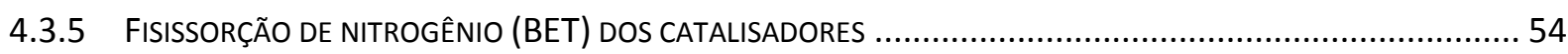

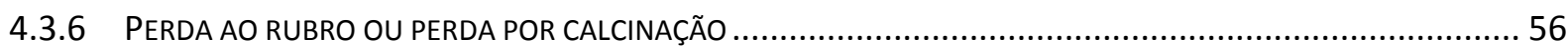




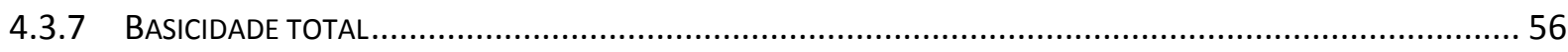

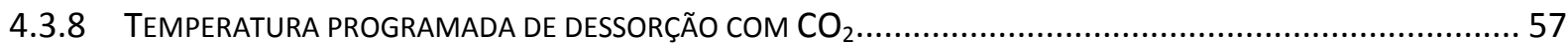

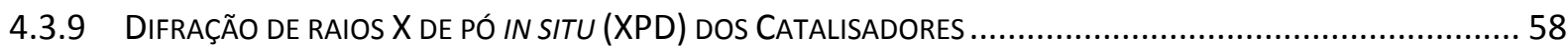

4.3.10 Energia Dispersiva de RaIOS X / EDS (Energy-Disperse X-RAY SPECtroscopy) e Microscopia

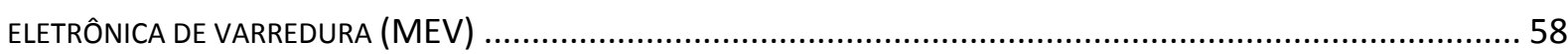

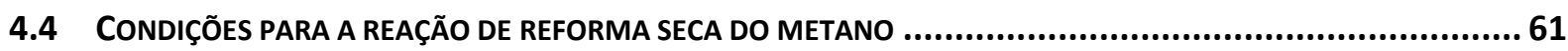

5 RESULTADOS E DISCUSSÃO

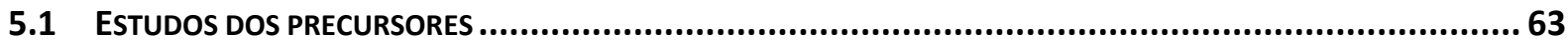

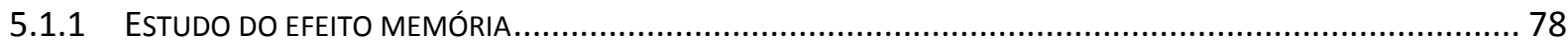

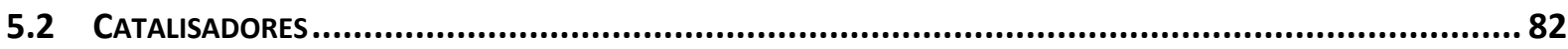

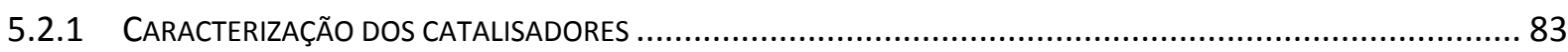

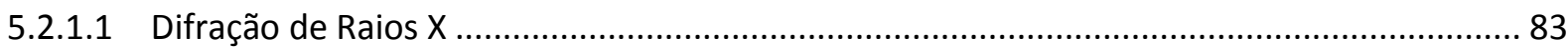

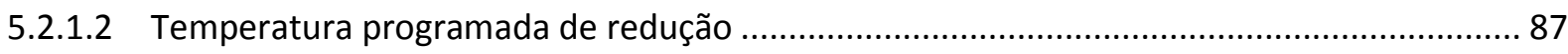

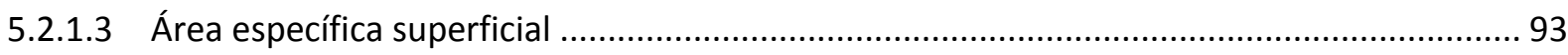

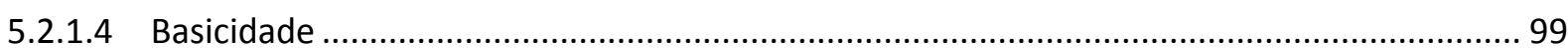

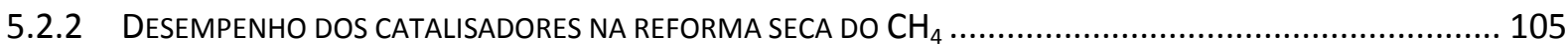

5.2.2.1 Reação com os catalisadores obtidos a $550^{\circ} \mathrm{C}, 650^{\circ} \mathrm{C}$ e $750^{\circ} \mathrm{C}$........................................ 105

5.2.2.1.1 Estudo da formação de carbono dos catalisadores reduzidos a $550^{\circ}, 650^{\circ}$ e $750^{\circ} \mathrm{C}$...... 122

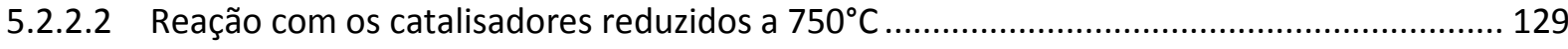

5.2.2.2.1 Estudo do carbono formado dos catalisadores reduzidos a $750^{\circ} \mathrm{C}$............................... 132

6 CONSIDERAÇÕES FINAIS...............................................................................134

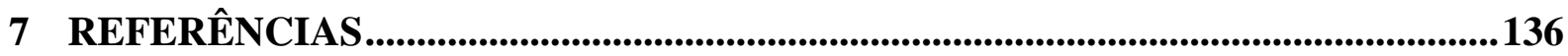

APÊNDICE A - Resultados..............................................................................................146

APÊNDICE B - Cálculos...............................................................................................149

Cálculo para determinar o valor de n presente na fórmula molecular das hidrotalcitas. 


\section{INTRODUÇÃO}

Nos últimos anos têm ocorrido uma preocupação global com o aumento das emissões de $\mathrm{CO}_{2}$, que em grande quantidade é um poderoso e perigoso causador de diversos impactos ambientais, tais como o desequilíbrio das condições climáticas causado pelo efeito estufa (BRADFORD; VANNICE, 1999). O relatório publicado pela Agência Nacional Oceânica e Atmosférica Americana (NOAA) mostra que a concentração do $\mathrm{CO}_{2}$ na atmosfera global já ultrapassou 400 ppm em março de 2015. Todos esses fatores são resultados das atividades humanas, como a queima de combustíveis fósseis (carvão e petróleo) e do desmatamento. Uma das principais formas de reduzir as emissões do dióxido de carbono é a utilização de tecnologias mais limpas que emitam menos gases de efeito estufa do que as tecnologias convencionais. Devido a estes fatores, pesquisas no setor de produção de energia limpa têm concentrado suas forças em direção a reforma do $\mathrm{CH}_{4}$ na presença de $\mathrm{CO}_{2}$. $\mathrm{CH}_{4}+\mathrm{CO}_{2} \rightleftharpoons 2 \mathrm{CO}+2 \mathrm{H}_{2}\left(\Delta \mathrm{H}_{298 \mathrm{~K}}=+247 \mathrm{~kJ} \mathrm{~mol}^{-1}\right)$. Esses gases são duas matériasprimas relativamente baratas devido à sua abundância natural, podendo ser encontrados na forma de biogás, também conhecido como gás do pântano, obtido a partir da digestão anaeróbica de matéria orgânica e que tipicamente contém de $50-80 \%$ de $\mathrm{CH}_{4}$ e $20-50 \%$ de $\mathrm{CO}_{2}$, além de outros gases, por exemplo $\mathrm{H}_{2} \mathrm{~S}, \mathrm{NH}_{3}$ e $\mathrm{H}_{2}$ presentes em pequenas quantidades (RUEANGJITT et al., 2012). A conversão do $\mathrm{CH}_{4}$ na presença do $\mathrm{CO}_{2}$ gera compostos com alto valor agregado, a saber, o gás de síntese, uma mistura de $\mathrm{H}_{2}$ e $\mathrm{CO}$ (CHEN et al., 2001). Esse gás obtido pela reforma seca do metano possui uma razão $\mathrm{H}_{2} / \mathrm{CO}$ igual à unidade com grande potencial para síntese de vários produtos químicos, tais como compostos oxigenados policarbonatos e produção de hidrocarboneto líquido via processo de Fischer-Tropsch. (BUDIMAN et al., 2012; RUCKENSTEIN; HU, 1995).

As reações de reforma seca ocorrem na presença de catalisadores que sejam ativos e estáveis para essa finalidade. Devido a isso, as reações geralmente são realizadas com catalisadores baseados em metais nobres como Pt, $\mathrm{Rh}$ e $\mathrm{Ru}$, além de outros metais como níquel ou cobalto. Os metais nobres são mais resistentes à formação de carbono em relação aos outros metais de transição, porém acarretam um alto custo ao processo (PAKHARE; SPIVEY, 2014). Outros catalisadores que vêm ganhando espaço nas reações de reforma seca do metano são os óxidos mistos derivados de hidrotalcitas, que são hidroxicarbonatos, cuja estrutura é baseada na brucita (FROST et al., 2005). Esses óxidos mistos possuem características essenciais como catalisadores, tais como elevada área superficial, fator de grande importância no processo catalítico. 
Nesse trabalho, reporta-se a aplicação de óxidos mistos, baseados em níquel, derivados da decomposição térmica dos hidróxidos duplos lamelares (hidrotalcitas). No primeiro estudo, as amostras foram calcinadas a $550^{\circ}, 650^{\circ}$ e $750^{\circ} \mathrm{C}$ e posteriormente foi realizada a etapa de caracterização estrutural das mesmas. Na etapa seguinte, realizou-se a aplicação das mesmas na reforma seca do metano, visando a obtenção de gás de síntese. Finalmente, realizou-se a quantificação e identificação do carbono formado. 


\section{REVISÃO BIBLIOGRÁFICA}

\subsection{Biogás}

O biogás é uma fonte de energia gerada em diversos ambientes e, atualmente existem milhões de unidades de geração de biogás em operação em todo mundo. A sua obtenção ocorre a partir do processo de decomposição da matéria orgânica na ausência de oxigênio. Para ser formado, alguns fatores devem ser levados em consideração, por exemplo: $\mathrm{pH}$, temperatura e tipo de substrato (MARTINS DAS NEVES et al., 2009). O processo de formação do biogás ocorre em etapas, inicia-se com o processo de hidrólise, que consiste na quebra de moléculas maiores (proteínas, carboidratos e lipídios) em menores (aminoácidos, ácidos graxos e açúcares). Em seguida, ocorre a etapa da acidogênese, onde as bactérias fermentativas acidogênicas promovem a decomposição dos produtos obtidos em ácido acético, propiônico, butírico, dióxido de carbono e hidrogênio. Na etapa da oxidação anaeróbica, as bactérias acetogênicas promovem a formação do ácido acético, hidrogênio e dióxido de carbono. Finalmente, acontece a última etapa designada de metanogênese, na qual as bactérias metanogênicas transformam o ácido cético, hidrogênio e dióxido de carbono em metano (FACHAGENTUR, 2010; KARLSSON, 2014).

Sabe-se que, o biogás é constituído por uma mistura de metano (55 - 70\% volume), dióxido de carbono (27 - 44\% volume), e em menor quantidade, hidrogênio, sulfeto de hidrogênio, amônio e outros (Ver Tabela 1) (BOND; TEMPLETON, 2011; KOLBITSCH et al., 2008; RUEANGJITT et al., 2012). Por apresentar um alto poder calorífico, o mesmo pode substituir os gases nomeados de combustíveis fósseis, a saber, gás natural veicular, GLP e diesel, dessa forma, colaborando na redução $\mathrm{CO}_{2}$. No meio rural, o biogás é utilizado como fonte para a obtenção de chama em fogões, contribuindo para a proteção do solo, ar e vegetação lenhosa. No entanto, o uso em sua forma natural possui algumas desvantagens devido à presença do ácido sulfídrico (sulfeto de hidrogênio), que tende a sofrer o processo de oxidação em motores de combustão, suscitando a formação de dióxido de enxofre, o qual é corrosivo e altamente tóxico. Outrossim, o alto teor de $\mathrm{CO}_{2}$ pode diminuir o poder calorífico e aumentar a emissão de $\mathrm{CO}_{2}$. Logo, para que seja utilizado é necessário realizar o processo de separação, o que faz com que, consequentemente, possa ser utilizado em diversas finalidades. Outra forma de utilizar o biogás é na obtenção de gás de síntese (mistura de $\mathrm{H}_{2}$ e CO) através das reação de reforma seca do metano (SERRANO-LOTINA et al., 2012; XU et al., 2009). 
Tabela 1- Composição percentual de compostos resultantes da degradação anaeróbica ( Biogás).

\begin{tabular}{cc}
\hline Composto & Percentual médio \\
\hline Metano $\left(\mathrm{CH}_{4}\right)$ & $55-70 \%$ \\
Dióxido de carbono $\left(\mathrm{CO}_{2}\right)$ & $27-44 \%$ \\
Hidrogênio $\left(\mathrm{H}_{2}\right)$ & $1 \%$ a $3 \%$ \\
Nitrogênio $\left(\mathrm{N}_{2}\right)$ & $0,5 \%$ a $2,5 \%$ \\
Oxigênio $\left(\mathrm{O}_{2}\right)$ & $0,1 \%$ a $1 \%$ \\
Sulfeto de hidrogênio $\left(\mathrm{H}_{2} \mathrm{~S}\right)$ & $0,1 \%$ a $0,5 \%$ \\
Amônia $\left(\mathrm{NH}_{3}\right)$ & $0,1 \%$ a $0,5 \%$ \\
Monóxido de carbono $(\mathrm{CO})$ & $0 \%$ a $0,1 \%$ \\
Água $\left(\mathrm{H}_{2} \mathrm{O}\right)$ & Variáveis \\
\hline BOND; TEMPLETON, 2011; KOLBITSCH et al., 2008; RUEANGJTT et al., 2012).
\end{tabular}

\subsection{Reações de reforma do metano}

\subsubsection{Reforma a vapor}

A reforma a vapor do metano consiste no processo de conversão do metano na presença da molécula de água (Reação 1), gerando como produto moléculas de $\mathrm{H}_{2}, \mathrm{CO}$ e $\mathrm{CO}_{2}$, com uma razão de $\mathrm{H}_{2} / \mathrm{CO}$ próximo a 3 . Essa reação tende a ser favorável em alta temperatura, visto que é endotérmica $\left(700^{\circ} \mathrm{C}\right.$ a $\left.800^{\circ} \mathrm{C}\right)$ e em pressões reduzidas (SHIGEYUKI UEMIYA, NOBORU SATO, HIROSHI ANDO, TAKESHI MATSUDA, 1990). Paralelamente, ocorre a reação de deslocamento gás-água (shift) em menor extensão, pois é favorecida em baixas temperaturas (Reação 2) (ROSTRUP-NIELSEN, 1993).

$$
\begin{array}{lr}
\mathrm{CH}_{4}+\mathrm{H}_{2} \mathrm{O} \rightleftarrows \mathrm{CO}+3 \mathrm{H}_{2}\left(\Delta \mathrm{H}_{298 \mathrm{~K}}=206,3 \mathrm{~kJ} / \mathrm{mol}\right), & \text { Reação 1 } \\
\mathrm{CO}+\mathrm{H}_{2} \mathrm{O} \rightleftarrows \mathrm{CO}_{2}+\mathrm{H}_{2}\left(\Delta \mathrm{H}_{298 \mathrm{~K}}=-41 \mathrm{~kJ} / \mathrm{mol}\right) . & \text { Reação } 2
\end{array}
$$

A reforma de vapor é uma das rotas mais utilizadas para produção de gás de síntese e/ou hidrogênio, todavia possui algumas desvantagens relacionadas à estabilidade térmica do catalisador, pois favorece o processo de sinterização do mesmo, e a desativação do catalisador devido à deposição do carbono. 


\subsubsection{Oxidação parcial do metano}

A oxidação parcial do metano (Reação 3) é uma reação com alta atividade e seletividade, o que permite oferecer um potencial para conversão do metano. A razão $\mathrm{H}_{2} / \mathrm{CO}$ obtida para essa reação é de 2:1. Por ser uma reação fortemente exotérmica, pode provocar a combustão completa do metano, caso ocorra um pequeno decréscimo na seletividade para o CO (ELI RUCKENSTEIN, 1999).

$$
\mathrm{CH}_{4}+1 / 2 \mathrm{O}_{2} \rightarrow \mathrm{CO}+2 \mathrm{H}_{2}\left(\Delta \mathrm{H}_{298}=-35,6 \mathrm{~kJ} / \mathrm{mol}\right)
$$

$\mathrm{O}$ mecanismo para esta reação consiste na oxidação total do $\mathrm{CH}_{4}$ produzindo $\mathrm{H}_{2} \mathrm{O}$ e $\mathrm{CO}_{2}$ (produtos primários) (Reação 4), podendo em seguida reagir com $\mathrm{CH}_{4}$ gerando $\mathrm{CO}$, como produto secundário. Tal mecanismo é favorecido em temperaturas acima de $850^{\circ} \mathrm{C}$ (PRETTRE, M., EICHNER, C., AND PERRIN, 1946).

$$
\mathrm{CH}_{4}+2 \mathrm{O}_{2} \rightarrow \mathrm{CO}_{2}+2 \mathrm{H}_{2} \mathrm{O}
$$

Reação 4

\subsubsection{Reforma seca do Metano}

A reforma do biogás vem despertando interesse nas pesquisas acadêmicas, uma vez que tais reações possuem várias vantagens: (i) a redução de $\mathrm{CO}_{2}$ na atmosfera ; (ii) transformação de biogás em gás de síntese; (iii) produção de gás de síntese com razão $\mathrm{H}_{2} / \mathrm{CO}$ igual a unidade e (iv) obtenção de CO puro para a produção de policarbonatos. O gás de síntese obtido pode ser convertido em eficientes combustíveis, por exemplo, gasolina, metanol e éter dimetílico (usado como combustível alternativo para motores a diesel) sem a presença de enxofre e subprodutos aromáticos (CHOUDHARY; CHOUDHARY, 2008). A reforma seca foi investigada pela primeira vez por Fischer e Tropsch em 1928 empregando um catalisador de Ni e Co. Além disso, esses pesquisadores observaram o processo de desativação pela deposição do carbono. Sabe-se atualmente que esta reação é favorável em temperaturas acima de 973K. A reação de equilíbrio para a produção de gás de síntese a partir dos gases $\mathrm{CH}_{4}$ e $\mathrm{CO}_{2}$ é estabelecida na Reação 5 (LIMA, 2006) seguinte: 
$\mathrm{CH}_{4}+\mathrm{CO}_{2} \rightleftharpoons 2 \mathrm{CO}+2 \mathrm{H}_{2}\left(\Delta \mathrm{H}_{298 \mathrm{~K}}=+247 \mathrm{~kJ} \mathrm{~mol}^{-1}\right)$

Reação 5

Sendo a reação de reforma seca altamente endotérmica, faz-se necessária uma grande quantidade de energia para que as moléculas do $\mathrm{CH}_{4}$ possam reagir com as de $\mathrm{CO}_{2}$, com isso gerando gás de síntese com uma razão $\mathrm{H}_{2} / \mathrm{CO}$ igual à unidade. $\mathrm{O}$ gás de síntese é considerado uma chave intermediária na indústria química, pois consiste numa mistura de hidrogênio e monóxido de carbono. Além disso, pode ser produzido a partir de qualquer fonte de carbono, tais como o biogás, óleos pesados, carvão e biomassa. Portanto, a reforma seca do metano é mais eficiente que a gaseificação do carvão (KAMBOLIS et al., 2010; RAMOS et al., 2011), por exemplo. Comparando com outras reações de reforma, como a reação a vapor e oxidação parcial do metano descrita pelas Reaçoes 1 e 3, respectivamente, a reforma seca é uma das mais promissoras para a produção do gás de síntese, visto que além dos custos totais de operação e investimentos inferiores ao do processo com vapor, tem-se que o produto obtido possui um alto valor agregado, podendo ser convertido em derivados oxigenados, nas reações de Fischer-Tropsch de hidrocarboneto de cadeia longa e em reações de hidroformilação (SERRANO-LOTINA et al., 2012; DJAIDJA et al., 2006).

A reação de equilíbrio para a produção de gás de síntese a partir de $\mathrm{CO}_{2}$ e $\mathrm{CH}_{4}$ é tipicamente influenciada pela reação reversa de shift (ver a Reação 6), que é reversível e endotérmica, sendo favorecida em alta temperatura. A reação reversa de shift tende a provocar uma redução na razão de $\mathrm{H}_{2} / \mathrm{CO}$, isto é, valores menores que a unidade (BRADFORD; VANNICE, 1999). Outro fator a ser ressaltado é que a deposição de carbono, que é favorecida termodinamicamente, pode acarretar a desativação dos catalisadores (WANG, 1998). O carbono pode ser obtido pelas reações de decomposição do metano (ver Reação 7), reação de Boudouard (Reação 8) e redução do CO (Reação 9). As duas últimas reações têm uma energia livre negativa em baixas temperaturas, o que denota que são espontâneas neste regime (KOHN, 2012)

$$
\begin{array}{lr}
\mathrm{CO}_{2}+\mathrm{H}_{2} \rightleftharpoons \mathrm{CO}+\mathrm{H}_{2} \mathrm{O}\left(\Delta \mathrm{H}_{298 \mathrm{~K}}=+41 \mathrm{~kJ} \cdot \mathrm{mol}^{-1}\right), & \text { Reação } 6 \\
\mathrm{CH}_{4} \rightleftharpoons 2 \mathrm{H}_{2}+\mathrm{C}\left(\Delta \mathrm{H}_{298 \mathrm{~K}}=+74,9 \mathrm{~kJ} \cdot \mathrm{mol}^{-1}\right), & \text { Reação 7 } \\
2 \mathrm{CO} \rightleftharpoons \mathrm{CO}_{2}+\mathrm{C}(\mathrm{s})\left(\Delta \mathrm{H}=-41,2 \mathrm{~kJ} \cdot \mathrm{mol}^{-1}\right), & \text { Reação } 8 \\
\mathrm{CO}+\mathrm{H}_{2} \rightleftharpoons \mathrm{H}_{2} \mathrm{O}+\mathrm{C}_{(\mathrm{s})}\left(\Delta \mathrm{H}_{298 K}=-131 \mathrm{~kJ} \cdot \mathrm{mol}^{-1}\right) . & \text { Reação 9 }
\end{array}
$$


De acordo com Wang, Lu e Millarn (1996), as etapas da reação de reforma seca são as seguintes: (i) decomposição do metano para formar a superfície de carbono e hidrogênio, (ii) adsorção dissociativa do $\mathrm{CO}_{2}$ e $\mathrm{H}_{2}$ e (iii) a redução do $\mathrm{CO}_{2}$ para $\mathrm{CO}$. O mecanismo de dissociação do metano na superfície do metal ativo ocorre inicialmente pelo $\mathrm{CH}_{4}$ adsorvido e dissociado para produzir hidrogênio e espécies de hidrocarbonetos $\left(\mathrm{CH}_{x}\right)$. $\mathrm{O}$ valor de $x$ varia entre 0 e 4, dependendo das condições da reação. Quando $x=0$ tem-se o carbono presente na superfície do sítio ativo. As espécies de hidrogênio adsorvidas são então recombinadas, produzindo moléculas de hidrogênio e, posteriormente, são liberadas na fase gasosa, de acordo com as Reações 10 - 14 (FAN et al., 2009a).

$$
\begin{aligned}
& \mathrm{CH}_{4}+2 \mathrm{M} \rightleftharpoons \mathrm{CH}_{3}-\mathrm{M}+\mathrm{H}-\mathrm{M}, \\
& \mathrm{CH}_{3}-\mathrm{M}+2 \mathrm{M} \rightleftharpoons \mathrm{CH}_{2}-\mathrm{M}+\mathrm{H}-\mathrm{M}, \\
& \mathrm{CH}_{2}-\mathrm{M}+2 \mathrm{M} \rightleftharpoons \mathrm{CH}-\mathrm{M}+\mathrm{H}-\mathrm{M}, \\
& \mathrm{CH}-\mathrm{M}+2 \mathrm{M} \rightleftharpoons \mathrm{C}-\mathrm{M}+\mathrm{H}-\mathrm{M}, \\
& 2 \mathrm{H}-\mathrm{M} \rightleftharpoons \mathrm{H}_{2}-2 \mathrm{M} .
\end{aligned}
$$

Em relação ao processo de formação da molécula de $\mathrm{CO}$, dois mecanismos são propostos para descrever o papel dos suportes ácidos (Reações 15 a 17) e básicos (Reações 18 a 22) durante a reforma seca do metano. Durante a adsorção da molécula de $\mathrm{CO}_{2}$ sobre os suportes ácidos pode ocorrer a acumulação de depósitos de carbono altamente desidrogenados. Esta concentração tende a provocar a perda continua da atividade por deposição, enquanto que a adsorção sobre um suporte básico ocorre na vizinhança do metal para a formação de espécies de carbonato, que posteriormente é reduzida gerando CO. (BUDIMAN et al., 2012; FAN et al., 2009b):

$$
\begin{array}{lr}
\mathrm{CO}_{2} \rightleftharpoons \mathrm{CO}_{2}-\mathrm{M}, & \text { Reação } 15 \\
\mathrm{CO}_{2}-\mathrm{M} \rightleftharpoons \mathrm{CO}-\mathrm{M}+\mathrm{O}-\mathrm{M}, & \text { Reação } 16 \\
\mathrm{CO}-\mathrm{M} \rightleftharpoons \mathrm{CO}-\mathrm{M} . & \text { Reação } 17 \\
\mathrm{CO}_{2} \rightleftharpoons \mathrm{CO}_{2}-\mathrm{S}, & \text { Reação } 18
\end{array}
$$




$$
\begin{array}{lr}
\mathrm{CO}_{2}-\mathrm{S}+\mathrm{O}^{2-} \rightleftharpoons \mathrm{CO}_{2}-\mathrm{S}, & \text { Reação } 19 \\
2 \mathrm{H}-\mathrm{M} \rightleftharpoons 2 \mathrm{H}-\mathrm{S}, & \text { Reação 20 } \\
\mathrm{CO}_{3}^{2-}-\mathrm{S}+2 \mathrm{H}-\mathrm{S} \rightleftharpoons \mathrm{HCO}_{2}^{-}-\mathrm{S}+\mathrm{OH}^{-}-\mathrm{S}, & \text { Reação 21 } \\
\mathrm{CO}-\mathrm{S} \rightleftharpoons \mathrm{CO} . & \text { Reação 22 }
\end{array}
$$

Quando a razão $\mathrm{CH}_{4} / \mathrm{CO}_{2}$ possui um valor próximo a unidade, a geração do carbono não é termodinamicamente esperada, uma vez que existe uma quantidade suficiente de oxigênio do $\mathrm{CO}_{2}$ para oxidar o carbono derivado da decomposição do metano (KOHN, 2012). O termo coque é bastante utilizado para os materiais carbonáceos, os quais são formados e depositados sobre a superfície dos catalisadores durante a reação, principalmente de hidrocarbonetos. Segundo o trabalho reportado por Wolf e Alfani (1982), o coque consiste na mistura de anéis aromáticos mono e policíclicos conectados a fragmentos alifáticos e alicíclicos. A composição do coque depende do reagente, catalisador, condição e tempo de reação. Entre as espécies de carbono formadas por reações gasosas estão os alcatrões e fuligens. Tais espécies podem se formar após uma etapa de difusão e, posteriormente, uma precipitação sobre a Esse superfície dos catalisadores metálicos, ocasionando a produção de filamentos de carbono, como reportado na Figura 1 (BAKER, 1989). Estes filamentos podem não obstruir imediatamente a superfície metálica, porém tendem a provocar a fratura dos grãos do catalisador e um possível encapsulamento. Tal fenômeno provoca perda de carga dos reatores, seguida da desativação (VALENTINI et al., 2003). Dentre as formas filamentosas, podem-se citar as fibras, tubos ou whiskers. Até $675 \mathrm{~K}$, o carbono é dito amorfo, também denominado de Ca, considerado aforma mais reativa do carbono, enquanto que as plaquetas de grafite, também denominadas de "hard" são formadas acima de 975K. Além do mais, é considerado pouco reativo, requerendo alta temperatura para a sua oxidação. carbono pode provocar o bloqueamento dos sítios ativos, acarretando a desativação dos mesmos. Nas temperaturas intermediárias, uma mistura dos dois tipos é obtida (AUDIER et al., 1981; PAKHARE; SPIVEY, 2014). Estudos microestruturais revelam que os filamentos de grafite possuem uma estrutura tipo espinha de peixe (fishbone), de maneira que as camadas estão empilhadas paralelamente à superfície do metal (YANG, 1989). Estudos realizados por Guo e colaboradores (2007) sobre a deposição de carbono no catalisador de $\mathrm{Ni} / \mathrm{MgAl}_{2} \mathrm{O}_{4}$ verificaram a presença de três tipos de carbono $(\alpha, \beta$ e $\gamma)$, sendo que $C_{\gamma}$ representa o carbono tipo grafite $(\gamma)$, enquanto que os $C_{\alpha}$ e $C_{\beta}$ são atribuídos as espécies de carbono amorfo e poliaromático. . 
Figura 1 - Representação da formação do filamento de carbono.

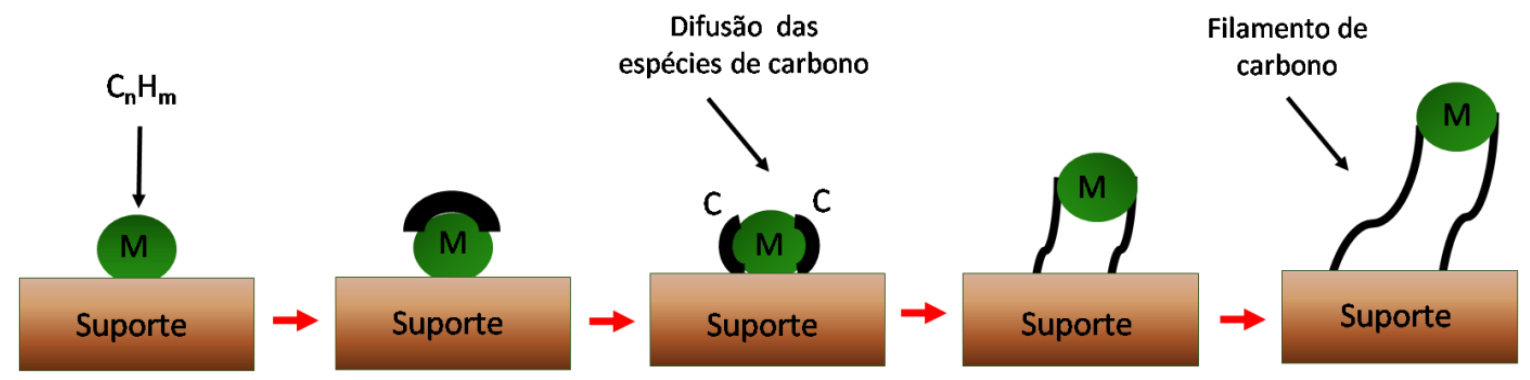

Fonte: Adaptado do trabalho de BAKER, 1989 e NOGUEIRA, 2014.

A temperatura pode ser considerada com um dos fatores para a formação do carbono, no entanto, a composição do catalisador igualmente deve ser considerada (AUDIER et al., 1981). Reporta-se que a deposição do carbono pode ser suprimida quando o metal está suportado num óxido com basicidade de Lewis forte. Em resumo, pode-se dizer que a formação do carbono é influenciada por vários fatores, tais como: o metal utilizado e sua estrutura cristalina, interação metal-suporte, acidez e a basicidade dos suportes (BRADFORD; VANNICE, 1999). A formação de carbono tende a ocasionar a desativação de catalisadores, entretanto, é importante ressaltar que outros fatores externos também contribuem para essa desativação, por exemplo, sinterização do metal, formação de espécies inativas e a oxidação do metal durante a reação de reforma (BUDIMAN et al., 2012).

Visando a busca de catalisadores mais eficientes com o propósito de amenizar os problemas encontrados na reforma seca do metano, muitas pesquisas vêm sendo desenvolvidas nos âmbitos acadêmicos e industriais, se refletindo no número de publicações encontradas na literatura, conforme ilustrado na Figura 2. Verifica-se que a quantidade de artigos no intervalo de 1984 a 2016 é crescente. Nota-se ainda que a China e os Estados Unidos são os países que mais publicaram nesse intervalo com $\sim 18$ e $15 \%$ do total de publicações, respectivamente. Enquanto que no Brasil a porcentagem é de $4,31 \%$ do total de publicações. Tal aumento de publicações vem sendo alavancado devido aos problemas ambientais previstos para as próximas décadas, visto que o $\mathrm{CO}_{2}$ é o principal responsável pela amplificação do efeito estufa. No Brasil, o $\mathrm{CO}_{2}$ é proveniente de várias fontes, destacando-se as destilarias de álcool, as termelétricas e unidades de regeneração do craqueamento catalítico. 
Figura 2 - (a) Histograma de artigos publicados e indexados por ano pela Scopus; (b) Distribuição em porcentgem $(\%)$ dos primeiros doze países que mais publicaram na temática reforma seca do metano, onde mostramos a participação do Brasil com 4,31\%. Na pesquisa, as expressões 'dry reforming of the methane' foram utilizadas.

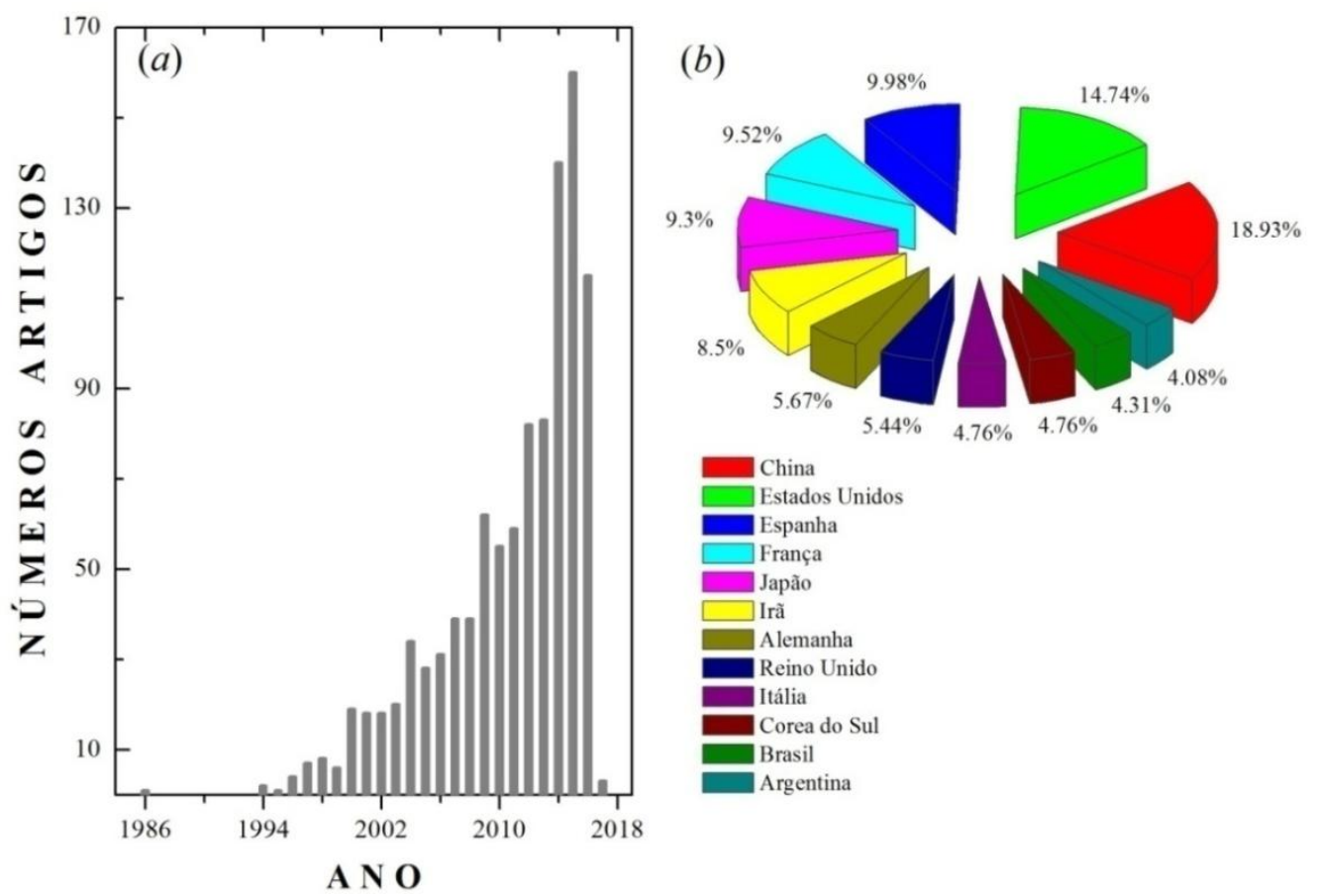

Fonte: Autoria própria com os dados estatísticos obtidos na base Scopus no dia 25/10/2016.

\subsection{Catalisadores estudados nas reações de reforma}

O uso de metal nobre para aplicação como catalisador na reforma seca do metano é progressivamente inviabilizado pelo seu elevado custo no mercado. Alternativas ao uso destes metais vêm sendo implementadas, visando a diminuição da energia de ativação da reação de reforma seca e o aumento da seletividade para $\mathrm{H}_{2}$ e $\mathrm{CO}$, induzindo, por conseguinte, a diminuição da formação de carbono (KOHN, 2012). Geralmente, os metais do grupo VIII da tabela periódica são os mais empregados na obtenção de catalisadores, estando presentes sobre uma variedade de suportes. Entre os metais estudados estão Co, Ni, Ru, Rh, Pd e Pt. Geralmente o níquel metálico $\left(\mathrm{Ni}^{0}\right)$ é utilizado por razões econômicas, alta reatividade e por estar no seu estado reduzido em boa parte das condições (ROSS, 1978). Os catalisadores desenvolvidos utilizando o níquel possuem diversas aplicações, especificamente: reforma do metano com $\mathrm{CO}_{2}$ (NEWNHAM, 2012); craqueamento catalítico do metano para produzir hidrogênio (MONNERAT et al., 2001); reforma a vapor do etanol (BUSCA et al., 2010) e reforma de hexadecano (ROSA; NAVARRO, 06). Entre os óxidos utilizados como suportes estão $\mathrm{CeO}_{2}$, $\mathrm{Al}_{2} \mathrm{O}_{3}, \mathrm{La}_{2} \mathrm{O}_{3}, \mathrm{MgO}, \mathrm{CaO}, \mathrm{SiO}_{2}, \mathrm{TiO}_{2}$ e $\mathrm{ZrO}_{2}$. (ZHANG et al., 2003). Uma das formas de a- 
menizar o problema da deposição do carbono é a utilização de suportes com caráter básico e que promova uma elevada dispersão de sua fase ativa (GENNEQUIN et al., 2011). Catalisadores de $\mathrm{Ni}$ suportados em material inerte, como $\alpha-\mathrm{Al}_{2} \mathrm{O}_{3}$, apresentam atividades nas reações de reforma principalmente devido a sua basicidade, porém normalmente sofrem desativação. Uma maneira de melhorar a atividade e estabilidade do catalisador é a escolha de um suporte adequado. Encontra-se na literatura estudos com catalisadores de $\mathrm{Ni}^{0}$ em diferentes suportes, tais como $\mathrm{ZrO}_{2}$, em substituição aos suportes clássicos $\mathrm{Al}_{2} \mathrm{O}_{3}$ e $\mathrm{SiO}_{2}$. Dentre as vantagens do $\mathrm{ZrO}_{2}$, tem-se a sua alta condutividade iônica, estabilidade térmica e baixa acidez. Dentre as desvantagens, reporta-se uma baixa área superficial e custo elevado frente aos suportes clássicos comerciais. Não obstante, tal óxido é considerado um bom suporte catalítico nas reações de reforma (DENG et al., 2008), tal como o ZnO, que apresenta propriedades básicas e redox, além de melhorar a dispersão das partículas de níquel na estrutura (CHEN, 2008). Vale ressaltar ainda que catalisadores de Ni preparados a partir de precursores do tipo hidróxidos duplos lamelares (HDL's: hidroxide double lamelar) apresentam maior atividade e menor formação de carbono por área superficial na reforma seca do metano, comparativamente aos catalisadores preparados por método tradicional de impregnação (SHISHIDO et al., 2001). Catalisadores obtidos de HDL's contêm o metal distribuído homogeneamente na estrutura. Durante o processo de ativação do catalisador, uma parte substancial das espécies reduzidas de Ni pode migrar do interior da estrutura para a superfície, formando partículas de $\mathrm{Ni}$ altamente dispersas e resultando em uma maior atividade. Como reportado na literatura, um dos produtos da queima da hidrotalcita em alta temperatura é a fase de espinélio. Logo, a importância desta fase, a exemplo do $\mathrm{NiAl}_{2} \mathrm{O}_{4}$, como suporte está em ser mais ativo contra a formação de carbono na reação de reforma, dada a sua resistência à sinterização, além da presença de ambientes ácidos e básicos (BARTHOLOMEW, 2001).

\subsubsection{Hidróxidos duplos lamelares}

Alguns hidróxidos duplos lamelares (HDL's) pertencem ao grupo das estruturas lamelares pilarizadas (PLS: pillared lamelar structure). Tais compostos remetem à brucita, consistindo no hidróxido de magnésio $\left[\mathrm{Mg}\left(\mathrm{OH}_{2}\right)\right]$, esse composto é formado pela presença dos cátions de magnésio numa coordenação octaédrica com hidroxilas (CREPALDI; VALIM, 1998). A estrutura de um HDL é baseada em unidades de $\mathrm{M}(\mathrm{OH})_{6}$ ligados pelas arestas para 
construir as camadas do tipo brucita ( ver Figura 3). Sabe-se que, tais compostos possuem a fórmula geral apresentada a seguir (RIVES, 2001; ZHAO et al., 2012):

$$
\left[\mathrm{M}_{1-\mathrm{x}}^{\mathrm{II}} \mathrm{M}_{x}^{\mathrm{III}}(\mathrm{OH})_{2}\right]^{\mathrm{q}+}\left[\mathrm{A}^{\mathrm{n}-}\right]_{\mathrm{q} / \mathrm{n}} \cdot m \mathrm{H}_{2} \mathrm{O}
$$

onde, $\mathrm{M}^{\mathrm{II}}$ representa o cátion metálico divalente $[\mathrm{Mg}, \mathrm{Fe}, \mathrm{Co}, \mathrm{Cu}, \mathrm{Ni}$ ou $\mathrm{Zn}], \mathrm{M}^{\mathrm{III}}$ um cátion metálico trivalente [Al, Cr, Ga, Mn ou Fe], os quais estão localizados nas lamelas, e que necessitam das cargas dos ânions de compensação. Nesse caso, além das pontes de hidrogênio, ocorrem atrações eletrostáticas entre as a lamelas e os ânions. $A$ representa um ânion intercalado com carga $n, x(0,2$ a 0,4$)$ denota a densidade de carga, podendo ser calculado pela razão entre os cátions di e trivalente $\left[\mathrm{M}^{\mathrm{III}} /\left(\mathrm{M}^{\mathrm{II}}+\mathrm{M}^{\mathrm{III}}\right)\right]$ e $m$ o número de mols de água localizada na intercamada, podendo ser determinado pelas medidas termogravimétricas (CONCEIÇÃO et al., 2007). Tais compostos podem possuir os seguintes ânions: $\mathrm{F}^{-}, \mathrm{Cl}^{-}, \mathrm{Br}^{-}, \mathrm{I}^{-},\left(\mathrm{ClO}_{4}\right)^{-},\left(\mathrm{NO}_{3}\right)^{-}$, $\left(\mathrm{ClO}_{3}\right)^{-},\left(\mathrm{IO}_{3}\right)^{-}, \mathrm{OH}^{-},\left(\mathrm{CO}_{3}\right)^{2-},\left(\mathrm{SO}_{4}\right)^{2-},\left(\mathrm{S}_{2} \mathrm{O}_{3}\right)^{2-},\left(\mathrm{WO}_{4}\right)^{2-},\left(\mathrm{CrO}_{4}\right)^{2-}, \mathrm{Fe}\left(\mathrm{CN}_{6}\right)^{3-}, \mathrm{Fe}\left(\mathrm{CN}_{6}\right)^{4-}$ e Si$\mathrm{O}(\mathrm{OH})^{-}$(inorgânicos); hexanodióico, oxálico, succínico e malônico (ácidos orgânicos); $\left(\mathrm{PMo}_{12} \mathrm{O}_{40}\right)^{3-}$, $\left(\mathrm{PW}_{12} \mathrm{O}_{40}\right)^{3-}$ (heteropoliácidos). A estrutura de HDL contém uma variável quantidade de água presente na intercamada e no contorno de grão.

Figura 3 - Representação esquemática da estrutura dos hidóxidos duplos lamelares ( HDL's).

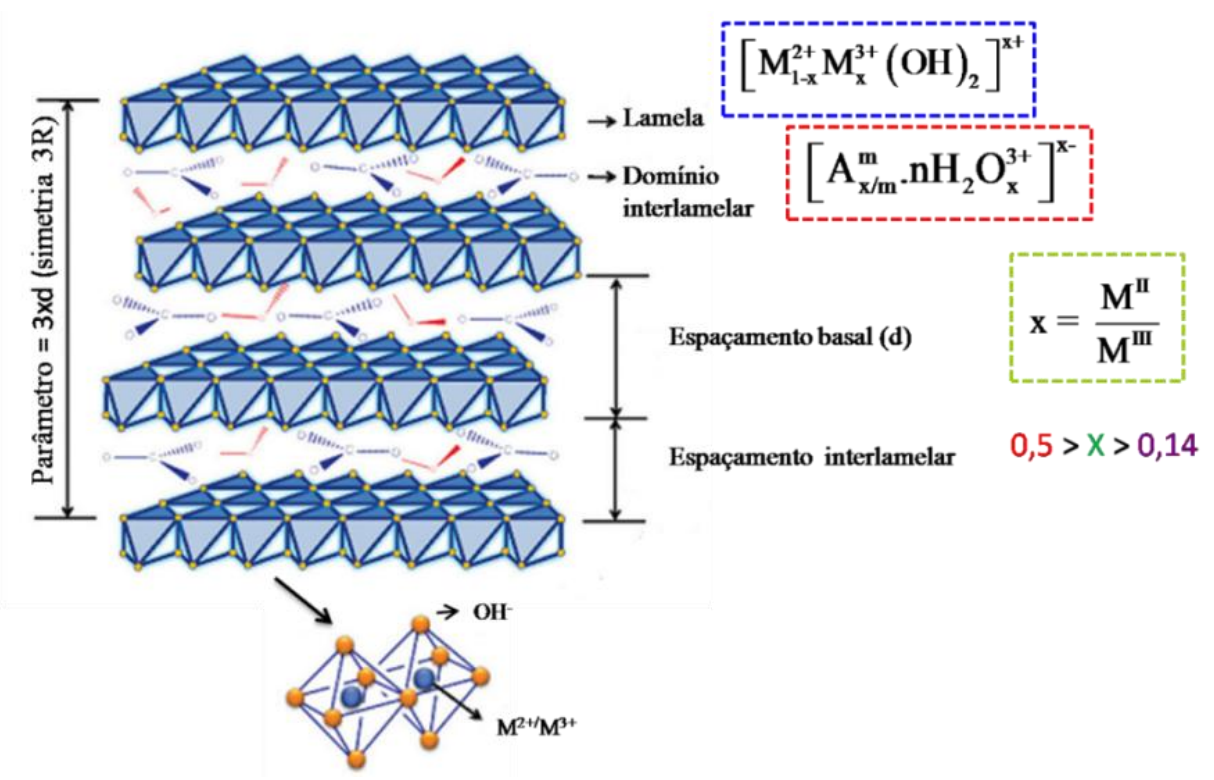

Fonte: (CUNHA et al., 2010) 
As propriedades dos cátions $\mathrm{M}^{\mathrm{II}}$ e $\mathrm{M}^{\mathrm{III}}$ influenciam diretamente na formação dos hidróxidos duplos lamelares. Por exemplo, um cátion de raio iônico igual ao íon $\mathrm{Ca}^{+2}$ e outro de menor raio, tal como o íon $\mathrm{Be}^{+2}$ podem influenciar a não formação da fase de HDL (CAVANI et al., 2010). Vale ressaltar que a diferença entre os raios iônicos de $\mathrm{M}^{\mathrm{II}}$ e $\mathrm{M}^{\mathrm{III}}$ não pode variar mais do que 30\% (KLOPROGGE et al., 2004).

Um fenômeno que ocorre no HDL o chamado politipismo, consistindo em arranjos estruturais tridimensionais distintos, porém com mesma estequiometria. Vários fatores podem induzir o politipismo, por exemplo: a estrutura eletrônica dos átomos; extensão da interação entre os segundos vizinhos mais próximos e defeitos estruturais (ATKINS). Em 1930, Aminoff e Broom reconheceram a existência de dois politipos para a estrutura do tipo brucita, uma de simetria romboédrica $(\mathrm{R} 3 m)$ e outra hexagonal $\left(\mathrm{P}_{3} m m c\right)$, conforme sumarizado na Tabela 2 (LOZANO et al., 2012). Do ponto de vista cristalográfico, a estrutura dos demais compostos do tipo HDL's são similares ou idênticas à hidrotalcita natural reportada pela primeira vez em 1842, com fórmula $\mathrm{MgAl}_{2}(\mathrm{OH})_{16}\left(\mathrm{CO}_{3}\right) \cdot 4 \mathrm{H}_{2} \mathrm{O}$ (RODRIGUES, 2007).

Tabela 2 - Exemplo de hidróxidos duplos lamelares (HDL’s) com suas respectivas fórmulas químicas e sistema cristalinos (3R, romboédrico; $2 \mathrm{H}$, hexagonal).

\begin{tabular}{ccc}
\hline Nome & \multicolumn{1}{c}{$\begin{array}{c}\text { Fórmula } \\
\text { Ideal }\end{array}$} & $\begin{array}{c}\text { Estrutura } \\
\text { Cristalina }\end{array}$ \\
\hline Hidrotalcita & $\mathrm{Mg}_{6} \mathrm{Al}_{2}(\mathrm{OH})_{16} \mathrm{CO}_{3} \cdot 4 \mathrm{H}_{2} \mathrm{O}$ & $3 \mathrm{R}$ \\
Manasseita & $\mathrm{Mg}_{6} \mathrm{Al}_{2}(\mathrm{OH})_{16} \mathrm{CO}_{3} \cdot 4 \mathrm{H}_{2} \mathrm{O}$ & $2 \mathrm{H}$ \\
Piroaurita & $\mathrm{Mg}_{6} \mathrm{Fe}_{2}(\mathrm{OH})_{16} \mathrm{CO}_{3} \cdot 4 \mathrm{H}_{2} \mathrm{O}$ & $3 \mathrm{R}$ \\
Barbertonita & $\mathrm{Mg}_{6} \mathrm{Cr}_{2}(\mathrm{OH})_{16} \mathrm{CO}_{3} \cdot 4 \mathrm{H}_{2} \mathrm{O}$ & $2 \mathrm{H}$ \\
Takovita & $\mathrm{Ni}_{6} \mathrm{Al}_{2}(\mathrm{OH})_{16} \mathrm{CO}_{3} \cdot 4 \mathrm{H}_{2} \mathrm{O}$ & $3 \mathrm{R}$ \\
\hline
\end{tabular}

Fonte: (CREPALDI; VALIM, 1998) - Reproduzido com permissão - Copyright @ 9 2016, Elsevier.

Em 1942, Feiknetch misturou as soluções aquosas de sais com soluções básicas, com isso sintetizou um grande número de compostos com estrutura do tipo HDL's, para o qual denominou de doppelschichtstrukturen (ou estrutura de dupla camada). Tal estrutura seria constituída pela intercalação de duas camadas formadas individualmente pelos hidróxidos de cada um dos cátions, uma formada pelo hidróxido do cátion divalente e outra pelo hidróxido do cátion trivalente. No entanto, essa ideia foi refutada por Allmann e Taylor com base em medidas de raios $\mathrm{X}$ de monocristais. Concluíram que os dois cátions são localizados nas camadas e, entre estas, os íons carbonatos e as moléculas de água estão presentes (CAVANI; TRIFIRO; VACCARI, 2010; RODRIGUES, 2007; REICHLE, 1986).. 
Recentemente, tais sistemas vêm atraindo a atenção da comunidade científica para aplicações como catalisadores (DIAS et al., 2011), por exemplo, nas reações orgânicas (reações de epoxidação de estireno usando Mg/Al LDHs) (KIRM et al., 2004); hidroxilação de fenol sobre Co/Ni/Al LDH's (RIVES, 2003); aplicação médica de LDH's como agente antiácido e antipepsina, e nos processos bioquímicos de intercalação de vitaminas (A, C e D) nas intercamadas para manter a estabilidade das mesmas, por serem sensíveis a luz (MEYER; SAUVAGE, 2014). A principal vantagem do emprego dos HDL's como catalisadores básicos é que podem ser direcionados para reações específicas, bem como a obtenção de biodiesel (CANTRELL et al., 2005). No que concerne a estabilidade térmica dos HDL's, o processo de desintegração induz a desidratação, desidroxilação, perda de ânions e o desaparecimento dos planos cristalográficos (003), (006) e (012) característicos de HDL's resultando na mistura de óxidos em temperaturas superiores a $400{ }^{\circ} \mathrm{C}$ (CORTEZ; MEIRA, 2008; ERICKSON; BOSTROM; FROST, 2005). Na literatura, reporta-se que o produto natural da decomposição térmica de HDL's têm sido óxidos binários livres, em baixas temperaturas, e espinélios em altas temperaturas (CAVANI, 1991, MA et al., 2011). Outro ponto importante é que óxidos derivados da decomposição térmica de HDL's apresentam as seguintes propriedades (BREVY, 2006; KUŚTROWSKI et al., 2005):

Elevada área superficial, resultante do processo de decomposição térmica das hidrotalcitas;

Alta estabilidade térmica;

Propriedades básicas (sítios de Lewis);

Formação de misturas homogêneas de óxidos metálicos em escala nanométrica e estáveis no tratamento térmico, que geralmente são denominados na literatura de óxidos mistos ou soluções de óxidos mistos;

Apresentam partículas metálicas dispersas que são obtidas após o processo de redução;

“Efeito memória”, consistindo na regeneração da estrutura original de HDL's.

O efeito memória consiste na reestruturação de HDL's ao entrarem em contato com soluções contendo os ânions ou na presença do ar úmido. Esta propriedade permite que haja uma a intercalação de ânions específicos nas intercamadas, dessa forma, essa habilidade de remover os ânions é que torna os HDL's compostos que podem ser aplicados em diversas áreas (ERICKSON et al., 2005). A Figura 4 mostra o fenômeno do efeito memória, onde,verifica-se que após o tratamento térmico ocorre a formação de uma mistura atômica de 
óxidos metálicos. Após ser colocada em uma solução contendo íons carbonatos, estes são adsorvidos nas intercamadas juntamente com as moléculas de água, enquanto que as camadas são reconstruídas pela formação dos octaedros ligados pelas arestas. No segundo caso, ao submeter os óxidos na presença de água ocorrerá a formação da intercamada, além disso, as hidroxilas formarão as ligações com os íons metálicos dando origem aos octaedros.

Figura 4 - Representação do efeito memória que ocorre nos hidróxidos duplos lamelares (HDL's).

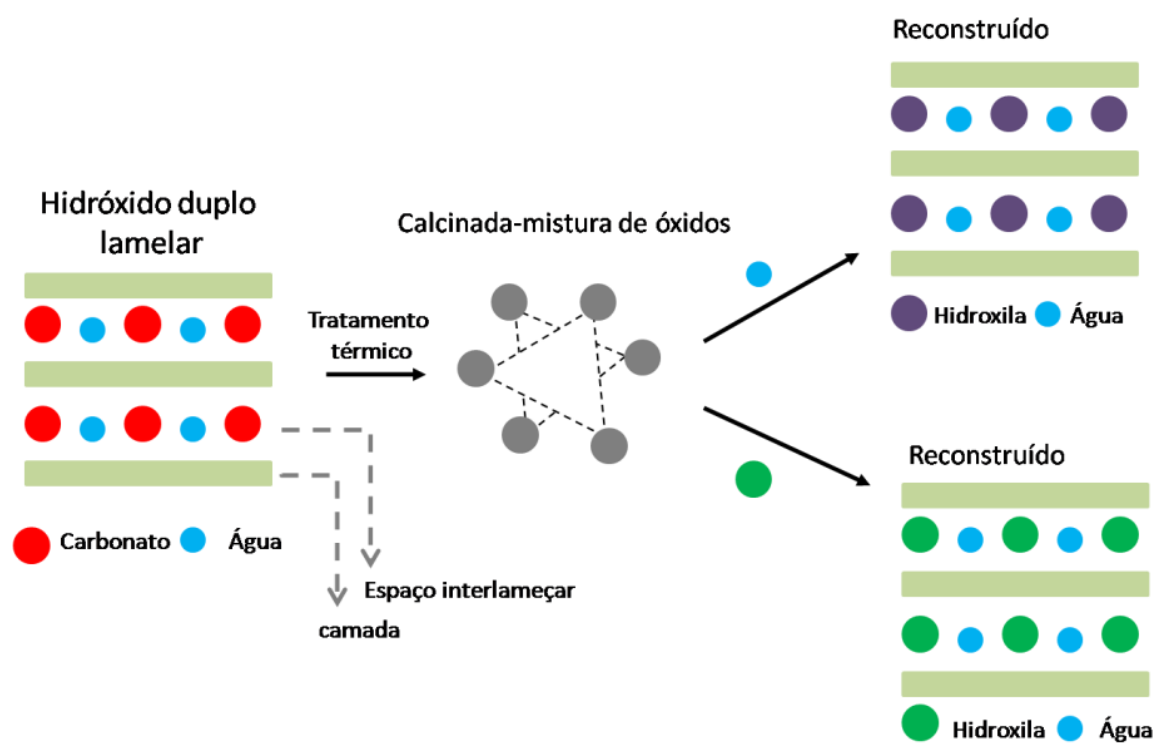

Fonte: Autoria própria.

É válido ressaltar que o óxido derivado de HDL possui uma vasta aplicação, dentre as quais se destacam: (i) polimerização de alcenos; (ii) condensação aldólica de aldeídos e cetonas (RAO, 1998); (iii) reforma seca e a vapor de hidrocarbonetos (GENNEQUIN et al., 2011; LUCRÉDIO et al., 2011a); (iv) metanação; (v) síntese de metanol e alcoóis mais pesados (BUSETTO, 1984); (vi) síntese de hidrocarbonetos (Fischer-Tropsch) e (vii) hidrólise de nitrilas (CAVANI et al., 2010). Finalmente, cabe mencionar que muito embora o termo hidrotalcita se refere originalmente aos minerais de fórmula $\mathrm{Mg}_{6} \mathrm{Al}_{2}(\mathrm{OH})_{16} \mathrm{CO}_{3} .4 \mathrm{H}_{2} \mathrm{O}$, na literatura este termo é amplamente empregado para designar quaisquer sistemas de fórmula geral $\left[\mathrm{M}^{\mathrm{II}}{ }_{1 \text { - }}\right.$ $\left.{ }_{x} \mathrm{M}^{\mathrm{IIII}}{ }_{x}(\mathrm{OH})_{2}\right]^{\mathrm{q}+}\left[\mathrm{A}^{n-}\right] \mathrm{q} / \mathrm{n} . m \mathrm{H}_{2} \mathrm{O}$, principalmente quando há substituições parciais nos sítios dos cátions $\mathrm{M}^{\mathrm{II}}$ e $\mathrm{M}^{\mathrm{III}}$. Portanto, empregaremos daqui em diante o termo hidrotalcita para nos referirmos aos precursores investigados na presente tese. 


\subsubsection{Metodos de síntese para obtenção HDL's}

Entre os métodos mais utilizados para a síntese de hidrotalcitas estão os de precipitação a pH constante ( também denominado de coprecipitação), precipitação a pH variável, reação de deposição/precipitação síntese pelo método hidrotermal, métodos eletroquímicos e reações de hidrólise. É importante salientar que muitos fatores podem influenciar a síntese das argilas aniônicas, como ilustrado na Tabela 3.

Tabela 3 - Fatores que influenciam a síntese de argilas aniônicas.

\begin{tabular}{cc}
\hline Variáveis estruturais & Variáveis de preparação \\
\hline Tamanho de cátions & $\mathrm{pH}$ \\
Valor de $\mathrm{x}$ & Método de precipitação \\
Estequiometria dos cátions & Concentrações dos reagentes \\
Mistura dos cátions & Lavagem e secagem \\
Natureza dos cátions & Presença de impurezas \\
\hline
\end{tabular}

Fonte: (VACCARI, 1998) - Reproduzido com permissão - Copyright @ 2016, Elsevier.

\subsection{Método de coprecipitação}

O método de coprecipitação foi realizado pela primeira vez por Feitknecht. Foi realizada a síntese do sistema $\mathrm{Mg}-\mathrm{Cr}-\mathrm{CO}_{3}$ partindo das soluções diluídas ( 0,01 a 0,1 mol. $\mathrm{L}^{-1}$ ). Durante a etapa de lavagem prolongada, o precipitado inicialmente amorfo começa a cristalizar-se em hidrotalcita de baixo ordenamento (FEITKNECHT, 1938). Esse método foi aperfeiçoado por Reichle em 1930, permitindo uma considerável variabilidade no que diz respeito à natureza do cátion $\mathrm{M}^{\mathrm{II}}$ e $\mathrm{M}^{\mathrm{III}}$, além do controle da morfologia e da área superficial. No método esmerado por Reichle, as soluções aquosas dos cátions (alumínio / magnésio) e dos precipitantes (carbonato/ hidróxido sódio) foram adicionadas rapidamente com agitação à temperatura ambiente. A quantidade em mols de hidróxido de sódio usadafoi duas vezes a de magnésio e três vezes de alumínio. Prontamente, o gel obtido foi deixado sob aquecimento para cristalização durante longo período (18 h). (CREPALDI; VALIM, 1998; REICHLE, 1986). A síntese de coprecipitação pode ser entendida de acordo com a Reação 23. Nesse método, vários são os fatores que podem influenciar a sínteses, por exemplo, velocidade de adição de uma solução sobre a outra, o pH final da suspensão, grau de agitação e temperatura da mistura (VACCARI, 1998). Na literatura existem vários trabalhos reportando a síntese de hidrotalcita 
pelo método de coprecipitação a pH constante e variável. (FRAILE et al., 2010; PAVEL et al., 2011). O aparato mais utilizado para a obtenção desse composto é denominado titulador automático (ver, Figura 5). Esse sistema é constituído de um reator, titulador com fluxo constante, controlador de $\mathrm{pH}$ e controle de temperatura. Esse tipo de aparato permite controlar simultaneamente a taxa de adição das soluções, temperatura e pH da síntese (ROY et al., 1992).

$(1-\mathrm{x}) \mathrm{M}^{\mathrm{II}}\left(\mathrm{X}^{-}\right)_{2}+\mathrm{x} \mathrm{M}^{\mathrm{III}}\left(\mathrm{X}^{-}\right)_{3}+2 \mathrm{M}^{\mathrm{I}} \mathrm{OH}+(\mathrm{x} / \mathrm{m}) \mathrm{M}_{\mathrm{m}}^{\mathrm{I}}\left(\mathrm{A}^{\mathrm{m}-}\right) \rightarrow$ $\mathrm{M}_{1-\mathrm{x}}^{\mathrm{II}} \mathrm{MIII}_{\mathrm{x}}(\mathrm{OH})_{2}\left(\mathrm{~A}_{\mathrm{x} / \mathrm{n}}^{\mathrm{m}-}\right) \mathrm{nH}_{2} \mathrm{O}+(2+\mathrm{x}) \mathrm{M}^{\mathrm{I} X}$.

Figura 5 - Esquema do aparato experimental para uma preparação por coprecipitação a pH constante.

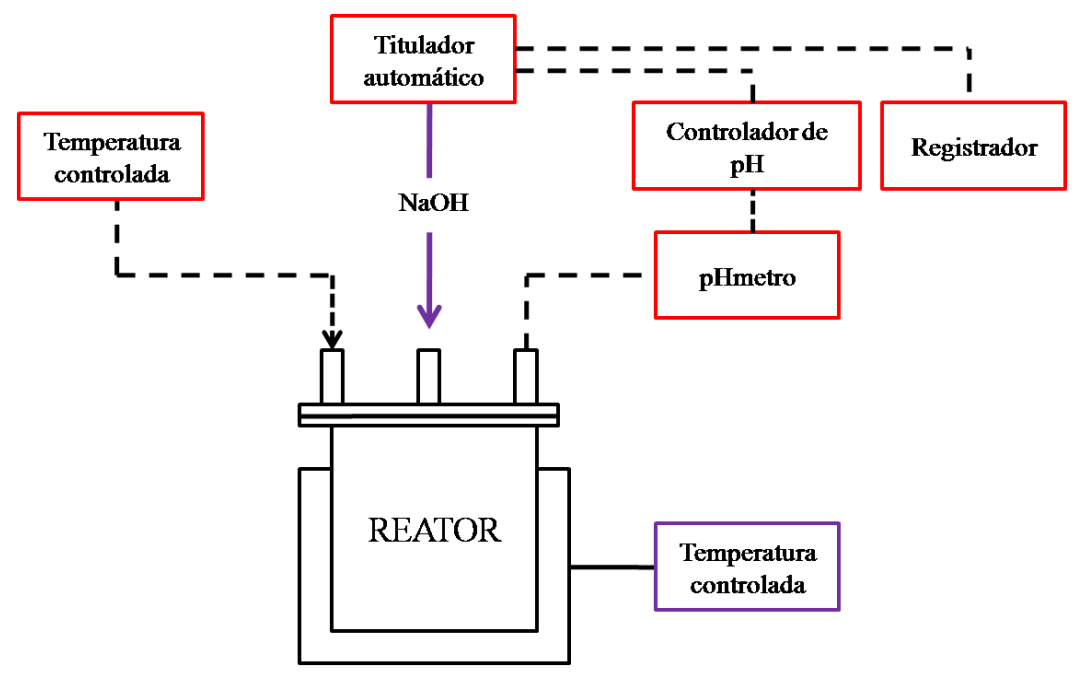

Fonte: (ROY et al., 1992) 


\section{OBJETIVO}

\subsection{Objetivo Geral}

O presente trabalho tem por objetivo avaliar o desempenho frente à reforma seca do metano dos catalisadores de $\mathrm{Ni}$ dispersos nas matrizes $\mathrm{Zn} / \mathrm{Al} / \mathrm{Zr}$, Zn/Al e Zn/Zr. Tais catalisadores serão obtidos a partir da calcinação dos precursores, visando o aumento da dispersão do Ni nas matrizes e a minimização da perda da atividade na reforma seca do metano por processos de desativação.

\subsection{Objetivo Específico}

- $\quad$ Sintetizar os precursores NiZn/Al, NiZn-AlZr e NiZn-Zr com estrutura do tipo hidrotalcita baseado na substituição parcial do cation $\mathrm{Ni}^{2+}$ pelo $\mathrm{Zn}^{2+}$ (no sítio $\mathrm{M}^{\mathrm{II}}$ ) e $\mathrm{M}^{\mathrm{III}}=$ $\mathrm{Al}^{3+}$. No último caso, foi realizada a substituição parcial e total do $\mathrm{Al}^{3+}$ pelo cátion tetravalente $\left(\mathrm{Zr}^{4+}\right)$ a fim de verificar a formação da hidrotalcita.

- Obter os óxidos mistos (catalisadores) pelo tratamento térmico dos precursores nas temperaturas $550^{\circ} \mathrm{C}(5), 650^{\circ} \mathrm{C}(6)$ e $750^{\circ} \mathrm{C}(7)$, definindo os sistemas que serão estudados, nomeadamente, Ni/ZnAl (5,6 e7), Ni/ZnAlZr (5,6 e7) e Ni/ZnZr (5,6 e7).

- Caracterizar os precursores por análise química, termogravimetria, Difração de raios $X$ (DRX), fisissorção de $\mathrm{N}_{2}$, espectroscopia no infravermelho e Raman, microscopia eletrônica de varredura e transmissão a fim de avaliar suas características estruturais e morfológicas;

- Caracterizar os diferentes catalisadores por DRX, fisissorção de $\mathrm{N}_{2}$, basicidade usando indicador de Hammett, redução à temperatura programada $\left(\mathrm{RTP}-\mathrm{H}_{2}\right)$, dessorção à temperatura programada com $\mathrm{CO}_{2}\left(\mathrm{DTP}-\mathrm{CO}_{2}\right)$ e microscopia eletrônica de varredura com a finalidade de avaliar suas características estruturais e morfológicas;

- Avaliar o comportamento dos catalisadores frente à reação de reforma seca do metano. As reduções serão feitas em duas temperaturas diferentes: a primeira considerando o pico máximo de redução (catalisadores obtidos a $550^{\circ} \mathrm{C}, 650^{\circ} \mathrm{C}$ e $750^{\circ} \mathrm{C}$ ) e a segunda considerando a redução de $750^{\circ} \mathrm{C}$ (catalisadores obtidos a $650^{\circ} \mathrm{C}$ e $750^{\circ} \mathrm{C}$ );

- Realizar a caracterização dos catalisadores após a reação por DRX, espectroscopia Raman e microscopia eletrônica de varredura. 


\section{METODOLOGIA EXPERIMENTAL}

Neste capítulo, os materiais, reagentes, métodos de obtenção e caracterização dos precursores/catalisadores serão sumarizados, como a seguir.

\subsection{Preparação dos precursores/catalisadores}

Os materiais utilizados nesse trabalho foram: tubo de ensaio, becker, bastão, bureta, pipeta, balão volumétrico, erlenmeyer, reator, filtro de Büchner, bomba a vácuo, balança e mufla. Os reagentes utilizados para os experimentos estão listados na Tabela 4.

Tabela 4 - Reagentes químicos utilizados na síntese dos precursores com as respectivas fórmulas, valores de massa molecular, teor e as marcas dos regentes.

\begin{tabular}{|c|c|c|c|c|}
\hline Reagentes & Fórmula & $\mathrm{MM}\left(\mathrm{g} \cdot \mathrm{mol}^{-1}\right)$ & Teor & Marca \\
\hline Nitrato de níquel & $\mathrm{Ni}\left(\mathrm{NO}_{3}\right)_{2} \cdot 6 \mathrm{H}_{2} \mathrm{O}$ & 290,81 & $99,99 \%$ & Alta Aesar \\
\hline Nitrato de zinco & $\mathrm{Zn}\left(\mathrm{NO}_{3}\right)_{2} \cdot 6 \mathrm{H}_{2} \mathrm{O}$ & 297,49 & $96,0-103,0 \%$ & Synth \\
\hline Nitrato de zircônio & $\mathrm{Zr}\left(\mathrm{NO}_{3}\right)_{4} .5 \mathrm{H}_{2} \mathrm{O}$ & 339,00 & $99 \%$ & Vetec \\
\hline Nitrato de alumínio & $\mathrm{Al}\left(\mathrm{NO}_{3}\right)_{3} \cdot 9 \mathrm{H}_{2} \mathrm{O}$ & 375,13 & $98,0-102,0 \%$ & Vetec \\
\hline Hidróxido de sódio & $\mathrm{NaOH}$ & 40,00 & $97 \%$ & Synth \\
\hline Carbonato de sódio & $\mathrm{Na}_{2} \mathrm{CO}_{3}$ & 105,99 & $99,5 \%$ & Synth \\
\hline Ácido benzóico & $\mathrm{C}_{6} \mathrm{H}_{5} \mathrm{COOH}$ & 122,12 & $99,5 \%$ & Synth \\
\hline Tolueno & $\mathrm{C}_{6} \mathrm{H}_{5} \mathrm{CH}_{3}$ & 92,14 & $99,5 \%$ & Synth \\
\hline Fenolftaleína & $\mathrm{C}_{20} \mathrm{H}_{14} \mathrm{O}_{4}$ & 318,31 & - & Synth \\
\hline
\end{tabular}

Fonte: Autoria própria

Inicialmente, os cálculos para determinação da quantidade dos sais de nitrato, do carbonato e do hidróxido de sódio foram realizados com base nas seguintes fórmulas químicas:

$$
\begin{aligned}
& \mathrm{NiZn-AL} \equiv\left[(\mathrm{NiZn})_{0.750}(\mathrm{Al})_{0.250}(\mathrm{OH})_{2}\right]^{0.250}\left[\left(\mathrm{CO}_{3}{ }^{2-}\right)_{0.1250}\right]^{-0.250} \cdot \mathrm{mH}_{2} \mathrm{O} \\
& \mathrm{NiZn}-\mathrm{AlZr} \equiv\left[(\mathrm{NiZn})_{0.750}(\mathrm{Al})_{0.175}(\mathrm{Zr})_{0.075}(\mathrm{OH})_{2}\right]^{0.325}\left[\left(\mathrm{CO}_{3}{ }^{2-}\right)_{0.1625}\right]^{-0.325} \cdot \mathrm{mH}_{2} \mathrm{O} \\
& \mathrm{NiZn}-\mathrm{Zr} \equiv\left[(\mathrm{NiZn})_{0.750}(\mathrm{Zr})_{0.250}(\mathrm{OH})_{2}\right]^{0.500}\left[\left(\mathrm{CO}_{3}{ }^{2-}\right)_{0.2500}\right]^{-0.500} \cdot \mathrm{mH}_{2} \mathrm{O}
\end{aligned}
$$


Em seguida foram determinadas as quantidades molares de cada cátion, conforme Tabela 5 .

Tabela 5 - Quantidade molar dos cátions $\mathrm{Ni}^{2+}, \mathrm{Zn}^{2+}, \mathrm{Al}^{3+} \mathrm{e} \mathrm{Zr}^{4+}$ presentes nos precursores tipo hidrotalcita.

\begin{tabular}{ccccccc}
\hline \multirow{2}{*}{ Temperatura } & \multirow{2}{*}{ Metais } & \multirow{2}{*}{ Nomenclatura } & \multicolumn{4}{c}{ Cátions } \\
& & & $\mathrm{Ni}^{2+}$ & $\mathrm{Zn}^{2+}$ & $\mathrm{Al}^{3+}$ & $\mathrm{Zr}^{4+}$ \\
\hline \multirow{2}{*}{$100^{\circ} \mathrm{C}$} & $\mathrm{Ni} / \mathrm{Zn} / \mathrm{Al}$ & $\mathrm{NiZn}-\mathrm{Al}$ & 0,5 & 2,5 & 0,7 & 0,3 \\
& $\mathrm{Ni} / \mathrm{Zn} / \mathrm{Al} / \mathrm{Zr}$ & $\mathrm{NiZn}-\mathrm{AlZr}$ & 0,5 & 2,5 & 1 & 0 \\
& $\mathrm{Ni} / \mathrm{Zn} / \mathrm{Zr}$ & $\mathrm{NiZn}-\mathrm{Zr}$ & 0,5 & 2,5 & 0 & 1 \\
\hline
\end{tabular}

Fonte: Autoria própria.

A Figura 6 ilustra um diagrama para obtenção do precursor tipo hidrotalcita pelo método de coprecipitação química. Inicialmente, realizou-se a dissolução dos sais e hidróxido de sódio/carbonato em $100 \mathrm{~mL}$ de água deionizada. A primeira etapa do processo foi a precipitação da hidrotalcita, mantendo-se um $\mathrm{pH}=10,5$ (1. $\left.{ }^{\circ} \mathrm{PASSO}\right)$. Após isso, o material foi envelhecido e colocado em banho de areia numa temperatura de $65^{\circ} \mathrm{C}$ durante $15 \mathrm{~h}$, com o objetivo de promover o crescimento dos cristais de hidrotalcita (2. ${ }^{\circ}$ PASSO). Em seguida, o precipitado volumoso (coloração verde) obtido foi separado por filtração a vácuo ( 3 . $^{\circ}$ PASSO) e lavado com água destilada até um $\mathrm{pH}$ neutro para a retirada do sódio residual (4. ${ }^{\circ} \mathrm{PASSO}$ ). $\mathrm{O}$ material foi colocado numa estufa por $24 \mathrm{~h}$ a $100^{\circ} \mathrm{C}\left(5 .^{\circ} \mathrm{PASSO}\right)$ e reservado para a maceração manual num almofariz de porcelana ( $\left.6 .^{\circ} \mathrm{PASSO}\right)$. Finalmente, os precursores assim obtidos foram tratados termicamente a $550^{\circ}, 650^{\circ}$ e $750^{\circ} \mathrm{C}$ por $15 \mathrm{~h}$ num forno mufla com atmosfera de ar sintético e com uma rampa de aquecimento de $10^{\circ} \mathrm{C} / \mathrm{min}$, sendo devidamente condicionados em navículas de alta alumina, para formação dos catalisadores (7. ${ }^{\circ}$ PASSO). O material foi armazenado em um porta-amostra fechado para evitar efeitos higroscópicos. As nomenclaturas dos catalisadores na temperatura em $550^{\circ}, 650^{\circ}$ e $750^{\circ} \mathrm{C}$ estão apresentadas na Tabela 6.

Tabela 6 - Nomenclatura dos catalisadores obtidos nas temperaturas de $550^{\circ} \mathrm{C}, 650^{\circ} \mathrm{C}$ e $750^{\circ} \mathrm{C}$.

\begin{tabular}{cccc}
\hline $\begin{array}{c}\text { Temperatura } \\
\left({ }^{\circ} \mathrm{C}\right)\end{array}$ & $\mathrm{Ni} / \mathrm{Zn} / \mathrm{Al}$ & $\mathrm{Ni} / \mathrm{Zn} / \mathrm{Al} / \mathrm{Zr}$ & $\mathrm{Ni} / \mathrm{Zn} / \mathrm{Zr}$ \\
\hline 550 & $\mathrm{Ni} / \mathrm{ZnAl}-5$ & & $\mathrm{Ni} / \mathrm{ZnZr}-5$ \\
650 & $\mathrm{Ni} / \mathrm{ZnAl}-6$ & $\mathrm{Ni} / \mathrm{ZnAlZr}-6$ & $\mathrm{Ni} / \mathrm{ZnZr}-6$ \\
750 & $\mathrm{Ni} / \mathrm{ZnAl}-7$ & $\mathrm{Ni} / \mathrm{ZnAlZr}-7$ & $\mathrm{Ni} / \mathrm{ZnZr}-7$ \\
\hline
\end{tabular}

Fonte: Autoria própria. 
Figura 6 - Diagrama de preparação dos precursores tipo hidrotalcitas e catalisadores pelo método de coprecipitação química, onde se ilustra cada etapa do processo: Precipitação (1. ${ }^{\circ}$ PASSO); Decantação (2. ${ }^{\circ}$ PASSO); Filtração (3. ${ }^{\circ}$ PASSO); Lavagem (4. ${ }^{\circ}$ PASSO); Secagem (5. ${ }^{\circ}$ PASSO); Maceração (6. ${ }^{\circ}$ PASSO) e Tratamento térmico para obtenção dos catalisadores ( $\left.7 .^{\circ} \mathrm{PASSO}\right)$.

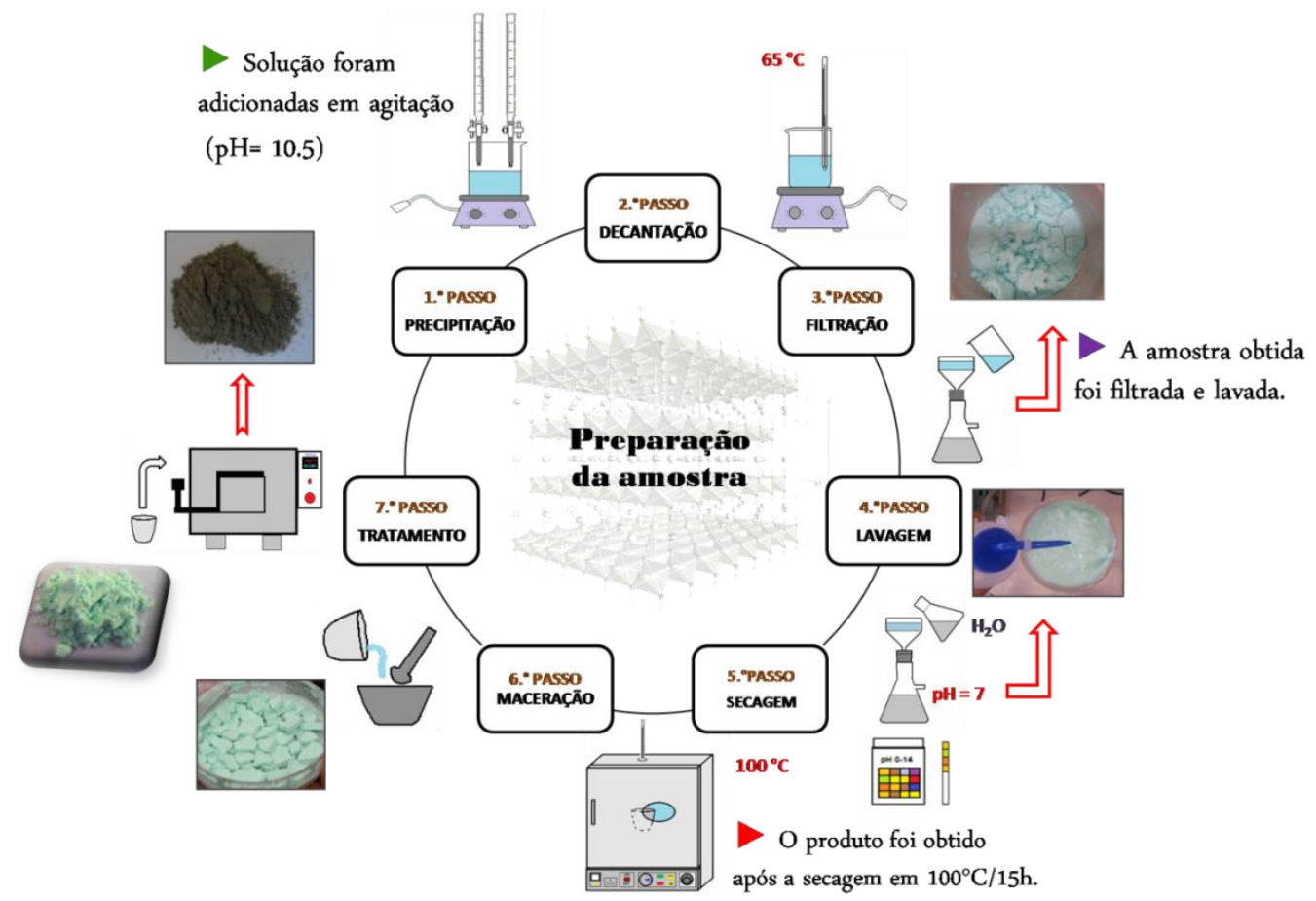

Fonte: Autoria própria.

\subsection{Teste de efeito Memória}

O diagrama para o teste de efeito memória está reportado na Figura 7. Inicialmente, pesou-se um grama de amostra calcinada, em seguida foi adicionada a solução de $\mathrm{Na}_{2} \mathrm{CO}_{3}$ em diversas concentrações e condicionadas dentro do tubo de ensaio. Posteriormente, a amostra foi lavada com água deionizada até um $\mathrm{pH}$ igual a 7. Por último, a amostra foi seca a uma temperatura de $100^{\circ} \mathrm{C}$.

Figura 7 - Metodologia utilizada para a realização do teste de efeito memória na presença da solução de $\mathrm{Na}_{2} \mathrm{CO}_{3}$.

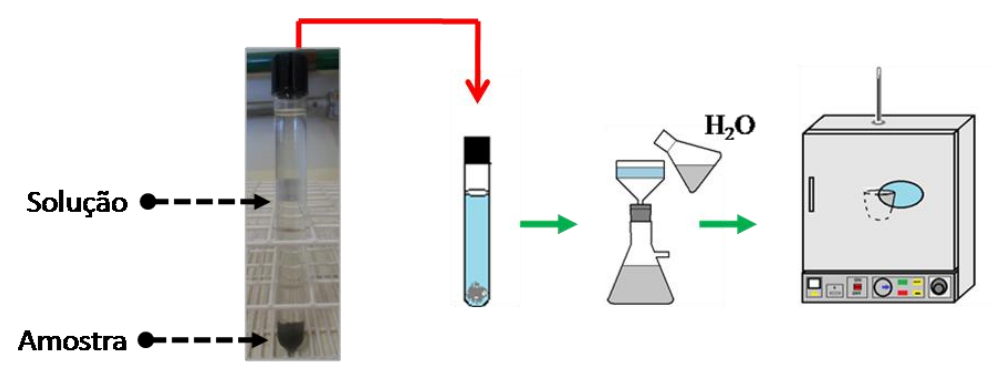

Fonte: Autoria própria. 


\subsection{Caracterização dos precursores/catalisadores}

\subsubsection{Difração de raios $X$ de pó}

A teoria de difração de raios X teve origem 1912 com Max Von Laue, que foi fortemente influenciado pelas discussões de Ewald, o qual estudou a periodicidade de algumas estruturas no fenômeno de refração. Os raios X são produzidos quando os elétrons em alta velocidade colidem com um alvo metálico (ânodo). Dessa forma, são gerados dois tipos de espectros: raios $\mathrm{X}$ contínuos e raios $\mathrm{X}$ característicos. Nos espectros de raios $\mathrm{X}$ característicos ocorre a transição de elétrons de camadas mais externas para as mais internas. Deve-se ressaltar que os comprimentos de onda das linhas $\mathrm{K} \alpha$ e $\mathrm{K} \beta$ são característicos de cada elemento. As Figuras $8 \mathrm{a}$ e $8 \mathrm{~b}$ ilustram o tubo de raios $\mathrm{X}$ e os espectros de raios $\mathrm{X}$ (contínuos e característicos), respectivamente (SMART; MOORE, 2013).

Figura 8 - (a) Esquema geral de um tubo de raios X (b) Espectros de raios X contínuo e característico.

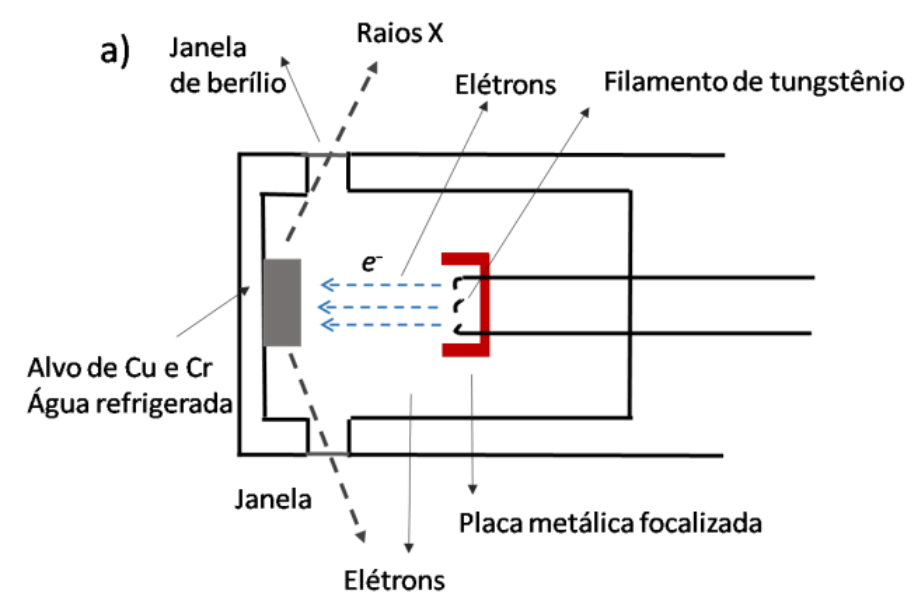

b)

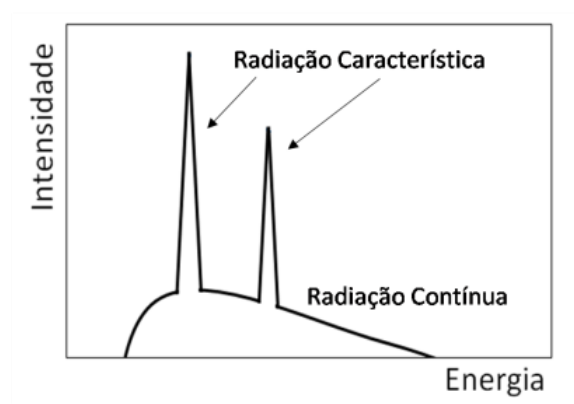

Fonte:Adaptado do trabalho de(CULLITY, 1956; SURYANARAYANA, C., NORTON, 1998).

Quando um feixe de raios X atinge um arranjo ordenado, as ondas são espalhadas provocando as vibrações dos elétrons na mesma freqüência da radiação dos raios X. William Lawrence Bragg salientou que os raios difratados agem como se estivessem refletidos nos planos internos dos cristais. Utilizando um dado comprimento de onda, $\lambda$, mostrou que a reflexão ocorre a partir de uma família de planos paralelos somente sob certas condições. Essas condições devem satisfazer a equação: $\mathrm{n} \lambda=2 \operatorname{dsen} \theta$, onde $\mathrm{n}$ é um numero inteiro $(1,2,3 \ldots \mathrm{n}), \lambda$ é o comprimento de onda, $\mathrm{d}$ é a distância entre os planos paralelos sucessivos e $\theta$ consiste no ângulo de incidência e reflexão do feixe de raios $\mathrm{X}$ em relação a um dado plano atômico. 
(DUTROW, 2012; SMART; MOORE, 2013). A Figura 9 ilustra as direções de propagação de feixes de raios $\mathrm{X}$ sendo refletidos em planos orientados em uma mesma direção cristalográfica, onde P1, P2 e P3 representam os planos atômicos com espaçamento d.

Figura 9 - Representação da propagação de feixes de raios X em camadas de átomos como planos de reflexão.

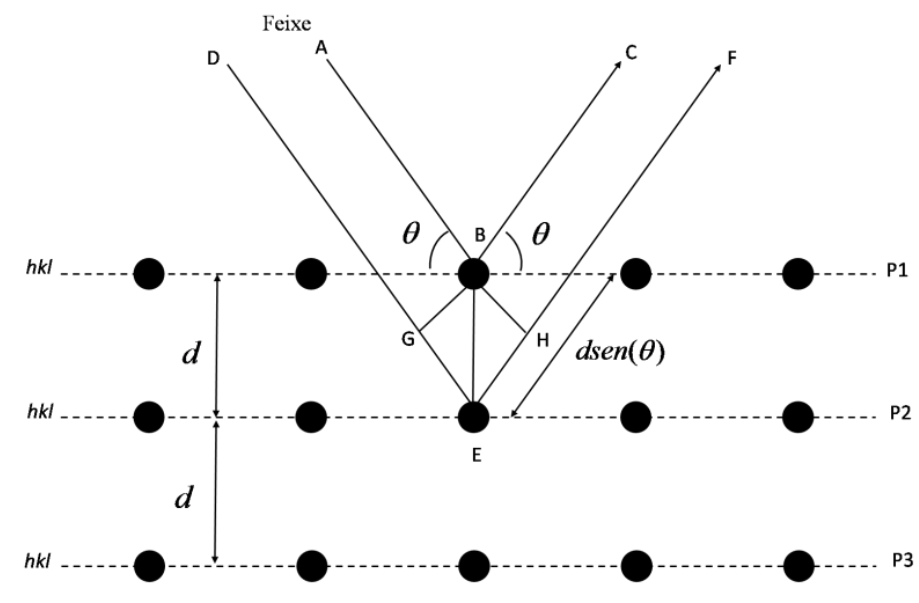

Fonte: Autoria própria.

Os feixes de raios $\mathrm{X}$ atingem os planos e são refletidos num ângulo igual ao ângulo incidente $\theta$. Para que os caminhos ópticos estejam em fase, é necessário que a diferença entre os caminhos $\mathrm{ABC}$ e $\mathrm{DEF}$, denominado de $\delta$, seja igual a um número inteiro do comprimento de onda (nג) ( Equação 1) (DUTROW, 2012):

$\delta=\mathrm{n} \lambda$

Equação 1

Para que duas ondas estejam em fase, o somatório de GE+EH deve ser igual a um número inteiro de comprimento de onda (Equação 2) :

$\mathrm{GE}+\mathrm{EH}=\delta$

Equação 2

Da trigonometria elementar:

$\mathrm{d} \operatorname{sen} \theta=\mathrm{GE}$

Equação 3

$\mathrm{d} \operatorname{sen} \theta=\mathrm{EH}$

Equação 4

Logo,

$\mathrm{GE}+\mathrm{EH}=\delta$, como $\delta=\mathrm{n} \lambda$, tem-se 
$\mathrm{d} \operatorname{sen} \theta+\mathrm{d} \operatorname{sen} \theta=\mathrm{n} \lambda$

Equação 5

$2 \mathrm{~d} \operatorname{sen} \theta=\mathrm{n} \lambda$

Equação 6

A equação 6 é conhecida como a lei de Bragg.

O dispositivo utilizado para a medição de raios $\mathrm{X}$ é o difratômetro de policristais ou difratômetro em pó esquematizado na Figura 10. A amostra na forma de pó é colocada no porta amostra, posteriormente é compactada com um material amorfo ou pode ser espalhada sobre uma placa de vidro. Em seguida, a amostra é montada para que esteja em uma orientação aleatória. Quando o feixe atinge a amostra todas as difrações possíveis ocorrem simultaneamente. Por fim, a amostra e o controlador de raios $\mathrm{X}$ são movimentados de forma que a amostra rotaciona em um ângulo $\theta$ e o detector rotaciona por $2 \theta$, permitindo observar as reflexões de Bragg em gráfico, denominado de difratograma, o qual mostra a intensidade em função de $2 \theta$ (CULLITY, 1956).

Figura 10 - Ilustração esquemática dos componentes de um difratômetro de raios X.

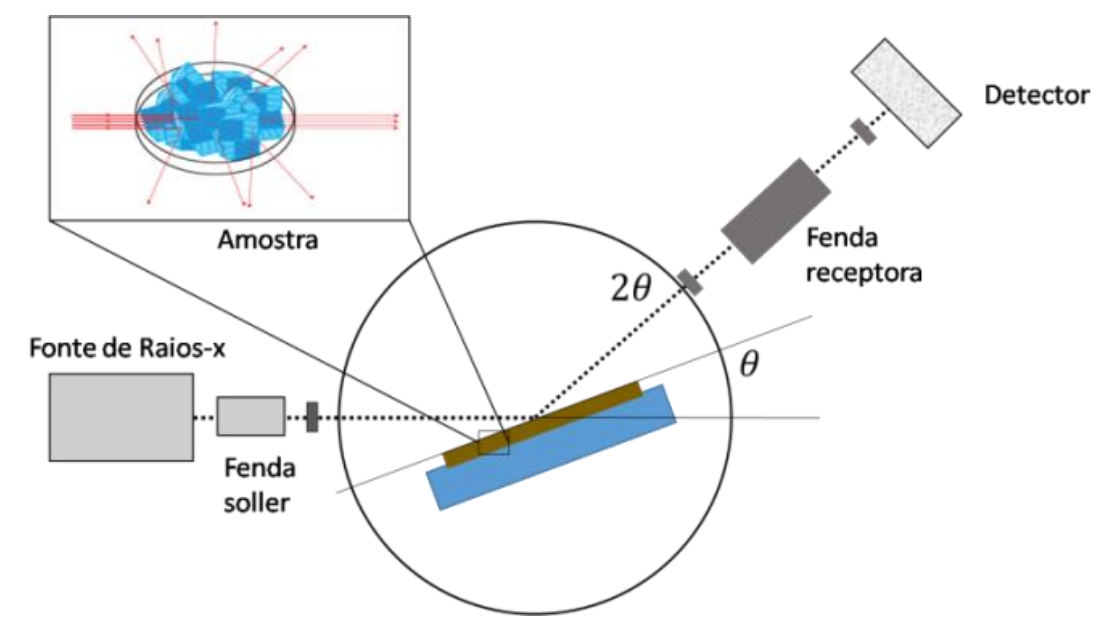

Fonte: Autoria própria.

Os precursores e catalisadores tiveram suas fases cristalinas e parâmetros de rede identificados por difração de raios X. As amostras foram caracterizadas utilizando um difratômetro automático (Rigaku, Rotaflex RU200B) com radiação Cu - Ka ( 50 kV , 100 mA , $\lambda=$ $1,54056 \AA$ ) equipado com um monocromador de grafite; $2 \theta: 10^{\circ}-80^{\circ}$ na velocidade de $2 \%$ min e passo de $0,02^{\circ}$. Para identificação do difratograma, foi utilizado o programa $\mathrm{X}$ ’PertHighScore Plus. O espaçamento interplanar para um sistema cristalino hexagonal foi 
calculado utilizando-se a Equação de Bragg (Equação 7), a partir da reflexão de maior ordem possível, neste caso (003). Os parâmetros de rede foram determinados utilizando o Cellcal. Para a determinação do espaçamento interplanar teórico foi utilizado à Equação 8 para o sistema hexagonal e a Equação 9 para o romboédrico.

$2 \mathrm{~d}_{\mathrm{hkl}} \operatorname{sen} \theta=\mathrm{n} \lambda$

Equação 7

tal que, $\mathrm{d}_{\mathrm{hkl}}$ é o espaçamento interplanar, $\lambda$ o comprimento de onda da radiação $\mathrm{Cu}-\mathrm{K} \alpha$ e $\mathrm{n}=$ 1 o máximo de primeira ordem da difração.

Conhecendo a célula unitária e os índices de Miller (hkl) associados aos planos cristalográficos responsáveis pela difração de raios X é possível calcular o valor da distância interplanar, $\mathrm{d}_{\mathrm{hkl}}$, utilizando as Equações 8 e 9 para um sistema cristalino hexagonal e romboédrico, respectivamente. Essas equações mostram a relação entre espaçamento interplanar $\left(\mathrm{d}_{\mathrm{hkl}}\right)$, parâmetros da célula unitária (a,b,c), ângulos $\alpha$, ( entre os eixos y e z), $\beta$ ( entre os eixos x e z), $\gamma$ (entre os eixos x e y) e os planos cristalinos (hkl).

$\frac{1}{\mathrm{~d}_{\mathrm{hkl}}^{2}}=\frac{4}{3} \times \frac{1}{\mathrm{a}^{2}}\left(\mathrm{~h}^{2}+\mathrm{hk}+\mathrm{k}^{2}\right)+\frac{\mathrm{l}^{2}}{\mathrm{c}^{2}}$
$\frac{1}{\mathrm{~d}_{\mathrm{hkl}}^{2}}=\frac{\left(\mathrm{h}^{2}+\mathrm{k}^{2}+\mathrm{l}^{2}\right) \operatorname{sen}^{2} \alpha+2(\mathrm{hk}+\mathrm{kl}+\mathrm{hl})\left(\cos ^{2} \alpha-\cos \alpha\right)}{\mathrm{a}^{2}\left(1-3 \cos ^{2} \alpha+2 \cos ^{3} \alpha\right)}$

Equação 8

Equação 9

Para a obtenção do ângulo foi realizado o ajuste utilizando o Fityk, com a função Pseudo Voigt, que corresponde à soma de uma gaussiana e uma lorentziana; uma vez que os perfis de difração de raios $\mathrm{X}$ se aproximan de gaussianas para baixos ângulos e lorentizianas para grandes ângulos. A Figura 11 representa o modelo do ajuste dos picos usando Fityk com a função Pseudo Voig.

Figura 11 - Modelo do ajuste dos picos usando Fityk com a função Pseudo Voig.
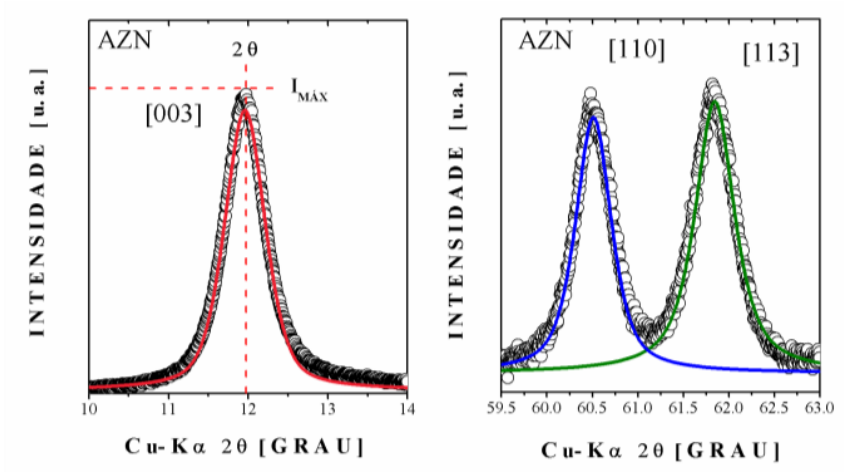

Fonte: Autoria própria. 


\subsubsection{Espectroscopia Vibracional}

\subsubsection{Análise de Espectroscopia Raman}

Ao incidir uma radiação eletromagnética de conteúdo energético sobre uma molécula, a energia pode ser transmitida, absorvida ou espalhada. No caso do espalhamento, este pode ser do tipo elástico ou inelástico. O espalhamento elástico também é denominado de espalhamento Rayleigh e não é de interesse, no entanto, o espalhamento inelástico nos fornece muitas informações sobre o material estudado. Esse fenômeno (espalhamento inelástico) foi observado pela primeira vez em 1928 por Landsberg e Mandelstam em cristais; por outro lado, o físico indiano Chandrasekhara Venkata Raman o observou nos líquidos, ressaltando que este efeito já tinha sido previsto teoricamente por Smekal em 1923 (DELAHAY et al., 1963; SALA, 2008).

Para exemplifica o efeito Raman, usou-se um método representativo ilustrado na Figura 12. Na ilustração é possível observar o estado fundamental representado por $\mathrm{E}_{0}$, o estado excitado simbolizado por $E_{1}$ e o virtual, $E_{V}$. A incidência de um fóton sobre uma molécula tende a provocar uma excitção a um estado virtual $\left(\mathrm{E}_{\mathrm{V}}\right)$. Por ser um estado instável, a molécula tende a retornar ao estado fundamental $\left(\mathrm{E}_{0}\right)$, reemitindo um fóton com a mesma energia do fóton incidente, nesse caso, ocorre o efeito de espalhamento sem perda de energia denominado espalhamento Rayleigh. Além disso, pode ocorrer o processo de decaimento da molécula para um estado vibracional $\mathrm{E}_{1}$. Nessa situação, a energia do espalhamento é menor que a incidente, ou seja, o processo de espalhamento absorve energia, gerando o efeito Raman na região de Stokes. Por fim, a incidência de um fóton sobre a molécula que esteja vibrando com uma energia $E_{1}$ provoca uma elevação ao estado virtual $\left(E_{V}\right)$, ocorrendo logo em seguida o seu decaimento para o estado fundamental $\left(\mathrm{E}_{0}\right)$, em tal caso, o fóton espalhado possui uma energia maior que a incidente, ou seja, esse espalhamento cede energia. Esse efeito é chamado de espalhamento inelástico na chamada região anti-Stokes, também considerado um efeito Raman. (FARIA et al., 1997; LARKIN, 2011; SALA, 2008). 
Figura 12 - Espalhamento da luz: (I) espalhamento elástico (Rayleigh); (II) espalhamento inelástico (região Stokes) (III) e espalhamento inelástico ( região anti-stokes).

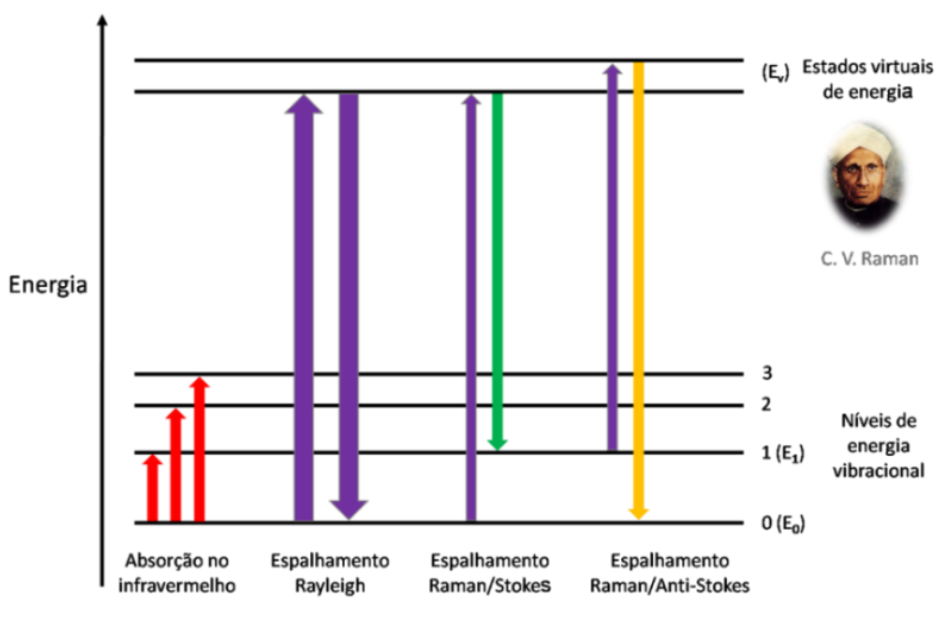

Fonte: Autoria própria.

Ao submeter uma molécula ao campo elétrico ocorre uma modificação do momento dipolo, ou seja , $\mu=\alpha$ E, onde $\alpha$ é uma constante de proporcionalidade denominada de polarizabilidade. Assim, para ocorrer o efeito Raman deve haver uma mudança na polarizabilidade. A Equação 10 representa a polarização do meio modificada pela incidência da radiação (EGERTON; HARDIN, 2007; OLIVEIRA, 2009).

$P(t)=\alpha_{0} E_{0} \cos \left(2 \pi v_{0} t\right)+\frac{1}{2}\left(\frac{d \alpha}{d q}\right) q_{0} E_{0}\left\{\cos \left[2 \pi\left(v_{0}+v_{v}\right) t\right]+\cos \left[2 \pi\left(v_{0}-v_{v}\right) t\right]\right\}$

\section{Onde:}

$\mathrm{E}_{0}$ é uma constante;

$\alpha_{0}$ consiste na polarizabilidade de equilíbrio;

$\mathrm{q}_{0}$ é a coordenada normal;

d $\alpha /$ dq é a taxa de variação da polarizabilidade com relação a q.

Essa equação mostra que o momento dipolar induzido varia com os três componentes de freqüência $v_{0}, v_{0}+v_{v}$ e $v_{0}-v_{v}$, onde o primeiro termo representa o espalhamento elástico de luz, ou seja, espalhamento Rayleigh. O segundo membro representa a espalhamento Raman anti-Stokes e Stokes. A condição para a atividade de um modo vibracional na espectroscopia Raman é: 


$$
\left(\frac{\mathrm{d} \alpha}{\mathrm{dq}}\right)_{\mathrm{q}=0} \neq 0
$$

se a taxa variação da polarizabilidade com relação a $\left(\frac{\mathrm{d} \alpha}{\mathrm{dq}}\right)$ é igual a zero, o segundo termo desaparece, dessa forma, a vibração não é Raman ativa.

O espectro Raman consiste em um gráfico mostrando a intensidade da radiação espalhada em função de sua energia (número de onda). A Figura 13 ilustra o espectro da amostra de $\mathrm{CCl}_{4}$, onde é possível verificar a banda Rayleig. Ademais, nota-se as bandas anti-Stokes e Stokes de baixa e alta intensidades, respectivamente.

Figura 13 - Banda Rayleigh, banda Raman-Stokes e banda Raman-antiStokes.

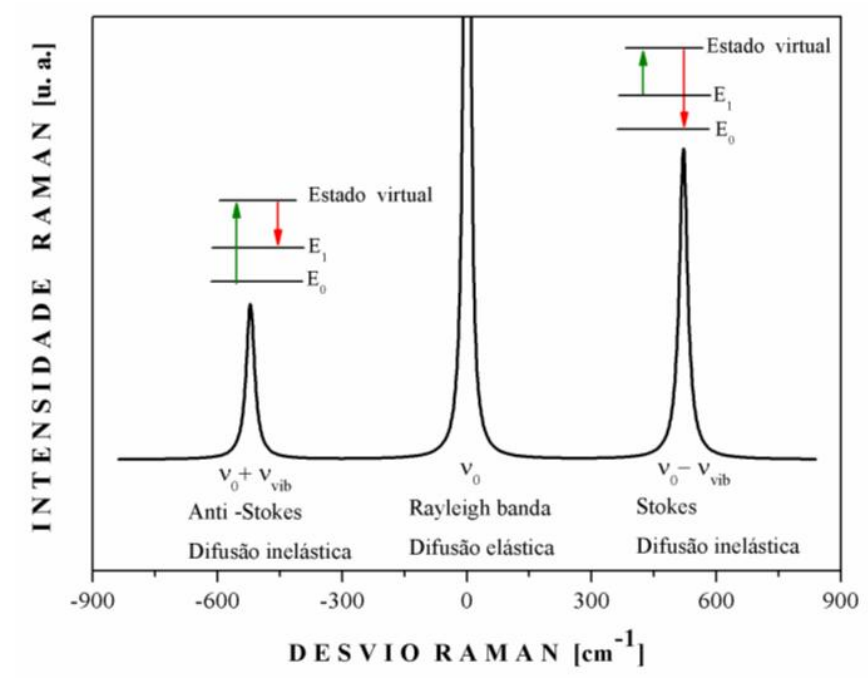

Fonte: Autoria própria

O esquema do sistema de um espectrômetro Raman está reportado na Figura 14. O efeito inicia com a focalização do laser sobre a amostra, em seguida ocorre o processo de espalhamento da luz pela amostra. A maior parte dessa dispersão é de Rayleigh e uma pequena quantidade é Raman disperso. Nesse caso, ocorre uma mudança no comprimento de onda. Ao passar pelo filtro ocorre a remoção da luz de espalhamento Rayleigh. A grade presente no equipamento difrata a luz incidente sobre ela visando selecionar os diferentes comprimentos de onda. Por último, a CCD produz um sinal elétrico de acordo com a intensidade da luz (A.SKOOG et al., 2002).

A Tabela 7 mostra as principais vantagens e desvantgens da aplicação da espectroscopia Raman. 
Tabela 7 - Vantagens e desvantagens da espectroscopia Raman.

\section{Espectroscopia Raman}

\section{Vantagens}

Pode ser usado com sólido e líquido

Não precisa de preparação da amostra

Não destrutiva

Escala de tempo curto para obtenção do espectro

Fonte: Autoria própria

Figura 14 - Diagrama ilustrando o sistema de espectroscopia Raman.

Não pode ser utilizado em metais ou ligas

Difícil de medir em concentrações baixas

Pode ser interferido por fluorescência

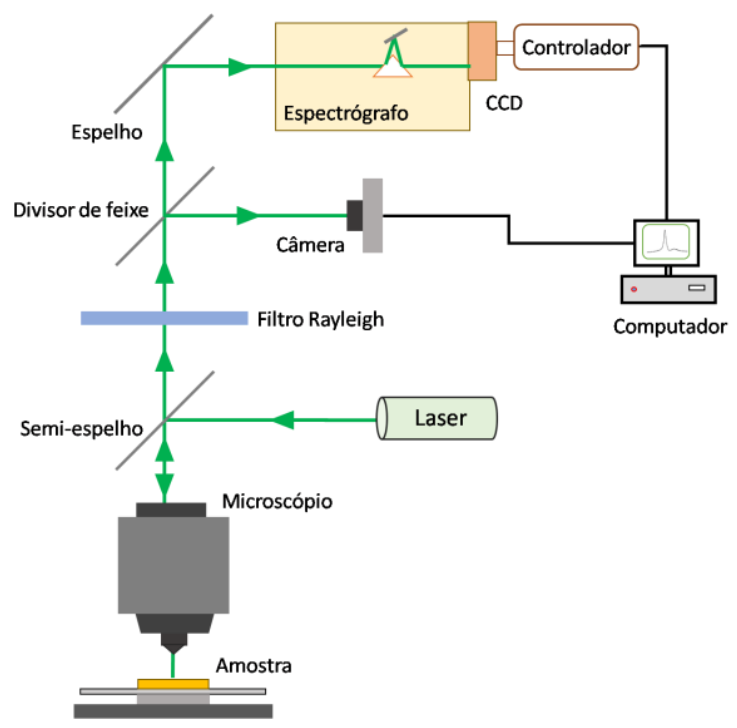

Fonte: Autoria própria.

As medidas de espalhamento Raman foram realizadas utilizando um laser de argônio operando em 514nme $\sim 0,3 \mathrm{~mW}$ como fonte excitadora. Uma baixa potência do feixe foi configurada visando evitar efeitos de sobreaquecimento no ponto focal da objetiva $(50 \times)$. Para os precursores, duas regiões entre 50 a1500 $\mathrm{cm}^{-1}$ e 2800 a $3800 \mathrm{~cm}^{-1}$ foram avaliadas. Finalmente, a análise da formação do carbono (após os ensaios catalíticos) foi concentrada na região espectral de 50 a $1800 \mathrm{~cm}^{-1}$. Nesse trabalho a espectroscopia Raman será utilizada para identificar os modos vibracionais presentes nas hidrotalcitas e para o carbono formado após o processo de reação. 


\subsubsection{Análise de Espectroscopia Infravermelho}

A investigação das propriedades vibracionais dos precursores à temperatura ambiente foi realizada no espectrofotômetro Shimadzu de infravermelho por transformada de Fourier (FTIR) na região do infravermelho médio. Para a coleta dos espectros no infravermelho médio (região de 4000-400 $\mathrm{cm}^{-1}$ ), a amostra foi moída juntamente com o sal de brometo de potássio ( $\mathrm{KBr}$ ) seco, e em seguida foi prensada produzindo uma pastilha transparente. Posteriormente, a amostra foi colocada no porta-amostra e posicionada no feixe do instrumento para análise espectroscópica.

\subsubsection{Análise termogravimétrica (TG/DTG)}

A termogravimetria ou análise termogravimétrica ( TG) é uma técnica que permite monitorar a perda de massa da amostra em função do tempo ou da temperatura. Quando a análise é feita em função da temperatura que está programada ou pré-determinada, denominase de termogravimetria dinâmica (ÉDER T. G. CAVALHEIRO, MASSAO IONASHIRO, SUSETE T. BREVIGLIERI, 1995).

As principais informações fornecidas pela TG são: a temperatura inicial de decomposição, temperatura em que a velocidade de cada decomposição é máxima, temperatura final de decomposição e massa perdida pela amostra. Visando melhorar a avaliação e visualização das curvas de TG é comum utilizar concomitantemente a derivada, denominada de DTG. A DTG mostra as curvas da derivada da massa em relação ao tempo (dm/dt) em função da temperatura ou do tempo $[(\mathrm{dm} / \mathrm{dt})=\mathrm{f}(\mathrm{T}$ ou t $)]$ (MOTHÉ; AZEVEDO, 2002). A Figura 15 exemplifica uma curva de TG e DTG do precursor de zinco obtido pelo método de coprecipitação. 
Figura 15 - Curvas de TG e DTG do precursor de Zinco obtido pelo método de coprecipitação.

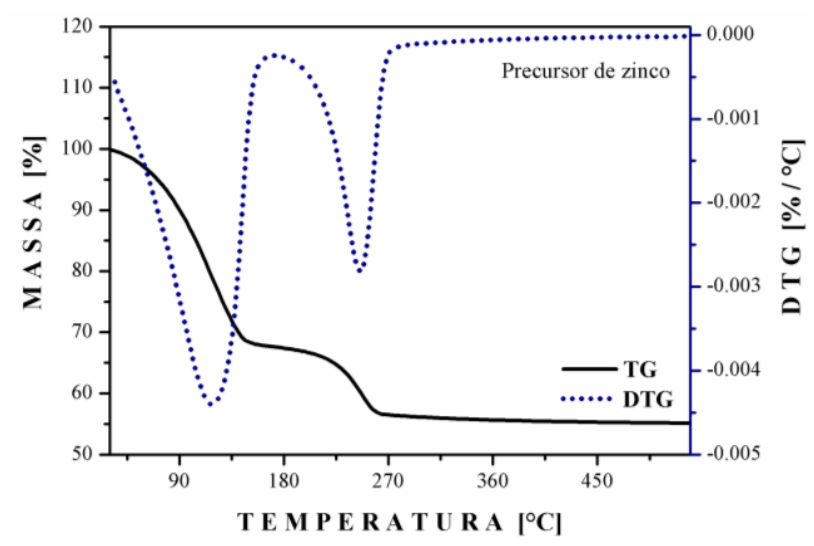

Fonte: Autoria própria.

A termobalança é a parte mais importante de um analisador térmico. O equipamento tem como os principais componentes : balança registradora, forno, suporte de amostra, sensor de temperatura e o programador de temperatura de forno. A Figura 16 mostra uma ilustração esquemática de um equipamento termogravimétrico. Durante análise termogravimétrica, a amostra é colocada em um pequeno cadinho de porcelana inerte em suspensão no forno de um braço de balança, o qual é contrabalançado por uma tara, seja eletricamente aplicada na bobina ou adicionada à panela de referência. $\mathrm{O}$ forno pode ser posicionado em vários locais de equilíbrio, operando a partir da temperatura ambiente até $1500^{\circ} \mathrm{C}$. Além do mais, um controle no forno é usado para controlar a temperatura da amostra. A presença de gás corrosivo ou oxidante perto do mecanismo de balança é indesejável. Assim sendo, o forno é muitas vezes purgado com um gás inerte (nitrogênio ou argônio) na temperatura ambiente (A.SKOOG et al., 2002; HAINES, 2002).

Figura 16 - Esquema dos componentes do TG.

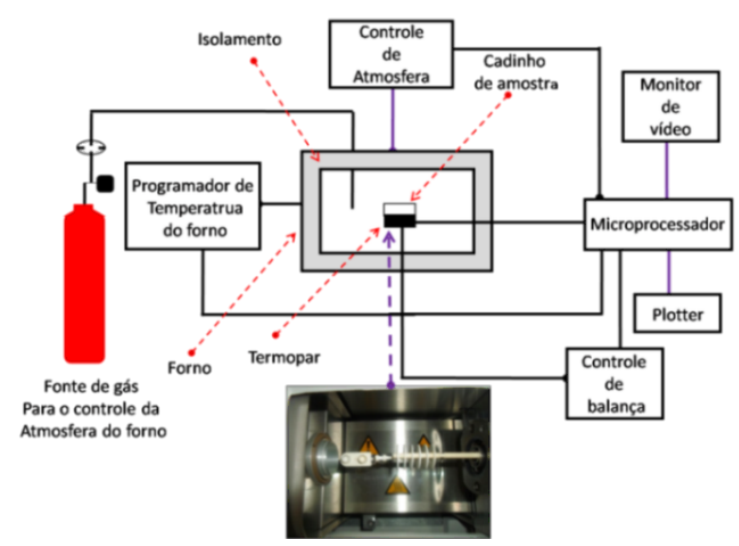

Fonte: Adaptado do trabalho de MOTHÉ; AZEVEDO. (2002). 
As análises termogravimétricas (TG/DTG) para os precursores foram realizadas através de uma termobalança Mettler Toledo, operando sob fluxo de nitrogênio $(50 \mathrm{ml} / \mathrm{min})$ a uma taxa de aquecimento de $10^{\circ} \mathrm{C} / \mathrm{min}$ até $900^{\circ} \mathrm{C}$. Além disso, a quantificação dos resíduos carbonáceos foi realizada por esta técnica, onde se determinou a perda de massa relativa a partir da área do pico da primeira derivada dos termogramas.

\subsubsection{Redução à temperatura programada}

A redução à temperatura programada $\left(\mathrm{TPR}-\mathrm{H}_{2}\right)$ é uma técnica de caracterização que faz parte de um conjunto de técnicas denominadas termoanalíticas. A técnica é totalmente sensível à presença de espécies na forma redutível e tem sido amplamente aplicada ao estudo de catalisadores suportados e não suportaodos, com isso fornecendo informações sobre o estado de oxidação, interação entre metal /suporte e formação de ligas em catalisadores bimetálicos.

Tal técnica consiste na passagem de um gás redutor, normalmente $\mathrm{o} \mathrm{H}_{2}$ diluído em gás inerte ( $\mathrm{N}_{2}$ ou Ar) pela amostra, com um aumento da temperatura programada. Ao final, obtém-se um perfil de TPR, onde verifica-se o consumo de $\mathrm{H}_{2}$ pela amostra. A reação entre o óxido (MO) e o hidrogênio $\left(\mathrm{H}_{2}\right)$ para formar o metal $(\mathrm{M})$ e o vapor de $\mathrm{H}_{2} \mathrm{O}$ pode ser representado pela Reação 24 (HURST et al., 1982):

$$
\mathrm{MO}_{(\mathrm{s})}+\mathrm{H}_{2(g)} \rightarrow \mathrm{M}_{(\mathrm{s})}+\mathrm{H}_{2} \mathrm{O}_{(\mathrm{g})}
$$

Nesse trabalho foi usado um sistema Micrometrics modelo ChemiSorb 2750 com uma corrente de $10 \% \mathrm{H}_{2} / \mathrm{Ar}$ a $25 \mathrm{~mL} / \mathrm{min}$ e taxa de aquecimento de $10^{\circ} \mathrm{C} / \mathrm{min}$ na obtenção de tais perfis. Uma quantidade de $100 \mathrm{mg}$ de catalisador foi condicionada num reator de quartzo, e aquecida até $1000^{\circ} \mathrm{C}$.

\subsubsection{Consumo de hidrogênio}

Para a determinação do consumo real de hidrogênio foi realizada a redução do padrão, no caso, óxido de prata $\left(\mathrm{Ag}_{2} \mathrm{O}\right)$ ( ver Figura 17). Após essa etapa, determinou-se a área do pico, $\mathrm{A}_{\mathrm{Ag} 2 \mathrm{O}}(25,1558)$ referente ao consumo de $1,3 \times 10^{-4}$ mol de $\mathrm{H}_{2}\left(\mathrm{n}_{\mathrm{H} 2-\mathrm{Ag} 2 \mathrm{O}}\right)$. Logo o consumo real de $\mathrm{H}_{2}$ para as amostras preparadas neste traabalho foi determinado de acordo com 
Equação 11. Pela reação, verifica-se que $1 \mathrm{~mol}$ de $\mathrm{H}_{2}$ é necessário para promover a redução de $1 \mathrm{~mol}$ de $\mathrm{Ag}_{2} \mathrm{O}$ a $2 \mathrm{Ag}^{0}$ ( Reação 25).

$$
\begin{aligned}
& \mathrm{Ag}_{2} \mathrm{O}+\mathrm{H}_{2} \rightarrow 2 \mathrm{Ag}^{0}+\mathrm{H}_{2} \mathrm{O} . \\
& \mathrm{n}_{\mathrm{H} 2}=\frac{\mathrm{A} \cdot \mathrm{n}_{\mathrm{H}_{2}-\mathrm{Ag}_{2} \mathrm{O}}}{A_{\mathrm{Ag} 2 \mathrm{O}}}=5,2 \times 10^{-6} \cdot A
\end{aligned}
$$

Figura 17 - Perfil de RTP- $\mathrm{H}_{2}$ do padrão utilizado de $\mathrm{Ag}_{2} \mathrm{O}$ para a quantificação do consumo de $\mathrm{H}_{2}$ nas análises dos catalisadores

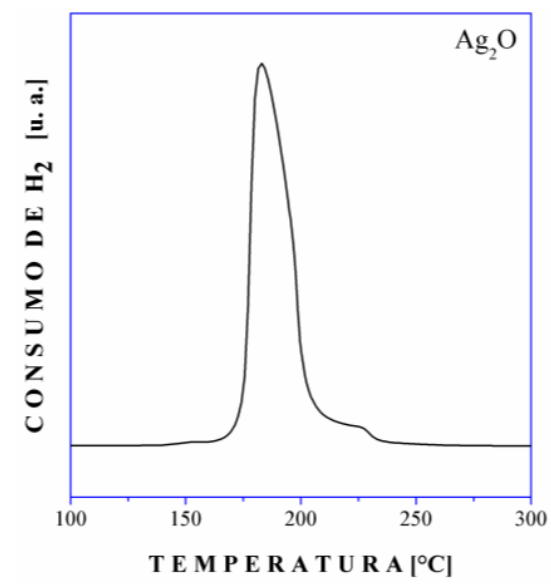

Fonte: Autoria própria

Para determinação do consumo teórico foi calculada a quantidade em massa do óxido níquel a partir de $0.1 \mathrm{~g}$ da amostra. Para a redução de $1 \mathrm{~mol} \mathrm{Ni(II)}$ é necessário $1 \mathrm{~mol}$ de $\mathrm{H}_{2}$, como observado na Reação 26. Logo, o consumo teórico de $\mathrm{H}_{2}$ para reduzir o $\mathrm{Ni}$ (II) presente na amostra pode ser descrito pela Equação 12, onde m será a massa de $\mathrm{H}_{2}$ consumido durante a redução do $\mathrm{NiO}$ e $\mathrm{MM}_{\mathrm{NiO}}$ equivale massa molecular do $\mathrm{NiO}$.

$$
\begin{aligned}
& \mathrm{Ni}^{2+}+\mathrm{H}_{2} \rightarrow \mathrm{Ni}^{0}+2 \mathrm{H}^{+} \\
& \mathrm{n}_{\mathrm{H} 2}=\frac{\mathrm{m}}{\mathrm{MM}_{\mathrm{NiO}}}
\end{aligned}
$$




\subsubsection{Fisissorção de nitrogênio (BET) dos catalisadores}

A caracterização textural é muito importante para entender o comportamento do catalisador. Sendo que em todo sistema catalítico gás/sólido, o reagente deve primeiro ser adsorvido sobre a superfície do catalisador . Assim, algumas propriedades devem ser determinadas a partir da adsorção do gás: área superficial específica, volume do poro e distribuição do tamanho de poro (ROTHENBERG, 2008). Essas caracterizações podem ser determinadas pelas isotermas que relacionam a quantidade de gás adsorvido com a pressão à temperatura constante, além de fornecer informação da forma do poro. De acordo com a IUPAC são classificados seis tipos de isotermas, e as histereses dependem da textura dos sólidos porosos. Em relação aos poros, estes são classificados de acordo com tamanho em: microporos (tamanho < 2 $\mathrm{nm}$ ), ultramicroporos (tamanho $<0.7 \mathrm{~nm}$ ); mesoporos $(2 \mathrm{~nm}<$ tamanho $<50 \mathrm{~nm}$ ) (LEOFANTI et al., 1998).

O modelo desenvolvido por Brunauer, Emmet e Teller (1938) foi baseado no modelo teórico de Langmuir com algumas exceções, por exemplo, cada espécie adsorvida na primeira camada serve como sítio para a adsorção da segunda camada, que por sua vez, servirá de sítio para a terceira camada, e assim por diante, sem considerar as interações laterais das moléculas adsorvidas. O método BET é usado para determinar o volume da monocamada do adsorbato $\left(\mathrm{V}_{\mathrm{m}}\right)$, que representa o volume de gás adsorvido por grama de sólidos necessários para que o gás forme uma camada completa na superfície do sólido. Com base nas ideias expressadas acima, determinou-se a equação de BET (Equação 13) (B. CONDON, 2013; LEOFANTI et al., 1998; SING et al., 2008).

$\frac{\mathrm{P}}{\mathrm{V}\left(\mathrm{P}_{0}-\mathrm{P}\right)}=\frac{1}{\mathrm{~V}_{\mathrm{m}} \mathrm{C}}+\frac{\mathrm{C}-1}{\mathrm{~V}_{\mathrm{m}} \mathrm{C}} \times \frac{\mathrm{P}}{\mathrm{P}_{0}}$

Equação 13

A área superficial $\left(A_{s}\right)$ pode ser determinada pela Equação 14, enquanto que o parâmetro $\mathrm{V}_{\mathrm{m}}$ pode ser determinado pela equação de BET (Equação 14).

$$
\mathrm{A}_{\mathrm{s}}=\left(\frac{\mathrm{V}_{\mathrm{m}}}{22414}\right) \mathrm{N}_{\mathrm{a}} \sigma
$$

Equação 14

Onde:

$\mathrm{N}_{\mathrm{a}}$ consiste no número de Avogadro; $\sigma$ equivale a área coberta por uma molécula de nitrogênio. 
As principais técnicas e métodos utilizados para caracterização morfológica estão reportados na Tabela 8 .

Tabela 8 - Técnicas e métodos para a determinação da caracterização morfológica.

\begin{tabular}{|c|c|c|c|c|c|}
\hline Técnica & Método & Informação & Microporos & Mesoporos & Macroporos \\
\hline \multirow{3}{*}{$\begin{array}{c}\text { Adsorção de } \mathrm{N}_{2} \\
\text { a } 77 \mathrm{~K}\end{array}$} & BET & & & $X$ & $X$ \\
\hline & t-plot & Área superficial & & $\mathrm{X}$ & $\mathrm{X}$ \\
\hline & $\mathrm{a}_{\mathrm{s}}$-plot & & & & \\
\hline $\begin{array}{l}\mathrm{Kr}, \mathrm{Ar}, \mathrm{He}, \\
\text { ads,em baixa } \\
\text { temperatura }\end{array}$ & BET & & & $X$ & $X$ \\
\hline \multirow{2}{*}{$\begin{array}{c}\text { Adsorção de } \mathrm{N}_{2} \\
\text { a } 77 \mathrm{~K}\end{array}$} & $\mathrm{BJH}$ & Área superficial & & $\mathrm{X}$ & \\
\hline & DFT & & $X$ & $X$ & \\
\hline \multirow{5}{*}{$\begin{array}{c}\text { Adsorção de } \mathrm{N}_{2} \\
\text { a } 77 \mathrm{~K}\end{array}$} & t-plot & Pore volume & $\mathrm{X}$ & $\mathrm{X}$ & \\
\hline & $\mathrm{a}_{\mathrm{s}}$-plot & & $\mathrm{X}$ & $\mathrm{X}$ & \\
\hline & DR & & $\mathrm{X}$ & & \\
\hline & MP & & $X$ & & \\
\hline & BJH & & & $X$ & \\
\hline
\end{tabular}

Fonte: - (LEOFANTI et al., 1998) - Reproduzido com permissão - Copyright @ 2016 Elsevier.

A análise de fisissorção de nitrogênio foi conduzida num sistema NOVA 1000e Quantachrome Instruments ${ }^{\circledR}$. Inicialmente, a amostra foi condicionada num tubo de quartzo e desgaseificada para remover contaminante e água, visando obter uma medida de alta precisão. A etapa seguinte consistiu em resfriar a temperatura do nitrogênio líquido $(77 \mathrm{~K})$ e, logo em seguida ela foi exposta a uma mistura de $\mathrm{He} / \mathrm{N}_{2}$. A cada variação de pressão, o número de moléculas adsorvidas foi determinado, dessa forma gerando uma curva denominada de isoterma de adsorção. Convém saber, que o Hélio (He) é empregado como diluente, posto que nestas condições de temperatura não ocorre sua adsorção. A adsorção do nitrogênio ocorre a cada pressão parcial causando uma alteração na composição de saída, a qual é identificado por um detector de condutividade térmica ligado a um registrador potenciométrico. Após retirar o frasco de Dewar, a amostra fica aquecida provocando a dessorção do nitrogênio (FIGUEIREDO; RIBEIRO, 1989). 


\subsubsection{Perda ao rubro ou perda por calcinação}

A amostra foi aquecida a $110^{\circ} \mathrm{C}$ até o peso constante. Em seguida, a mesma foi colocada em um cadinho de alumina e submetido à mufla até $1100^{\circ} \mathrm{C}$ durante $1 \mathrm{~h}$. Prontamente, o cadinho é retirado e pesado. A perda ao rubro foi calculada pela Equação 15.

$\%$ perda por calcinação $=\frac{\text { peso da amostra seca }- \text { peso da amostra calcinada }}{\text { peso da amostra seca }} \times 100 \quad$ Equação 15

\subsubsection{Basicidade total}

A determinação da força e quantidade de sítios básicos pode ser obtida por diversas técnicas: titulometria, nesse caso, utiliza-se indicadores preparados com solventes orgânicos (benzeno, tolueno e isoctano); espectroscopia no infravermelho usando $\mathrm{CO}_{2}$ e pirrol ( moléculas sondas); dessorção à temperatura programada com $\mathrm{CO}_{2}$ (AUROUX; GERVASINI, 1990). Para o método titulométrico usa-se um indicador ácido eletricamente neutro, o qual é adsorvido sobre um sólido básico a partir de uma solução não polar, desse modo, a cor do indicador é modificada para sua base conjugada. Deve-se ressaltar que a cor do indicador é modificada somente quando o sólido possui uma força básica suficiente para doar um par de elétrons ao ácido. Essa titulação acontece na presença de um titulante, por exemplo, solução de ácido benzóico em tolueno.

A reação entre um indicador ácido $(\mathrm{BH})$ e um sólido básico $(\mathrm{B})$ está ilustrado na na Reação 27 (TANABE et al., 1989).

$\mathrm{BH}+\overline{\mathrm{B}} \rightleftharpoons \mathrm{B}^{-}+\overline{\mathrm{B}} \mathrm{H}^{+}$

Reação 27

A basicidade é influenciada pela natureza, número e a força dos sítios básicos. A determinação de sítios expostos sobre a superfície de um sólido (origem e localização) e sua distribuição são importantes fatores para entender a propriedade catalítica dos sólidos básicos. A basicidade equivale à quantidade de sítios básicos presentes no sólido, sendo expressa em número de sítios básicos por unidade de massa ou área $\left(\mathrm{mmol} / \mathrm{g}\right.$ ou $\left.\mathrm{mmol} / \mathrm{m}^{2}\right)$ (TANABE, YAMAGUCHI, 1968). 
A quantidade de sítios básicos dos catalisadores foi medida via titulação com ácido benzóico na presença de um indicador de Hammet (fenolftaleína). Para este fim, a basicidade foi realizada pela titulação com ácido benzóico em tolueno. Inicialmente, pesou-se $0,15 \mathrm{~g}$ de um catalisador e, em seguida foram adicionados $2 \mathrm{ml}$ da solução de fenolftaleína em tolueno e titulou-se com a solução de ácido benzóico em tolueno (0,01M) ( ver Figura 18). A basicidade foi determinada de acordo com a Equação 16.

$$
\mathrm{B}=\frac{\mathrm{C} \times \mathrm{V}}{\mathrm{m}_{\mathrm{a}}}
$$

Onde:

$\mathrm{C}=$ Concentração ácido benzóico $\left(\text { mol. }^{-1}\right)^{-1}$;

$\mathrm{V}=$ Volume da solução gasta na titulação(l);

$\mathrm{m}_{\mathrm{a}}=$ Massa da amostra a ser determinada a basicidade $(\mathrm{g})$;

$\mathrm{B}=$ basicidade da amostra $\left(\mathrm{mol} \cdot \mathrm{g}^{-1}\right)$.

Figura 18 - Sistema utilizado para determinação da basicidade pelo método de titulação.

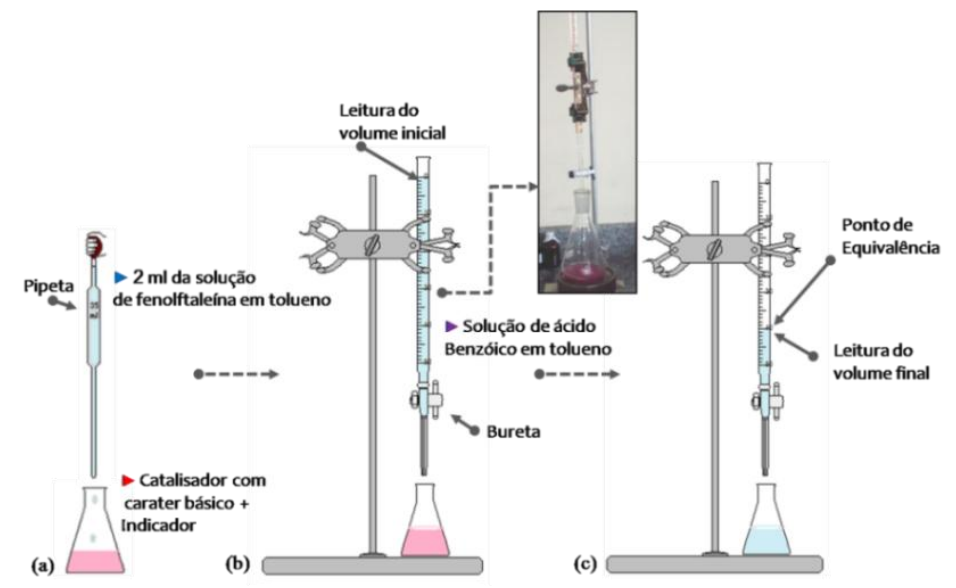

Fonte: Autoria própria.

\subsubsection{Temperatura programada de dessorção com $\mathrm{CO}_{2}$}

Dessorção à temperatura programada com $\mathrm{CO}_{2}\left(\mathrm{DTP}-\mathrm{CO}_{2}\right)$ é uma das técnicas mais utilizadas para avaliar as propriedades básicas da superfície do sólido. A temperatura de dessorção representa a força de interação entre o adsorvente e adsorbato. Presume-se que sítios 
básicos fortes dessorvem moléculas de $\mathrm{CO}_{2}$ em altas temperaturas. O número de sítios básicos é obtido a partir da área dos picos de dessorção.

Para análise, as amostras foram submetidas a um tratamento térmico a $550{ }^{\circ} \mathrm{C} / 0,5 \mathrm{~h}$ sob fluxo de $\mathrm{He}\left(30 \mathrm{cc} \cdot \mathrm{min}^{-1}\right)$. Após o resfriamento até $35^{\circ} \mathrm{C}$ sob fluxo de $\mathrm{He}$, a adsorção de $\mathrm{CO}_{2}$ foi realizada durante $0,5 \mathrm{~h}$ a $35^{\circ} \mathrm{C}$ sob uma corrente de $\mathrm{CO}_{2}$. Em seguida, o $\mathrm{CO}_{2}$ foi então substituído por He. O TPD iniciado após a estabilização da linha de base, à mesma temperatura.

\subsubsection{Difração de raios X de pó in situ (XPD) dos Catalisadores}

Os catalisadores foram investigados por difração de raios $\mathrm{X}$ in situ, utilizando um difratômetro de 6-círculos Huber $\operatorname{com} \lambda=1,5498 \AA$, detector Mythen, no intervalo $2 \theta=10-80^{\circ}$, velocidade angular de $0,5^{\circ} \mathrm{s}^{-1}$, na beamline D10B - XPD do Laboratório Nacional de Luz Synchrotron (LNLS), em Campinas, Brasil. O primeiro padrão de DRX foi adquirido em temperatura ambiente; o segundo foi coletado num catalisador reduzido com $\mathrm{H}_{2}\left(5 \% \mathrm{H}_{2} / \mathrm{He}\right.$, $60 \mathrm{ml} / \mathrm{min}$ ) na temperatura de redução; o terceiro foi coletado na temperatura de $750^{\circ} \mathrm{C}$ após o processo de redução. E, finalmente, os padrões restantes foram coletados nas condições de reação, onde o catalisador já reduzido foi exposto a um fluxo de $\mathrm{CH}_{4}(15,4 \mathrm{~mL} / \mathrm{min}, 20 \%$ $\left.\mathrm{CH}_{4} / \mathrm{He}\right), \mathrm{CO}_{2}\left(10,3 \mathrm{~mL} / \mathrm{min}, 20 \% \mathrm{CO}_{2} / \mathrm{He}\right)$ na temperatura desejada.

\subsubsection{Energia Dispersiva de Raios X / EDS (Energy-Disperse X-Ray Spectroscopy) e Microscopia eletrônica de varredura (MEV)}

A análise microscopia eletrônica de varredura (MEV) consiste basicamente na emissão de feixes de elétrons sobre amostras, onde uma série de radiações são emitidas: elétrons secundários, elétrons retroespalhados, raios $\mathrm{X}$ característicos, elétrons Auger, fótons e etc (Ver Figura 19a). Na análise de microscopia eletrônica de varredura são utilizados os elétrons secundários e retroespalhados. Os elétrons secundários fornecem imagem de topografia da superfície da amostra, enquanto que os elétrons retroespalhados fornecem imagens da variação da composição química do material (ROTHENBERG, 2008).

O equipamento de microscopia eletrônica de varredura é constituído basicamente pela coluna ótica eletrônica (canhão de elétrons e sistema de demagnificação), unidade de varredura, câmara da amostra, sistema de detectores e de visualização de imagens. Na Figura 19b está reportado o esquema de um canhão eletrônico tradicional, o qual é constituído por um fila- 
mento de tungstênio, cilindro de Wehnelt e o ânodo. Deve-se ressaltar que o filamento de tungstênio tem o seu funcionamento baseado no efeito termiônico de emissão de elétrons (DEDAVID et al., 2007; GOLDSTEIN et al., 1992). Os sinais que derivam da interação entre elétron-amostra revelam as seguintes informações: morfologia externa (textura); composição química; estrutura cristalina; distribuição de fases e orientação dos materiais que compõem as amostras; presença e localização de defeitos. Além disso, o MEV também é capaz de realizar análises de localizações de pontos selecionados na amostra. Esta abordagem é especialmente útil para caracterização de materiais metálicos e semicondutores, permitindo ao pesquisador identificar a composição de sua amostra em pontos específicos da imagem pela Espectrometrometria de raios X por Dispersão de Energia ou EDS (Energy-Disperse X - Ray Spectroscopy)(CHANDLER, 1972).

Figura 19 - (a) Representação de um feixe de elétrons ao colidir com a superfície da amostra desencadeando uma série de processos; (b) Canhão eletrônico tradicional com filamento de tungstênio.
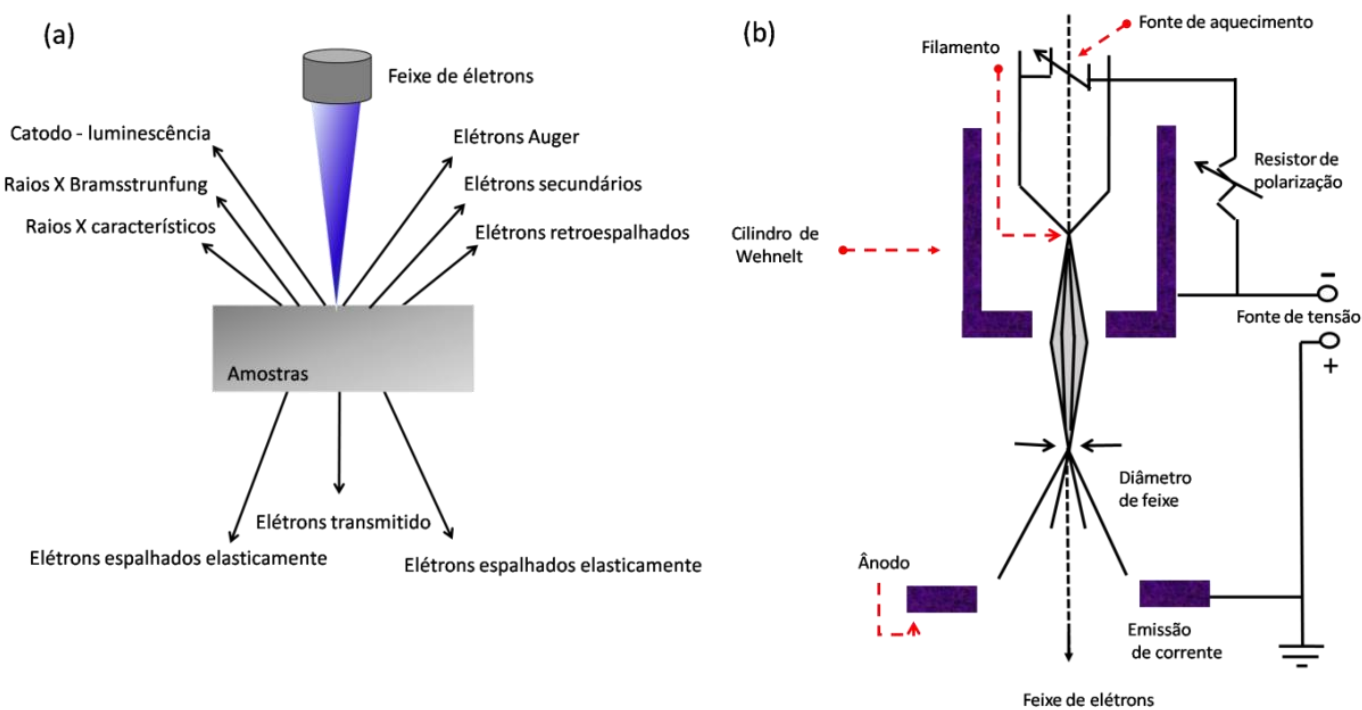

Fonte: Adaptado do trabalho de ROTHENBERG, 2008 e GOLDSTEIN et al., 1992.

Com objetivo de fornecer informações sobre a morfologia e identificação de elementos químicos dos precursores (concentração percentual em massa) foram realizadas as análises de microscopia eletrônica de varredura e energia dispersiva de raios X. A energia Dispersiva (EDS) foi realizada em um equipamento EDS LINK ANALYTICAL, (Isis System Series 200), com detector de SiLi Pentafet, janela ultrafina ATW II (Atmosphere Thin Window), de resolução de $133 \mathrm{eV}$ à $5,9 \mathrm{keV}$ e área de $10 \mathrm{~mm}^{2}$, acoplado a um Microscópio Eletrônico ZEISS LEO 440 (Cambridge, England). Utilizou-se padrão de Co para calibração, feixe de 
elétrons de $20 \mathrm{kV}$, distância focal de $25 \mathrm{~mm}$, dead time de $30 \%$, corrente de 2,45A e I probe de 1,5nA. A área da amostra analisada foi de 640x640 $\mu \mathrm{m}$.

As Equações 19 e 20 são utilizadas para determinar a porcentagem atômica. Para essa finalidade, calcula-se inicialmente o número de moles dos elementos presentes nos compostos pelas Equações 17 e 18:

$$
\begin{gathered}
\mathrm{n}_{\mathrm{A}}=\frac{\% \mathrm{ELMT}_{\mathrm{A}}}{\mathrm{M}_{\mathrm{A}}} \\
\mathrm{n}_{\mathrm{B}}=\frac{\% \mathrm{ELMT}_{\mathrm{B}}}{\mathrm{M}_{\mathrm{B}}}
\end{gathered}
$$

onde $\mathrm{M}(\mathrm{A})$ e $\mathrm{M}(\mathrm{B})$ são as massas atômicas de A e B. Enquanto que a \% ELMET equivale a concentração percentual em massa.

$$
\begin{aligned}
& \operatorname{ATOM}_{\mathrm{A}}=100 \times \frac{\mathrm{n}_{\mathrm{A}}}{\mathrm{n}_{\mathrm{A}}+\mathrm{n}_{\mathrm{B}}} \\
& \text { ATOM } \%_{\mathrm{B}}=100 \times \frac{\mathrm{n}_{\mathrm{B}}}{\mathrm{n}_{\mathrm{A}}+\mathrm{n}_{\mathrm{B}}}
\end{aligned}
$$

Onde ATOM\% consiste no número de átomos do elemento em 100 átomos de todos os elementos analisados.

\section{Microscopia eletrônica de transmissão ( TEM)}

A microscopia eletrônica de Transmissão é uma ferramenta poderosa para a ciência dos materiais. Essa técnica permite esclarecer os traços estruturais com escalas em dimensões de 100 a 1000 Á. Logo, os estudos de TEM permitem a identificação de partículas extremamente pequenas. Para realizar as análises de TEM, primeiramente o material deve ser disperso em álcool, logo em seguida ocorre a sonicação por alguns minutos. Uma gota é colocado em suporte denominado de grade, que deve ser recoberto por um filme de carbono e uma camada fina de Formvar, cujo diâmetro pode variar de 2 a $3 \mathrm{~nm}$.

As análises de microscopia eletrônica de transmissão dos precursores foram performa-

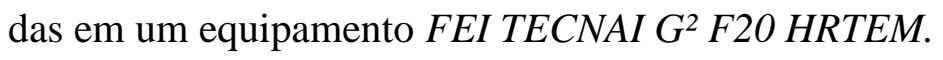




\subsection{Condições para a reação de reforma seca do metano}

Os ensaios catalíticos foram realizados num reator tubular de leito fixo a fim de avaliar a conversão do metano e dióxido de carbono, bem como a atividade dos catalisadores para a produção de $\mathrm{H}_{2}$ e CO. Tais ensaios foram realizados em uma linha de reação constituída de uma unidade do reator e um sistema analítico ( Figura 20). A unidade do reator contém quatro válvulas para o controle dos gases alimentados no reator $\left(\mathrm{H}_{2}, \mathrm{CH}_{4}, \mathrm{~N}_{2}, \mathrm{CO}_{2}\right)$ e um forno controlado para manter constante a temperatura do leito catalítico. O sistema analítico consiste em um cromatógrafo a gás (Varian, modelo 3800) com dois detectores de condutividade térmica, permitindo a análise química dos reagentes e produtos gasosos. O ensaio catalítico foi realizado do seguinte modo: o catalisador $(100 \mathrm{mg})$ foi depositado num leito de lã de quartzo, juntamente com quartzo moído no interior de um microreator de quartzo amorfo $(13 \mathrm{~mm}$ de diâmetro) para suportar altas temperaturas (sempre manuseado com luvas). Com o reator posicionado verticalmente no interior do forno, pressurizava-se a linha com o nitrogênio para verificar vazamentos no sistema. Posteriormente, a válvula do hidrogênio $\left(\mathrm{H}_{2}\right)$ era aberta para a redução da amostra sob fluxo de $50 \mathrm{~mL} / \mathrm{min}$, numa taxa de aquecimento de $10^{\circ} \mathrm{C} / \mathrm{min}$ e patamar de 1h. Nessa etapa, o catalisador passa por um tratamento de redução para que tome a sua forma ativa, logo essa etapa é também denominada de ativação. Em seguida, a amostra foi mantida em atmosfera de nitrogênio para promover a saída do hidrogênio. Para a reação ajustaram-se as vazões do $\mathrm{CH}_{4}$ e $\mathrm{CO}_{2}$ e foi iniciada a alimentação do reator. Na reação catalítica foi usada uma proporção entre os gases de $1,5 \mathrm{CH}_{4}: 1 \mathrm{CO}_{2}$ para simular os componentes principais de um biogás com uma composição típica (60\% de $\mathrm{CH}_{4}$ e $40 \%$ de $\mathrm{CO}_{2}$ ), ou seja, com excesso de $\mathrm{CH}_{4}$. As condições das reações de reforma foram configuradas de acordo com a temperatura de tratamento térmico dos catalisadores. Para os catalisadores tratados a 550 ${ }^{\circ} \mathrm{C} / 15 \mathrm{~h}$, a reação foi conduzida a $550{ }^{\circ} \mathrm{C}$ por um período de tempo de $6 \mathrm{~h}$. Para aqueles tratados a $650{ }^{\circ} \mathrm{C} / 15 \mathrm{~h}$, a reação foi conduzida a $650{ }^{\circ} \mathrm{C}$ por um período de tempo de $6 \mathrm{~h}$. Finalmente, os catalisadores calcinados $750^{\circ} \mathrm{C} / 15 \mathrm{~h}$, a reação foi realizada na temperatura de $750^{\circ} \mathrm{C}$ por um período de 6h ( ver Tabela 9) . Em seguida, empregou-se a Equação 21 para a determinação da conversão do metano, a Equação 22 para o dióxido de carbono e a Equação 23 para o produto da seletividade via razão $\mathrm{H}_{2} / \mathrm{CO}$, como a seguir:

$\mathrm{XCH}_{4 \text { conversão }}(\%)=\frac{\left(\mathrm{CH}_{4}\right)_{\text {inicial }}-\left(\mathrm{CH}_{4}\right)_{\text {final }}}{\left(\mathrm{CH}_{4}\right)_{\text {inicial }}} \times 100$, 
$\mathrm{XCO}_{2 \text { conversão }}(\%)=\frac{\left(\mathrm{CO}_{2}\right)_{\text {inicial }}-\left(\mathrm{CO}_{2}\right)_{\text {final }}}{\left(\mathrm{CO}_{2}\right)_{\text {inicial }}} \times 100$,

Equação 22

$\mathrm{H}_{2} / \mathrm{CO}_{\text {razão }}=\frac{\text { Mols de } \mathrm{H}_{2} \text { produzido }}{\text { Mols de } \mathrm{CO}_{\text {produzido }}}$

Equação 23

Figura 20 - Esquema do sistema catalítico. Os números destacados em amarelo correspondem os componentes da linha: (1) Linha de gás; (2) Controlador com as válvulas dos gases utilizados na redução $\left(\mathrm{H}_{2}\right)$ e reação $\left(\mathrm{N}_{2}\right.$, $\mathrm{CH}_{4}$ e $\mathrm{CO}_{2}$ ).; (3) Forno (4) Condensador; (5) Cromatógrafo e (6) Computador.

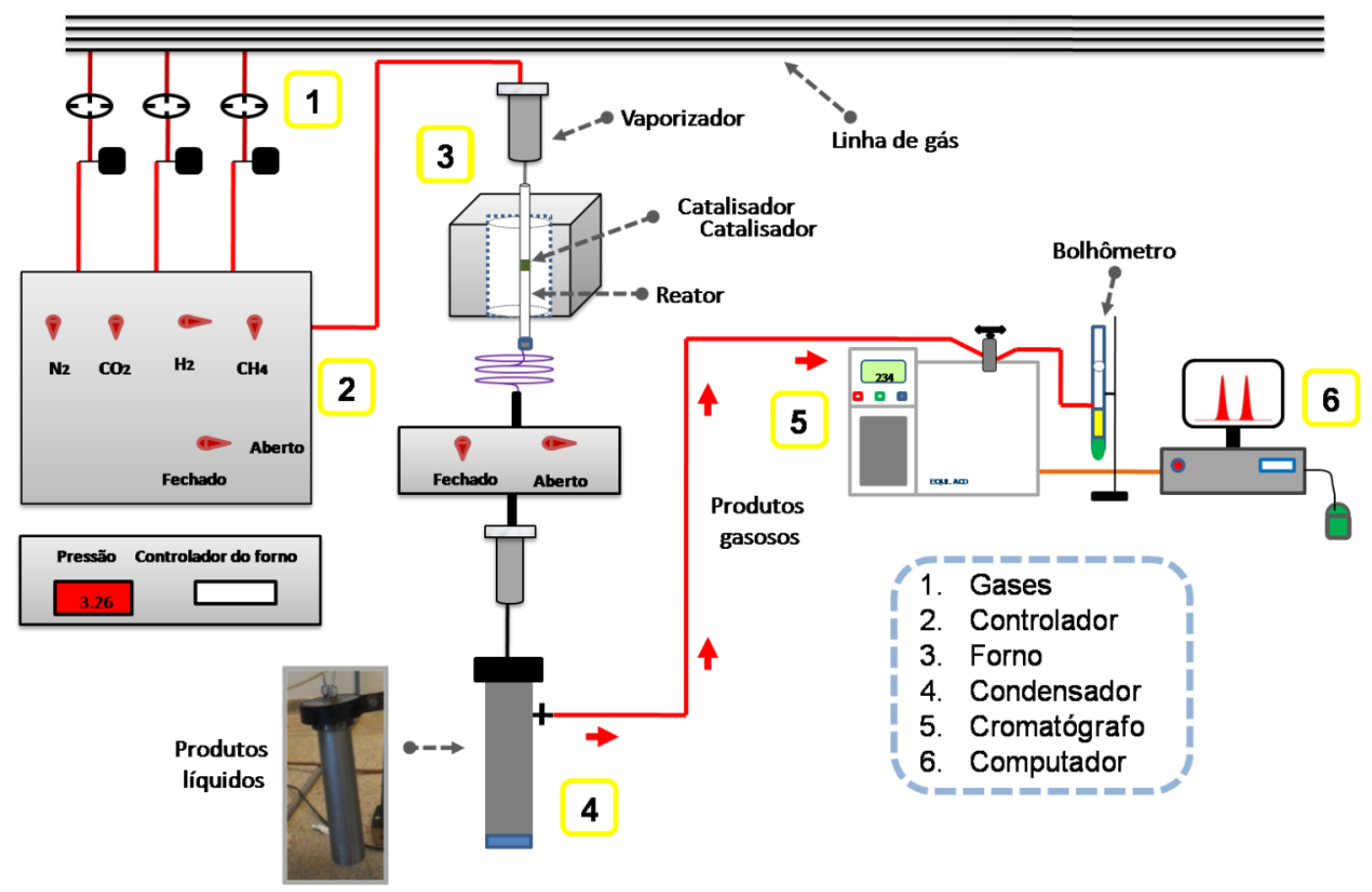

Fonte: Autoria própria

Tabela 9- Temperaturas utilizadas na obtenção, redução e reação dos catalisadores estudados $\left(\mathrm{T}^{*}=\right.$ Temperatura).

\begin{tabular}{|c|c|c|c|}
\hline Catalisador & $\begin{array}{c}\mathrm{T}^{*} \text {. de calcinação } \\
\left({ }^{\circ} \mathrm{C}\right)\end{array}$ & $\begin{array}{l}\text { T. de redução } \\
\left({ }^{\circ} \mathrm{C}\right)\end{array}$ & $\begin{array}{c}\text { T. de reação } \\
\left({ }^{\circ} \mathrm{C}\right)\end{array}$ \\
\hline $\begin{array}{c}\mathrm{Ni} / \mathrm{ZnAl5} \\
\mathrm{Ni} / \mathrm{ZnAlZr-5} \\
\mathrm{Ni} / \mathrm{ZnZr}-5 \\
\end{array}$ & $550^{\circ} \mathrm{C}$ & $550^{\circ} \mathrm{C}$ & $550^{\circ} \mathrm{C}$ \\
\hline $\begin{array}{c}\mathrm{Ni} / \mathrm{ZnAl}-6 \\
\mathrm{Ni} / \mathrm{ZnAlZr-6} \\
\mathrm{Ni} / \mathrm{ZnZr}-6\end{array}$ & $650^{\circ} \mathrm{C}$ & $650^{\circ} \mathrm{C}$ & $650^{\circ} \mathrm{C}$ \\
\hline $\begin{array}{c}\mathrm{Ni} / \mathrm{ZnAl}-7 \\
\mathrm{Ni} / \mathrm{ZnAlZr-7} \\
\mathrm{Ni} / \mathrm{ZnZr}-7\end{array}$ & $750^{\circ} \mathrm{C}$ & $650^{\circ} \mathrm{C}$ & $750^{\circ} \mathrm{C}$ \\
\hline
\end{tabular}

Fonte: Autoria própria. 


\section{RESULTADOS E DISCUSSÃO}

Neste capítulo, os precursores e catalisadores foram devidamente caracterizados e discutidos pelas técnicas reportadas acima. Além disso, os resultados referentes a reação de reforma seca do metano serão apresentados.

\subsection{Estudos dos precursores}

Com o objetivo de determinar a composição química dos precursores foi utilizada a técnica de Energia Dispersiva de Raios X. Pela Tabela 10, notou-se que os valores experimentais referentes ao $\mathrm{Ni}, \mathrm{Zn}$ e $\mathrm{Zr}$ ficaram abaixo do esperado, enquanto que os valores experimentais para Al ficaram acima do esperado. Por tanto, concluiu-se que o comportamento dos resultados obtidos podem estar relacionados com a etapa de obtenção das amostras.

Tabela 10 - Porcentagem teórica e experimental em massa dos metais presentes nos precursores.

\begin{tabular}{ccccccccc}
\hline \multirow{2}{*}{ Precursor } & $\begin{array}{c}\% \mathrm{Ni} \\
\text { teo }\end{array}$ & $\begin{array}{c}\% \mathrm{Ni} \\
\exp \end{array}$ & $\begin{array}{c}\% \mathrm{Al} \\
\text { teo }\end{array}$ & $\begin{array}{c}\% \mathrm{Al} \\
\exp \end{array}$ & $\begin{array}{c}\% \mathrm{Zn} \\
\text { teo }\end{array}$ & $\begin{array}{c}\% \mathrm{Zn} \\
\exp \end{array}$ & $\begin{array}{c}\% \mathrm{Zr} \\
\exp \end{array}$ & $\begin{array}{c}\% \mathrm{Zr} \\
\text { teo }\end{array}$ \\
\hline NiZn-AL & 13,35 & 12,49 & 12,27 & 14,47 & 74,36 & 73,04 & - & - \\
NiZn-AlZr & 12,27 & 11,35 & 7,90 & 10,48 & 68,38 & 64,30 & 11,44 & 13,86 \\
NiZn-Zr & 10,33 & 10,15 & - & - & 57,55 & 55,69 & 32,11 & 34,15 \\
\hline Fonte: Autoria própria. & & & & & & &
\end{tabular}

Na Figura 21 estão ilustrados os padrões de difração de raios $\mathrm{X}$ à temperatura ambiente dos precursores NiZn-AlZr, NiZn-AL e NiZn-Zr obtidos pelo método de coprecipitação química. A fase hidrotalcita típica é apenas observada nos precursores NiZn-AlZr e NiZn-Al, cujos os picos característicos são indexados pelos índices (003), (006), (009), (012), (110) e (113), não sendo confirmada na amostra NiZn-Zr. De acordo com Hines et al.(2000), os picos de difração em $2 \theta<30^{\circ}$ são característicos de estruturas lamelares. Particularmente, o pico (003) em $2 \theta \sim 11,5^{\circ}$ que corresponde à reflexão dos planos basais típicos de estruturas em camadas. Tais picos são de elevada intensidade nas amostras NiZn-AlZr e NiZn-Al, evidenciando a formação de uma estrutura lamelar, porém de baixa intensidade na amostra NiZn-Zr. Todavia, não há evidência da ocorrência deste pico (006) na amostra NiZn-Zr, possivelmente indicando o colapso das camadas (LI et al., 2011). Por fim, a presença dos picos largos e deslocados em $2 \theta=33,1^{\circ}, 12,9^{\circ}$ e $69,9^{\circ}$ no padrão de difração da NiZn-Zr atesta uma possível 
formação das fases de hidróxido, a saber, hidróxido de níquel, hidróxido de zinco $\left[\mathrm{Zn}(\mathrm{OH})_{2}\right.$ (JCPDS \# 00-012-0142/ 00-038-0356)] e hidróxido de zircônio ( ver Figura 22). Ressaltando que esses compostos foram sintetizados também pelo método de copreciptação.

Para a formação de estruturas tipo hidrotalcitas, alguns fatores devem ser levados em consideração, tais como: (i) o raio iônico dos cátions; (ii) número de coordenação; (iii) tamanho da esfera de coordenação e (iv) energia do retículo. Os raios dos cátions presentes na amostra NiZn-Zr possuem valores próximos, por exemplo, o raio iônico do $\mathrm{Zr}^{4+}$ é de $0,72 \AA$ $(\mathrm{CN}=6)$, enquanto que os raios iônicos dos íons $\mathrm{Zn}^{2+}$ e $\mathrm{Ni}^{2+}$ são, respectivamente, 0,74 e $0,69 \AA(\mathrm{CN}=6)$ (SHANNON, 1976). Portanto, pode-se dizer que as diferenças nos valores desses raios não foi um fator predominante para a não formação da estrutura em camadas na amostra NiZn-Zr.

Figura 21 - Padrões de difração de raios X dos precursores NiZn-AlZr, NiZn-Al e NiZn-Zr. O detalhe da figura ilustra a estrutura em camadas típicas de HDL's. O segundo detalhe traz o deslocamento referente ao pico (012).

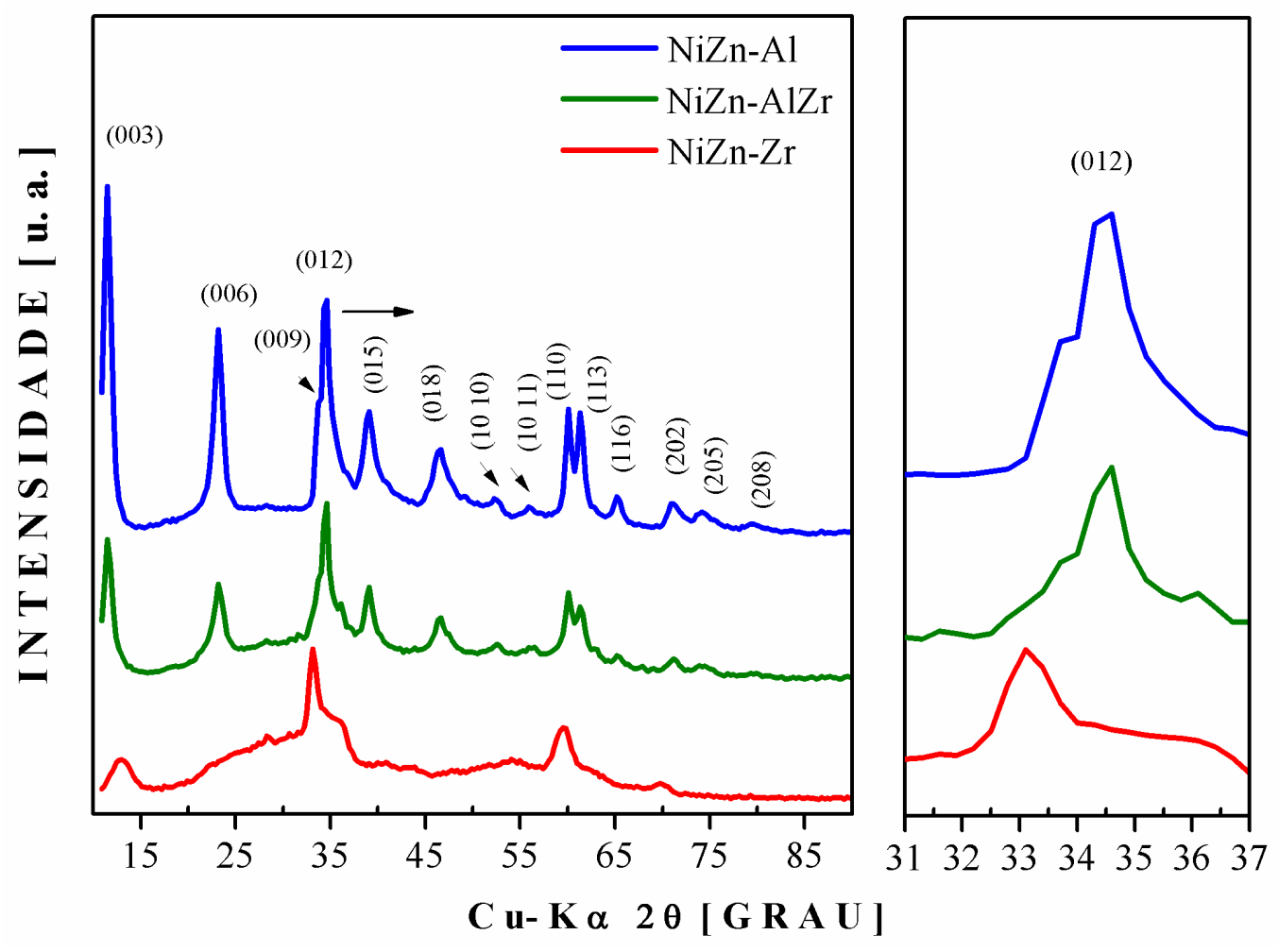

Fonte: Autoria própria. 
Figura 22 - Padrões de difração de raios X dos precursores de NiZn-Zr, Zinco, Níquel e Zircônio.

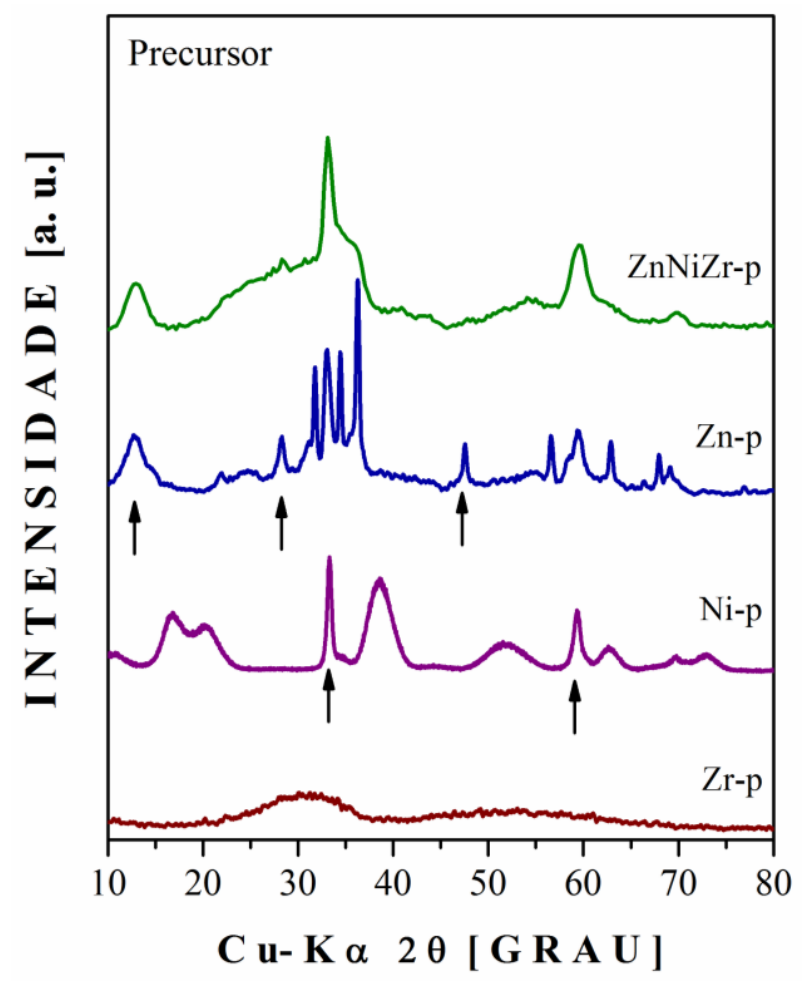

Fonte: Autoria própria.

As estruturas tipo hidrotalcita são usualmente subdivididas em dois grupos politípicos, a depender da ordem de empilhamento das lamelas na HDL's, sendo o primeiro pertencente ao grupo espacial romboédrico $(3 \mathrm{R} ; \mathrm{R} 3 m)$ e o segundo de grupo espacial hexagonal $(2 \mathrm{H}$; P6 $_{3} m m c$ ) (CREPALDI; VALIM, 1998), sendo que esses materiais terão as mesmas propriedades físicas, conforme ilustrado na Figura 23. Notou-se a relação de proporcionalidade entre o parâmetro $c$ e o espaçamento interplanar $d$ referente à reflexão (003), dito espaçamento basal, é dependente do politipismo. No caso romboédrico, $\mathrm{c}=3 d_{(003)}$, por outro lado, $\mathrm{c}=2 d_{(003)}$ para o grupo espacial hexagonal. O que define qual o tipo de politipismo é, portanto, o parâmetro de rede $c$, que representa a altura da cela unitária e é fortemente dependente da natureza e orientação dos ânions nas intercamadas (RIVES, 2002). Logo, o espaçamento basal $d_{(003)}$ é utilizado para avaliar o politipo dos precursores tipo hidrotalcita NiZn-AlZr e NiZn-Al, juntamente com os parâmetros $a$ e $c$ calculados pela Lei de Bragg. Para este fim, a posição de cada pico de difração foi precisamente obtida. Os valores experimentais e teóricos dos espaçamentos basais foram calculados pelas equações 1 e 2 , respectivamente. 
Figura 23 - Polítipos para as estruturas HDL's: (a) politipo romboédrico $3 \mathrm{R}$ e (b) politipo hexagonal $2 \mathrm{H}$. No caso romboédrico, $\mathrm{c}=3 \mathrm{~d}_{(003)}$. Por outro lado, $\mathrm{c}=2 \mathrm{~d}_{(003)}$ para o polítipo hexagonal.

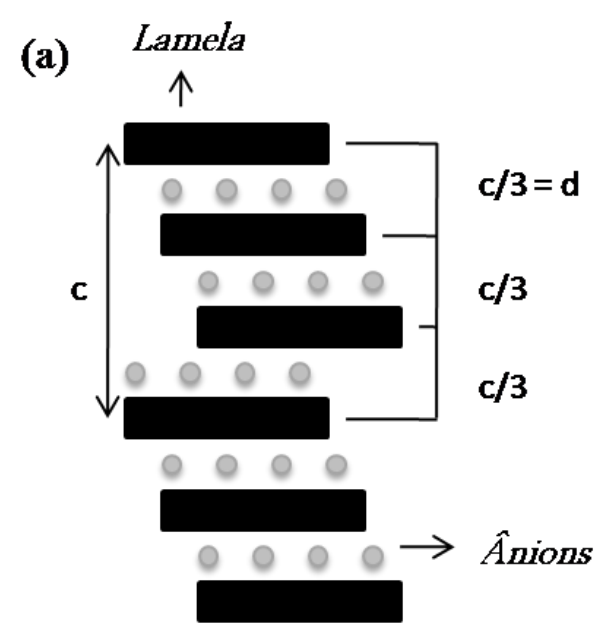

Hidróxidos Duplo Lamelar Politipo $3 R$ (b)

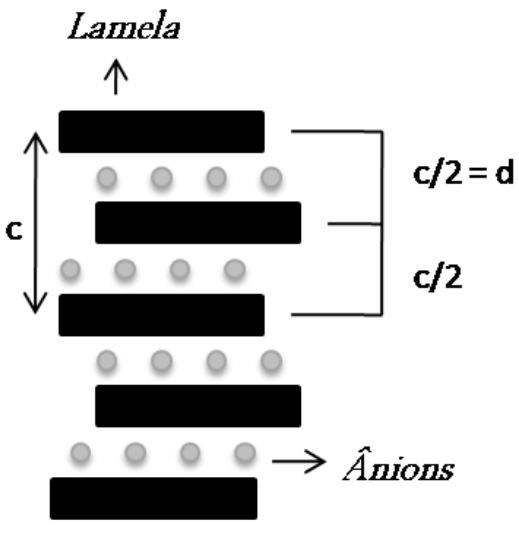

Hidróxidos Duplo Lamelar Politipo $2 H$

Fonte: (CREPALDI; VALIM, 1998).

Particularmente, o parâmetro $a$ é fortemente dependente da distância entre os cátions metálicos no interior das lamelas que constituem a estrutura tipo hidrotalcita (CANTRELL et al., 2005). Nas Tabelas 11 e 12, os índices $h k l$ de cada pico, a posição $2 \theta$ desses picos, o espaçamento interplanar observado e calculado seguem sumarizados para as amostras NiZn-Al e NiZn-AlZr. Vale ressaltar que os parâmetros da cela hexagonal são hábeis na descrição das celas tanto de estruturas romboédricas, hexagonais e trigonais, conforme definido pela União Internacional de Cristalografia (IUCr, International Union of Crystallography), explicando o uso da Equação 8 na obtenção dos parâmetros de rede dos precursores tipo hidrotalcitas investigados nesta tese. Comparando os espaçamentos dos planos basais (003) e o parâmetro de rede $c$ das amostras NiZn-AlZr e NiZn-Al, verificou-se que $\mathrm{c} \approx 3 d_{(003)}$ nos dois casos, atestando que o politipo nas hidrotalcitas de NiZn-AlZr e NiZn-Al é 3R, isto é, descrito por um grupo espacial romboédrico $\mathrm{R} 3 \mathrm{~m}$. Outro ponto é que o valor de $d_{(003)}$ está contido no intervalo entre 7,6 a 7,8 $\AA$, asseverando, possivelmente, a existência de um elevado grau de hidratação entre camadas na estrutura das hidrotalcitas de NiZn-AlZr e NiZn-Al (CAVANI et al., 2010).

Por fim, pode-se observar que o parâmetro $c$ da amostra NiZn-AlZr é menor em relação ao da hidrotalcita NiZn-Al. Tal diminuição pode estar relacionada ao aumento da interação eletrostática entre as camadas e intercamadas da HDL's como consequência da presença do íon $\mathrm{Zr}^{+4}$. De acordo com o trabalho de GAO et al. (2012), esta diminuição ocorre exata- 
mente pelo excesso de carga introduzido na estrutura. No parâmetro $a$, também ocorre esta diminuição. Logo, estes processos induzem a redução do volume da cela unitária.

Tabela 11 - Índices hkl de cada pico de difração de raios X do precursor NiZn-Al, com seus respectivos centros e espaçamentos interplanares determinados pela Lei de Bragg. A partir desses dados, os parâmetros de rede foram determinados pela Equação 8, ver texto. O espaçamento interplanar teórico é obtido através da aplicação dos parâmetros recém-calculados novamente na Equação 8, fornecendo informação sobre a qualidade do processo de cálculo. [* experimental (exp ) \# téorico (teor)].

\begin{tabular}{cccc}
\hline Hkl & \multicolumn{3}{c}{ Cela hexagonal } \\
& $2 \theta$ & $\mathrm{d}_{\text {exp }}(\AA)$ & $\mathrm{d}_{\text {teo }}(\AA)$ \\
\hline$[003]$ & 11,484 & 7,7762 & 7,6411 \\
{$[006]$} & 23,160 & 3,8456 & 3,8205 \\
{$[012]$} & 34,475 & 2,5911 & 2,5971 \\
{$[015]$} & 39,007 & 2,3082 & 2,3050 \\
{$[018]$} & 46,535 & 1,9478 & 1,9520 \\
{$[110]$} & 60,060 & 1,5360 & 1,5395 \\
{$[113]$} & 61,373 & 1,5094 & 1,5091 \\
\hline Parâmetro de rede & $\mathrm{a}(\AA)$ & $\mathrm{c}(\AA)$ & $\mathrm{V}(\AA)$ \\
& 3,07899 & 22,92343 & 188,203 \\
\hline
\end{tabular}

Fonte: Autoria própria.

Tabela 12 - Índices hkl de cada pico de difração de raios X do precursor NiZn-AlZr, com seus respectivos centros e espaçamentos interplanares determinados pela Lei de Bragg. A partir desses dados, os parâmetros de rede foram determinados pela Equação 8, ver texto. O espaçamento interplanar teórico é obtido através da aplicação dos parâmetros recém-calculados novamente na Equação 8, fornecendo informação sobre a qualidade do processo de cálculo. [* experimental (exp ) \# téorico (teor)]

\begin{tabular}{cccc}
\hline Hkl & \multicolumn{3}{c}{ Cela hexagonal } \\
& $2 \theta$ & $\mathrm{d}_{\exp }(\AA)$ & $\mathrm{d}_{\text {teo }}(\AA)$ \\
\hline$[003]$ & 11,563 & 7,6467 & 7,6309 \\
{$[006]$} & 23,172 & 3,8354 & 3,8155 \\
{$[012]$} & 34,480 & 2,5991 & 2,5951 \\
{$[015]$} & 39,075 & 2,3034 & 2,3029 \\
{$[018]$} & 46,577 & 1,9483 & 1,9500 \\
{$[110]$} & 60,099 & 1,5383 & 1,5383 \\
{$[113]$} & 61,407 & 1,5086 & 1,5080 \\
\hline Parâmetro de rede & $\mathrm{a}(\AA)$ & $\mathrm{c}(\AA)$ & $\mathrm{V}(\AA)$ \\
\hline
\end{tabular}

Fonte: Autoria própria. 
A espectroscopia vibracional tem se mostrado uma ferramenta precisa na verificação da ocorrência de ânions interlamelares, da presença de água estrutural e de ligações $\mathrm{M}-\mathrm{OH}$ na estrutura dos precursores tipo hidrotalcita. Tipicamente, as vibrações oriundas das camadas octaedrais que constituem as lamelas podem ser obtidas no intervalo $250-800 \mathrm{~cm}^{-1}$, dos espectros infravermelho/Raman, cuja atribuição advém dos movimentos translacionais dos oxigênios (MORENO et al., 1985). Para este fim, espectros infravermelho/Raman foram coletados à temperatura ambiente para os precursores NiZn-AlZr, NiZn-Al e NiZn-Zr. Na Figura 24, os espectros na região do infravermelho médio dos precursores seguem ilustrados. As bandas centradas no intervalo de 427 a $758 \mathrm{~cm}^{-1}$ foram associadas às vibrações oriundas da ligação Al-OH nas amostras de NiZn-AlZr e NiZn-Al, o mesmo não ocorrendo no precursor NiZn-Zr, pois não há presença do alumínio na estrutura. O ânion carbonato livre, por sua vez, é caracterizado por uma simetria pontual $\mathrm{D}_{3 \mathrm{~h}}$. Logo, esperam-se três bandas ativas no infravermelho para ânion carbonato livre: modo flexão não planar em $1063 \mathrm{~cm}^{-1},\left(v_{2}, \mathrm{~A}{ }_{2}\right)$, estiramento antisimétrico em $1415 \mathrm{~cm}^{-1}\left(v_{3}, E^{\prime}\right)$ e flexão angular em $680 \mathrm{~cm}^{-1}\left(v_{4}, E^{\prime}\right)$. Entretanto, o modo de estiramento simétrico ( $\left.v_{1}, \mathrm{~A}^{\prime}{ }_{1}\right)$ é somente ativo no Raman (HICKEY et al., 2000). No entanto, o comportamento da banda é modificado quando o íon carbonato está intercalado devido a interação com a molécula de $\mathrm{H}_{2} \mathrm{O}$ ou grupos $\mathrm{OH}$ nas estruturas de hidrotalcitas (J. THEO KLOPROGGE, DAVID WHARTON, LEISEL HICKEL, 2002). A banda em $849 \mathrm{~cm}^{-1}$ referese ao modo de flexão do grupo carbonato presentes nas amostras NiZn-AlZr, NiZn-Al e NiZn-Zr. Enquanto que a banda em $1362 \mathrm{~cm}^{-1}$ (NiZn-Al), $1362 \mathrm{~cm}^{-1}(\mathrm{NiZn}-\mathrm{AlZr})$ e $1388 \mathrm{~cm}^{-1}$ (NiZn-Zr) representam o modo de estiramento anti-simétrico da ligação $\mathrm{C}=\mathrm{O}$ do ânion carbonato.

Os modos característicos da molécula de $\mathrm{H}_{2} \mathrm{O}$ na estrutura lamelar das hidrotalcitas podem ser sondados em duas regiões: $1600-1750 \mathrm{~cm}^{-1}$ e $2500-4000 \mathrm{~cm}^{-1}$. Essas bandas são derivadas do modo de flexão $\left[\delta\left(\mathrm{A}_{1}\right) \sim 1594 \mathrm{~cm}^{-1}\right]$, estiramento simétrico $\left[v_{\mathrm{s}}\left(A_{l}\right) \sim 3656 \mathrm{~cm}^{-1}\right]$ e estiramento anti-simétrico $\left[v_{\mathrm{as}}\left(\mathrm{B}_{1}\right) \sim 3755 \mathrm{~cm}^{-1}\right]$. No espectro de infravermelho, o modo de flexão apareceu em torno de $1639 \mathrm{~cm}^{-1}$ para todas as amostras. As bandas em $3074 \mathrm{~cm}^{-1} \mathrm{e}$ $3137 \mathrm{~cm}^{-1}$ estão associadas à ligação $\mathrm{H}_{2} \mathrm{O}-\mathrm{CO}_{3}$ presentes na NiZn-Al e NiZn-AlZr, respectivamente, enquanto que as bandas em $3368 \mathrm{~cm}^{-1}$ (NiZn-Al) e $3396 \mathrm{~cm}^{-1}$ (NiZn-AlZr) são atribuídas à molécula de $\mathrm{H}_{2} \mathrm{O}$ em torno dos ânions nas intercamadas na estrutura de HDL. Além disso, as bandas em torno de $3510 \mathrm{~cm}^{-1}$ (NiZn-Al) e $3532 \mathrm{~cm}^{-1}$ (NiZn-AlZr) correspondem ao modo de estiramento da ligação entre M-OH (KLOPROGGE et al., 2004). 
Figura 24 - Espectros de infravermelho por transformada de Fourier dos precursores (a) NiZn-Al, (b) NiZn$\mathrm{AlZr}$ e (c) NiZn-Zr coletados à temperatura no modo de absorbância. No detalhe, as decomposições por funções Gaussianas foram conduzidas visando à obtenção dos centros das bandas pertinentes às vibrações das hidroxilas.

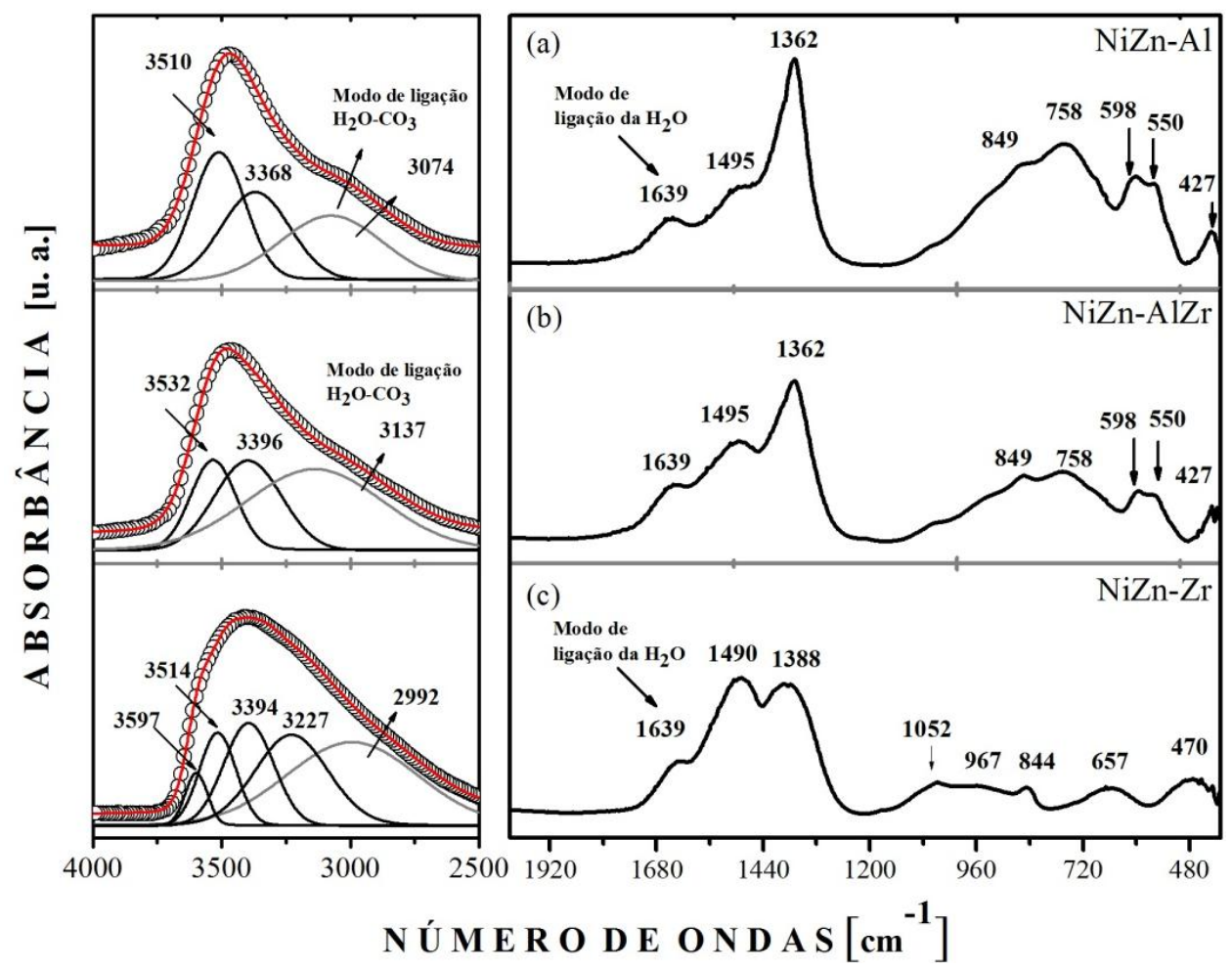

Fonte: Autoria própria.

Os espectros Raman à temperatura ambiente dos precursores NiZn-AlZr, NiZn-Al e NiZn-Zr estão ilustrados na Figura 25. Na região de baixo número de onda, apareceu um modo em torno de $151 \mathrm{~cm}^{-1}$ em todos os precursores referentes ao modo de estiramento em vários grupos $\mathrm{OH}$ nas camadas do tipo brucita ( Figura 25a). O pico centrado em $\sim 480 \mathrm{~cm}^{-1}$, nos espectros dos precursores NiZn-AlZr, NiZn-Al, foram atribuídos ao modo de estiramento simétrico da ligação M-O-M, o que pode indicar a presença de íons trivalentes na forma da ligação Al-O-Al. Um terceiro pico em $541 \mathrm{~cm}^{-1}$, foi atribuído à vibração da ligação Al-O-M nos precursores NiZn-Al e NiZn-AlZr, nesse caso, $\mathrm{M}=\mathrm{Zn}^{2+}, \mathrm{Ni}^{2+}$ e $\mathrm{Zr}^{4+}$. Os espectros Raman de todos os precursores revelaram uma banda em 1061-1062 $\mathrm{cm}^{-1}$, sendo atribuída ao movimento de estiramento simétrico da ligação $\mathrm{C}=\mathrm{O}$ do grupo $\mathrm{CO}_{3}{ }^{2-}$ ( Figura $25 \mathrm{c} / \mathrm{d} / \mathrm{e}$ ). (MORA et al., 2014).

A molécula de água exibe os seguintes modos Raman: modo de flexão em $1594 \mathrm{~cm}^{-1}$ (fracamente Raman ativo), modo de estiramento simétrico em $3656 \mathrm{~cm}^{-1}$ (Raman ativo) e o modo de estiramento assimétrico em $3755 \mathrm{~cm}^{-1}$ (fracamente Raman ativo). No entanto, essas bandas não foram identificadas nas amostras investigadas nesta tese. A banda em $3075 \mathrm{~cm}^{-1}$ 
para NiZn-Al (alta intensidade), NiZn-AlZr (alta intensidade) e NiZn-Zr (baixa intensidade), além de outra banda em $3172 \mathrm{~cm}^{-1}$ foram atribuídas à ligação $\mathrm{CO}_{3}-\mathrm{H}_{2} \mathrm{O}$ (KLOPROGGE et al., 2004). A fraca banda centrada em $3588 \mathrm{~cm}^{-1}$ referente ao modo de estiramento M-OH (BURRUECO et al., 2013) ocorreu em todas as amostras. Portanto, o espectro Raman dos precursores NiZn-Al e NiZn-AlZr apresenta comportamento característico de HDL, enquanto que o espectro do precursor NiZn-Zr mostrou uma característica incompleta de uma estrutura de HDL.

Figura 25 - Espectros Raman à temperatura ambiente dos precursores NiZn-Al, NiZn-AlZr e NiZn-Zr. Número no top de cada banda indica a posição aproximada de seu centro.

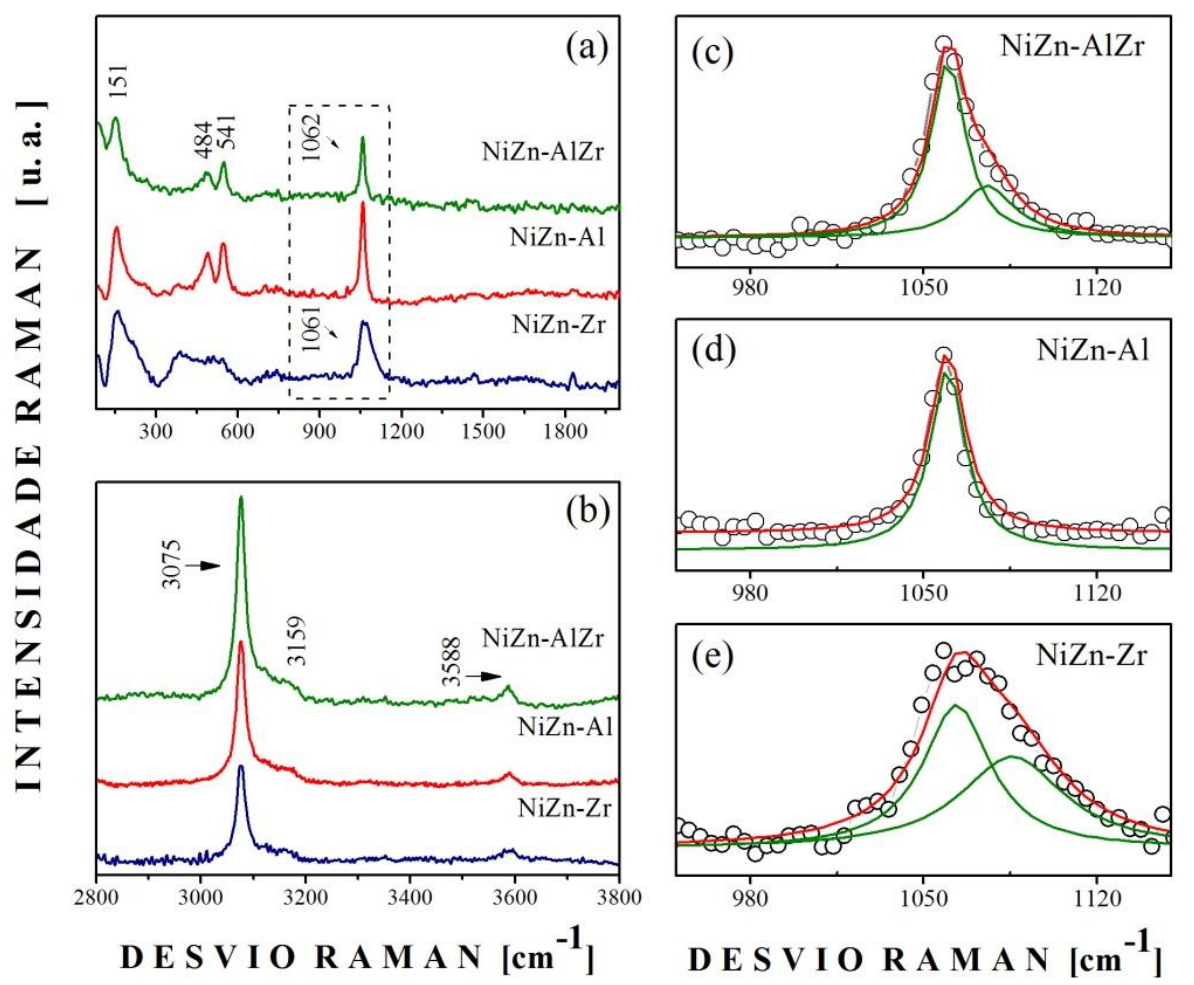

Fonte: Autoria própria.

A área superficial específica para hidrotalcita descrito na literatura geralmente varia de 50 a $80 \mathrm{~m}^{2} \cdot \mathrm{g}^{-1}$ (CREPALDI; VALIM, 1998). A amostra NiZn-Zr exibiu uma elevada área superficial específica em torno de $165 \mathrm{~m}^{2} / \mathrm{g}$ (ver Tabela 13). Esse resultado revelou que a presença das fases referentes aos hidróxidos influenciaram para que esse precursor apresentasse uma alta área superficial. Enquanto que as áreas superficiais obtidas das hidrotalcitas NiZn-Al e NiZn-AlZr foram de 46 e $98 \mathrm{~m}^{2} / \mathrm{g}$, respectivamente. O valor da área superficial da hidrotalcira corresponde somente à área externa e influencia na forma da isoterma de adsorção de nitrogênio (Rives, 2002). Analisando os valores referentes as áreas das hidrotalcitas, nota-se 
que a presença do Zr na estrutura favoreceu o aumento da área específica. Esse resultado pode estar relacionado ao aumento do tamanho de partícula, uma vez que o processo de aglomeração dos cristalitos pode ter gerado uma maior formação de poros. Além disso, o tamanho do cristalito pode ter influenciado também na maior área especifica apresentada para o precursor NiZn-AlZr em relação ao NiZn-Al. Este fato pode estar relacionado a área superficial externa de um cristalito $\left[\mathrm{S}_{\text {ext }}=6 /(\mathrm{D} \delta)\right.$ ], que dependerá somente do tamanho do mesmo (D), considerando que a densidade teórica da hidrotalcita (densidade do cristal, $\delta$ ) seja igual a $2 \mathrm{~g} / \mathrm{cm}^{3}$ (RIVES, 2001). Dessa forma, a redução volume da célula unitária apresentado pelo precursor NiZn-AlZr (Tabela 9) provocou diminuição do tamanho de cristalito, o qual pode ser verificado pela diminuição da intensidade do pico de difração nesse precursor, como reportado na Figura 12.

As isotermas recordadas para essas amostras geralmente são do tipo II ou IV de acordo com a classificação da IUPAC (International Union of Pure and Applied Chemistry). Na Figura 26a reporta-se as isotermas de adsorção (I)/dessorção (II) a 77K para as amostras NiZn-Al, NiZn-AlZr e NiZn-Zr. A análise das isotermas mostrou que todas são do tipo IV, por conseguinte, esses sistemas apresentam o fenômeno de condensação capilar nos mesoporos, o qual representa uma forte interação entre adsorvente e adsorbato. Analisando a isoterma da amostra NiZn-Al, verificou-se uma extensa região relacionada à presença de pequenos poros até uma pressão relativa $\left(\mathrm{P} / \mathrm{P}_{\mathrm{o}}\right)$ de 0,82 . A presença de mesoporos foi evidenciada por um ciclo de histerese estreito entre 0,82 e 0,98. O volume máximo de gás adsorvido por esse precursor foi em torno de $104 \mathrm{~cm}^{3} / \mathrm{g}$. O ciclo de histerese para amostra NiZn-AlZr fecha em uma pressão relativa $\sim 0,68$ revelando que essa amostra exibe uma pequena quantidade de poros menores. O volume máximo de gás adsorvido foi em torno de $255 \mathrm{~cm}^{3} / \mathrm{g}$. Por outro lado, a amostra NiZn-Zr demonstrou um comportamento diferente para o ciclo de histerese ao ser comparado com as amostras anteriores. O fechamento do ciclo de histerese ocorre a uma pressão relativa 0,43 , provavelmente devido uma baixa quantidade de poros menores na amostra. Para esse precursor, o máximo de volume adsorvido de gás foi aproximadamente de $215 \mathrm{~cm}^{3}$. De acordo com a classificação IUPAC, podem ser identificados quatro tipos de histereses correspondente à diferentes tipos de poros (SING et al., 2008). Portanto, concluiu-se que as curvas de histerese são do tipo $\mathrm{H} 3$, associada com poros de tamanhos não uniformes e de canais em forma de fenda entre placas paralelas. 
O estudo complementar da distribuição do tamanho de poros foi realizado pelo método $\mathrm{BJH}$, desenvolvido por Barrer, Joiyner e Halenda, com a finalidade de executar cálculos em mesoporos (volume e distribuição do tamanho de poros) (LEOFANTI et al., 1998). A Figura 26b ilustra a distribuição usando a função dV/dlog (D) pelo diâmetro do poro. Analisando as curvas, notou-se o predomínio de mesoporos em um intervalo de 20 a 500 Á de diâmetro. Outrossim, pela distribuição foi possível verificar a presença de poros maiores com diâmetros acima de 500 Á, porém em menores quantidades. O diâmetro máximo de poros encontrado nas hidrotalcitas NiZn-Al e NiZn-AlZr foi de 451 Á e 255 Á, respectivamente. Por fim, amostra NiZn-Zr apresentou um diâmetro máximo de poro em torno de $376 \AA$, porém não foi reportado a presença de poros maiores que $800 \AA$ Á. Comparando as hidotalcitas formadas, verificou-se que o comportamento da isoterma para a amostra NiZn-Zr pode estar relacionado à presença de poros rasos e largos, corroborando com o resultado de distribuição de poros, tendo em vista que a amostra NiZn-Zr apresentou uma menor concentração de poros em diâmetros menores.

Tabela 13- Basicidade total e perda por rubro dos precursores NiZn-Al, NiZn-AlZr e NiZn-Zr a $100^{\circ} \mathrm{C}$ por $15 \mathrm{~h}$.

\begin{tabular}{ccc}
\hline Precursor & $\begin{array}{c}\text { Área superficial } \\
\left(\mathrm{m}^{2} / \mathrm{g}\right)\end{array}$ & $\begin{array}{c}\text { Perda por rubro } \\
(\%)\end{array}$ \\
\hline NiZn-Al & 46 & $35 \%$ \\
NiZn-AlZr & 98 & $34 \%$ \\
NiZn-Zr & 165 & $24 \%$ \\
\hline Autoria própria. & &
\end{tabular}

Fonte: Autoria própria. 
Figura 26 - Isotermas de adsorção para os precursores (NiZn-Al, NiZn-AlZr e NiZn-Zr ), onde (I) representa adsorção (condensação dos líquidos nos poros) e II a dessorção (evaporação dos líquidos nos poros) partir das quais foram determinado os valores das áreas superficiais específicas pelo método de BET. Detalhe: distribuição de tamanho dos poros (BJH, ramo dessorção de isotérmica).

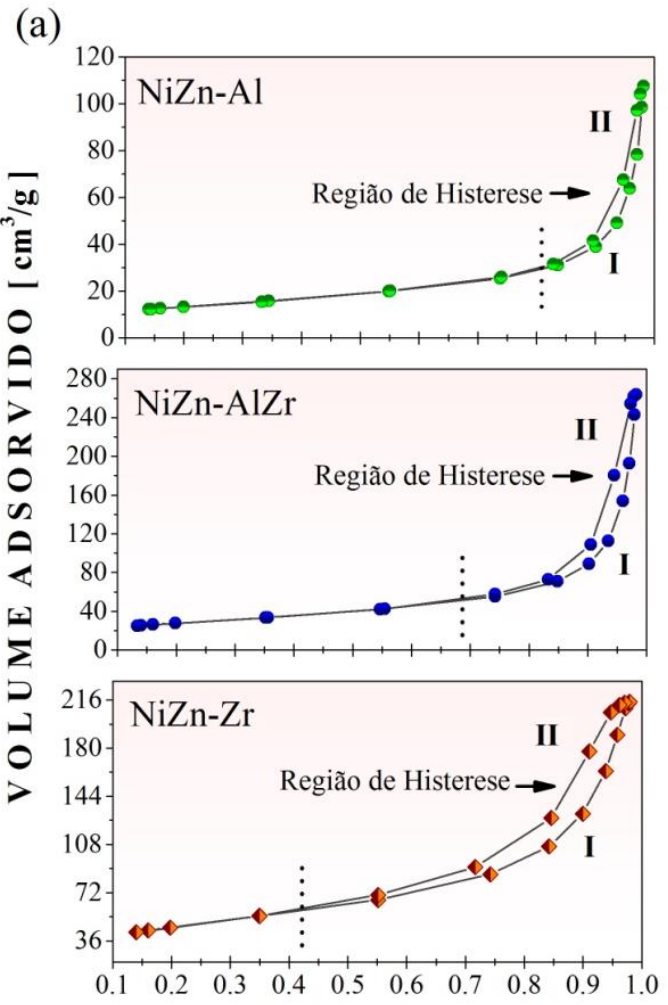

PRESS ÃO RELATIVA $\left[\mathrm{P} / \mathrm{P}_{0}\right]$ (b)
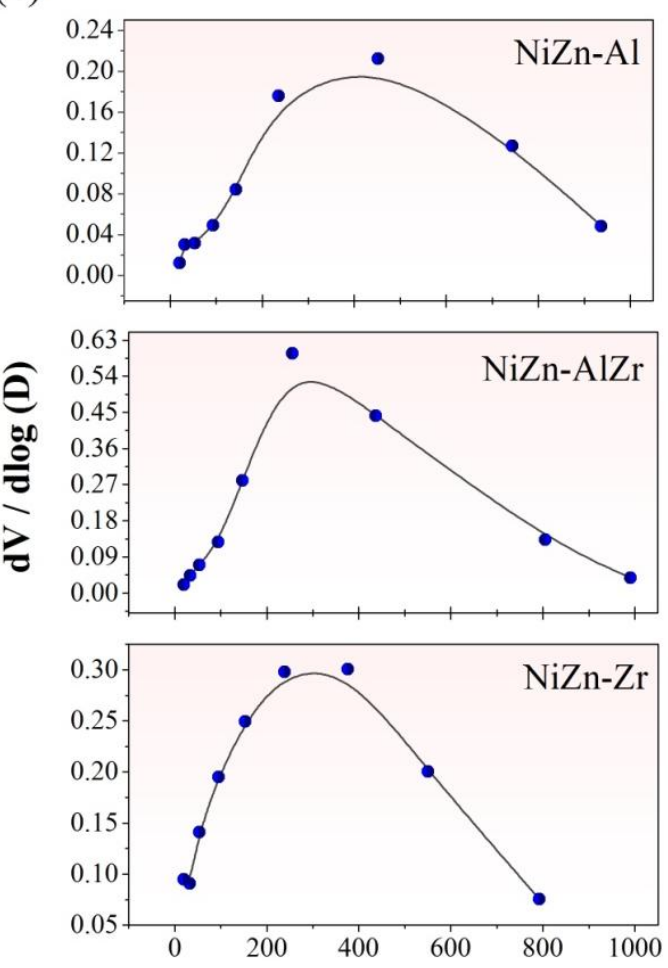

DI ÂM ETRO DE PORO [Å]

Fonte: Autoria própria.

A microscopia eletrônica de varredura foi aplicada com a finalidade de determinar o tamanho e forma das partículas. As Figuras 27a, 28a e 29a exibem as micrografias das amostras investigadas nesse trabalho. As morfologias das amostras NiZn-Al e NiZn-AlZr exibiram tendências semelhantes devido à formação da estrutura de hidrotalcita, com dimensões variáveis e aspectos irregulares. A amostra NiZn-Al exibiu algumas partículas em forma de bastões com diferentes tamanhos e espessuras. Além disso, é possível observar a formação de aglomerados nos precursores NiZn-Al e NiZn-AlZr, originando uma estrutura porosa. Devese observar que não foi possível identificar as plaquetas hexagonais características das hidrotalcitas, ao passo que para o NiZn-Zr, algumas partículas de dimensões variáveis, incluindo esferas de tamanho pequeno e aglomerados foram observados.

O tamanho médio das partículas (TMP) foi obtido a partir da distribuição de tamanho de partícula, ilustrados nas Figuras 27b, 28b e 29b. O TMP para as amostras NiZn-Al e NiZnAlZr foi em torno de $~ 120$ and $131 \mathrm{~nm}$, respectivamente. No entanto, um maior valor foi 
reportado para a amostra NiZn-Zr em torno de $235 \mathrm{~nm}$, sendo este atribuído a formação de aglomerados. Além disso, grandes partículas foram observadas na micrografia da NiZn-Zr ( $1000 \mathrm{~nm}$ ) provavelmente devido a aglomeração dessas partículas. De acordo com Paganno et $a l$, 2007, o aglomerado pode ser formado devido a supersaturação da base empregada no processo de co-precipitação, geralmente usado para manter o $\mathrm{pH}$ desejado, com isso induzindo a diminuição da área superficial e sua baixa porosidade.

Figura 27 - (a) Imagem representativa da microscopia eletrônica de varredura do precursor NiZn-Al; (b) Distribuição das partículas utilizando o image $\mathrm{J}$.
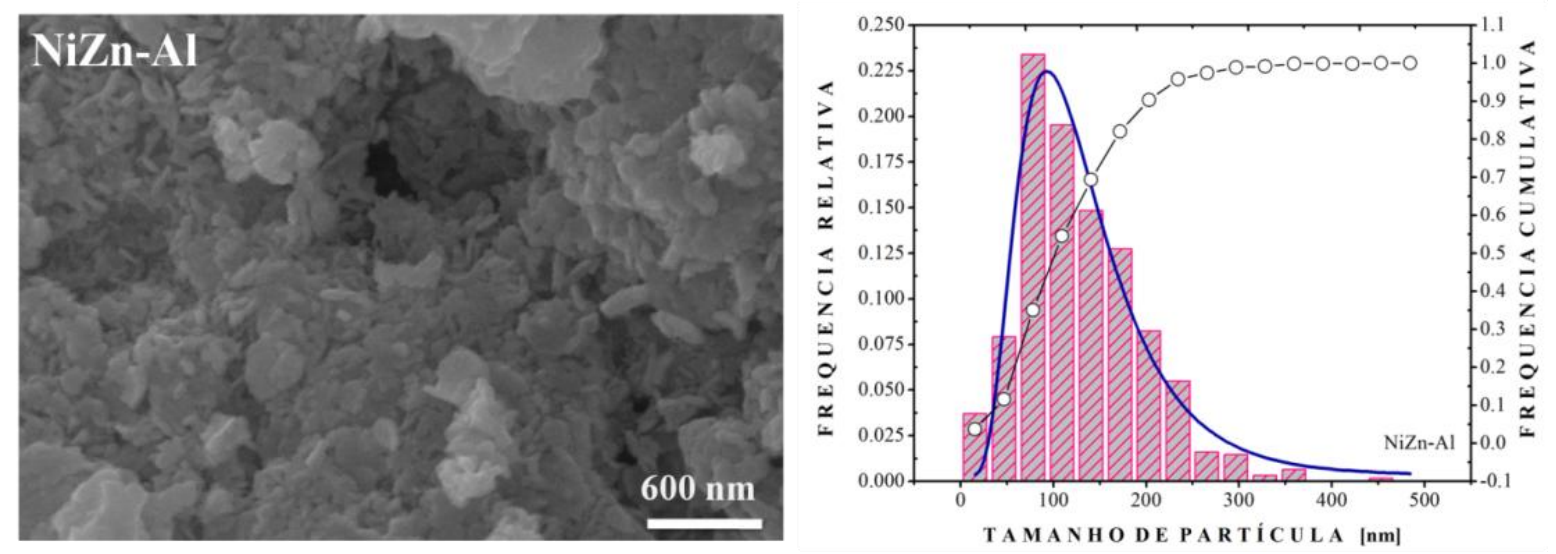

Fonte: Autoria própria.

Figura 28 - (a) Imagem representativa da microscopia eletrônica de varredura do precursor NiZn-AlZr; (b) Distribuição das partículas utilizando o image $\mathrm{J}$.
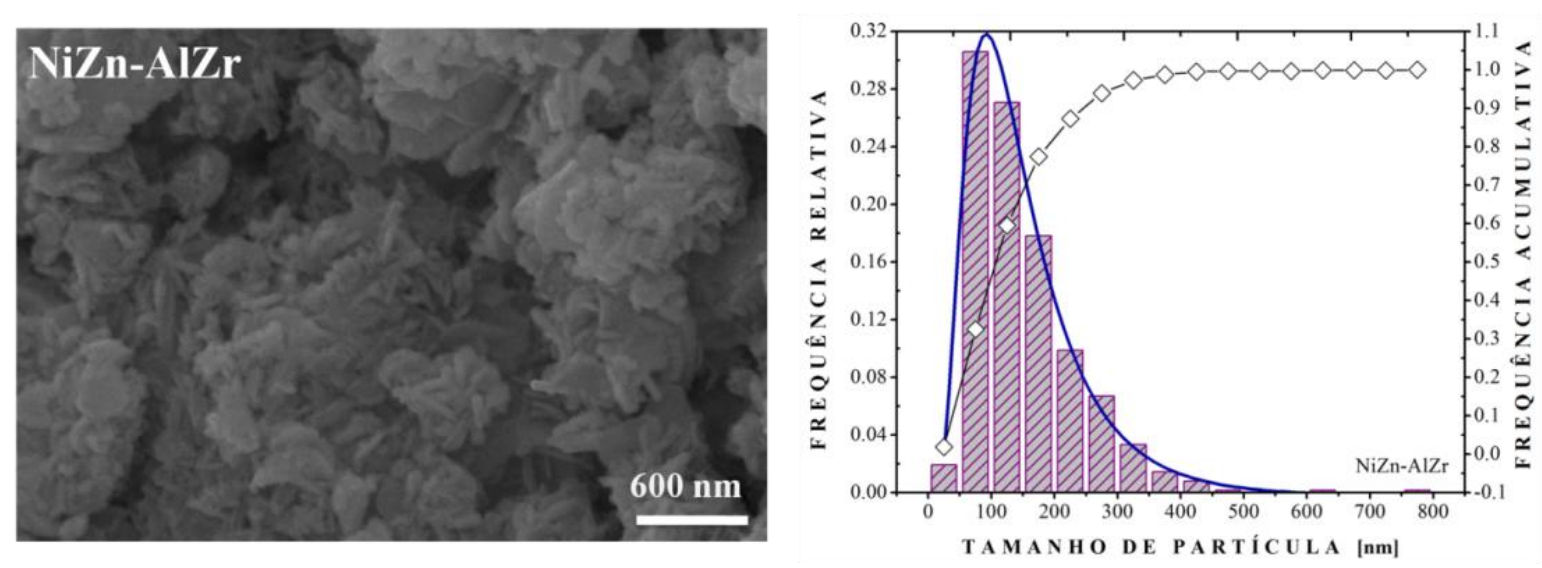

Fonte: Autoria própria. 
Figura 29 - (a) Imagem representativa da microscopia eletrônica de varredura do precursor NiZn-Zr; (b) Distribuição das partículas utilizando o image $\mathrm{J}$.
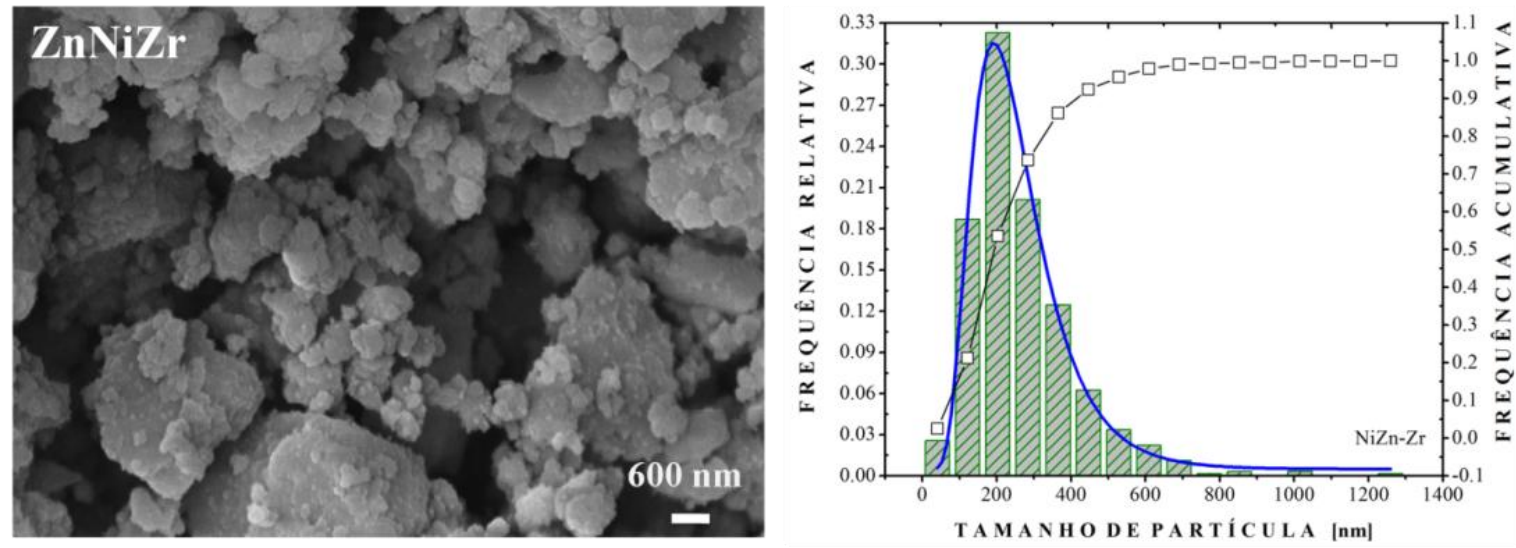

Fonte: Autoria própria

A Figura 30 mostra um conjunto de imagens obtidas por microscopia eletrônica de transmissão (TEM) para amostras NiZn-Al, NiZn-AlZr e NiZn-Zr. É possível identificar partículas que exibiram plaquetas hexagonais nas amostras NiZn-Al, NiZn-AlZr. Não obstante, as micrografias de ambos os compostos mostraram um conglomerado de partículas pequenas, porém com as formas não bem definidas. Para a amostra NiZn-Zr foi verificada a presença de um aglomerado sem a formação de plaquetas.

Figura 30 - Imagens representativas da microscopia eletrônica de transmissão dos precursores $\mathrm{NiZn}-\mathrm{Al}$, NiZnAlZr and NiZn-Zr. As setas indicam a formação das plaquetas hexagonais presentes nas amostras.
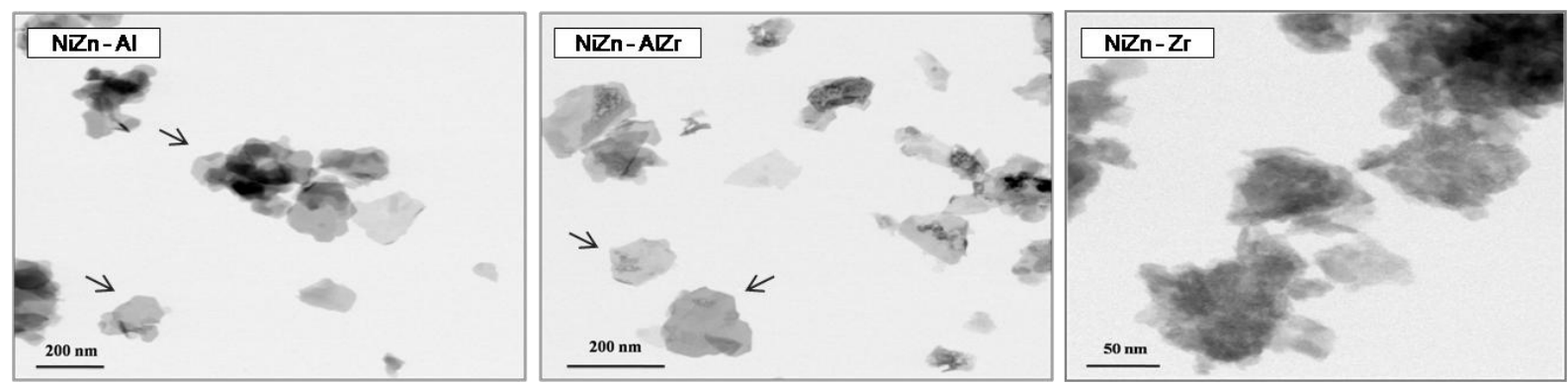

Fonte: Autoria própria.

A Tabela 11 reporta a perda ao rubro dos precursores realizado até a temperatura de $1100^{\circ} \mathrm{C}$. O resultado representa a porcentagem da diferença entre massa seca pela massa calcinada. Os precursores NiZn-Al e NiZn-AlZr apresentaram perdas de 35 e $34 \%$, respectivamente, enquanto que o precursor $\mathrm{NiZn}-\mathrm{Zr}$ exibiu uma menor perda ao rubro de $24 \%$. Visando confirmar esses resultados, realizou-se a análise termogravimétrica das amostras. 
Os perfis de degradação induzidos pela temperatura para a NiZn-Al, NiZn-AlZr e NiZn-Zr foram obtidos através da análise termogravimétrica (TGA) ilustrados nas Figuras 31, 32 e 33 . Na literatura, dois pontos de perda de massa são geralmente reportados para as hidrotalcitas: o primeiro ponto de perda é decorrente da eliminação de água fisicamente adsorvida sobre a superfície externa do cristalito e remoção de água na intercamada, preservando a estrutura lamelar. O segundo ponto endotérmico é atribuído à perda dos grupos nas camadas (CAVANI et al., 2010). Essas transições dependem qualitativamente e quantitativamente de muitos fatores, tais como, natureza e quantidade relativa dos cátions das camadas, tipos de ânions na intercamada e cristalinidade (RIVES, 2002). O tratamento térmico a temperatura superior a $450{ }^{\circ} \mathrm{C}$ induz a transformação da estrutura da hidrotalcita em uma mistura homogênea de óxidos binário e/ou ternários. A Tabela 12 sumariza a perda de massa dos precursores NiZn-Al, NiZn-AlZr e NiZn-Zr. A primeira perda $(\sim 15,6 \%$ e $17,3 \%)$ entre 40 e $240^{\circ} \mathrm{C}$ ocorreu no perfil de TG dos precursores NiZn-Al e NiZn-AlZr, respectivamente, sendo atribuída à remoção das moléculas de água intersticiais (FROST et al., 2005). A segunda perda de massa $(\sim 10,8 \%$ and $10,1 \%)$, entre 240 e $450{ }^{\circ} \mathrm{C}$, está relacionada à remoção do carbonato intercamadas e ao processo de desidroxilação, todos esses fatores tendem a elevar o volume de poros (VALENTE et al., 2010). Por fim, a perda entre 450 e $650{ }^{\circ} \mathrm{C}$ foi atribuída ao processo de decomposição de hidroxilas remanescentes na estrutura.

Figura 31 - Perfis de perda de massa (TG) e sua derivada (DTG) para os precursores de NiZn-Al. A quantificação porcentual da perda e sua respectiva atribuição seguem sumarizadas na Tabela 13.

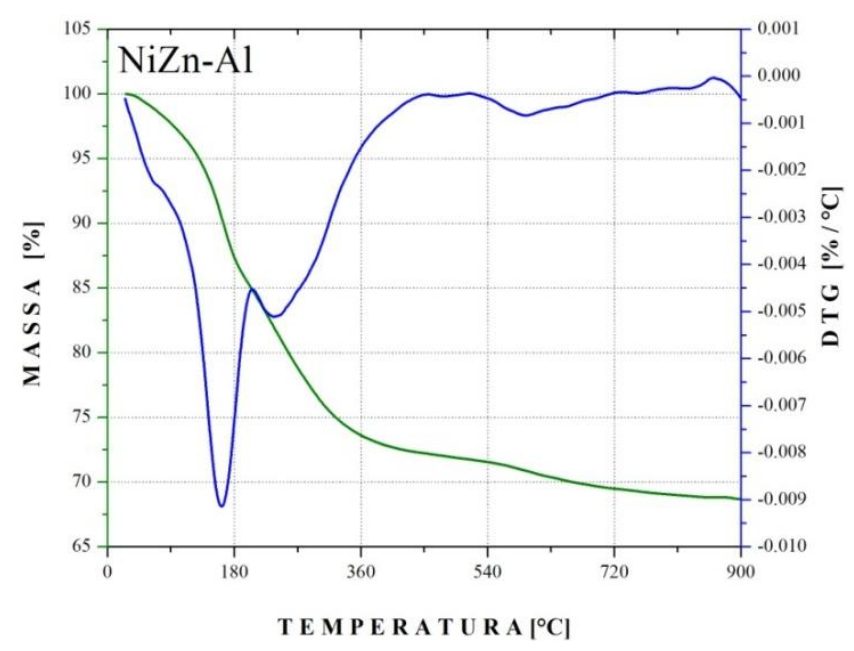

Fonte: Autoria própria. 
Figura 32 - Perfis de perda de massa (TG) e sua derivada (DTG) para os precursores de NiZn-AlZr. A quantificação porcentual da perda e sua respectiva atribuição seguem sumarizadas na Tabela 13.

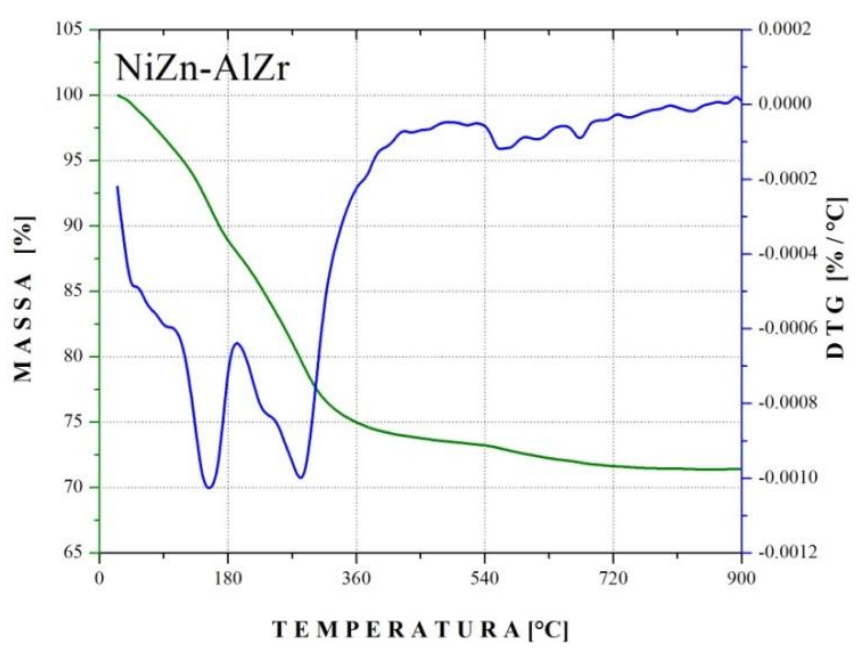

Fonte: Autoria própria.

A Figura 33 ilustra a termogravimetria do precursor NiZn-Zr. Embora não tenha ocorrido a formação da estrutura para o precursor NiZn-Zr, a saída da hidroxila e do carbonato é esperada na curva de perda de massa. Entre 40 e $450{ }^{\circ} \mathrm{C}$ ocorreu uma perda $(\sim 13,9 \%)$, atribuída à água estrutural (ver Tabela 14). Similarmente, uma perda de $8,7 \%$ foi detectada entre 240 e $450{ }^{\circ} \mathrm{C}$ assinalado a remoção de íons carbonatos, visto que a água remanescente foi eliminada entre 450 e $650^{\circ} \mathrm{C}$. De tudo o que precede, concluiu-se que as fases óxidas foram formadas a $550{ }^{\circ} \mathrm{C}$ com algumas hidroxilas remanescentes adsorvidas sobre as suas superfícies.

Figura 33 - Perfis de perda de massa (TG) e sua derivada (DTG) para os precursores de NiZn-Zr. A quantificação porcentual da perda e sua respectiva atribuição seguem sumarizadas na Tabela 13.

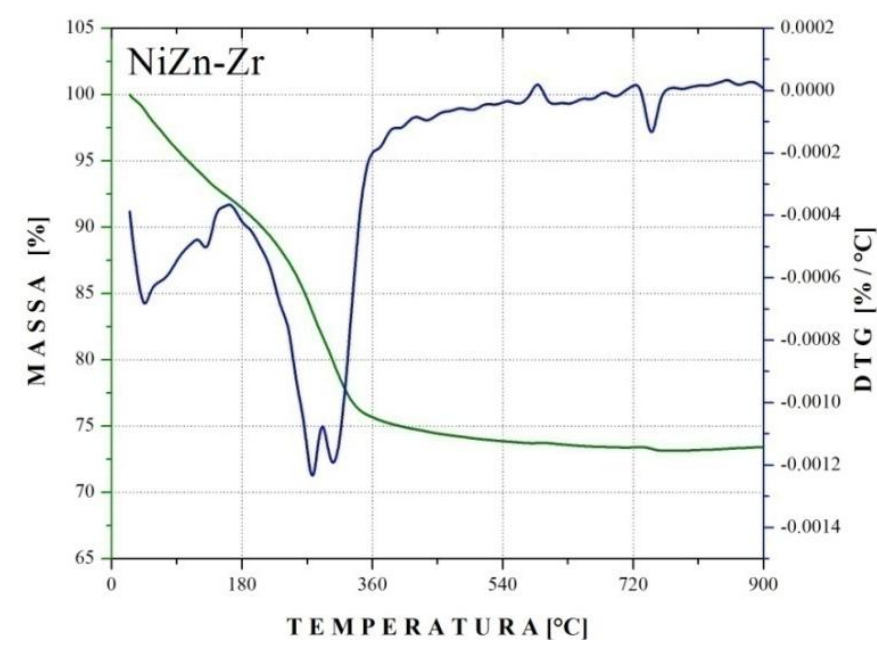

Fonte: Autoria própria. 
Tabela 14 - Valores das perdas porcentuais obtidos pelos perfis de perda de massa de cada precursor nos seus respectivos intervalos de ocorrência.

\begin{tabular}{ccccccc}
\hline Precursor & $1{ }^{\circ}$ Perda & $\begin{array}{c}\text { Temperatura } \\
1{ }^{\circ} \text { Perda }\end{array}$ & $2^{\circ}$ Perda & $\begin{array}{c}\text { Temperatura } \\
2{ }^{\circ} \text { Perda }\end{array}$ & 3 Perda & $\begin{array}{c}\text { Temperatura } \\
3{ }^{\circ} \text { Perda }\end{array}$ \\
\hline NiZn-Al & $15,6 \%$ & & $10,8 \%$ & & $1,3 \%$ & \\
NiZn-AlZr & $17,3 \%$ & $40-240^{\circ} \mathrm{C}$ & $10,1 \%$ & $240-450^{\circ} \mathrm{C}$ & $1,6 \%$ & $450-650^{\circ} \mathrm{C}$ \\
& & & & & & \\
NiZn-Zr & $13,9 \%$ & & $8,7 \%$ & & $0,6 \%$ & \\
\hline Fonte: Autoria própria. & & & & &
\end{tabular}

Fonte: Autoria própria.

\subsubsection{Estudo do efeito memória}

Os padrões de difração das hidrotalcitas reconstruídas (NiZn-Al) estão ilustrados na Figura 34. Antes do processo de calcinação, verificou-se que a hidrotalcita é constituída de uma estrutura em camadas. A destruição dessas camadas foi verificada pela ausência dos pi$\cos d(001)$ e d (006), originando picos referentes a uma mistura de óxidos ( $\mathrm{NiO}$ e $\mathrm{ZnO}$ ), porém de baixa cristalinidade. A formação dos óxidos ocorre pelo processo de remoção da água, ânions da intercamada e pela desidroxilação, como reportado na discussão de termogravimetria. O processo de reconstrução da hidrotalcita foi realizado à temperatura ambiente, ao submeter à mistura de óxidos em uma solução de $\mathrm{Na}_{2} \mathrm{CO}_{3}$ em diferentes concentrações $(0,5 \mathrm{M}$ /1M/ 2M). Pelos resultados, notou-se que reconstrução da hidrotalcita ocorreu em todas as concentrações utilizadas. Pelo difratograma, observam-se picos de alta intensidade, além da diminuição da largura dos mesmos, atestando um possível aumento do tamanho de cristalito. Além disso, notou-se um pequeno deslocamento para maiores ângulos em relação aos picos da hidrotalcita formada pelo método de co-precipitação. Foi realizada a determinação dos parâmetros de rede da hidrotalcita reconstruída com a solução de $2 \mathrm{M}$, aludida na Tabela 15 . A diminuição dos valores referentes aos parâmetros de rede foi observada. 
Figura 34 - Padrões de difração de raios X do precursor NiZn-Al; do pó resultante da desintegração deste precursor a $500{ }^{\circ} \mathrm{C}$; dos precursores submetidos ao efeito memória em diferentes concentrações de carbonato de sódio, (I) 0,5 M; (II) $1 \mathrm{M}$ e (III) $2 \mathrm{M}$. Os símbolos $\alpha$ e $\beta$ denotam a ocorrência das fases de ZnO e NiO nos catalisadores.

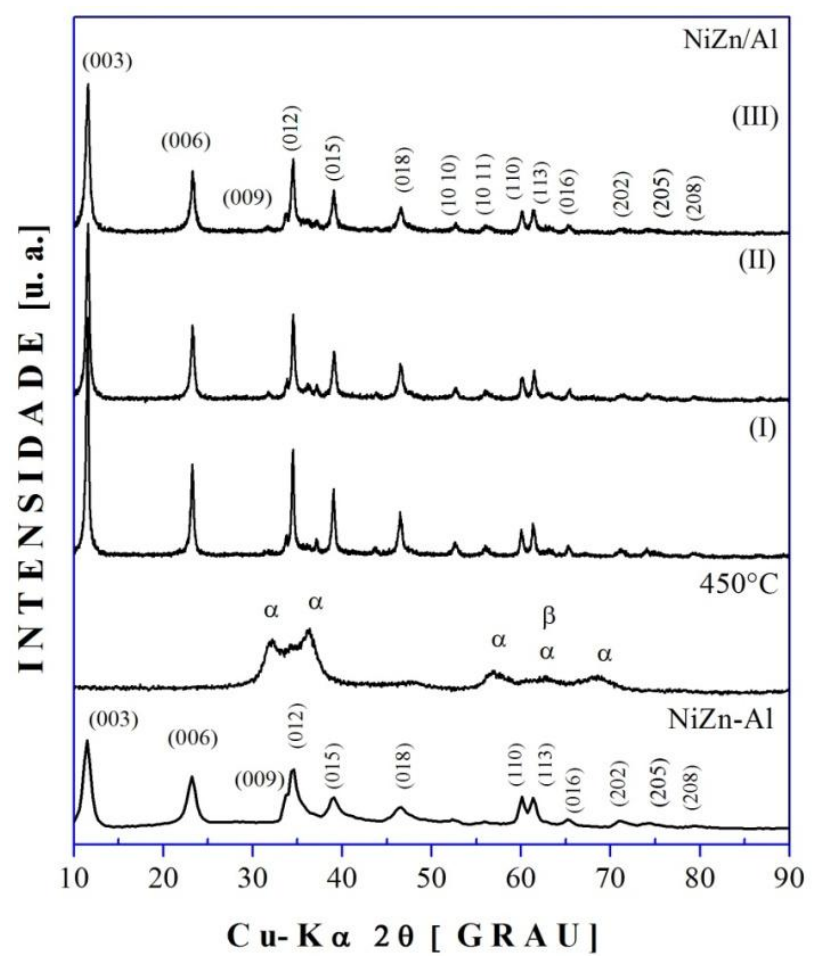

Fonte: Autoria própria.

Tabela 15 - Índices hkl de cada pico de difração de raios X do precursor NiZn-Al (III), com seus respectivos centros e espaçamentos interplanares determinados pela Lei de Bragg. A partir desses dados, os parâmetros de rede foram determinados pela Equação 8 ver texto. O espaçamento interplanar teórico é obtido através da aplicação dos parâmetros recém-calculados novamente na Equação 8, fornecendo informação sobre a qualidade do processo de cálculo.

\begin{tabular}{cccc}
\hline Hkl & \multicolumn{3}{c}{ Cela hexagonal } \\
& $2 \theta$ & $\mathrm{d}_{\text {exp }}(\AA)$ & $\mathrm{d}_{\text {teo }}(\AA)$ \\
\hline$[003]$ & 11.580 & 7.63560 & 7.62398 \\
{$[006]$} & 23.300 & 3.81464 & 3.81199 \\
{$[012]$} & 34.520 & 2.59615 & 2.59444 \\
{$[015]$} & 39.060 & 2.30422 & 2.30201 \\
{$[018]$} & 46.580 & 1.94823 & 1.94899 \\
{$[110]$} & 60.1200 & 1.53781 & 1.53801 \\
{$[113]$} & 61.3600 & 1.50967 & 1.50763 \\
\hline Parâmetro de rede & $\mathrm{a}(\AA)$ & $\mathrm{c}(\AA)$ & $\mathrm{V}(\AA)$ \\
& 3,07601 & 22,87195 & 187.417 \\
\hline
\end{tabular}

Fonte: Autoria própria. 
O difratograma do experimento de efeito memória para o precursor NiZn-AlZr segue ilustrado na Figura 35. O catalisador calcinado a $450{ }^{\circ} \mathrm{C}$ apresentou a formação da mistura de óxidos $[\mathrm{ZnO}(\alpha)$ e $\mathrm{NiO}(\beta)]$. Não foi possível observar as fases referente ao $\mathrm{ZrO}_{2}$ e $\mathrm{Al}_{2} \mathrm{O}_{3}$, demonstrando que as mesmas estão amorfas ou dispersas no catalisador. Ao adicionar o óxido na solução de carbonato, notou-se que ocorre a formação da fase referente à hidrotalcita, porém é possível observar ainda a presença da fase atribuída ao ZnO (JCPDS\#010800-075) e NiO (JCPDS\#01089-713) em todos os padrões de difração. À medida que ocorreu o aumento da concentração da solução de carbonato, notou-se um aumento da intensidade dos picos referente à hidrotalcita. Logo, concluiu-se que as concentrações das soluções de carbonato favoreceram a formação de hidrotalcita, porém na presença de fases secundárias.

Figura 35 - Padrões de difração de raios X do precursor NiZn-AlZr; do pó resultante da desintegração deste precursor a $500{ }^{\circ} \mathrm{C}$; dos precursores submetidos ao efeito memória em diferentes concentrações de carbonato de sódio, a saber, (I) 0,5 M; (II) $1 \mathrm{M}$ e (III) 2M. Os símbolos $\alpha$ e $\beta$ denotam a ocorrência das fases de ZnO e NiO nas amostras.

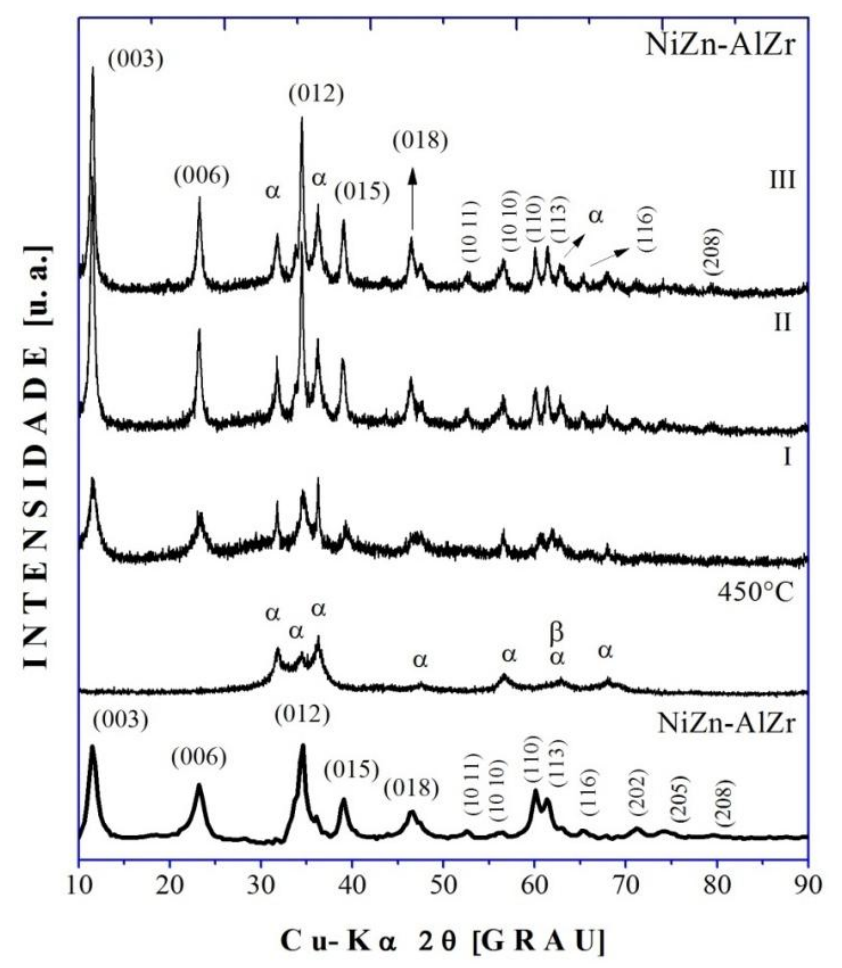

Fonte: Autoria própria

Com base no estudo de efeito memória, realizou-se o experimento referente ao precursor NiZn-Zr visando obter a fase de hidrotalcita. Os padrões do precursor NiZn-Zr e da mistura de óxidos resultante da desintegração a $500{ }^{\circ} \mathrm{C}$ são mostrados a título de comparação (ver 
Figura 36). A mistura de óxidos obtida depois do tratamento térmico exibiu somente as fases de ZnO (JCPDS\#010800-075) e NiO (JCPDS\#01089-713). A formação da estrutura de hidrotalcita foi favorecida somente quando a mistura de óxidos foi colocada na solução de $2 \mathrm{M}$. Este fato é comprovado pela ocorrência do pico (003) e (006) com alta intensidade. Entretanto, esse fenômeno não ocorreu quando a mistura de óxidos foi submetida às soluções de concentrações inferiores, isto é, $0,5 \mathrm{M}$ e $1 \mathrm{M}$. A determinação dos parâmetros de rede da amostra de NiZn-Zr reconstruída (2M) está resumida na Tabela 16. Similarmente aos casos anteriores, $\mathrm{c} \approx 3 \mathrm{~d}_{(003)}$, provando a formação do politipo romboédrico nesta estrutura reconstruída.

Figura 36 - Padrões de difração de raios X do precursor NiZn-Zr; do pó resultante da desintegração deste precursor a $500{ }^{\circ} \mathrm{C}$; dos precursores submetidos ao efeito memória em diferentes concentrações de carbonato de sódio, a saber, (I) 0,5 M; (II) $1 \mathrm{M}$ e (III) $2 \mathrm{M}$. Os símbolos $\alpha$ e $\beta$ denotam a ocorrência das fases de $\mathrm{ZnO}$ e $\mathrm{NiO}$ nas amostras.

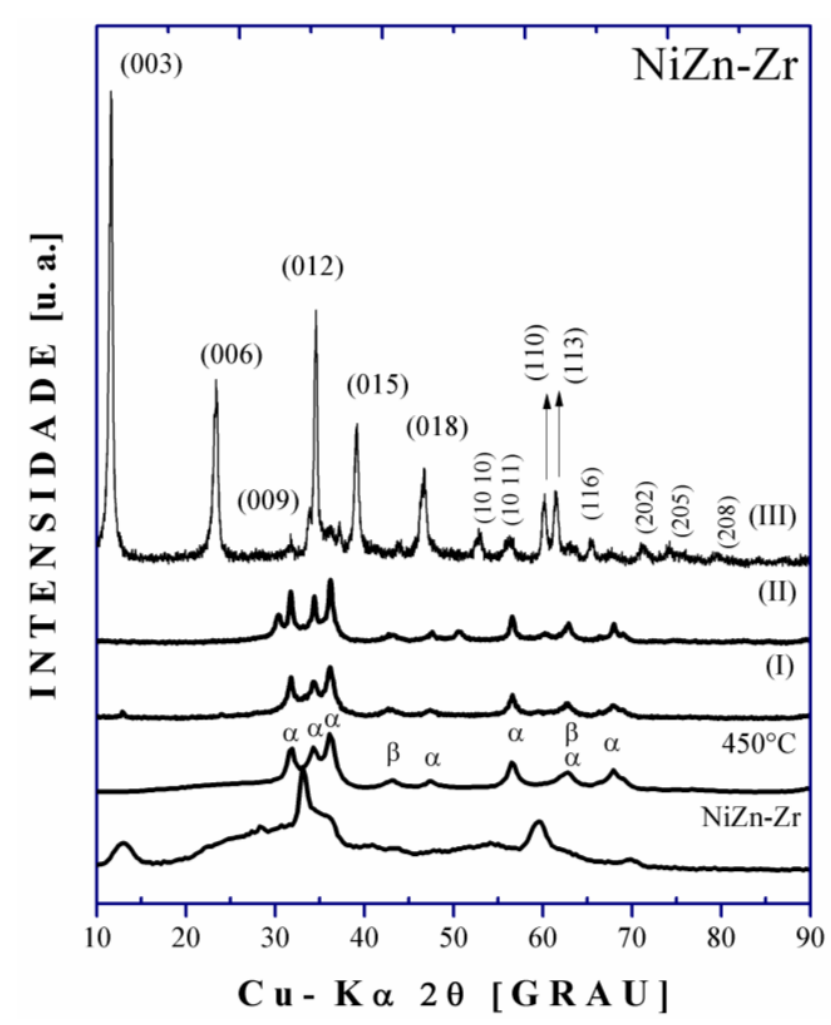

Fonte: Autoria própria. 
Tabela 16 - Índces hkl de cada pico de difração de raios X do precursor NiZn-Zr reconstituído via efeito memória, com seus respectivos centros e espaçamentos interplanares determinados pela Lei de Bragg. A partir desses dados, os parâmetros de rede foram determinados pela Equação 8, ver texto. O espaçamento interplanar teórico é obtido através da aplicação dos parâmetros recém-calculados novamente na Equação 8, fornecendo informação sobre a qualidade do processo de cálculo.

\begin{tabular}{cccc}
\hline Hkl & \multicolumn{3}{c}{ Cela hexagonal } \\
& $2 \theta$ & $\mathrm{d}_{\text {exp }}(\AA)$ & $\mathrm{d}_{\text {teo }}(\AA)$ \\
\hline$[003]$ & 11,597 & 7,62427 & 7,60441 \\
{$[006]$} & 23,348 & 3,80694 & 3,80221 \\
{$[012]$} & 34,564 & 2,59296 & 2,59214 \\
{$[015]$} & 39,140 & 2,29967 & 2,29914 \\
{$[018]$} & 46,655 & 1,94529 & 1,94583 \\
{$[110]$} & 60,164 & 1,53680 & 1,53678 \\
{$[113]$} & 61,513 & 1,50629 & 1,50633 \\
\hline Parâmetro de rede & $\mathrm{a}(\AA)$ & $\mathrm{c}(\AA)$ & $\mathrm{V}(\AA)$ \\
& 3,07356 & 22,81323 & 186,638 \\
\hline
\end{tabular}

Fonte: Autoria própria.

\subsection{Catalisadores}

Nesta seção, os resultados das caracterizações dos catalisadores tratados termicamente a $550^{\circ}, 650^{\circ}$ e $750{ }^{\circ} \mathrm{C}$ por $15 \mathrm{~h}$ serão apresentados e devidamente discutidos. Além disso, reporta-se o desempenho catalítico dos mesmos na reação de reforma seca do metano. Os catalisadores obtidos da desintegração do precursor $\mathrm{Ni} / \mathrm{ZnAl}$ a 550,650 e $750{ }^{\circ} \mathrm{C}$ foram denominados de Ni/ZnAl-5, Ni/ZnAl-6 e Ni/ZnAl-7, respectivamente. Nomenclatura similar é definida para os catalisadores obtidos pela desintegração dos precursores NiZn-AlZr e NiZn$\mathrm{Zr}$. 


\subsubsection{Caracterização dos catalisadores}

\subsubsection{Difração de Raios X}

$\mathrm{Na}$ Figura 37, os padrões de difração raios $\mathrm{X}$ dos catalisadores Ni/ZnAl-5(I), Ni/ZnAlZr-5(II) e Ni/ZnZr-5(III) seguem ilustrados, juntamente com os padrões de difração dos óxidos de zinco $(\mathrm{ZnO})$, níquel $(\mathrm{NiO})$ e zircônia $\left(\mathrm{ZrO}_{2}\right)$. Óxidos binários foram sintetizados pelo método de co-precipitação visando a obtenção de óxidos de referência para a identiação das fases presentes nos catalisadores. De forma geral, constatou-se a perda da estrutura hidrotalcita nos padrões da Ni/ZnAl 5 e Ni/ZnAlZr 5, mediante o desaparecimento dos picos característicos da fase precursora. Ademais, os picos de difração possuem um alargamento e similaridade entre si. Particularmente, ocorreu no padrão de difração da Ni/ZnAl 5 picos oriundos das fases sal gema (NiO) com ficha JCPDS\#01089-713 e wurtizita (ZnO) com ficha JCPDS\#010800-075. A fase NiO possui simetria cúbica pertencente ao grupo espacial Fm-3m (\#225), enquanto a wurtizita possui simetria hexagonal pertencente ao grupo espacial P63mc (\#186). Por outro lado, a fase de óxido de alumínio $\left(\mathrm{Al}_{2} \mathrm{O}_{3}\right)$ não foi identificada em nenhum padrão de difração dos catalisadores, indicando a ocorrência de um estado amorfo de tal óxido nos catalisadores de Ni/ZnAl-5 e Ni/ZnAlZr-5. Reporta-se na literatura que a fase de $\mathrm{Al}_{2} \mathrm{O}_{3}$ pode formar solução sólida com a zincita $(\mathrm{ZnO})$. Para verificar a formação dessa solução sólida é necessário observar um deslocamento dos picos referentes ao óxido de zinco $(\mathrm{ZnO})$. É importante ressaltar que os íons $\mathrm{Al}^{3+}$ na fase óxida possuem um $\mathrm{NC}=4$, enquanto que o $\mathrm{Zn}^{2+}$ possui um $\mathrm{NC}=6$, e seus respectivos raios nessas coordenações serão 0,60 e 0,53 Å. Pela análise dos difratogramas, verificou-se que não há deslocamento nos picos referentes ao $\mathrm{ZnO}$, dessa forma, concluiu-se que nesses catalisadores não ocorreu a formação da solução sólida. Nas amostras Ni/ZnAlZr-5 e Ni/ZnZr-5, um pico de alta intensidade centrado em $2 \theta \approx 34^{\circ}$ é decorrência da fase de $\mathrm{ZnO}$. Além disso, a fase $\mathrm{ZrO}_{2}$ ( estrutura cristalina cúbica e tetragonal) foi evidenciada nas amostras Ni/ZnAlZr-5, porém apresentando baixa de intensidade. Finalmente, o catalisador $\mathrm{Ni} / \mathrm{ZnZr}-5$ apresentou a fase de $\mathrm{ZrO}_{2}$ com picos mais visíveis em relação ao catalisador $\mathrm{Ni} / \mathrm{ZnAlZr}-5$ em $2 \theta \sim 50^{\circ}$ e $2 \theta \sim 60^{\circ}$. 
Figura 37 - Padrões de difração de raios X dos catalisadores Ni/ZnAl-5 (I), Ni/ZnAlZr-5 (II) e Ni/ZnZr-5(III), além dos óxidos binários $\mathrm{ZnO}, \mathrm{NiO}$ e $\mathrm{ZrO}_{2}$. Os símbolos $\alpha, \beta$ e $\lambda$ denotam a ocorrência das fases de $\mathrm{ZnO}, \mathrm{NiO}$ e $\mathrm{ZrO}_{2}$ nos catalisadores, respectivamente.

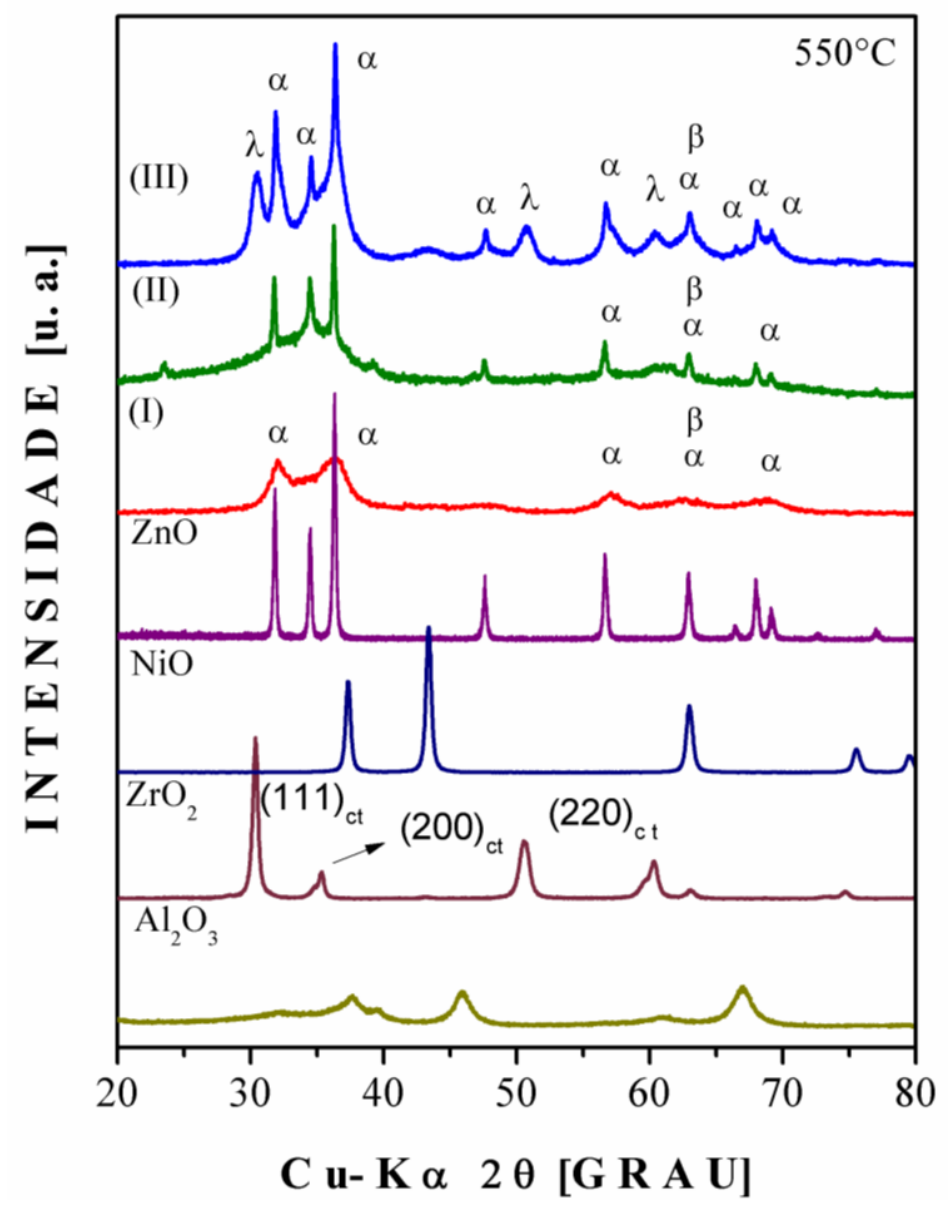

Fonte: Autoria própria.

Na Figura 38 estão reportados os difratogramas correspondentes aos catalisadores tratados termicamente a $650^{\circ} \mathrm{C}(\mathrm{Ni} / \mathrm{ZnAl}-6$ (I) , Ni/ZnAlZr-6 (II) e Ni/ZnZr-6 (III)) e os respectivos padrões sintetizados e calcinados na mesma temperatura ( $\mathrm{ZnO}, \mathrm{NiO}, \mathrm{ZrO}_{2}$ e $\mathrm{Al}_{2} \mathrm{O}_{3}$ ). Nesse difratograma, verificou-se que as amostras tratadas a $650^{\circ} \mathrm{C}$ apresentaram uma maior cristalinidade em relação aos catalisadores obtidos a $550^{\circ} \mathrm{C}$. O catalisador Ni/ZnAl-6 apresentou uma menor quantidade de picos. As fases identificadas para esse catalisador foram de óxido de níquel (NiO) identificado pela ficha JCPDS\#01089-713 e óxido de zinco (ZnO) referente à ficha JCPDS\#010800-075. Além do mais, constatou-se dois picos de baixa intensidade referentes à fase de aluminato de zinco ( $\left.\mathrm{ZnAl}_{2} \mathrm{O}_{4}, \mathrm{JCPDS} \# 010731-961\right)$ e $\mathrm{Al}_{2} \mathrm{O}_{3}$ (JCPDS\# 000231-009/ 010731-199). No catalisador Ni/ZnAlZr-6 as mesmas fases foram identificadas, porém é possível notar a presença da fase de $\mathrm{ZrO}_{2}$ (JCPDS\#000050-543) em torno de $2 \theta \approx$ $30^{\circ}, 50^{\circ}, 56^{\circ}, 60^{\circ}$ e $62^{\circ}$. E, por último, o catalisador $\mathrm{Ni} / \mathrm{ZnZr}-6$ apresentou as fases de $\mathrm{NiO}$, 
$\mathrm{ZnO}$ e $\mathrm{ZrO}_{2}$ (estrutura monoclínica). Além disso, foi observado um pico de baixa intensidade em torno de $2 \theta \approx 75^{\circ}$ atribuído ao $\mathrm{ZrO}_{2}$ na fase tetragonal. Notou-se na amostra Ni/ZnZr-6 uma maior cristalinidade em relação aos catalisadores contendo alumínio. O pico referente ao $\mathrm{NiO}$ em torno de $2 \theta \approx 43^{\circ}$ tornou-se mais visível no catalisador Ni/ZnZr-6. Além dos picos presentes entre $2 \theta \approx 66^{\circ}$ a $73^{\circ}$ referente ao $\mathrm{ZnO}$, o qual não estão bem definido no catalisador $\mathrm{Ni} / \mathrm{ZnAl}-6$.

Figura 38 - Padrões de difração de raios $X$ dos catalisadores Ni/ZnAl-6 (I), Ni/ZnAlZr-6 (II) e Ni/ZnZr-6 (III), além dos óxidos binários $\mathrm{ZnO}, \mathrm{NiO} \mathrm{Al}_{2} \mathrm{O}$ e $\mathrm{ZrO}_{2}$. Os símbolos $\alpha, \beta, \lambda$, $\phi$ e $\gamma$ denotam a ocorrência das fases de $\mathrm{ZnO}, \mathrm{NiO}, \mathrm{ZrO}_{2}, \mathrm{Al}_{2} \mathrm{O}_{3}$ e $\mathrm{ZnAl}_{2} \mathrm{O}_{4}$ nos catalisadores, respectivamente.

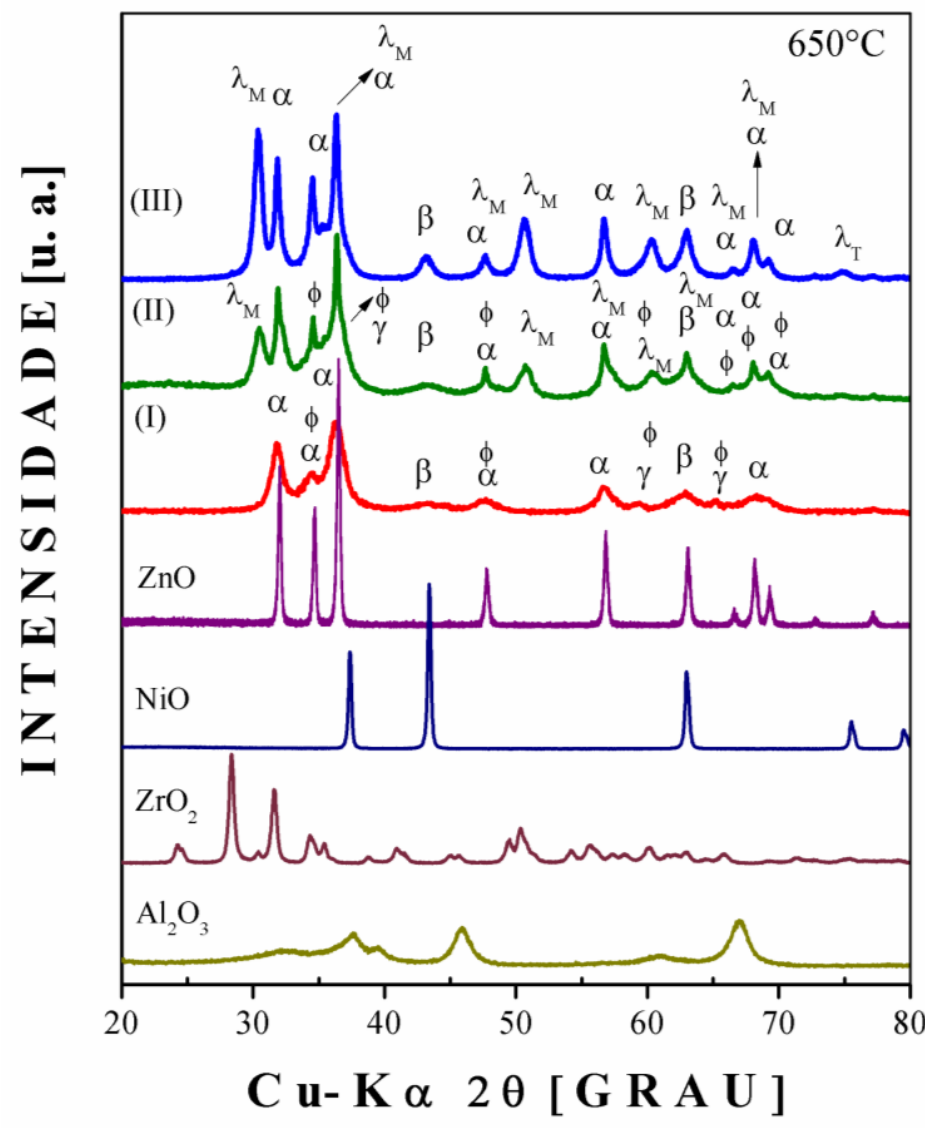

Fonte: Autoria própria.

Os padrões de difração de raios $\mathrm{X}$ dos catalisadores Ni/ZnAl-7 (I), Ni/ZnAlZr-7 (II) e Ni/ZnZr-7 (III) podem ser observados na Figura 39. De pronto, pode-se afirmar que ocorreu um aumento na cristalinidade de todos os catalisadores. No catalisador Ni/ZnAl-7 foi possível observar a presença de fases binárias, além do mais, ocorreu o rearranjo dessas fases originando óxidos ternários. Entre essas fases observadas estão: NiO (JCPDS\#01089-713) em $2 \theta$ $43^{\circ}$ e $63^{\circ}, \mathrm{ZnO}$ (JCPDS\#010800-075), $\mathrm{Al}_{2} \mathrm{O}_{3}$ (JCPDS\# 000231-009/ 010731-199) em $2 \theta$ 
$31^{\circ}, 36^{\circ} 43^{\circ}, 44^{\circ}, 55^{\circ}, 63^{\circ}, 67^{\circ}$ e $69^{\circ}, \mathrm{NiAl}_{2} \mathrm{O}_{4}$ (JCPDS\#010730-239) ) em $2 \theta \sim 31^{\circ}, 36^{\circ}, 44^{\circ}$ e 66 ${ }^{\circ}$, além do $\mathrm{ZnAl}_{2} \mathrm{O}_{4}$ (JCPDS\#010731-961) ) em $2 \theta \sim 31^{\circ}, 36^{\circ}, 44^{\circ}, 55^{\circ}, 59^{\circ}$ e $65^{\circ}$. No catalisador $\mathrm{Ni} / \mathrm{ZnAlZr}$-7, as fases encontradas foram as que seguem: $\mathrm{NiO}$ (JCPDS\#01089713 ) em $2 \theta \sim 43^{\circ}$ e $63^{\circ}$; ZnO (JCPDS\#010800-075) em $2 \theta \sim 31^{\circ}, 34^{\circ}, 36^{\circ}, 47^{\circ}, 56^{\circ}, 62^{\circ}, 72^{\circ}$, $74^{\circ}$ e $77^{\circ} ; \mathrm{NiAl}_{2} \mathrm{O}_{4}$ (JCPDS\#010730-239) em $2 \theta^{\circ} \sim 31^{\circ}, 36^{\circ} 44^{\circ}$ e $65^{\circ}, \mathrm{ZnAl}_{2} \mathrm{O}_{4}$

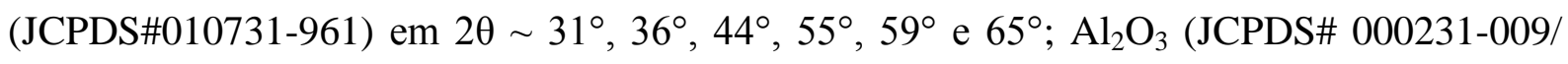
010731-199) em $2 \theta \sim 34^{\circ}, 43^{\circ}, 63^{\circ}, 67^{\circ}, 69^{\circ}$ e $72^{\circ}$. A fase referente ao $\mathrm{ZrO}_{2}$ (monoclínico e tetragonal) foi identificada em $2 \theta \sim 30^{\circ}, 31^{\circ}, 35^{\circ}, 40^{\circ}, 47^{\circ}, 50^{\circ}, 56^{\circ}, 59^{\circ}, 60^{\circ}, 68^{\circ}, 69^{\circ}, 72^{\circ}$, $74^{\circ}$ e $77^{\circ}$. A ocorrência das fases de $\mathrm{NiAl}_{2} \mathrm{O}_{4}$ e $\mathrm{ZnAl}_{2} \mathrm{O}_{4}$ no catalisador Ni/ZnAlZr-7 pode ser observada no detalhe da Figura 39, ver setas. As mesmas fases foram reportadas no trabalho de Resini e colaboradores (2009), onde estes sintetizaram precursores de hidrotalcitas contendo os mesmos cátions, porém com estequiometria diferente para a produção de hidrogênio a partir da reforma do etanol. Deve-se notar que não há formação de espinélios invertidos, principalmente devido ao fator de ocupação $(\lambda)$ do $\mathrm{Al}^{+3}$, demonstrando que íons $\mathrm{d}^{0}$, a estrutura normal é preferida $(\lambda=0)$ na presença de $\mathrm{Zn}^{+2}\left(\mathrm{~d}^{9}\right)\left(\mathrm{ZnAl}_{2} \mathrm{O}_{4}\right)$, pois a preferência do zinco para uma coordenação tetraédrica já tem sido observada experimentalmente. Já na presença de níquel $\left(\mathrm{NiAl}_{2} \mathrm{O}_{4}\right)$, adota uma estrutura de distribuição de cátions aleatórios, pois o níquel tende a ocupar a posição do alumínio, assim como o alumínio pode ocupar a posição do níquel nos sítios tetraédricos e octaédricos, ressaltando que o fator de ocupação para o Al na presença de Ni é em torno de 0,38, o que difere dos extremos estabelecidos em uma estrutura normal e invertida. Analisando o difratograma para o catalisador Ni/ZnZr 7, notou-se a presença da fase de $\mathrm{ZnO}$ (JCPDS\#010800-075) em $2 \theta \sim 31^{\circ}, 34^{\circ}, 36^{\circ}, 47^{\circ}, 56^{\circ}, 63^{\circ}, 66^{\circ}, 68^{\circ}$ e $69^{\circ}$. Ademais, uma elevada quantidade de fases de $\mathrm{ZrO}_{2}$ (JCPDS\#72-0597/37-1484-Monoclínica) e (JCPDS\#80-0965/79-1763-Tetragonal) foi constatada no padrão de difração do catalisador $\mathrm{Ni} / Z n Z r-7$. A outra fase identificada foi o $\mathrm{NiO}$ (JCPDS\#01089-713) em $2 \theta \sim 35^{\circ}, 43^{\circ}, 50^{\circ}$, $63^{\circ}$ e $75^{\circ}$. Para esse catalisador não foi observada a presença de fases ternárias . 
Figura 39 - Padrões de difração de raios $X$ dos catalisadores Ni/ZnAl-7 (I), Ni/ZnAlZr-7 (II) e Ni/ZnZr-7 (III), além dos óxidos binários $\mathrm{ZnO}, \mathrm{NiO}, \mathrm{Al}_{2} \mathrm{O}_{3}$ e $\mathrm{ZrO}_{2}$. Os símbolos $\alpha, \beta, \lambda, \phi, \delta$ e $\gamma$ denotam a ocorrência das fases de $\mathrm{ZnO}, \mathrm{NiO}, \mathrm{ZrO}_{2}, \mathrm{Al}_{2} \mathrm{O}_{3}, \mathrm{NiAl}_{2} \mathrm{O}_{4}$ e $\mathrm{ZnAl}_{2} \mathrm{O}_{4}$ nos catalisadores, respectivamente. O detalhe na figura ilustra a distribuição de picos no intervalo $2 \theta$ de $27^{\circ}$ a $39^{\circ}$, no qual as setas de cor preta evidenciam a ocorrência das fases $\mathrm{Al}_{2} \mathrm{NiO}_{4}$ e $\mathrm{Al}_{2} \mathrm{ZnO}_{4}$ no catalisador $\mathrm{Ni} / \mathrm{ZnAlZr}-7$.

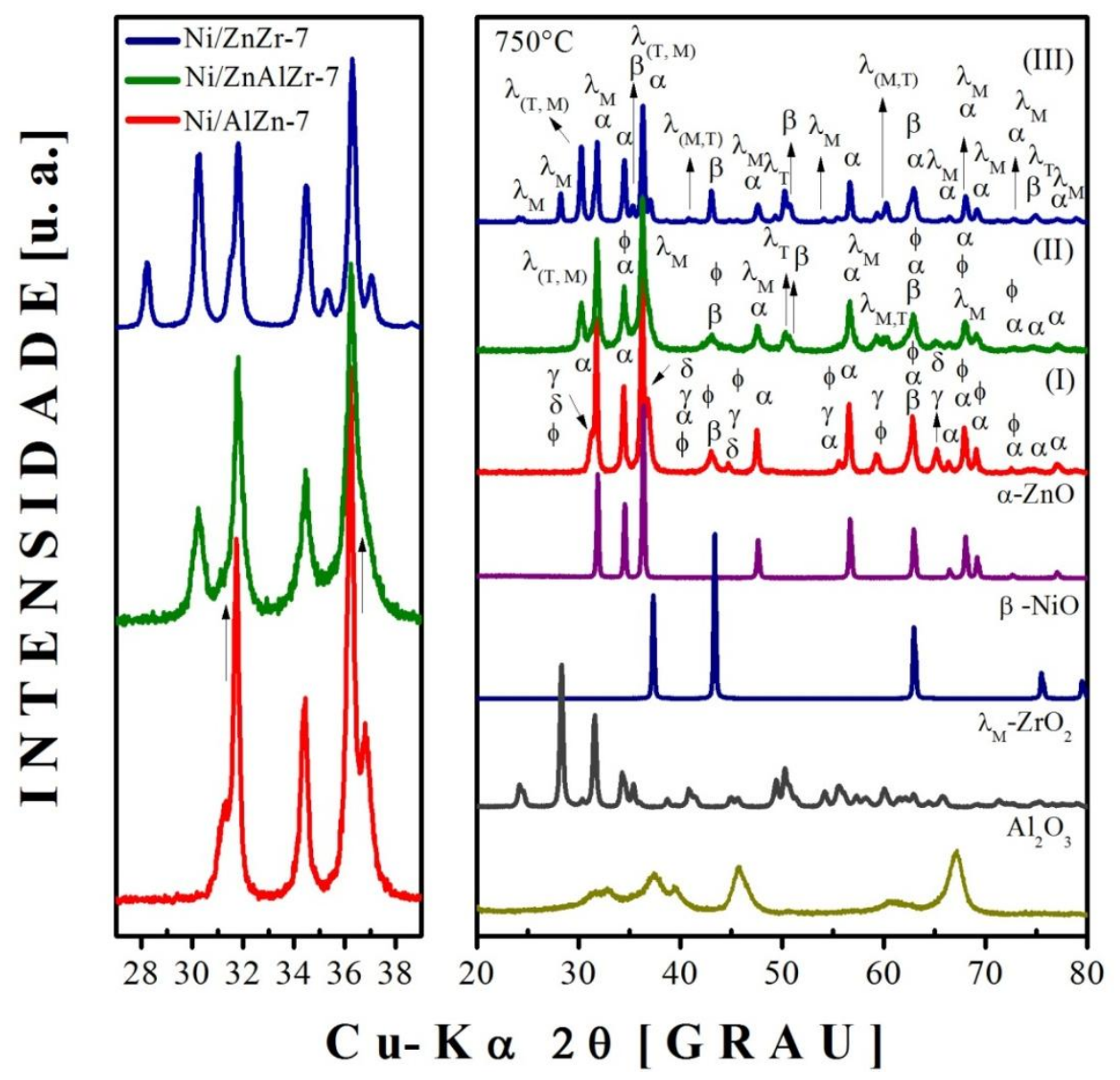

Fonte: Autoria própria.

\subsubsection{Temperatura programada de redução}

Os picos de redução contêm informações relacionadas às interações entre metal/suporte e o estado de oxidação mediante o deslocamento de tais picos. A exemplo da fase de $\mathrm{NiO}$, quando picos de redução ocorrem em baixas temperaturas, este fato pode significar uma fraca interação da fase ativa com o suporte. Por outro lado, quando picos de redução aparecem em altas temperaturas, tal fato pode indicar a redução da fase ativa fortemente ligada ao suporte ou ainda a existência de fases ternárias. Portanto, a interação da fase ativa $(\mathrm{NiO})$ com o suporte pode ser estimada mediante observação do pico de redução através da técnica de temperatura programada de redução. Os perfis de redução para os catalisadores tratados a $550^{\circ} \mathrm{C}, 650^{\circ} \mathrm{C}$ e $750^{\circ} \mathrm{C}$, devidamente decompostos, seguem ilustrados 
nas Figuras 40, 41 e 42. Para aqueles catalisadores tratados a $550^{\circ} \mathrm{C}$, os padrões de difração revelaram a existência de óxidos binários, a saber, $\mathrm{NiO}, \mathrm{ZnO}$ e $\mathrm{Al}_{2} \mathrm{O}_{3}$ (possivelmente no estado amorfo). Logo, espera-se que os picos de redução evidenciem a interação do $\mathrm{NiO}$ com as fases de $\mathrm{ZnO}, \mathrm{ZrO}_{2}$ e $\mathrm{Al}_{2} \mathrm{O}_{3}$. Analisando a Figura 40a, notou-se que o catalisador Ni/ZnAl5 apresentou um pico em $549^{\circ} \mathrm{C}$, associado à redução da fase $\mathrm{NiO}$ mais fracamente ligada ao suporte. Essa afirmação é apoiada em resultados da literatura, na qual se provou que o Ni interagindo com $\mathrm{Al}_{2} \mathrm{O}_{3}$ numa coordenação tetraédrica não se reduz a temperaturas menores que $400{ }^{\circ} \mathrm{C}$ (MENG et al., 2012). Em contrapartida, um segundo pico de alta intensidade ocorre em $635^{\circ} \mathrm{C}$, referente a uma possível interação intermediária com as outras fases presentes. Outro pico (baixa intensidade ) em $721^{\circ} \mathrm{C}$ foi atribuído a uma fase de $\mathrm{NiO}$ com uma interação mais forte. Para os catalisadores Ni/ZnAlZr-5 e Ni/ZnZr-5, pode-se afirmar que o NiO encontra-se em interação mais fraca com suporte, pois foi observado um deslocamento global dos picos de redução para menores temperaturas nesses catalisadores em comparação ao Ni/ZnAl-5. Para o catalisador Ni/ZnAlZr-5 foram observados três picos de redução em $514^{\circ} \mathrm{C}, 580^{\circ} \mathrm{C}$ e $669^{\circ} \mathrm{C}$. Enquanto que para o Ni/ZnZr-5 somente dois picos de redução foram observados em $545^{\circ} \mathrm{C}$ e $673^{\circ} \mathrm{C}$. De forma geral, a reação de redução do $\mathrm{NiO}$ é resumida pela expressão $\mathrm{NiO}+\mathrm{H}_{2} \rightarrow \mathrm{Ni}^{0}+\mathrm{H}_{2} \mathrm{O}$. Na Tabela 15 estão reportados os valores referentes ao consumo real e teórico dos catalisadores. O catalisador Ni/ZnAl-5 apresentou um menor consumo real de $\mathrm{H}_{2}\left(1,29677 \times 10^{-4} \mathrm{~mol}\right)$. Em contrapartida, o Ni/ZnAlZr-5 apresentou um consumo de $\mathrm{H}_{2}$ completo $\left(2,09139 \times 10^{-4} \mathrm{~mol}\right)$ referente à fase de NiO. E, finalmente, o catalisador Ni/ZnZr-5 teve um consumo real $\left(2,05076 \times 10^{-4} \mathrm{~mol}\right)$ maior que o teórico $\left(1,83069 \times 10^{-4}\right.$ mol), o qual pode ser atribuído à redução das outras fases presentes $\left(\mathrm{ZnO}\right.$ e $\left.\mathrm{ZrO}_{2}\right)$. Vale frisar que o $\mathrm{ZnO}$ e o $\mathrm{ZrO}_{2}$ sofrem redução, todavia, há uma dificuldade na determinação exata dos respectivos picos dada a sobreposição com picos de redução do NiO. A presença dessas reduções foi verificada por picos largos nos perfis. Liang e colaboradores (2009) realizaram um estudo comparativo da redução do $\mathrm{Fe}_{2} \mathrm{O}_{3}, \mathrm{ZnO}$ e $\mathrm{ZnFeO}_{4}$ e mostraram que $\mathrm{ZnO}$ possui um pico de redução amplo e de baixa intensidade em torno de $550^{\circ} \mathrm{C}$. Para complementar os estudos de redução dos catalisadores, realizou-se a síntese do $\mathrm{NiO}$ e, em seguida foi feita a análise de temperatura programada de redução do mesmo, com a finalidade de observar ocomportamento do pico de redução do $\mathrm{NiO}$ sem a presença de outras fases. (ver Figura 31b). 
Figura 40 - Perfis de redução dos catalisadores tratados termicamente a $550^{\circ} \mathrm{C}$ por 15 h. Os pontos representa os dados experimentais e a linha vermelha o ajuste da curva por uma soma de funções gaussiana. O número sobre cada pico indica a temperatura aproximada de redução.

(a)

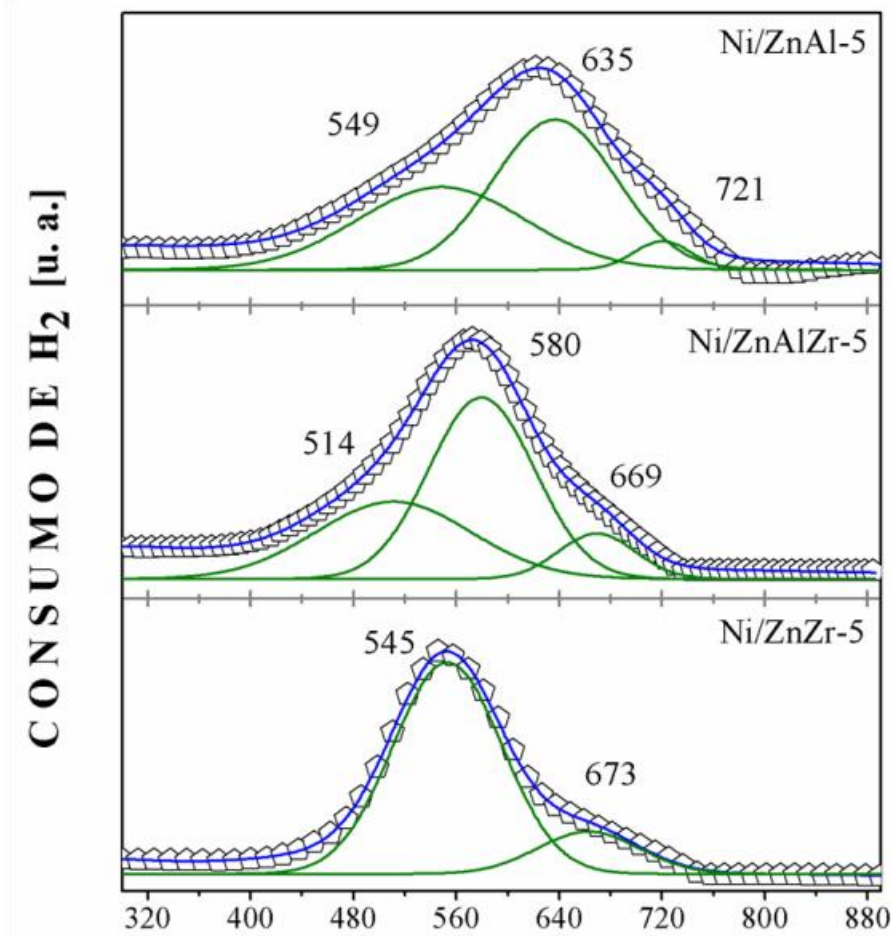

T E M P E R A T U R A $\left[{ }^{\circ} \mathrm{C}\right]$ (b)

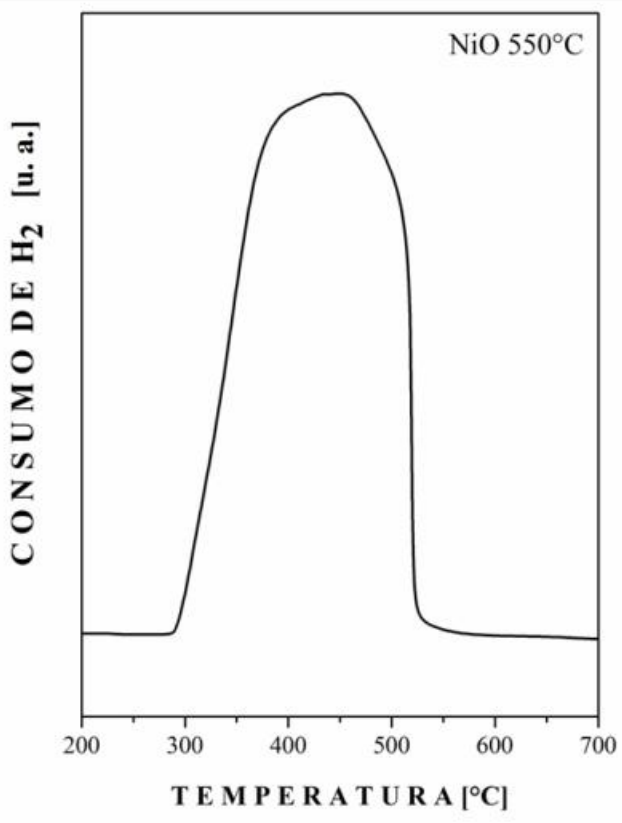

Fonte: Autoria própria.

Na Figura 41a estão reportados os perfis de TPR para os catalisadores calcinados a $650^{\circ} \mathrm{C}$. De acordo com o gráfico, verificou-se que o catalisador Ni/ZnAl-6 apresentou picos de redução em temperaturas menores quando comparados aos catalisadores Ni/ZnAlZr-6 e Ni/ZnZr-6. Pelo processo de redução foram observados três picos de redução para o catalisador $\mathrm{Ni} / \mathrm{ZnAl}-6$. Inicialmente, notou-se um pico largo e de baixa intensidade em $499^{\circ} \mathrm{C}$, referente a uma baixa interação da fase $\mathrm{NiO}$ com outras fases presentes , a saber, $\mathrm{ZnO}$ e $\mathrm{Al}_{2} \mathrm{ZnO}_{4}$ identificados pela difração de raios X. Além disso, um segundo pico em $560^{\circ} \mathrm{C}$ de baixa intensidade associado a uma interação intermediária. E, por fim, um terceiro pico em $616^{\circ} \mathrm{C}$ atribuído a uma interação mais forte com os suportes. No catalisador Ni/ZnAlZr-6, verificou-se um pico de maior intensidade em $655^{\circ} \mathrm{C}$ associado a uma interação intermediária. Além dos picos de baixa intensidade em $582^{\circ} \mathrm{C}$ e $738^{\circ} \mathrm{C}$ atribuídos a baixa e alta interação com os suportes, respectivamente. Ainda na Figura 41, o catalisador Ni/ZnZr-6 apresentou um comportamento semelhante em relação ao catalisador Ni/ZnAlZr-6, apresentando três picos de 
redução em $584^{\circ} \mathrm{C}, 642^{\circ} \mathrm{C}$ e $728^{\circ} \mathrm{C}$ atribuídos a redução do $\mathrm{NiO}$. O catalisador Ni/ZnAl-6 apresentou um consumo teórico $\left(2,27448 \times 10^{-4} \mathrm{~mol}\right)$ maior que o experimental $\left(8,3032110^{-5}\right.$ mol), enquanto que os catalisadores Ni/ZnAlZr-6 e Ni/ZnZr-6 apresentaram consumos experimentais $\left(2,09139 \times 10^{-4} \mathrm{~mol} \mathrm{e} 1,7602810^{-4} \mathrm{~mol}\right.$, respectivamente) maiores em relação aos teóricos ( $2,1582510^{-4} \mathrm{~mol}$ e $2,3080310^{-4} \mathrm{~mol}$, respectivamente).

Figura 41 - (a) Perfis de redução dos catalisadores tratados termicamente a $650^{\circ} \mathrm{C}$ por $15 \mathrm{~h}$. Os pontos representam os dados experimentais e a linha vermelha o ajuste da curva por uma soma de funções gaussiana. $\mathrm{O}$ número sobre cada pico indica a temperatura aproximada de redução.

(a)

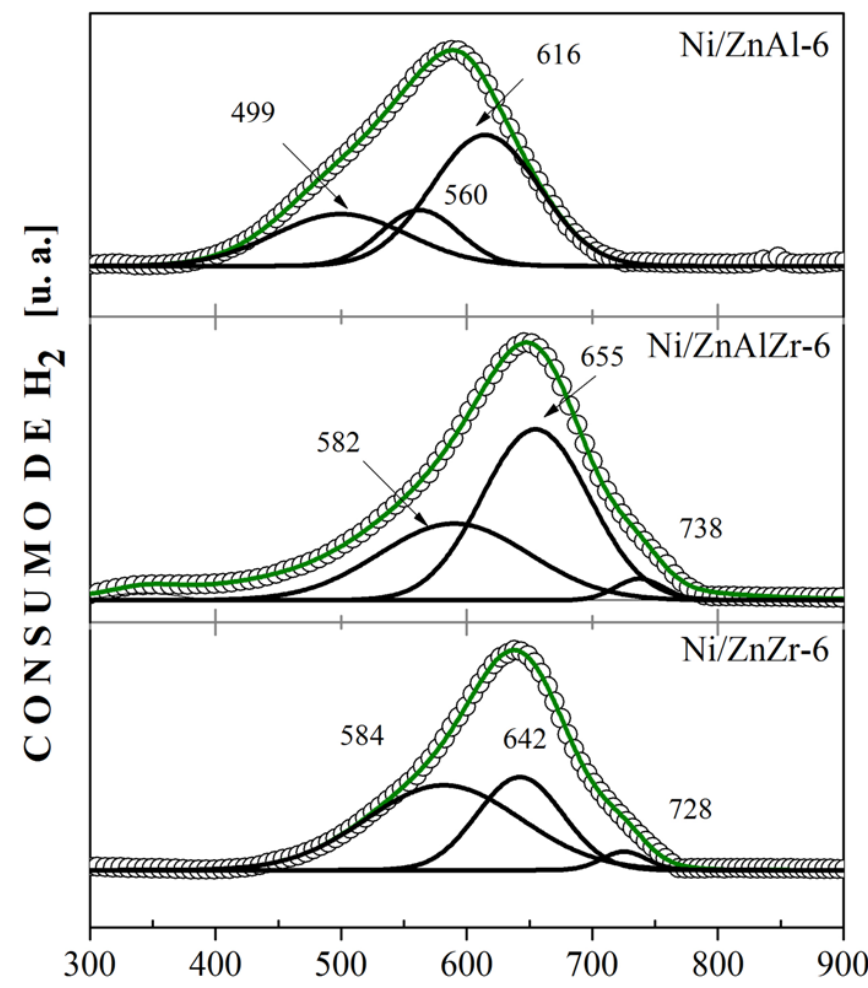

(b)

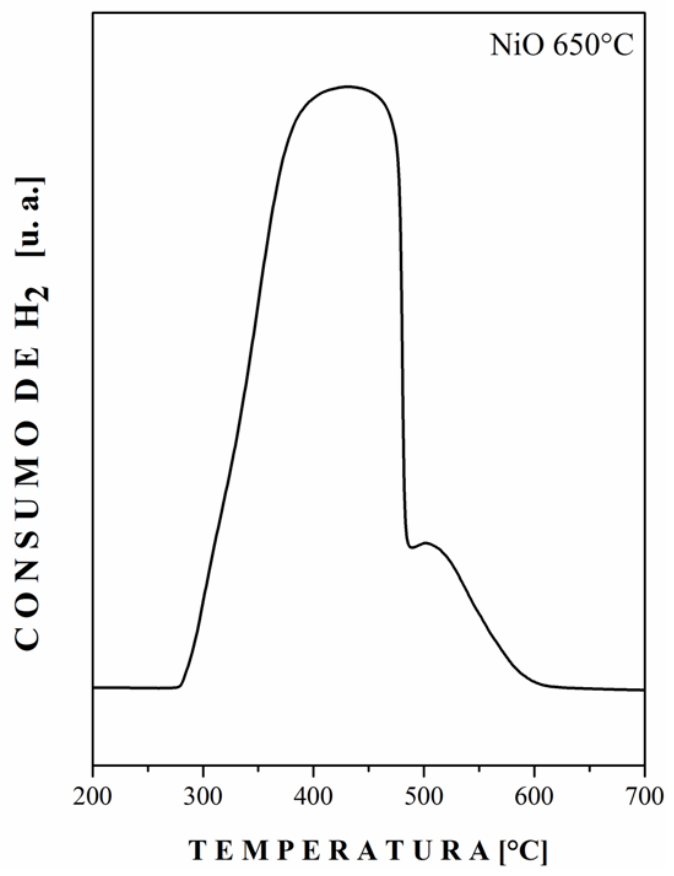

T E M P E R A T U R A $\left[{ }^{\circ} \mathrm{C}\right]$

Fonte: Autoria própria.

O gráfico, na Figura 42a, ilustra os perfis de redução das amostras Ni/ZnAl-7, Ni/ZnAlZr-7 e Ni/ZnZr-7. O perfil de redução do catalisador Ni/ZnAl-7 evidenciou a formação de picos em $494{ }^{\circ} \mathrm{C}$ e $567{ }^{\circ} \mathrm{C}$, referente ao menor grau de interação com as outras fases presentes, além dos picos em maiores temperaturas em torno de $634^{\circ} \mathrm{C}$ e $693^{\circ} \mathrm{C}$ atribuídos à interação mais forte, porém não atribuídos às fases de espinélios. Acima de $700^{\circ} \mathrm{C}$, observouse um pico de baixa intensidade em $831^{\circ} \mathrm{C}$, relacionado ao níquel presente na fase de $\mathrm{Ni}$ $\mathrm{Al}_{2} \mathrm{O}_{4}$, a reação que representa a redução do $\mathrm{NiAl}_{2} \mathrm{O}_{4}$ é resumida pela expressão $\mathrm{NiAl}_{2} \mathrm{O}_{4}+\mathrm{H}_{2}$ $\rightarrow \mathrm{Ni}^{0}+\mathrm{Al}_{2} \mathrm{O}_{3}+\mathrm{H}_{2} \mathrm{O}$. Uma alta temperatura de redução para a fase de espinélio é devido a 
diferença da energia de ativação aparente da redução do $\mathrm{NiO}(4,3 \mathrm{kcal} / \mathrm{mol})$ e $\mathrm{NiAl}_{2} \mathrm{O}_{4}(32$ $\mathrm{kcal} / \mathrm{mol}$ ), sendo esta um indicativo do fortalecimento relativo da ligação $\mathrm{Ni}-\mathrm{O}$ no $\mathrm{NiAl}_{2} \mathrm{O}_{4}$ (BRADFORD; VANNICE, 1999). Analisando a Figura 33, o catalisador Ni/ZnAlZr-7 apresentou pico de redução em torno de $622^{\circ} \mathrm{C}$ referente a uma interação intermediária com o suporte. Além disso, verificou-se a presença dos picos em $523^{\circ}$ e $689^{\circ} \mathrm{C}$ associados a uma baixa e alta interação, respectivamente. Pelos resultados obtidos, constatou-se que o pico máximo para o catalisador Ni/ZnAlZr-7 é deslocado para maiores temperaturas em relação ao $\mathrm{Ni} / \mathrm{ZnAl}$-7. Esse resultado prediz que a presença das fases contendo Al favorece a maior interação com NiO. Embora tenha ocorrido a identificação da fase ternária ( $\mathrm{NiAl}_{2} \mathrm{O}_{4}$ ), não foi possível observar a presença de picos de redução referentes a esse óxido, visto que a sua redução acontece tipicamente em torno de $800^{\circ} \mathrm{C}$ (LI; CHEN, 1995; RIVAS et al., 2008). O catalisador Ni/ZnZr-7 exibiu um pico de alta intensidade em $526^{\circ} \mathrm{C}$, oriundo da redução do $\mathrm{NiO}$ com baixa interação com os suportes, quando comparado àqueles em $557{ }^{\circ} \mathrm{C}$ e $662^{\circ} \mathrm{C}$ com interações mais fortes. Para o catalisador Ni/ZnZr-7, as interações entre as fases são mais fracas em comparação aos outros catalisadores tratados a $750^{\circ} \mathrm{C}$, o que será refletido no consumo de $\mathrm{H}_{2}$. Analisando a Tabela 17, verificou-se que o consumo de $\mathrm{H}_{2}$ para o catalisador Ni/ZnAl-7 foi menor em relaçao aos outros catalisadores, além de apresentar um consumo real $\left(1,63867 \times 10^{-4} \mathrm{~mol}\right)$ menor que o calculado $\left(2,29754 \times 10^{-4} \mathrm{~mol}\right)$. A presença das fases ternárias $\left(\mathrm{NiAl}_{2} \mathrm{O}_{4}\right.$ e $\left.\mathrm{ZnAl}_{2} \mathrm{O}_{4}\right)$, identificadas na difração de raios $\mathrm{X}$, contribuiu para o baixo consumo do $\mathrm{H}_{2}$. O mesmo comportamento foi observado para o catalisador Ni/ZnAlZr-7 , apresentando um consumo experimental e teórico em torno de $1,76207 \times 10^{-4}$ mol e 2,11231 x $10^{-4}$ mol, respectivamente. Por fim, o catalisador Ni/ZnZr-7 mostrou um maior consumo experimental $\left(2,02076 \times 10^{-4} \mathrm{~mol}\right)$ em comparação com as outras amostras do grupo. Além do mais, exibiu um consumo real superior ao teórico $\left(1,79549 \times 10^{-4} \mathrm{~mol}\right)$, evidenciando a influencia das fases de $\mathrm{ZnO}$ e $\mathrm{ZrO}_{2}$. 
Figura 42 - Perfis de redução dos catalisadores tratados termicamente a $750^{\circ} \mathrm{C}$ por $15 \mathrm{~h}$. Os pontos representam os dados experimentais e a linha vermelha o ajuste da curva por uma soma de funções gaussiana. O número sobre cada pico indica a temperatura aproximada de redução.

(a)

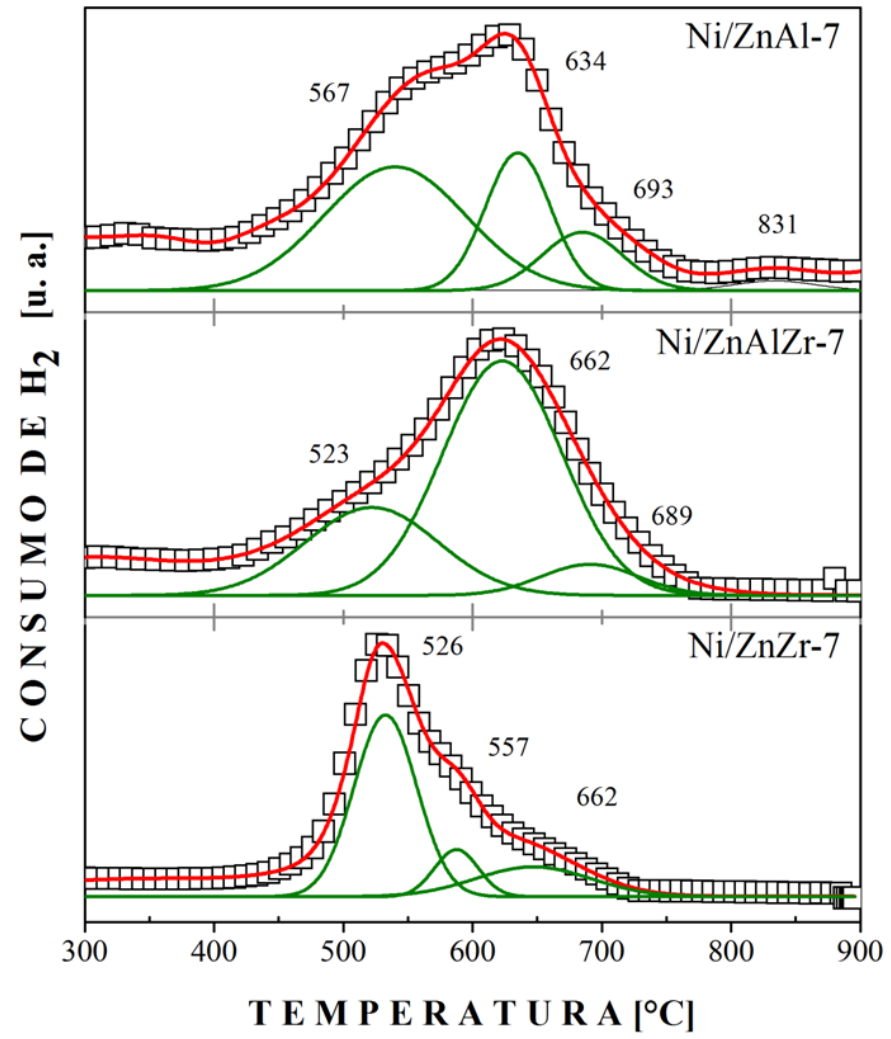

(b)

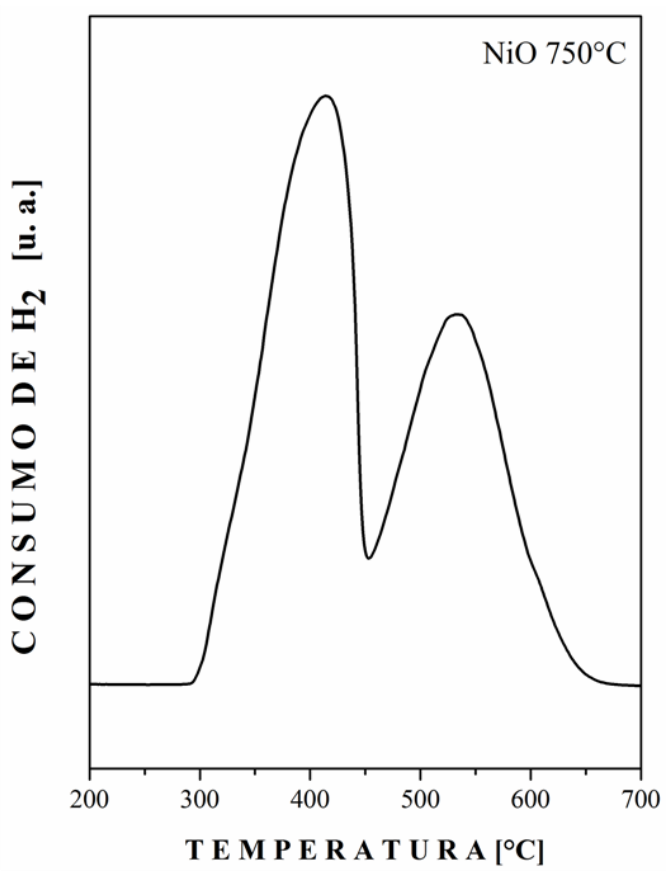

Fonte: Autoria própria.

Tabela 17 - Tabela contendo o consumo teórico e real dos catalisadores estudados.

\begin{tabular}{ccc}
\hline Amostras & $\begin{array}{c}\text { Consumo teórico } \\
(\mathrm{mol})\end{array}$ & $\begin{array}{c}\text { Consumo real } \\
(\mathrm{mol})\end{array}$ \\
\hline $\mathrm{Ni} / \mathrm{ZnAl}-7$ & $2,29754 \times 10^{-4}$ & $1,63867 \times 10^{-4}$ \\
$\mathrm{Ni} / \mathrm{ZnAlZr}-7$ & $2,11231 \times 10^{-4}$ & $1,76207 \times 10^{-4}$ \\
$\mathrm{Ni} / \mathrm{ZnZr}-7$ & $1,79549 \times 10^{-4}$ & $2,02076 \times 10^{-4}$ \\
$\mathrm{Ni} / \mathrm{ZnAl}-6$ & $2,2748 \times 10^{-4}$ & $8.30321 \times 10^{-5}$ \\
$\mathrm{Ni} / \mathrm{ZnAlZr}-6$ & $2,09139 \times 10^{-4}$ & $2,15825 \times 10^{-4}$ \\
$\mathrm{Ni} / \mathrm{ZnZr}-6$ & $1,76028 \times 10^{-4}$ & $2,30803 \times 10^{-4}$ \\
$\mathrm{Ni} / \mathrm{ZnAl}-5$ & $2,29754 \times 10^{-4}$ & $1,29677 \times 10^{-4}$ \\
$\mathrm{Ni} / \mathrm{ZnAlZr}-5$ & $2,09139 \times 10^{-4}$ & $2,09873 \times 10^{-4}$ \\
$\mathrm{Ni} / \mathrm{ZnZr}-5$ & $1,83069 \times 10^{-4}$ & $2,05076 \times 10^{-4}$ \\
\hline
\end{tabular}

Fonte: Autoria própria. 


\subsubsection{3 Área específica superficial}

O estudo da influência da temperatura de tratamento térmico e da composição nas propriedades texturais dos catalisadores foi realizado pela técnica de fisissorção de $\mathrm{N}_{2}$. As isotermas referentes aos catalisadores Ni/ZnAl-5, Ni/ZnAlZr-5 e Ni/ZnZr-5 estão reportadas na Figura 34a. Analisando os catalisadores calcinados a $550^{\circ} \mathrm{C}$, verificou-se que todas as amostras apresentaram o fenômeno de histerese, mostrando a curva de adsorção (I) e dessorção a 77K. Tais resultados evidenciaram uma característica de mesoporos (2 a $50 \mathrm{~nm}$ ), nesse caso, o gás condensado nos poros não evapora facilmente, pelo contrário, é recondensado devido à formação de menisco nos capilares. Pode-se observar que as isotermas apresentadas não são iniciadas na pressão zero, logo não é possível verificar o ponto de inflexão, que corresponde à ocorrência da formação da primeira camada adsorvida que recobre toda a superfície do material. Além disso, não foi possível observar a região acima de uma pressão relativa igual 0,97,a qual representa a região de grandes poros (FARRAUTO; BARTHOLOMEW, 1997). Segundo a classificação estabelecida pela IUPAC, observou-se que as amostras apresentaram um comportamento de histerese do tipo IV. É preciso ressaltar que vários são os fatores que podem provocar as diferentes isotermas, tais como as formas dos poros e as forças de interação entre adsovente e adsorbato (LEOFANTI et al., 1998). A isoterma apresentada para Ni/ZnAl5 exibiu um estreito distanciamento entre a adsorção (I) e dessorção (II), cujo ciclo de histerese ocorreu no intervalo de 0,977 a 0,403 , referente à condensação capilar no mesoporo. $\mathrm{O}$ catalisador Ni/ZnAlZr-5 apresentou um comportamento semelhante ao catalisador Ni/ZnAl-5, no entanto, o ciclo de histerese fechou em uma pressão relativa de 0,220 , dessa forma demonstrando uma área de histerese maior, além disso, apresentou uma distância maior entre as curvas de adsorção (I) e dessorção (II). Por outro lado, o catalisador Ni/ZnZr-5 apresentou um comportamento diferenciado, cujo fechamento dos ciclos de histerese ocorre em uma pressão relativa de 0,286. Disto concluiu-se, finalmente, que as amostras Ni/ZnAlZr-5 e Ni/ZnZr-5 apresentaram poros mais largos, enquanto que o catalisador Ni/ZnAl-5 apresentou poros de raio menor. Ao classificar as histereses, notou-se que os Ni/ZnAl 5 e Ni/ZnAlZr 5 apresentaram uma histerese do tipo H3. Esse tipo de histerese está associada a sólidos constituídos por agregados e aglomerados de partículas que geram poros em forma de fendas, com tamanho e forma variáveis. O catalisador Ni/ZnZr-5 apresentou uma histerese do H1 característica de sólido formado por agregados e aglomerados de partículas esferoidais de tamanho e forma também variáveis (LEOFANTI et al., 1998). 
A curva de distribuição do tamanho de poros ( $d V / d \log (D)$ versus raio do poro) está apresentada na Figura 43b. Inicialmente, notou-se picos no intervalo de 3 a 70 nm, sugerindo uma predominância de mesoporos em todos os catalisadores do grupo. As curvas referentes aos catalisadores Ni/ZnAl-5, Ni/ZnAlZr-5 e Ni/ZnZr-7 indicaram uma concentração de poros com diâmetros abaixo de 15, 10 e $10 \mathrm{~nm}$, respectivamente. Isso sugere que essencialmente toda a mesoporosidade nestes catalisadores ocorreu em pequenos mesoporos. Os diâmetros correspondentes ao volume máximo dos catalisadores Ni/ZnAl-5, Ni/ZnAlZr-5 e Ni/ZnZr-5 foram em torno de 38, 27 e $16 \mathrm{~nm}$, respectivamente. Além disso, notou-se a presença de poros com diâmetros maiores que $50 \mathrm{~nm}$ para todos os catalisadores. Os resultados do volume acumulativo de poros e o raio médio de poros foram obtidos pelo método BJH (GROEN et al., 2003), como ilustrado na Tabela 16. O catalisador Ni/ZnAlZr-5 apresentou um maior volume médio de poro em torno de $0,397 \mathrm{~cm}^{3} / \mathrm{g}$, com um raio de poro de $84,534 \mathrm{~nm}$. Enquanto que o catalisador $\mathrm{Ni} / \mathrm{ZnAl} 5$ apresentou um volume em torno de $0,328 \mathrm{~cm}^{3} / \mathrm{g}$ referente ao de raio15,951 nm. Por fim, o catalisador Ni/ZnZr 5 exibiu um volume de $0,127 \mathrm{~cm}^{3} / \mathrm{g}$ associado ao raio de $83,926951 \mathrm{~nm}$.

Figura 43 - Isotermas de adsorção para os catalisadores tratados termicamente a $550{ }^{\circ} \mathrm{C}$ por $15 \mathrm{~h}$, a partir das quais foram determinados os valores das áreas superficiais específicas pelo método de BET (a) e a distribuição do tamanho de poro (b).

(a)

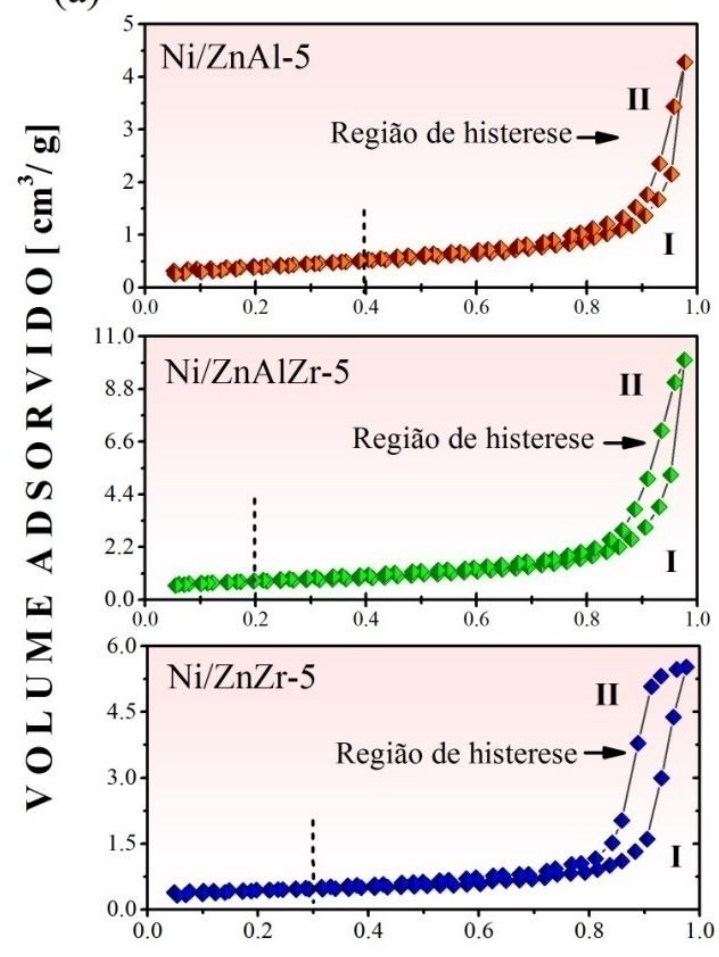

P R E S S Ã O RELATIVA $\left[P / P_{0}\right]$ (b)
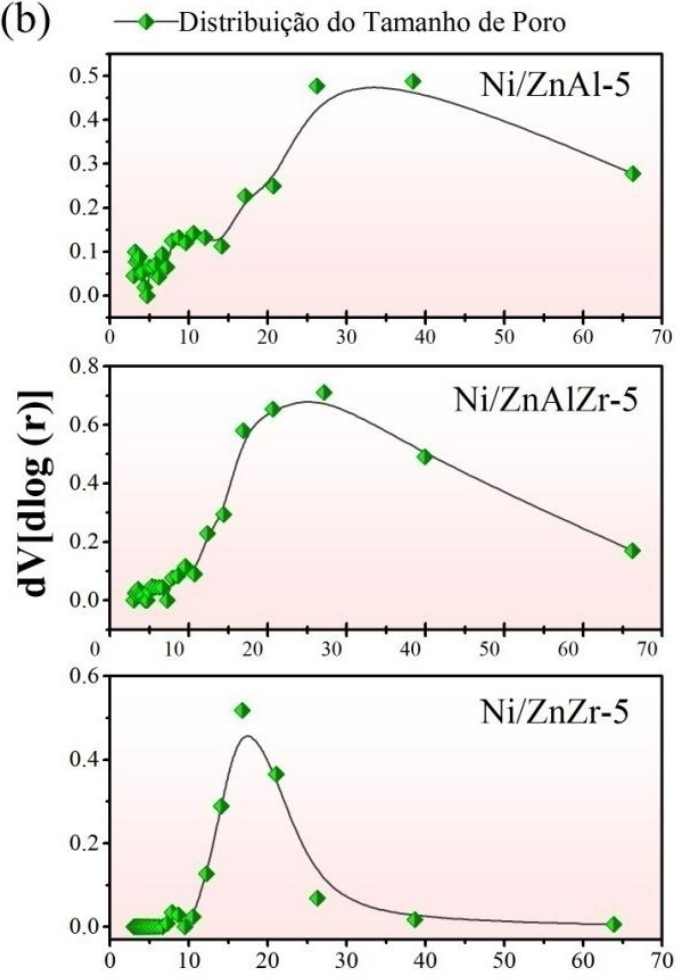

D I ÂM E T R O D O PORO [nm]

Fonte: Autoria própria. 
As isotermas e as distribuições para Ni/ZnAl-6, Ni/ZnAlZr-6 e Ni/ZnZr-6 estão reportadas nas Figuras 44a e 44b. A região de histerese foi observada para o catalisador Ni/ZnAl-6, e o ciclo de histerese fechou em uma pressão relativa em torno de 0,57. Ainda na Figura 35a, notou-se que o catalisador $\mathrm{Ni} / \mathrm{ZnAlZr} 6$ apresentou um comportamento semelhante, porém observou-se um maior distanciamento entre a isoterma de adsorção e dessorção, apresentando uma região de histerese cujo fechamento do ciclo ocorreu em uma pressão relativa em torno de 0,4 . Por último, o catalisador Ni/ZnZr-6 mostrou um ciclo de histerese no intervalo entre 0,60 e 0.94, apresentando um comportamento diferenciado, ma vez que a histerese apresentou uma distância entre a isoterma de adsorção e dessorção.

A distribuição do volume de poros está reportado na Figura 44b. É possível observar que os catalisadores Ni/ZnAl-6 e Ni/ZnAlZr-6 apresentaram um acúmulo de poros com raio abaixo de $20 \mathrm{~nm}$. Finalmente, o catalisador Ni/ZnZr-6 exibiu uma distribuição diferenciada em relação aos outros catalisadores. A concentração de poros pequenos foi observado abaixo de $10 \mathrm{~nm}$. Além do mais, esse catalisador não apresentou poros com raios maiores que $35 \mathrm{~nm}$. Os resultados do volume acumulativo de poros e o raio médio de poros foram obtidos pelo método $\mathrm{BJH}$, como reportado na Tabela 16. O catalisador Ni/ZnA-6 apresentou um maior volume médio de poro em torno de $0,196 \mathrm{~cm}^{3} / \mathrm{g}$ referente ao raio de poro de $17,777 \mathrm{~nm}$. Enquanto que o catalisador Ni/ZnAlZr 6 apresentou um volume em torno de $0,342 \mathrm{~cm}^{3} / \mathrm{g}$ associado ao raio de 104,067 $\mathrm{nm}$. E finalmente, o catalisador $\mathrm{Ni} / \mathrm{ZnZr}-6$ exibiu um volume de 0,031 $\mathrm{cm}^{3} / \mathrm{g}$ de raio de $29,694 \mathrm{~nm}$. 
Figura 44 - Isotermas de adsorção para os catalisadores tratados termicamente a $650{ }^{\circ} \mathrm{C}$ por $15 \mathrm{~h}$, a partir das quais foram determinados os valores das áreas superficiais específicas pelo método de BET (a) e a distribuição do tamanho de poro (b).

(a)
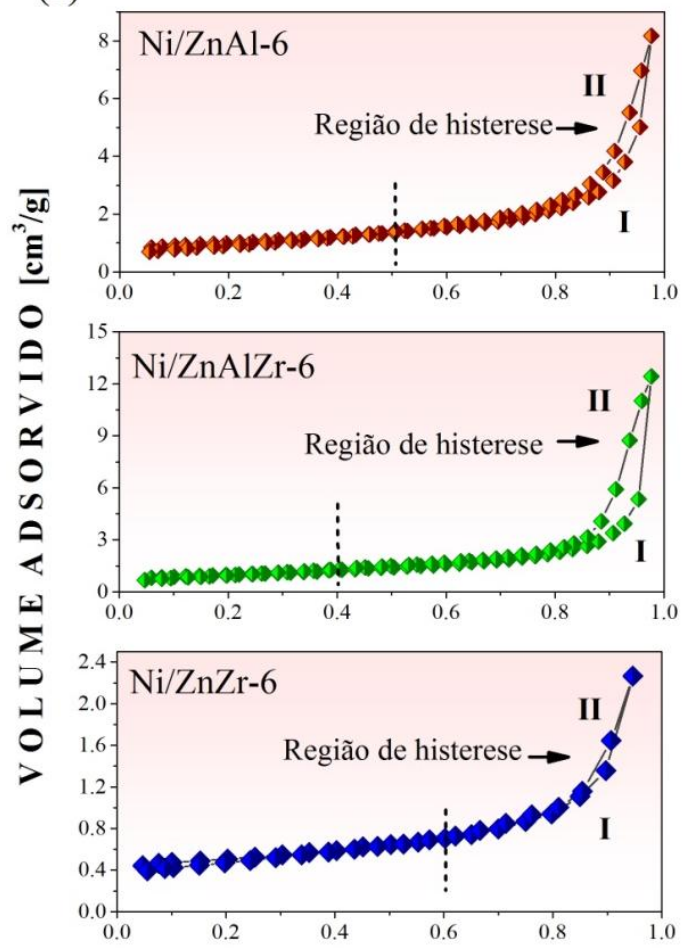

PRESS Ã O RELATIVA P/Po (b)
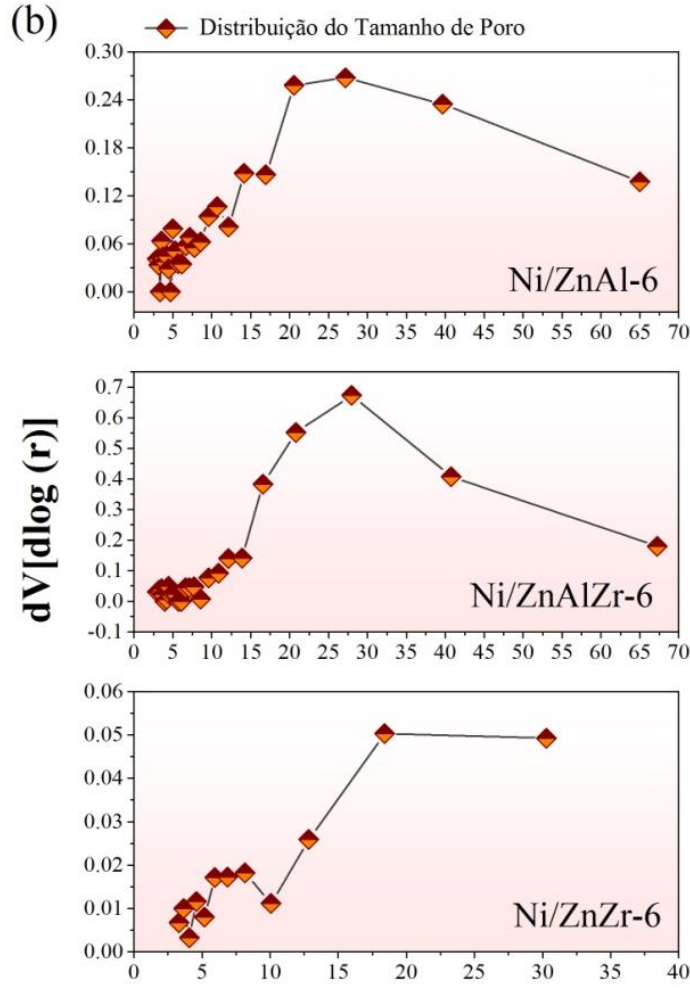

D I ÂM E T R O D O PO R O [nm]

Fonte: Autoria própria

O grafico, na Figura 45a, mostrou que não foi possível observar o ponto de inflexão associados às isotermas do Tipo II e IV. A isoterma referente ao catalisadorNi/ZnAl-7 apresentou um ciclo de histerese estreito entre 0,83 e 0,97 referente à condensação capilar no mesoporo. Por outro lado, o ciclo de histerese da amostra Ni/ZnAlZr-7 fechou a uma pressão relativa de $\sim 0,45$. Por fim, o catalisador $\mathrm{Ni} / \mathrm{ZnZr}-7$ exibiu um fechamento do ciclo de histerese em uma pressão relativa em torno de 0,38 provavelmente devido à menor quantidade de poros pequenos em relação aos outros catalisadores do grupo.

A distribuição do tamanho de poro com a $d V / \operatorname{dlog}(D)$ em função do diâmetro do poro está ilustrada na Figura 45b. Com base nos resultados obtidos é possível observar uma predominância de mesoporos, uma vez que a maior freqüência de diâmetro de poros foi observado no intervalo de 2-50nm. O catalisador Ni/ZnAl-7 evidenciou uma maior concentração no intervalo de diâmetro de poros entre 3 a $16 \mathrm{~nm}$ com baixo volume de poro. Os pequenos poros observados no catalisador $\mathrm{Ni} / \mathrm{ZnAl}-7$ apresentaram maiores volumes em comparação aos catalisadores Ni/ZnAlZr-7 e Ni/ZnZr-7. Ademais, o catalisador Ni/ZnAl-7 apresentou um 
volume máximo referente ao diâmetro de $40 \mathrm{~nm}$. Enquanto isso, o catalisador Ni/ZnAlZr-7 também exibiu uma concentração de poros com diâmetros pequenos em um intervalo entre 2,5 a $17 \mathrm{~nm}$ associados ao baixo volume de poros. Finalmente, o catalisador Ni/ZnZr-7 apresentou um volume máximo referente ao diâmetro em torno de $40 \mathrm{~nm}$. É preciso observar que todos os catalisadores apresentaram poros com diâmetros maiores que $50 \mathrm{~nm}$. Em relação ao volume médio de poro, o catalisador Ni/ZnAl-7 exibiu um valor em torno de $0,123 \mathrm{~cm}^{3} / \mathrm{g}$ para um raio de poro em torno de 16,807Á. Por outro lado, os catalisadores Ni/ZnAlZr-7 e $\mathrm{Ni} / \mathrm{ZnZr}$-7 apresentaram raios de poros referentes ao volume máximo de poro em torno de $0,245 \mathrm{~cm}^{3} / \mathrm{g}$ e $0,034 \mathrm{~cm}^{3} / \mathrm{g}$, respectivamente.

Figura 45 - Isotermas de adsorção para os catalisadores tratados termicamente a $750{ }^{\circ} \mathrm{C}$ por $15 \mathrm{~h}$, a partir das quais foram determinados os valores das áreas superficiais específicas pelo método de BET (a) e a distribuição do tamanho de poro (b).

(a)
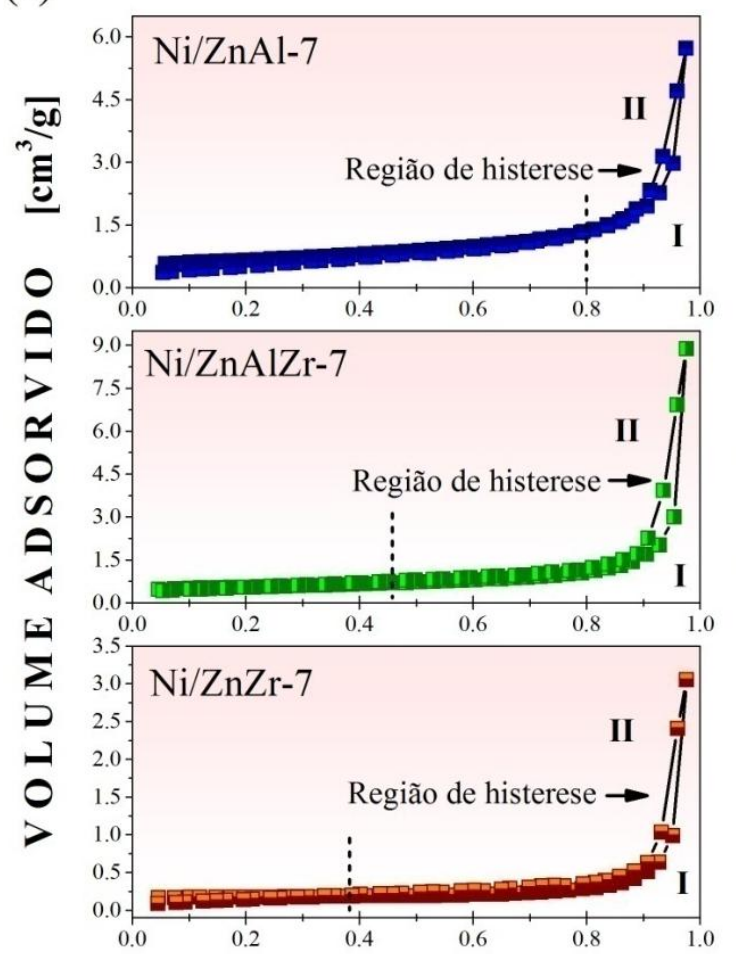

PRES S Ã O RELATIVA [P/P $]$ (b)
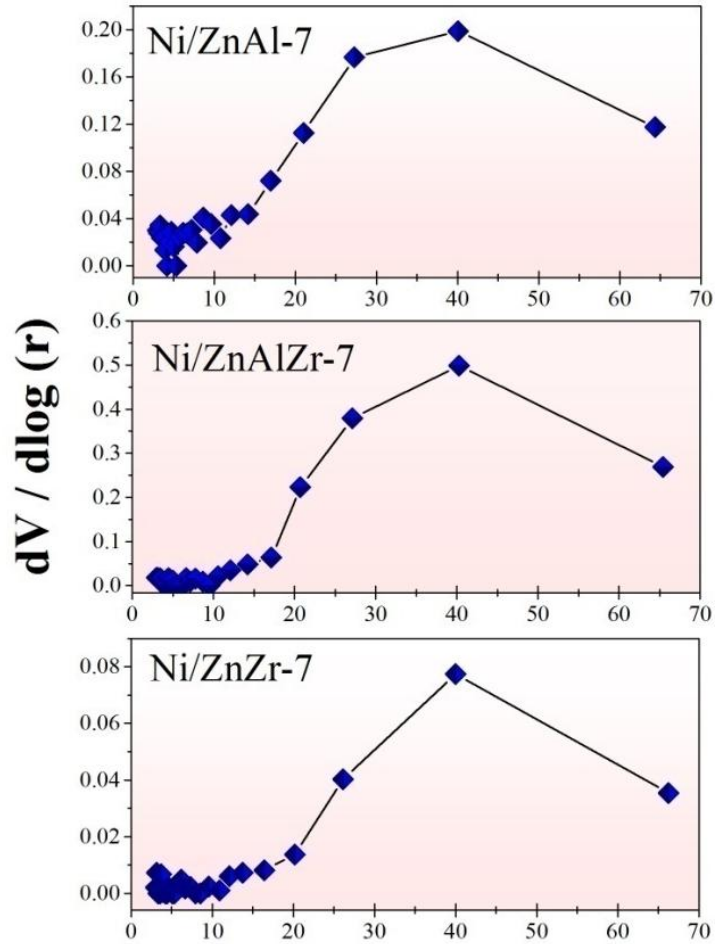

D I Â M E T R O D O PORO [nm]

Fonte: Autoria própria.

Os valores da área superficial dos catalisadores tratados termicamente a $550^{\circ}, 650^{\circ} \mathrm{e}$ $750^{\circ} \mathrm{C}$ estão sumarizados na Tabela 18 . Os catalisadores calcinados a $550{ }^{\circ} \mathrm{C}$ evidenciaram os maiores valores de área superficial. O valor da área superficial obtido pelo catalisador Ni/ZnAl-5 foi de $64 \mathrm{~m}^{2} / \mathrm{g}$. Não obstante, ocorreu um aumento da área superficial ao substituir 
parcialmente o $\mathrm{Al}^{3+}$ pelo $\mathrm{Zr}^{4+}$, dessa forma, obtendo um valor de $69 \mathrm{~m}^{2} / \mathrm{g}$ para o catalisador $\mathrm{Ni} / \mathrm{ZnAlZr}-5$. Os resultados obtidos pelas curvas termogravimetricas explicaria o comportamento desse resultado, uma vez que o Ni/ZnAlZr-5 apresentou uma maior perda de massa associado à remoção de carbonato e a desidroxilação. Portanto, constatou-se que os catalisadores obtidos a $550{ }^{\circ} \mathrm{C}$ são porosos e com boa capacidade de adsorção. Essas características permitem acessibilidade dos reagentes aos sítios ativos. Ainda na Tabela 18, os resultados dos catalisadores tratados a $650^{\circ} \mathrm{C}$ são mostrados. Os valores obtidos para os catalisadoreNi/ZnAl-6, Ni/ZnAlZr-6 e Ni/ZnZr-6 foram de 59, 53 e 16 m²/g, respectivamente. Logo, verificou-se que a subtituição parcial e total do $\mathrm{Al}^{3+}$ favoreceu a diminuição da área surperficial. Deve-se ressaltar que área superficial do $\mathrm{ZrO}_{2}$ tende a ficar abaixo de $25 \mathrm{~m}^{2} / \mathrm{g}$ quando calcinado em temperatura acima de $600^{\circ} \mathrm{C}$ (YAMAGUCHI, 1994).

As áreas superficiais apresentadas para os catalisadores Ni/ZnAl-7, Ni/ZnAlZr-7, $\mathrm{Ni} / \mathrm{ZnZr}-7$ foram de $31 \mathrm{~m}^{2} / \mathrm{g}, 30 \mathrm{~m}^{2} / \mathrm{g}$ e $3 \mathrm{~m}^{2} / \mathrm{g}$, respectivamente. A formação de aglomerados provocados pelo processo de coalescência favoreceu a baixa área superficial reportada para esses catalisadores. Notou-se, claramente, uma aproximidade nos valores das áreas nos catalisadores Ni/ZnAl-7 e Ni/ZnAlZr-7, diferindo do catalisador Ni/ZnZr-7 que apresentou a menor área superficial. Portanto, isso permitiu concluir que ocorreu o bloqueamento dos poros causado pelo crescimento das partículas. Esse processo foi induzido pelo tratamento térmico, uma vez que ocorreu o efeito de sinterização do pó mediante o transporte de massa para formação dos pescoços, processo este, similar à densificação de corpos cerâmicos. Possivelmente, a desintegração do precursor de hidrotalcita desempenha papel fundamental na obtenção de catalisadores com elevada área superficial, conforme mencionado anteriormente. Isso explicaria as baixas áreas superficiais observadas para os catalisadores Ni/ZnZr-5, Ni/ZnZr-6 e $\mathrm{Ni} / Z n Z r-7$. Em geral, a área superficial especifica de todos os catalisadores não ultrapassou de $70 \mathrm{~m}^{2} / \mathrm{g}$, evidenciando que o tempo de calcinação empregado durante o processo de calcinação influenciou nas áreas superficiais das amostras. 
Tabela 18 - Valores das áreas superficiais específicas para os catalisadores Ni/ZnAl, Ni/ZnAlZr e Ni/ZnZr tratados a $500{ }^{\circ} \mathrm{C}, 650^{\circ} \mathrm{C}$ e $750{ }^{\circ} \mathrm{C}$.

\begin{tabular}{cccc}
\hline Amostras & $\begin{array}{c}\text { Área superficial } \\
\left(\mathrm{m}^{2 / \mathrm{g}}\right)\end{array}$ & $\begin{array}{c}\text { Volume de poros } \\
\left(\mathrm{cm}^{3} / \mathrm{g}\right)\end{array}$ & $\begin{array}{c}\text { Raios de poro } \\
(\hat{\AA})\end{array}$ \\
\hline Ni/ZnAl-5 & 64 & 0.328 & 15.951 \\
Ni/ZnAlZr-5 & 69 & 0.397 & 84.534 \\
Ni/ZnZr-5 & 19 & 0.127 & 83.926 \\
Ni/ZnAl-6 & 59 & 0.196 & 17.777 \\
Ni/ZnAlZr-6 & 53 & 0.342 & 104.067 \\
Ni/ZnZr-6 & 16 & 0.031 & 29.694 \\
Ni/ZnAl-7 & 31 & 0.123 & 16.807 \\
Ni/ZnAlZr-7 & 30 & 0.245 & 135.559 \\
Ni/ZnZr-7 & 3 & 0.034 & 15.914 \\
\hline
\end{tabular}

Fonte: Autoria própria.

\subsubsection{Basicidade}

Inicialmente, é importante enfatizar que não existe uma técnica que possa ser empregada de uma forma geral para a determinação da basicidade, pois as mesmas tendem a apresentar restrições importantes. Logo, usou-se dois métodos para estudar a basicidade das amostras: método titulométrico e dessorção à temperatura programada. A quantidade de sítios básicos (ou basicidade) foi determinada pelo método de titulação, sendo esta grandeza expressa em unidade de sítios básicos por massa $(\mathrm{mmol} / \mathrm{g})$. O processo de decomposição de precursores tipo hidrotalcita origina uma mistura de óxidos dispersos, conforme citado anteriormente. A basicidade de óxidos mistos derivados de hidrotalcita, geralmente apresenta diferentes sítios básicos: (i) sítios fracos (grupos de $\mathrm{OH}^{-}$); (ii) moderados (pares de $\mathrm{M}-\mathrm{O}$ ) e (iii) sítios básicos fortes de Lewis (íons $\mathrm{O}^{2-}$ ) (YI et al., 2011). Vale ressaltar ainda que a acidez e a basicidade são fatores que dependem da natureza dos ligantes, da carga, do raio dos íons metálicos, do caráter da ligação metal-oxigênio e do enchimento dos orbitais d (AUROUX; GERVASINI, 1990). Outro fator ligado à basicidade são os defeitos estruturais das amostras, normalmente vacâncias (ATKINS, 2008). Pensando no estabelecimento de correlações entre a basicidade dos catalisadores e seu desempenho na reforma seca do metano, investigou-se nesta tese a propriedade básica dos catalisadores $\mathrm{Ni} / \mathrm{ZnAl}(5,6$ e 7), Ni/ZnAlZr (5, 6 e 7) e Ni/ZnZr (5, 6 e 7) utilizando titulação de Hammett cujos resultados estão listados na Tabela 
19. Verificou-se que o fator que contribuiu para a variação dos valores da basicidade foi a introdução dos íons $\mathrm{Zr}^{4+}$. Para o catalisador Ni/ZnAl-5, a basicidade obtida foi da ordem de $0,3056 \times 10^{-3} \mathrm{mmol} / \mathrm{g}$, enquanto que os catalisadores $\mathrm{Ni} / \mathrm{ZnAlZr}-5$ e Ni/ZnZr-5 apresentaram valores de $0,3333 \times 10^{-3} \mathrm{mmol} / \mathrm{g}$ e $0,1011 \times 10^{-3} \mathrm{mmol} / \mathrm{g}$, respectivamente . Para os catalisadores tratados a $650^{\circ} \mathrm{C}$, notou-se uma proximidade na basicidade para os catalisadores $\mathrm{Ni} / \mathrm{ZnAl}$ $6\left(0,2000 \times 10^{-3} \mathrm{mmol} / \mathrm{g}\right)$ e Ni/ZnAlZr-6 $\left(0,1944 \times 10^{-3} \mathrm{mmol} / \mathrm{g}\right)$. Paralelamente, o catalisador Ni/ZnZr-6 apresentou um valor de $0,0667 \mathrm{mmol} / \mathrm{g}$. Ainda na Tabela 19, pode-se ver que para os catalisadores a $750{ }^{\circ} \mathrm{C}$, os valores da basicidade foram globalmente decrescidos. No $\mathrm{Ni} / \mathrm{ZnAl}-7$, o valor obtido foi $0,0722 \times 10^{-3} \mathrm{mmol} / \mathrm{g}$, enquanto que para o $\mathrm{Ni} / \mathrm{ZnAlZr}-7$, o valor ficou em $0,1000 \times 10^{-3} \mathrm{mmol} / \mathrm{g}$. Finalmente, para a amostra Ni/ZnZr-7, o número de sítios básicos foi da ordem de $0,0333 \times 10^{-3} \mathrm{mmol} / \mathrm{g}$.

Os resultados mostram que há poucas diferenças em relação à basicidade obtida para os catalisadores Ni/ZnAl-5 e Ni/ZnAlZr-5. Conforme reportado na literatura, o $\mathrm{Al}_{2} \mathrm{O}_{3}$ é comumente empregado como suporte na reação de reforma seca, devido ao seu caráter básico capaz de promover a conversão do $\mathrm{CO}_{2}$ (NEWNHAM, 2012). Outro óxido utilizado como suporte é o ZnO, considerado um óxido tipicamente básico (ROSSI et al., 1991). Com a substituição parcial do $\mathrm{Al}^{3+}$ pelo $\mathrm{Zr}^{4+}$ para a formação do $\mathrm{Ni} / \mathrm{ZnAlZr}-5$, ocorreu um pequeno aumento da basicidade demonstrando que a presença do $\mathrm{ZrO}_{2}$ contribui para o aumento da quantidade de sítios básicos . Ao ser retirado totalmente o $\mathrm{Zr}^{4+}$ para a formação do Ni/ZnZr-5, a basicidade diminui bruscamente, ou seja, a presença dos sítios básicos é atribuída principalmente ao $\mathrm{Al}_{2} \mathrm{O}_{3}$. Além disso, reporta-se que a basicidade do $\mathrm{Al}_{2} \mathrm{O}_{3}$ advém de grupos $\mathrm{OH}$ livre fracamente adsorvidos, além de grupos $\mathrm{OH}$ remanescentes sobre a superfície após a desidratação. A Figura 46 representa os sítios básicose ácidos obtidos a partir da hidratação e desidratação da superfície (K. TANABE, T. YAMAGUCHI, 1968). Os catalisadores calcinados a temperatura de $650^{\circ} \mathrm{C}$ exibiram uma basicidade menor em relação aos de $550^{\circ} \mathrm{C}$, demonstrando a interferência da temperatura de calcinação na basicidade. Verificou-se uma pequena diferença nas basicidades entre os catalisadores Ni/ZnAl-6 e Ni/ZnAlZr-6. É possível notar que o catalisador sem a presença do $\mathrm{Al}^{3+}$ apresentou a menor basicidade. Finalmente, para os catalisadores a $750^{\circ} \mathrm{C}$ mostraram que a presença do $\mathrm{ZrO}_{2}$ juntamente com as fases contendo alumínio favoreceram a presença de sítios de básicos, logo, o catalisador Ni/ZnAlZr-7 apresentou a maior basicidade. Todos os catalisadores estudados apresentaram sítios básicos. Pela análise qualitativa da basicidade foi possível observar mudanças de coloração do indicador na presença de sítios básicos, ver Tabela 19. Constata-se que na presença do indicador, os catalisadores apresentaram coloração de viragem da fenolftaleína (cor rosa). Logo, os resultados in- 
dicaram que as amostras apresentaram sítios básicos em $\mathrm{pK}_{\mathrm{BH}} \approx 9,8$ com diferentes forças, a depender de sua coloração. A Figura 47 mostra o processo de desprotonação do indicador de fenolftaleína na presença do sítio básico, seguida da mudança de coloração do indicador.

Tabela 19 - Valores obtidos para a basicidade dos catalisadores tratados termicamente a $550{ }^{\circ}, 650^{\circ}$ e $750{ }^{\circ} \mathrm{C}$ por $15 \mathrm{~h}$. Em cada linha, a massa pesada, o volume gasto na titulação e o aspecto final do catalisador na presença do indicador podem ser visualizados.

\begin{tabular}{|c|c|c|c|c|}
\hline Catalisadores & $\begin{array}{c}\text { Massa } \\
\text { pesada (g) }\end{array}$ & $\begin{array}{l}\text { Volume gasto } \\
\quad(\mathrm{mL})\end{array}$ & $\begin{array}{l}\text { Basicidade } \\
(\mathrm{mmol} / \mathrm{g})\end{array}$ & $\begin{array}{l}\text { Catalisador c/ } \\
\text { Indicador }\end{array}$ \\
\hline $\mathrm{Ni} / \mathrm{ZnAl}-5$ & 0,03 & 0,22 & $0,3056 \times 10^{-3}$ & \\
\hline $\mathrm{Ni} / \mathrm{ZnAlZr}-5$ & 0,03 & 0,30 & $0,3333 \times 10^{-3}$ & \\
\hline $\mathrm{Ni} / \mathrm{ZnZr}-5$ & 0,03 & 0,10 & $0,1011 \times 10^{-3}$ & \\
\hline $\mathrm{Ni} / \mathrm{ZnAl}-6$ & 0,03 & 0,22 & $0,2000 \times 10^{-3}$ & \\
\hline Ni/ZnAlZr-6 & 0,03 & 0,30 & $0,1944 \times 10^{-3}$ & \\
\hline $\mathrm{Ni} / \mathrm{ZnZr}-6$ & 0,03 & 0,10 & $0,0667 \times 10^{-3}$ & \\
\hline $\mathrm{Ni} / \mathrm{ZnAl}-7$ & 0,03 & 0,22 & $0,0722 \times 10^{-3}$ & \\
\hline $\mathrm{Ni} / \mathrm{ZnAlZr}-7$ & 0,03 & 0,30 & $0,1000 \times 10^{-3}$ & \\
\hline $\mathrm{Ni} / \mathrm{ZnZr}-7$ & 0,03 & 0,10 & $0,0333 \times 10^{-3}$ & \\
\hline
\end{tabular}

Fonte: Autoria própria. 
Figura 46 - Sítios ácidos e básicos do $\mathrm{Al}_{2} \mathrm{O}_{3}$.

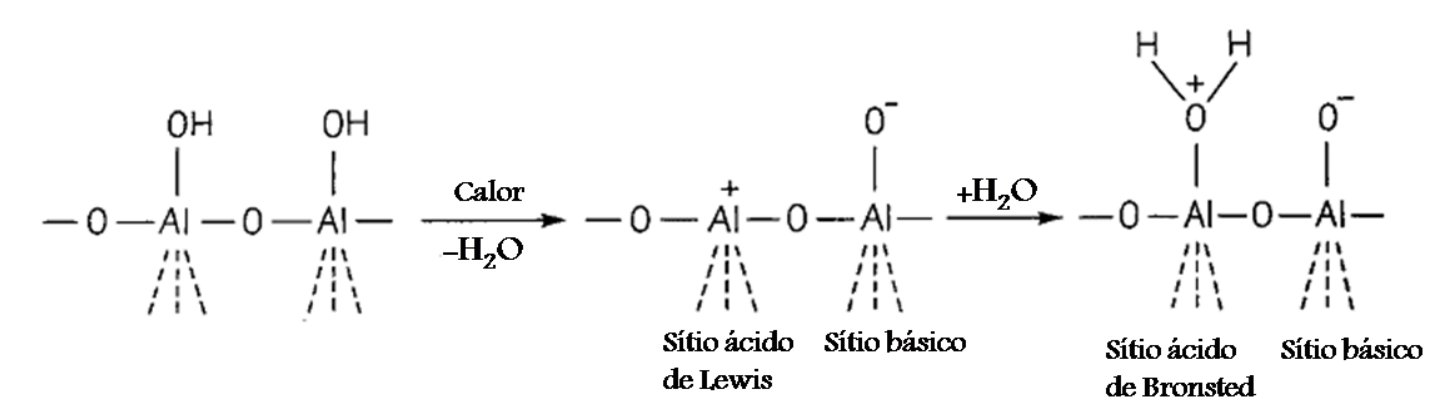

Fonte: K. TANABE, T. YAMAGUCHI, 1968.

Figura 47- Mecanismo da mudança de coloração do indicador fenolftaleína ao ser desprotonada na presença de sítios básicos.

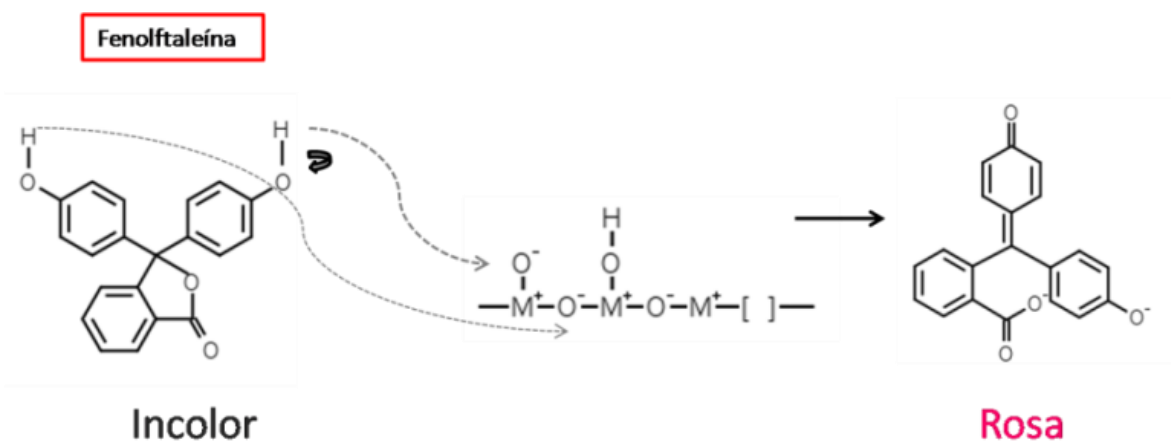

Fonte: Autoria própria

Os resultados referentes à dessorção de $\mathrm{CO}_{2}$ estão reportados na Figura 48. O catalisador $\mathrm{Ni} / \mathrm{ZnAl}-5$ apresentou picos de desssorção de alta intensidade em $66^{\circ}$ e $96^{\circ} \mathrm{C}$, além dos picos de baixa intensidade em torno de $144^{\circ}$ e $202^{\circ} \mathrm{C}$, os quais representam sítios básicos fortes. $\mathrm{O}$ catalisador $\mathrm{Ni} / \mathrm{ZnAlZr}-5$ exibiu picos em torno de $74^{\circ}, 101^{\circ}, 131^{\circ}, 176^{\circ}$ e $254^{\circ} \mathrm{C}$. Ainda na Figura 48, o catalisador Ni/ZnZr-5 apresentou picos de alta intensidade em $79^{\circ}$ e $100^{\circ} \mathrm{C}$, além de picos de baixa intensidade em $128^{\circ}, 188^{\circ}$ e $158^{\circ} \mathrm{C}$. Com base nos resultados apresentados, notou-se que os catalisadores apresentaram sítios básicos fracos, atribuídos à presença de hidroxilas adsorvidas sobre as superfícies dos mesmos, formando espécies de bicarbonato $\left(\mathrm{HCO}^{3-}\right)$; além da presença de pares ácido-base de Lewis , por exemplo, $\mathrm{Al}^{+3}-\mathrm{O}^{2}$. Nos catalisadores calcinados a $550^{\circ} \mathrm{C}$ não foram observados picos em alta temperatura, dessa forma, concluiu-se que não há sítios básicos fortes nesses catalisadores.

A Figura 49 mostra as interações entre a molécula sonda $\left(\mathrm{CO}_{2}\right)$ e os sítios básicos possivelmente presentes nos óxidos. Espécies de bicarbonatos sobre a superfície dos óxidos $\left(\mathrm{ZrO}_{2}\right.$ e $\left.\mathrm{Al}_{2} \mathrm{O}_{3}\right)$ podem ter sido formadas. Além disso, pode ocorrer a adsorção sobre os íons metálicos com a participação do oxigênio em excesso com formação de carbonato monoden- 
tado. E, por fim, a adsorção sobre os íons metálicos e o oxigênio vizinho, originando espécies de carbonato bidentados (ONO; HATTORI, 2011).

Figura 48 - Perfis de TPD- $\mathrm{CO}_{2}$ dos catalisadores tratados termicamente a $550^{\circ} \mathrm{C}$.

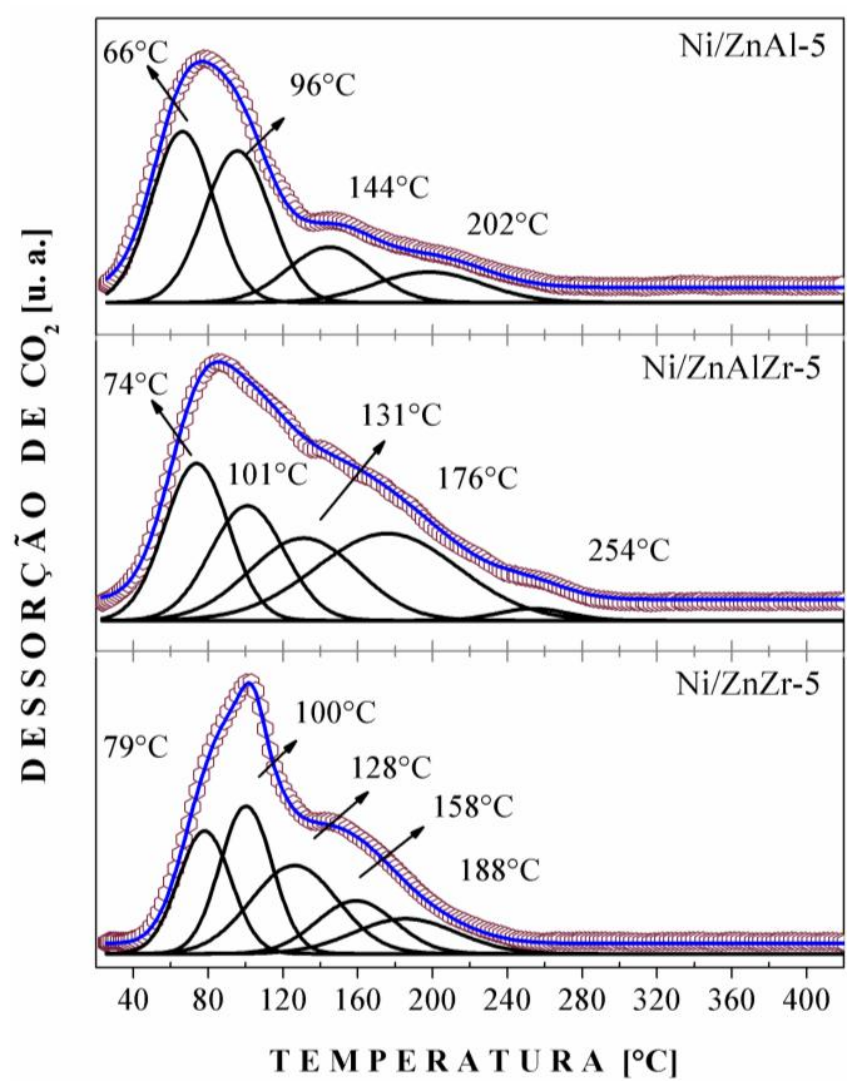

Fonte: Autoria própria

Figura 49 - Interações entre os sítios básicos presentes na superfície do $\mathrm{ZrO}_{2}$ com a molécula de $\mathrm{CO}_{2}$.

(I)<smiles>[Z7]OC(=O)C(=O)O</smiles><smiles></smiles>

(II)<smiles>[M]O[M]OC(=O)O</smiles><smiles></smiles><smiles>[M]OC(=O)O[M]</smiles>

$\mathrm{M}=\mathrm{Al}$

Fonte: Apatado do trabalho de (AUROUX; GERVASINI, 1990) 
Na Figura 50 estão ilustrados os perfis do TPD de $\mathrm{CO}_{2}$ para os catalisadores obtidos a $650{ }^{\circ} \mathrm{C}$. Verificou-se, claramente, que há um predomínio de sítios básicos fracos. O catalisador Ni/ZnAl-6 apresentou um pico de maior intensidade em torno de $87{ }^{\circ} \mathrm{C}$, além dos picos de baixa intensidade em torno de $70^{\circ}, 118^{\circ}, 154^{\circ}$ e $197{ }^{\circ} \mathrm{C}$. Passando para o catalisador $\mathrm{Ni} / \mathrm{ZnAlZr}-6$, constatou-se a presença dos picos em $90{ }^{\circ} \mathrm{C}$ (alta intensidade), $66^{\circ}, 112^{\circ} \mathrm{e}$ $146^{\circ} \mathrm{C}$. Um pico de baixa intensidade em $481{ }^{\circ} \mathrm{C}$ foi observado, nesse caso, pode ser atribuído a presença de sítios básicos mais fortes, por exemplo, íons $\mathrm{O}^{2-}$. Por último, o Ni/ZnZr-6 apresentou picos de alta intensidade em $68^{\circ} \mathrm{e} 90^{\circ} \mathrm{C}$, além dos picos de baixa intensidade em torno de $68^{\circ}, 211^{\circ}$ e $245^{\circ} \mathrm{C}$. Dessa forma, concluiu-se que os catalisadores calcinados a $650{ }^{\circ} \mathrm{C}$, assim como os catalisadorescalcinados a $550^{\circ} \mathrm{C}$ apresentaram uma predominância de sítios básicos fracos.

Figura 50 - Perfis de TPD- $\mathrm{CO}_{2}$ dos catalisadores tratados termicamente a $650^{\circ} \mathrm{C}$.

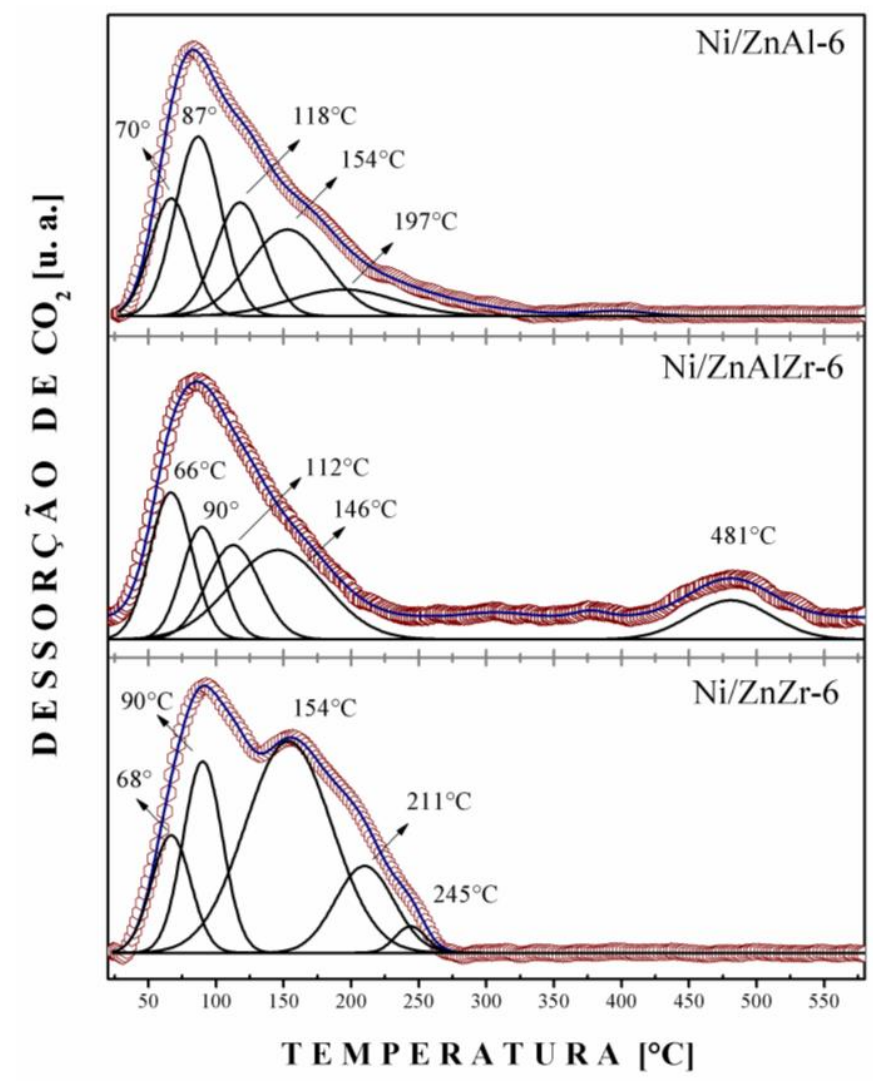

Fonte: Autoria própria

Perfis de TPD de $\mathrm{CO}_{2}$ para os catalisadores calcinados a $750^{\circ} \mathrm{C}$ está ilustrado na Figura 51. O processo de decomposição mostrou que o catalisador Ni/ZnAl-7 apresentou picos em $70^{\circ}, 91^{\circ}$ e $139^{\circ} \mathrm{C}$ (característicos de sítios fracos). O catalisador $\mathrm{Ni} / \mathrm{ZnAlZr}-7$ exibiu uma 
maior quantidade de picos em relação ao Ni/ZnAl-7, ademais, notou-se picos com maior força básica. Logo, observou-se a presença de cinco picos de dessorção em torno de $70^{\circ}, 91^{\circ}, 123^{\circ}$, $172^{\circ}$ e $199^{\circ} \mathrm{C}$. Do mesmo modo, o catalisador Ni/ZnZr-7 apresentou cinco picos de dessorção em torno de $71^{\circ}, 98^{\circ}, 153^{\circ}, 167^{\circ}$ e $222^{\circ} \mathrm{C}$. Disto concluiu-se que os catalisadores Ni/ZnAlZr7 e Ni/ZnZr-7 apresentaram picos com maior força básica em relação ao Ni/ZnAl-7.

Figura 51 - Perfis de TPD-CO $\mathrm{CO}_{2}$ dos catalisadores tratados termicamente a $750^{\circ} \mathrm{C}$.

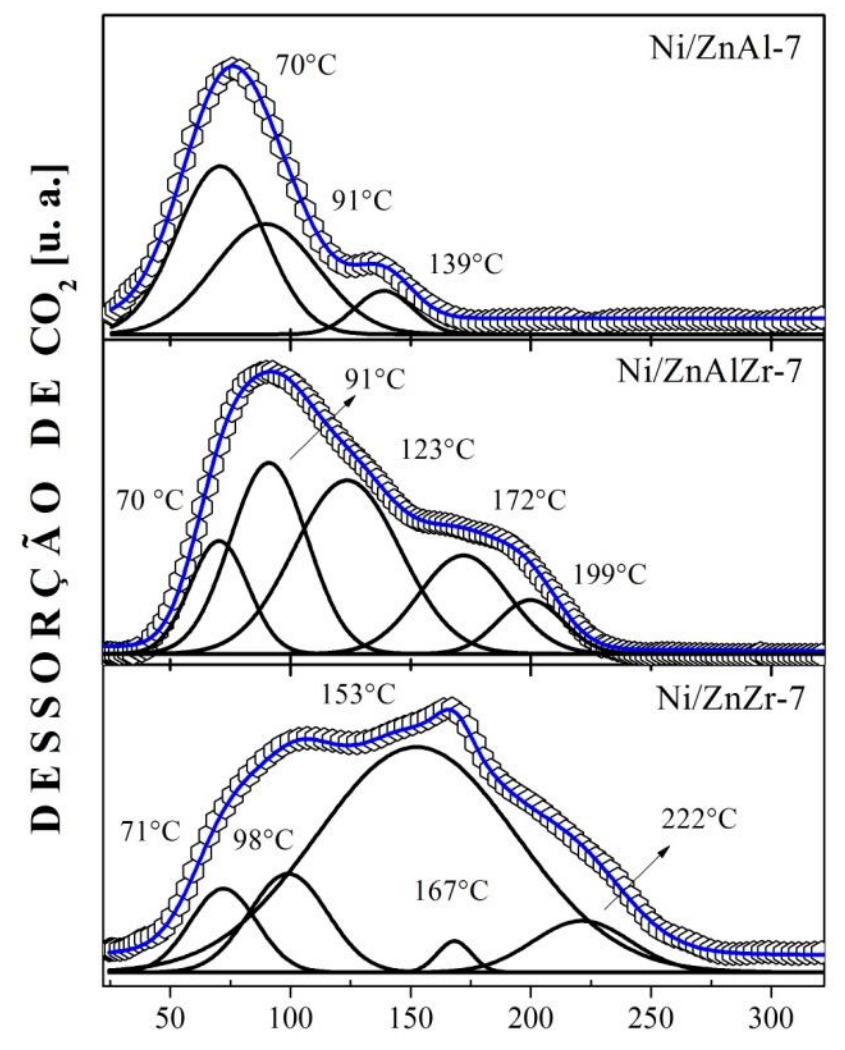

T E M P E R A T U R A $\left[{ }^{\circ} \mathrm{C}\right]$

Fonte: Autoria própria

\subsubsection{Desempenho dos catalisadores na reforma seca do $\mathrm{CH}_{4}$}

\subsubsection{Reação com os catalisadores obtidos a $550^{\circ} \mathrm{C}, 6^{\circ} 0^{\circ} \mathrm{C}$ e $750^{\circ} \mathrm{C}$}

A fim de avaliar o desempenho catalítico das amostras obtidas pela decomposição dos precursores NiZn-Al, NiZn-AlZr e NiZn-Zr, realizou-se o ensaio catalítico com excesso de $\mathrm{CH}_{4}$ em relação ao $\mathrm{CO}_{2}\left(\mathrm{CH}_{4}: \mathrm{CO}_{2}=1,5: 1,0\right)$, a fim de simular a composição do biogás. A dinâmica da reação de reforma na presença dos catalisadores calcinados e reduzidos a $550^{\circ} \mathrm{C}$ está ilustrado na Figura 52. A conversão de $\mathrm{CO}_{2}$ foi maior para todas as amostras estudas. 
Em primeiro lugar pode ser atribuído ao maior teor de $\mathrm{CH}_{4}$ em operação, uma vez que pelo equilíbrio termodinâmico era esperada uma conversão de $65 \%$ para $\mathrm{CH}_{4}$ e $96 \%$ para o $\mathrm{CO}_{2}$ (LUCRÉDIO et al., 2011b). Analisando o comportamento para o catalisador Ni/ZnAl-5, verificou-se que conversão do $\mathrm{CO}_{2}$ permaneceu constante durante todo período de reação, obtendo um valor em torno de $\sim 32 \%$. No que concerne ao $\mathrm{CH}_{4}$, a conversão foi em $\sim 10 \%$ para o catalisador Ni/ZnAl-5. A conversão para o catalisador Ni/ZnAlZr-5 em relação ao $\mathrm{CO}_{2}$ ficou em torno de $38 \%$ e em $22 \%$ para o $\mathrm{CH}_{4}$. Para o catalisador Ni/ZnZr-5, a conversão de $10 \%$ para o $\mathrm{CH}_{4}$ e $20 \%$ para o $\mathrm{CO}_{2}$ foi observada . Para as reações a $550^{\circ} \mathrm{C}$, a conversão do $\mathrm{CH}_{4}$ foi menor em relação ao $\mathrm{CO}_{2}$. Além disso, a conversão máxima para metano foi em torno de $66 \%$, e pelos resultados obtidos, notou-se que os valores ficaram abaixo dessa porcentagem. A baixa conversão reportada para o $\mathrm{CH}_{4}$ e $\mathrm{CO}_{2}$ pode estar relacionada à baixa temperatura de reação, visto que a reforma seca do metano é uma reação endotérmica. Deve-se ressaltar que a temperatura de ativação usada para esse grupo $\left(550^{\circ} \mathrm{C}\right)$ promoveu uma redução incompleta do $\mathrm{NiO}$ influenciando na baixa conversão do metano.

$\mathrm{O}$ catalisador $\mathrm{Ni} / \mathrm{ZnAlZr}-5$ apresentou uma maior conversão para o $\mathrm{CO}_{2}$ em relação aos outros catalisadores do grupo. Este resultado pode ter sido influenciado pelo maior número de sítios básicos, conforme reportado na Tabela 17. Este fato evidenciou uma maior capacidade de adsorver moléculas ácidas, tais como $\mathrm{CO}_{2}$, quanto maior for o valor da basicidade. NAKAMURA et al.( 1994) mostrou que a presença do $\mathrm{Al}_{2} \mathrm{O}_{3}$ promoveu a adsorção do $\mathrm{CO}_{2}$, dessa forma permitindo a formação de carbonato, o qual tende a sofrer redução, gerando moléculas de $\mathrm{CO}$. $\mathrm{O}$ mesmo ocorreu com $\mathrm{ZrO}_{2}$, que possui propriedades ácidas e básicas. Logo, concluiu-se que esses fatores contribuíram para maior conversão da molécula do $\mathrm{CO}_{2}$ para o catalisador Ni/ZnAlZr-5. Ainda na Figura 52, reportou-se que a maior conversão para o $\mathrm{CH}_{4}$ ocorreu para o catalisador $\mathrm{Ni} / \mathrm{ZnAlZr}-5$. Esse resultado demonstrou que a presença das fases de $\mathrm{Al}_{2} \mathrm{O}_{3}$ e $\mathrm{ZrO}_{2}$ promoveram a maior alta área superficial e o aumento da dispersão da fase de $\mathrm{Ni}^{0}$, com isso favorecendo a maior conversão do mesmo (NEWNHAM, 2012). A baixa conversão do $\mathrm{CH}_{4}$ observada para o catalisador Ni/ZnAl-5 também pode ser explicada pela redução, visto que sua temperatura máxima de redução é em torno de $635^{\circ} \mathrm{C}$, porém foi utilizada a temperatura de $550^{\circ} \mathrm{C}$ visando a comparação com os outros catalisadores pertencente a este grupo. Por fim, o catalisador Ni/ZnZr-5 também apresentou uma baixa conversão do $\mathrm{CH}_{4}$, atribuída a menor área superficial específica, como reportado na Tabela 16.

Em relação à razão $\mathrm{H}_{2} / \mathrm{CO}$, os catalisadores $\mathrm{Ni} / \mathrm{ZnAl}-5$ e Ni/ZnAlZr-5 apresentaram maior razão $\mathrm{H}_{2} / \mathrm{CO}$ em torno de 0,50 , enquanto que para o catalisador $\mathrm{Ni} / \mathrm{ZnZr}-5$, esta razão foi de 0,25, conforme ilustrado na Figura 52. Pelos resultados é possível concluir que o catali- 
sador $\mathrm{Ni} / \mathrm{ZnZr}-5$ apresentou menores valores referente à seletividade do $\mathrm{H}_{2}$ e $\mathrm{CO}$, refletindo na baixa razão $\mathrm{H}_{2} / \mathrm{CO}$. Além dos fatores citados acima, ressalta-se que durante a reforma outras reações paralelas tendem a ocorrer, influenciando a razão $\mathrm{H}_{2} / \mathrm{CO}$. Usualmente, a reação reversa da shift (Reação 27) é uma das principais reações paralelas que ocorrem durante a reforma seca do metano contribuindo para a baixa razão $\mathrm{H}_{2} / \mathrm{CO}$.

$\mathrm{CO}_{2}+\mathrm{H}_{2} \rightleftharpoons \mathrm{CO}+\mathrm{H}_{2} \mathrm{O}\left(\Delta \mathrm{H}_{298 \mathrm{~K}}=+41 \mathrm{~kJ} \cdot \mathrm{mol}^{-1}\right)$,

Figura 52 - Resultados dos testes catalíticos na reação de reforma seca do metano utilizando os catalisadores tratados termicamente $550^{\circ} \mathrm{C}$.
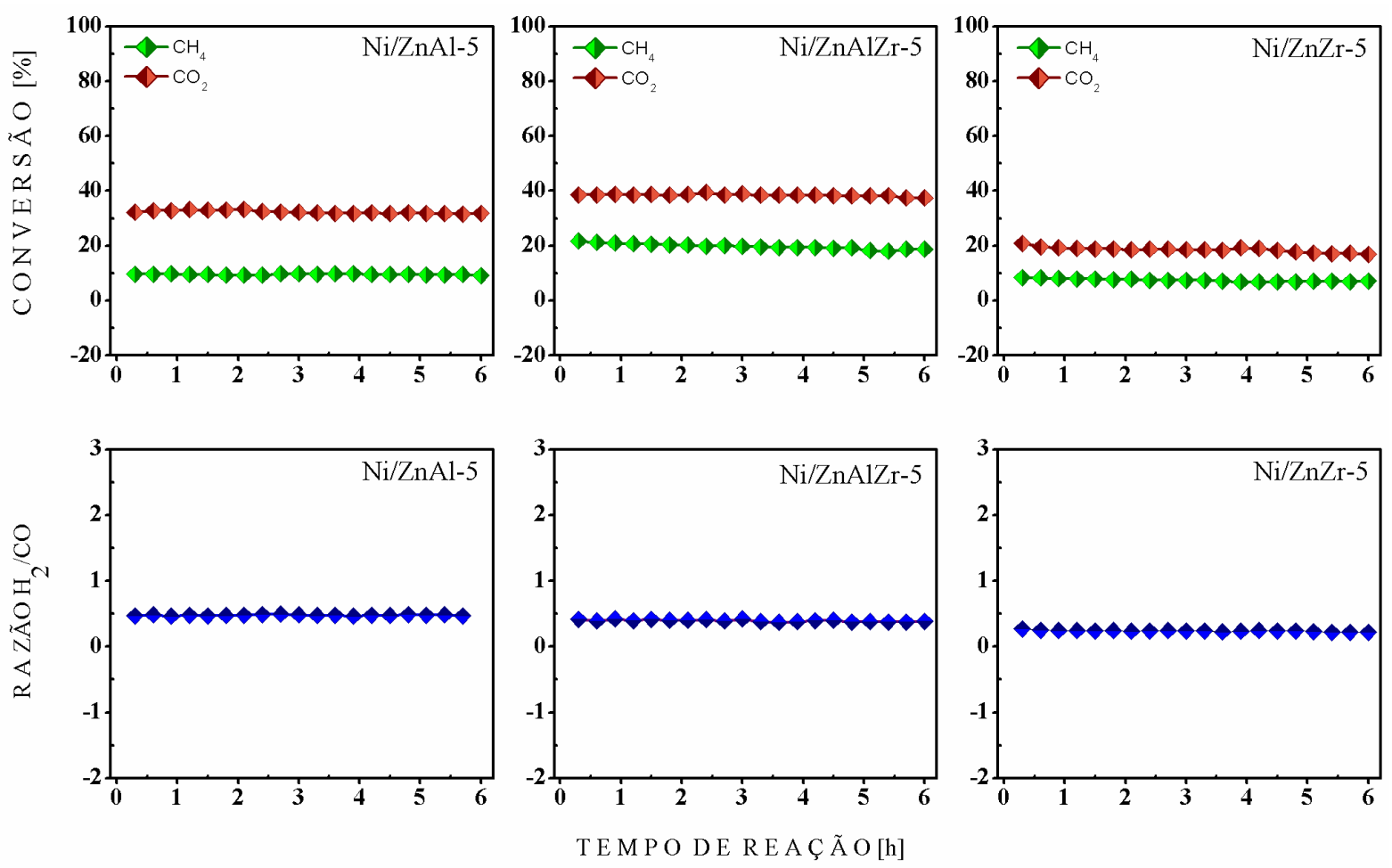

Fonte: Autoria própria.

$\mathrm{Na}$ Figura 53, estão reportados os valores referentes aos catalisadores Ni/ZnAl-6, Ni/ZnAlZr-6 e Ni/ZnZr-6. A conversão para a molécula de $\mathrm{CH}_{4}$ foi pouco perceptível. O catalisador $\mathrm{Ni} / \mathrm{ZnAl}-6$ iniciou-se com uma conversão em torno de $22 \%$, terminando com uma conversão de $18 \%$. Para o catalisador Ni/ZnAlZr-6 ocorreu uma conversão inicial de 27\%, sendo que depois de uma 1 h30 de reação, verificou-se uma diminuição para 23\%. E finalmente, no catalisador Ni/ZnZr-6 a conversão começou com 32\% diminuindo no decorrer da reação. Pelos resultados, verificou-se que o catalisador Ni/ZnAl-6 apresentou maior conversão para o $\mathrm{CO}_{2}$ em torno de $66 \%$, enquanto que a conversão para o Ni/ZnAlZr-6 exibiu uma con- 
versão de $47 \%$ durante 3 h e meia de reação, após isso ocorreu uma diminuição para $44 \%$ de conversão. Finalmente, o catalisador Ni/ZnZr-6 apresentou uma conversão inicial de 44\%, terminando em $41 \%$.

Os catalisadores calcinados a $650^{\circ} \mathrm{C}$ apresentaram um comportamento diferente em relação aos catalisadores calcinados a $550^{\circ} \mathrm{C}$. Analisando o comportamento no grupo, avaliouse que a conversão do $\mathrm{CH}_{4}$ foi maior à medida que ocorreu a substituição do Al pelo $\mathrm{Zr}$. Ao analisar todas as características referentes aos catalisadores, esperava-se uma maior conversão do $\mathrm{CH}_{4}$ para o catalisador Ni/ZnAl-6, visto que o mesmo apresentou maior área superficial. Além do mais, a temperatura utilizada na redução $\left(650^{\circ} \mathrm{C}\right)$ favoreceu a maior quantidade de fase metálica para esse catalisador. Porém, esse catalisador (Ni/ZnAl-6) apresentou uma menor conversão para $\mathrm{CH}_{4}$ em comparação aos catalisadores Ni/ZnAlZr-6 e Ni/ZnZr-6. Esse resultado pode estar relacionado ao processo de oxidação da fase ativa, promovido pelo oxigênio gerado a partir do processo de adsorção do $\mathrm{CO}_{2}$. Essa discussão corrobora os resultados da conversão do $\mathrm{CO}_{2}$, dado que o Ni/ZnAl-6 apresentou uma maior conversão para o mesmo. Estes resultados permitem concluir, primeiramente, que o mesmo aconteceu em menor grau com o catalisador Ni/ZnAlZr-6, e segundo, para o catalisador Ni/ZnZr-6. No que concerne a conversão do $\mathrm{CO}_{2}$, verificou-se que foi maior para o catalisador Ni/ZnAl-6. Enquanto que o catalisador $\mathrm{Ni} / \mathrm{ZnZr}-6$ apresentou uma menor conversão do mesmo. O resultado referente a maior conversão do $\mathrm{CO}_{2}$ pode estar relacionado com as reações que acontecem paralelamente à reforma seca do metano, tal como a reação reversa de Boudouard $\left(\mathrm{C}+\mathrm{CO}_{2} \rightleftharpoons 2 \mathrm{CO}\right)$, no caso, uma reação endotérmica que é favorecida em altas temperaturas.

Pelos resultados mencionados, notou-se que o catalisador Ni/ZnAl-6 apresentou uma razão $\mathrm{H}_{2} / \mathrm{CO}$ em torno de 0,60 , enquanto que o catalisador $\mathrm{Ni} / \mathrm{ZnAlZr}-6$ exibiu uma conversão em torno de 0,44 . Por fim, o catalisador $\mathrm{Ni} / \mathrm{ZnZr}-6$ apresentou uma razão $\mathrm{H}_{2} / \mathrm{CO}$ em torno de 0,78. Logo, verificou-se que o catalisador Ni/ZnZr-6 apresentou seletividades próximas em relação ao $\mathrm{CO}$ e $\mathrm{H}_{2}$. Enquanto que o catalisador Ni/ZnAlZr-6 exibiu a menor razão $\mathrm{H}_{2} / \mathrm{CO}$ em decorrência das reações paralelas, a saber, reação reversa da shift $\left(\mathrm{H}_{2}+\mathrm{CO}_{2} \rightleftarrows \mathrm{CO}+\mathrm{H}_{2} \mathrm{O}\right)$. Dessa forma, mostrou maior seletividade para CO. 
Figura 53 - Resultados dos testes catalíticos na reação de reforma seca do metano utilizando os catalisadores tratados termicamente $650^{\circ} \mathrm{C}$.
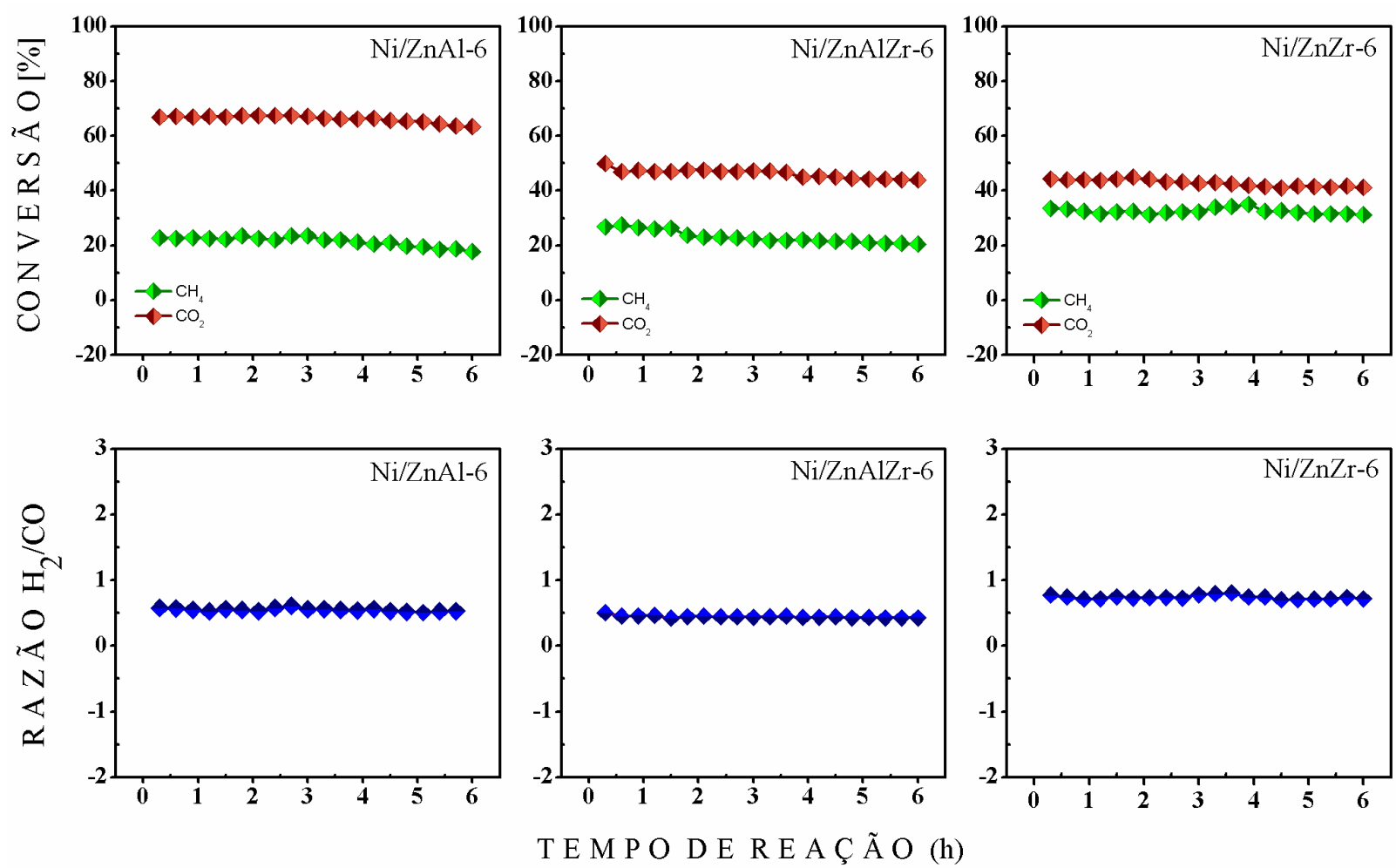

Fonte: Autoria própria.

Os gráficos da Figura 54a correspondem ao difratograma de raios $\mathrm{X}$ dos catalisadores calcinados na temperatura de $650^{\circ} \mathrm{C}$ no intervalo de $2 \theta$ em 40 a $70^{\circ}$, além do mapa de contorno bidimensional. Essa análise teve o objetivo de verificar a formação da fase de $\mathrm{Ni}^{0}$ e seu comportamente durante a reação. $\mathrm{Na}$ difração de raios $\mathrm{X}$ obtida na temperatura ambiente foi possível observar a presença dos picos referentes às fases de $\mathrm{ZnO}$ em torno de $2 \theta \sim 47^{\circ}, 48^{\circ}$, $56^{\circ}, 63^{\circ}, 68^{\circ}$ e $69^{\circ}$. No que concerne aos picos referentes ao $\mathrm{NiO}$, notou-se picos em $2 \theta \sim 53^{\circ}$, além dos picos sobrepostos com outras fases em $2 \theta \sim 47^{\circ}, 48^{\circ}, 56^{\circ}$ e $63^{\circ}$. Os pico referentes ao $\mathrm{ZnAl}_{2} \mathrm{O}_{4}$ apareceram em $2 \theta \sim 47^{\circ}, 59^{\circ}$ e $65^{\circ}, 68^{\circ}$ e $69^{\circ}$. Além disso, verificou-se a presença das fases de $\mathrm{NiAl}_{2} \mathrm{O}_{4}$ em $2 \theta \sim 59^{\circ}, 65^{\circ}$ e $69^{\circ}$. No decorrer do processo de redução, constatouse a diminuição dos picos referentes a fase de $\mathrm{NiO}$ e $\mathrm{ZnO}$. Enquanto que no final do processo de redução foi possivel verificar os picos mais intensos, os quais foram identificados como fases de espinélios, a saber, fases de $\mathrm{ZnAl}_{2} \mathrm{O}_{4}$ e $\mathrm{NiAl}_{2} \mathrm{O}_{4}$. Além do mais, foram observadas as fases de $\mathrm{Ni}^{\circ} \mathrm{em} 2 \theta \sim 44^{\circ}$ e $52^{\circ}$. Pelo mapa de contorno (Figura 54b), notou-se claramente o desaparecimento das fases, assim como, o aparecimento de outras fases, como reportado acima. 
Figura 54 - (a) Padrões de difração de raios $\mathrm{X}$ in situ da etapa de redução para o catalisador Ni/ZnAl-6, onde verifica-se a ocorrência das fases de $\mathrm{ZnO}(\alpha), \mathrm{NiO}(\beta), \mathrm{NiAl}_{2} \mathrm{O}_{4}(\delta), \mathrm{ZnAl}_{2} \mathrm{O}_{4}(\gamma)$ e Ni metálico; (b) Representação do mapa de contorno bidimensional para os difratogramas de raios $\mathrm{X}$ das amostras em função do tempo de redução.

(a)

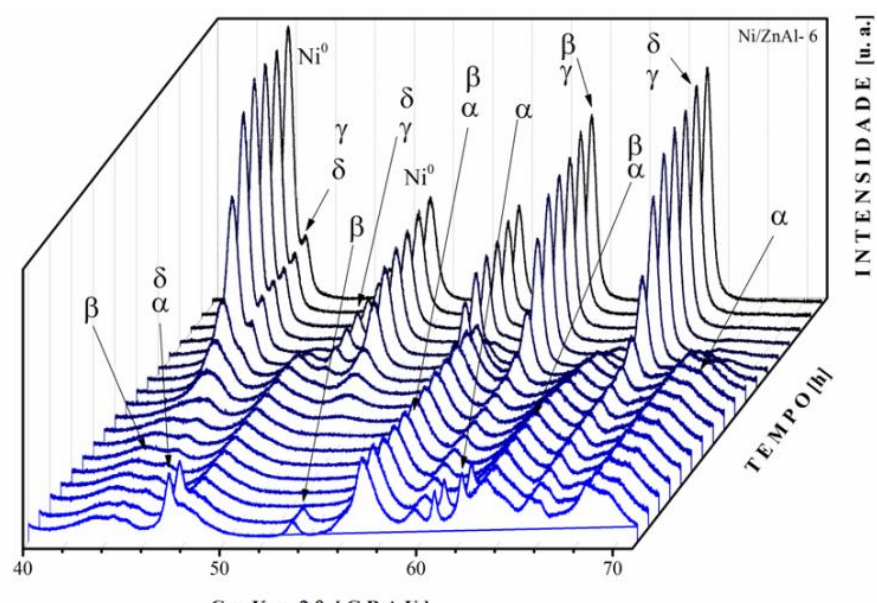

(b)

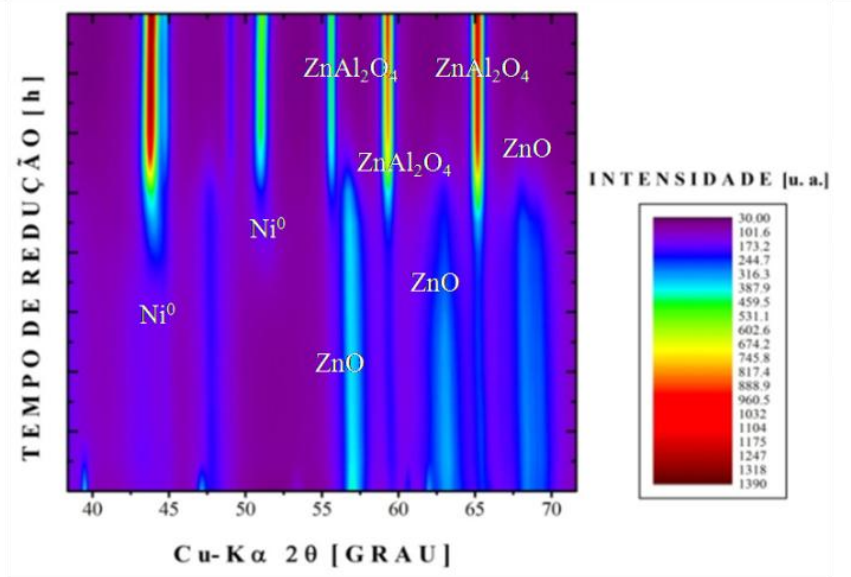

Fonte: Autoria própria.

Para estudar a dinâmica da reação dos catalisadores tratados a $650^{\circ} \mathrm{C}$ foi realizado a difração in situ da reação de reforma seca do metano. Na Figura 55 está reportado à reação para o catalisador Ni/ZnAl-6. Primeiramente, reporta-se o difratograma do catalisador a temperatura ambiente em um intervalo em $2 \theta \sim 20$ a $80^{\circ}$. As fases identificadas na temperatura ambiente foram : $\mathrm{NiO}, \mathrm{ZnO}, \mathrm{ZnAl}_{2} \mathrm{O}_{4}, \mathrm{NiAl}_{2} \mathrm{O}_{4}$ e $\mathrm{Al}_{2} \mathrm{O}_{3}$. Após o processo de redução ocorreu desaparecimento dos picos referentes ao $\mathrm{ZnO}, \mathrm{Al}_{2} \mathrm{O}_{3}$ e NiO. Deve-se notar também que ocorreu um aumento da intensidade e o aparecimento das fases de $\mathrm{ZnAl}_{2} \mathrm{O}_{4}$ e $\mathrm{NiAl}_{2} \mathrm{O}$ em $2 \theta \sim 31^{\circ}$, $36^{\circ}, 49^{\circ}, 55^{\circ}, 59^{\circ}$ e $65^{\circ}$. As fases associada ao $\mathrm{Ni}^{\circ}$ podem ser observados em $2 \theta \sim 44^{\circ}$ e $51^{\circ}$. No início da reação as fases permaneceram estáveis, porém observou-se que no decorrer da reação ocorre o aparecimento de novas fases, tais como, $\mathrm{ZnO}$ e $\mathrm{Al}_{2} \mathrm{O}_{3}$. No final da reação, verificou-se claramente a presença a fase de $\mathrm{Al}_{2} \mathrm{O}_{3}$ e a diminuição das fases de espinelios 
$\left(\mathrm{ZnAl}_{2} \mathrm{O}_{4}\right.$ e $\left.\mathrm{NiAl}_{2} \mathrm{O}\right)$. Por fim, a fase ativa permaneceu reduzida até o final da reação. Pelos resultados de difração de raios $\mathrm{X}$ não foi possível observar a presença do carbono.

Figura 55 - Difratograma in situ das reações catalíticas referentes ao catalisador Ni/ZnAl-6. Os símbolos $\alpha, \beta, \delta$, $\gamma, \mathrm{Ni}^{0}$, e $\mathrm{C}$ denotam a ocorrência das fases de $\mathrm{ZnO}, \mathrm{NiO}, \mathrm{Al}_{2} \mathrm{NiO}_{4}, \mathrm{Al}_{2} \mathrm{ZnO}_{4}, \mathrm{Ni}$ metálico e carbono nos catalisadores, respectivamente.

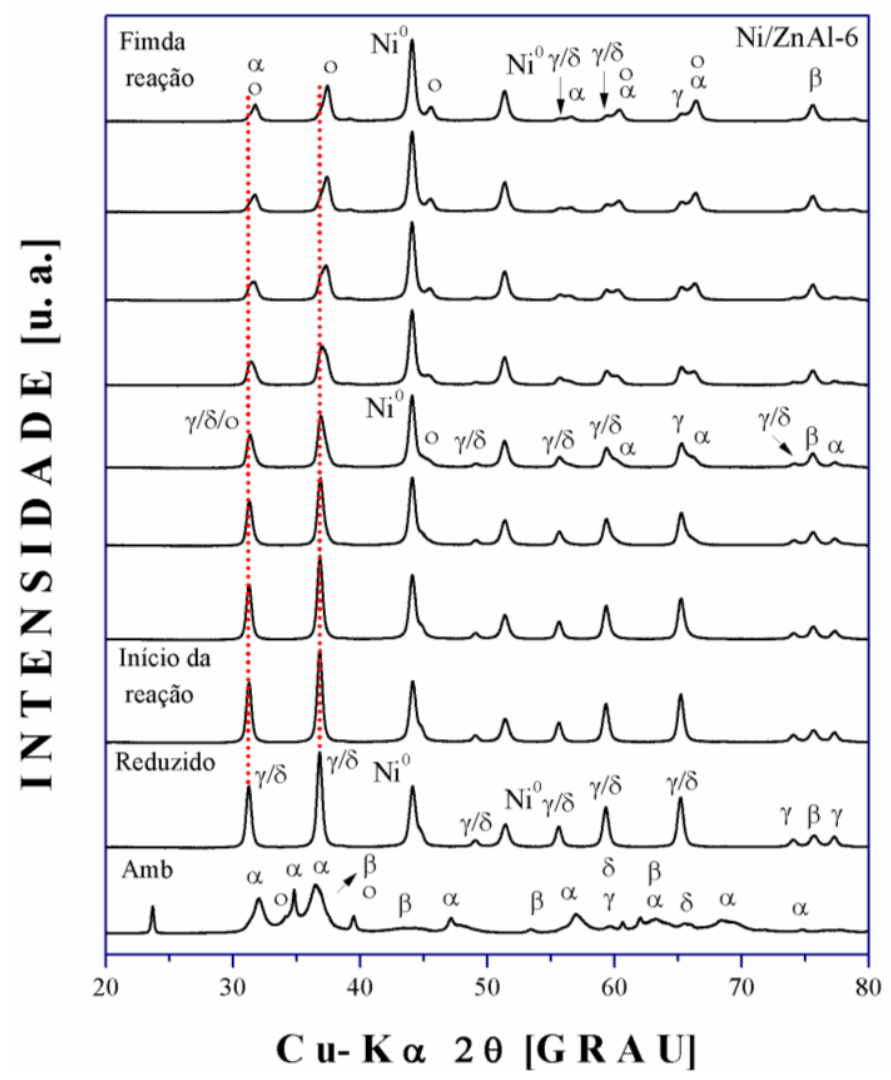

Fonte: Autoria própria

A Figura 56a ilustra o difratograma do catalisador Ni/ZnAlZr-6 durante o processo de redução. Inicialmente, reporta-se o difratograma da amostra na temperatura ambiente, onde foi possível observar os picos relacionados ao $\mathrm{ZnO}$ em torno de $2 \theta \sim 47^{\circ}, 56^{\circ}, 60^{\circ}, 62^{\circ}, 63^{\circ} \mathrm{e}$ $69^{\circ}$. Além disso, observou-se a sobreposição dos picos referentes ao $\mathrm{NiO}, \mathrm{ZnAl}_{2} \mathrm{O}_{4}$ e $\mathrm{ZrO}_{2}$. No decorrer do processo de redução, notou-se a diminuição dos picos referentes as fases de $\mathrm{ZnO}$ e NiO. Paralelamente, ocorreu o aumento e o aparecimento dos picos referentes as fases de $\mathrm{ZnAl}_{2} \mathrm{O}_{4}$ e $\mathrm{ZrO}_{2}$ em diferentes fases cristalinas ( tetragonal e monoclínica ). No final da redução, observou-se um pico de alta intensidade referente ao $\mathrm{Ni}^{0}\left(2 \theta \sim 44^{\circ}\right.$ e $\left.52^{\circ}\right), \mathrm{ZrO}_{2}$ e $\mathrm{ZnAl}_{2} \mathrm{O}_{4}$. A Figura 56b, mostra o mapa onde constatou-se claramente o aumento da intensidade referente as fases de $\mathrm{ZrO}_{2}, \mathrm{ZnAl}_{2} \mathrm{O}_{4} \mathrm{e} \mathrm{Ni}^{0}$. 
Figura 56 - (a) Padrões de difração de raios $X$ in situ da etapa de redução para o catalisador Ni/ZnAlZr-6, onde verifica-se a ocorrência das fases de $\mathrm{ZnO}(\alpha), \mathrm{NiO}(\beta), \mathrm{ZrO}_{2}(\lambda), \mathrm{NiAl}_{2} \mathrm{O}_{4}(\delta), \mathrm{ZnAl}_{2} \mathrm{O}_{4}(\gamma)$ e Ni metálico; (b) Representação do mapa de contorno bidimensional para os difratogramas de raios $\mathrm{X}$ das amostras em função do tempo de redução.

(a)

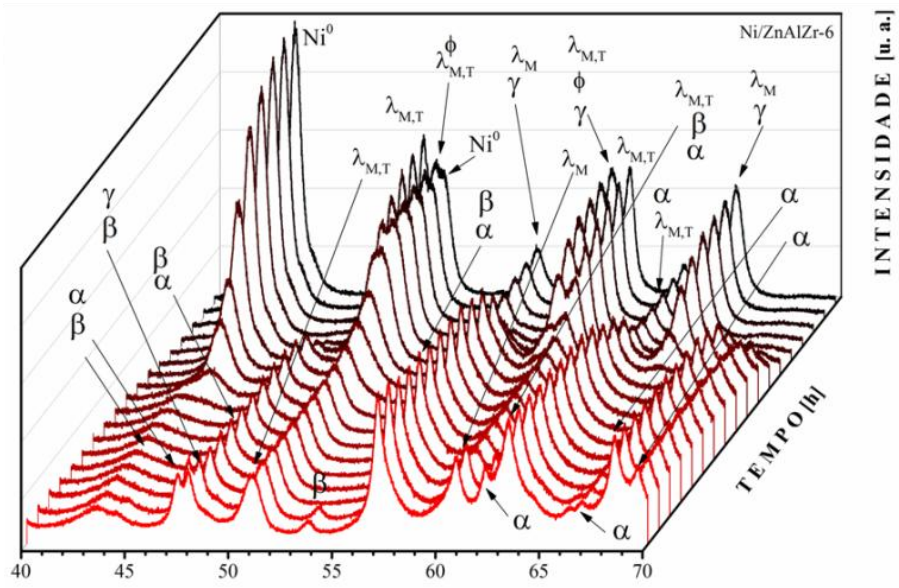

(b)

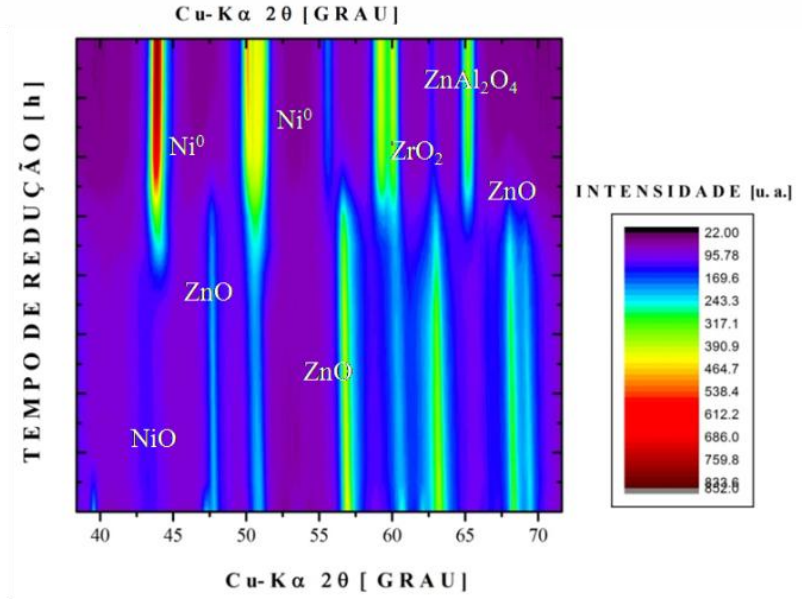

Fonte: Autoria própria

O gráfico, na Figura 57, reporta o padrão de difração do catalisador na temperatura ambiente. Foi possível observar a presença das fases de $\mathrm{ZnO}$ em $2 \theta \sim 32^{\circ}, 34^{\circ}, 36^{\circ}, 47^{\circ}, 57^{\circ}$, $66^{\circ}$ e $68^{\circ}$. Enquanto que os picos referentes a fase de $\mathrm{NiO}$ apareceram em torno de $43^{\circ} \mathrm{e} 63^{\circ}$. Também foram identificados picos associados a presença das fases de $\mathrm{ZrO}_{2}$ em $2 \theta \sim 23^{\circ}, 30^{\circ}$, $34^{\circ}, 50^{\circ}, 51^{\circ}$ e $60^{\circ}$. Durante o processo de redução, constatou-se um aumento na intensidade dos picos referentes ao $\mathrm{ZrO}_{2}$. Paralelamente, a redução da fase de $\mathrm{NiO}$ em $2 \theta \sim 44^{\circ}$ e $51^{\circ}$ foi verificada. No início da reação ocorreu uma mudança significativa das fases. Porém, após esse primeiro momento, observou-se um deslocamento e diminuição do pico em $2 \theta \sim 36^{\circ}$ identificado inicialmente como uma sobreposição das fases de $\mathrm{ZrO}_{2}, \mathrm{ZnAl}_{2} \mathrm{O}_{4}$ e $\mathrm{NiAl}_{2} \mathrm{O}_{4}$. O do pico em $2 \theta \sim 31^{\circ}$ está relacionado as fases de $\mathrm{NiAl}_{2} \mathrm{O}_{3}$ e $\mathrm{ZrO}_{2}$. Por último, ocorreu o processo de duplicação durante a reação, o primeiro em $2 \theta \sim 65^{\circ}$ associado ao $\mathrm{ZnAl}_{2} \mathrm{O}_{4}$ e $\mathrm{Al}_{2} \mathrm{O}$ e o segundo em $2 \theta \sim 66^{\circ}$ referente as fases de $\mathrm{ZnO}, \mathrm{NiO}$ e $\mathrm{Al}_{2} \mathrm{O}_{3}$. No final da reação foi possível 
observar as fases de $\mathrm{ZnO}$ e $\mathrm{Al}_{2} \mathrm{O}_{3}$. A fase ativa $\left(\mathrm{Ni}^{\circ}\right)$ permaneceu estável durante todo o período de reção $\left(2 \theta \sim 44^{\circ}\right.$ e $\left.51^{\circ}\right)$.

Figura 57 - Difratograma in situ das reações catalíticas realizadas com o catalisador Ni/ZnAlZr-6. Os símbolos $\alpha, \beta, \lambda_{(\mathrm{M}, \mathrm{T})}, \delta, \gamma, \mathrm{Ni}^{0}$, e $\mathrm{C}$ denotam a ocorrência das fases de $\mathrm{ZnO}, \mathrm{NiO}, \mathrm{ZrO}_{2}, \mathrm{Al}_{2} \mathrm{NiO}_{4}, \mathrm{Al}_{2} \mathrm{ZnO}_{4}, \mathrm{Ni}$ metálico e carbono nos catalisadores, respectivamente.

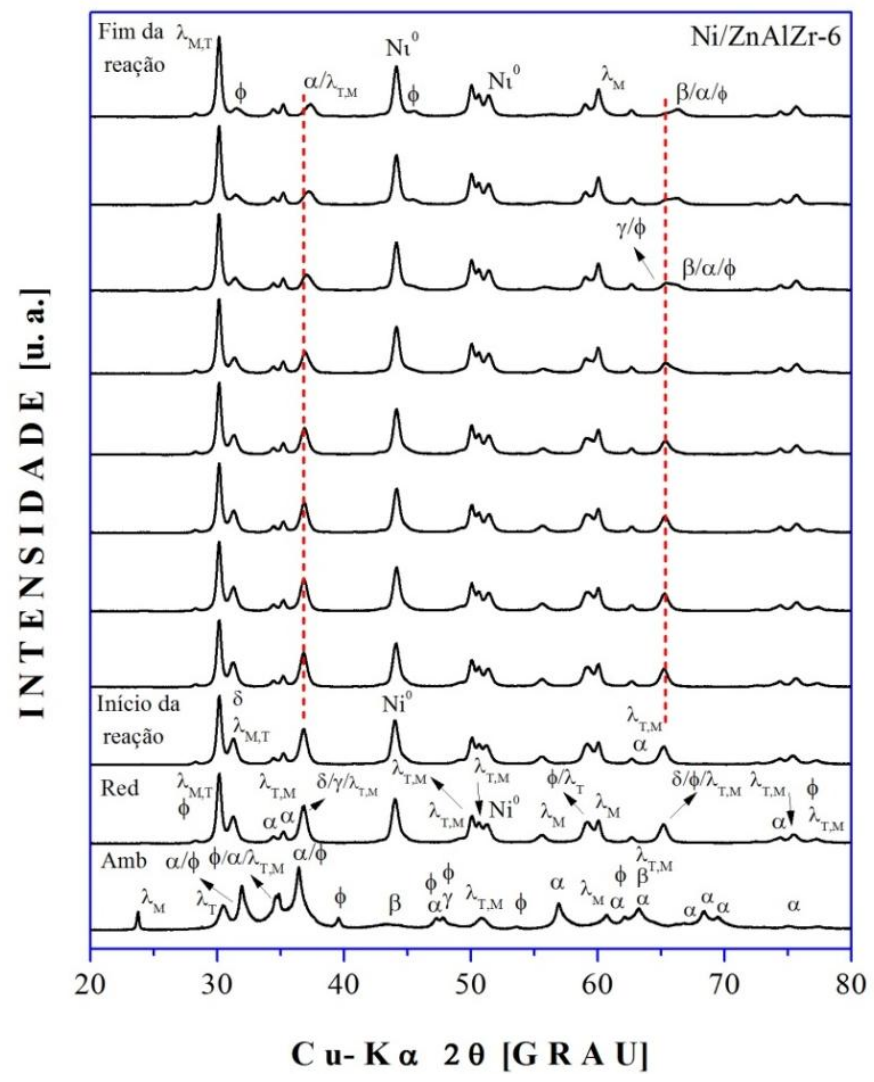

Fonte: Autoria própria

O processo de redução para o catalisador Ni/ZnZr-6 está ilustrado na Figura 58a. No padrão obtido na temperatura ambiente foi possível identificar a presença das fases de $\mathrm{ZnO}$ $\left(2 \theta \sim 47^{\circ}, 56^{\circ}, 63^{\circ}, 66^{\circ}, 68^{\circ}\right.$ e $\left.69^{\circ}\right)$ e $\mathrm{NiO}\left(2 \theta \sim 43^{\circ}\right.$ e $\left.63^{\circ}\right)$. No decorrer da redução ocorrem algumas modificações nos picos de difração, tal como, a diminuição da intensidade do pico referente a fase de $\mathrm{ZnO}$. Paralelamente, notou-se um aumento das intensidades dos picos associados ao $\mathrm{ZrO}_{2}$ em $2 \theta \sim 50^{\circ}, 59^{\circ}$ e $60^{\circ}$. A presença da fase metálica $\left(\mathrm{Ni}_{0}\right)$ pode ser observada em $2 \theta \sim 44^{\circ}$ e $52^{\circ}$, que no caso, aumenta no decorrer do tempo de redução . No final da redução, observou-se a presença de novos picos referente ao $\mathrm{ZrO}_{2}\left(2 \theta \sim 40^{\circ}\right.$, $45^{\circ}, 50^{\circ}, 53^{\circ}, 55^{\circ}, 56^{\circ}, 64^{\circ}$ e $\left.65^{\circ}\right)$ e $\mathrm{ZnO}\left(2 \theta \sim 40^{\circ}, 55^{\circ}, 56^{\circ}\right.$ e $\left.57^{\circ}\right)$. Finalmente, notou-se um pico de alta intensidade referente a fase ativa em torno de $2 \theta \sim 44^{\circ}$, e um segundo pico outro de 
menor intensidade em $2 \theta \sim 52^{\circ}$. Pelo mapa bidimensional (Figura 58b), constatou-se claramente o aumento da intensidade referente à fase de $\mathrm{Ni}^{0}$, além do pico referente a fase de $\mathrm{ZrO}_{2}$.

Figura 58 - (a Difratograma in situ das reações catalíticas referentes ao catalisador Ni/ZnZr-6, onde verificou-se a ocorrência das fases de $\mathrm{ZnO}(\alpha), \mathrm{NiO}(\beta), \mathrm{ZrO}_{2}(\lambda)$ e Ni metálico; (b) Representação do mapa de contorno bidimensional para os difratogramas de raios $\mathrm{X}$ das amostras em função do tempo de redução.

(a)

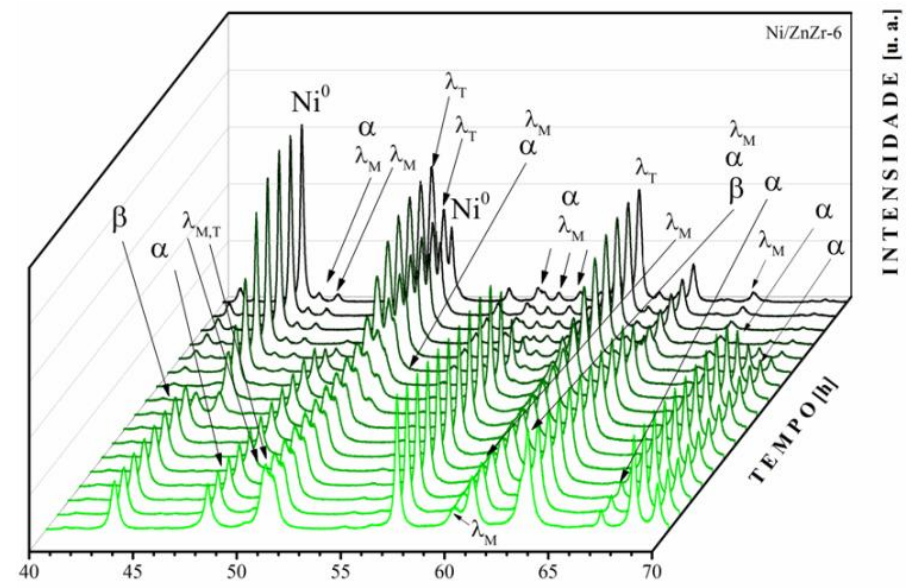

(b)

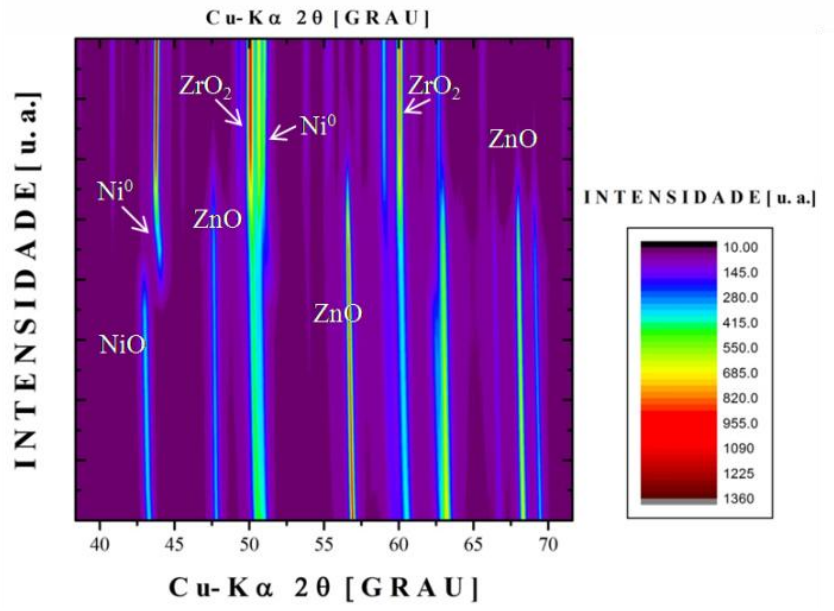

Fonte: Autoria própria

O difratograma da reação in situ do catalisador Ni/ZnZr-6 está ilustrado na Figura 59. A análise feita na temperatura ambiente reportou a fase referente ao $\mathrm{ZnO}$ em $2 \theta \sim$ $\left(32^{\circ}, 34^{\circ}, 36^{\circ}, 47^{\circ}, 56^{\circ}, 63^{\circ}, 66^{\circ}, 68^{\circ}, 69^{\circ}, 73^{\circ}\right.$ e $\left.77^{\circ}\right), \mathrm{NiO}\left(2 \theta \sim 43^{\circ}\right.$ e $\left.63^{\circ}\right)$ e $\mathrm{ZrO}_{2}(2 \theta \sim$ $\left.24^{\circ}, 30^{\circ}, 35^{\circ}, 36^{\circ}, 50^{\circ}, 54^{\circ}, 56^{\circ}, 59^{\circ}, 60^{\circ}, 63^{\circ}, 66^{\circ}, 68^{\circ}, 75^{\circ} \mathrm{e} 77^{\circ}\right)$. No difratograma após a redução ainda foi possível observar a presença da fase de $\mathrm{ZnO}$, além novos picos relacionados a fase de $\mathrm{ZrO}_{2}$ em $2 \theta \sim 40^{\circ}, 55^{\circ}, 57^{\circ}, 61^{\circ}, 64^{\circ}, 69^{\circ}, 71^{\circ}, 74^{\circ}$ e $76^{\circ}$. Simultaneamente, surgiu a presença da fase metálica em torno de $2 \theta \sim 44^{\circ}$ e $52^{\circ}$. Durante o período de reação não ocorreram mudanças significativas referentes as fases identificadas. 
Figura 59 - Difratograma in situ das reações catalíticas referentes ao catalisador Ni/ZnAl-6. Os símbolos $\alpha, \beta, \delta$, $\gamma, \mathrm{Ni}^{0}$, e C denotam a ocorrência das fases de $\mathrm{ZnO}, \mathrm{NiO}, \mathrm{Al}_{2} \mathrm{NiO}_{4}, \mathrm{Al}_{2} \mathrm{ZnO}_{4}$, Ni metálico e carbono nos catalisadores, respectivamente.
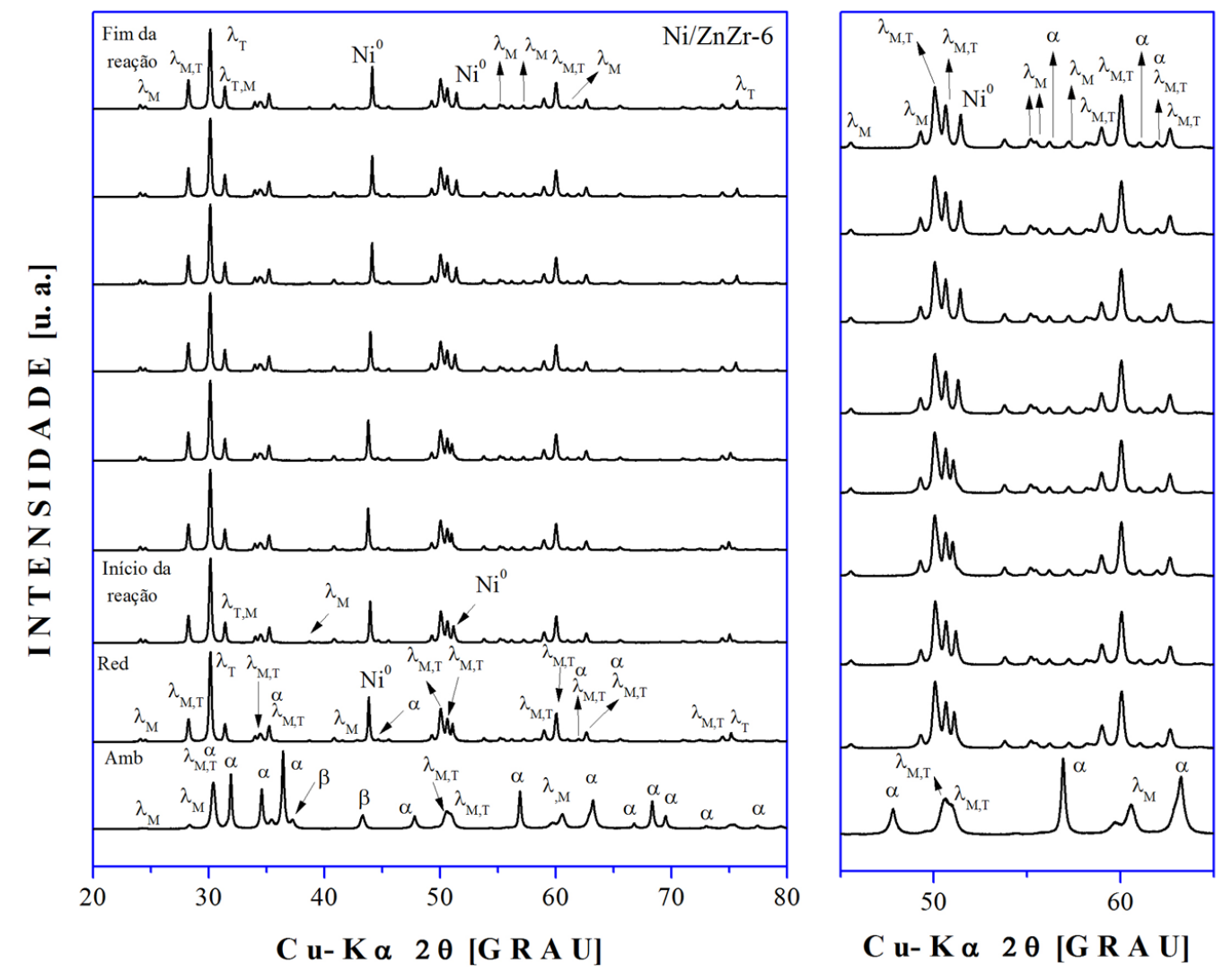

Fonte: Autoria própria.

Os valores da conversão para os catalisadores tratados termicamente a $750{ }^{\circ} \mathrm{C}$ por $15 \mathrm{~h}$ podem ser visualizados na Figura 60. Da mesma forma como reportado para os catalisadores calcinados a $550^{\circ}$ e $650^{\circ} \mathrm{C}$, esperava-se uma conversão máxima de $66 \%$ para $\mathrm{CH}_{4}$, porém a conversão do mesmo não ultrapassou um valor de 50\%. Inicialmente, o catalisador Ni/ZnAl-7

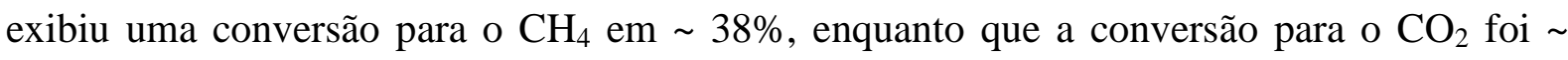
$60 \%$. Para o catalisador Ni/ZnAlZr-7, verificou-se uma conversão em $\sim 69 \%$ para $\mathrm{CO}_{2}$, havendo uma estabilidade entre 3 a 5 h de reação. Para o $\mathrm{CH}_{4}$, a conversão iniciou-se em $40 \%$, tendo uma diminuição após 3 h de reação. Por fim, o catalisador Ni/ZnZr-7 teve uma queda na conversão do $\mathrm{CO}_{2}$, enquanto isso, ocorreu um aumento na $\mathrm{CH}_{4} \mathrm{em} \sim 40 \%$. Ademais, este catalisador apresentou uma estabilidade durante $6 \mathrm{~h}$ de reação para os dois gases da conversão.

Muitos são os fatores que podem contribuir para o comportamento da conversão do catalisador Ni/ZnAl-7 para a molécula do $\mathrm{CH}_{4}$, tais como: (i) oxidação ou encapsulamento da fase ativa pela formação de filamentos de carbono; (ii) acumulação de grupos inativos adsor- 
vidos sobre $\mathrm{Ni}^{0}$ e (iii) sinterização da partícula do metal (PAKHARE; SPIVEY, 2014). Além do mais, uma das fases obtidas para esse catalisador foi o $\mathrm{NiAl}_{2} \mathrm{O}_{4}$, o que dificultou a sua redução, o que pode ter favorecido a menor conversão do metano. Apesar de apresentar a menor área superficial, ver Tabela 18, o catalisador apresentou a maior conversão do $\mathrm{CH}_{4}$ juntamente com o catalisador $\mathrm{Ni} / \mathrm{ZnAlZr}-7$. A temperatura de ativação $\left(650^{\circ} \mathrm{C}\right)$ aplicada para esses catalisadores favoreceu a redução completa da amostra Ni/ZnZr-7, e, por tanto, contribuiu para maior conversão da molécula $\mathrm{CH}_{4}$. Constatou-se que o catalisador Ni/ZnAlZr-7 apresentou a maior conversão para a molécula de $\mathrm{CO}_{2}, \log$ a a presença de sítios básicos pode ter contribuído para ativação do $\mathrm{CO}_{2}$. Para os catalisadores tratados a $750{ }^{\circ} \mathrm{C}$, a maior conversão para o $\mathrm{CO}_{2}$ pode ter sido ainda influenciada pela a reações de hidrogenação do $\mathrm{CO}_{2}$ ( Reação 28), e reação inversa de Boudoard (Reação 29), normalmente favorecidas em altas temperaturas. Para os catalisadores $\mathrm{Ni} / \mathrm{ZnAl}-7$ e Ni/ZnZr-7, notou-se uma menor razão $\mathrm{H}_{2} / \mathrm{CO}$ dada a presença de reações paralelas que induzem a formação de $\mathrm{CO}$, a exemplo da reação reversa de shift, tida como a principal responsável pela baixa razão $\mathrm{H}_{2} / \mathrm{CO}$. Finalmente, o catalisador $\mathrm{Ni} / \mathrm{ZnAlZr}-7$, apresentou a maior razão $\mathrm{H}_{2} / \mathrm{CO} \approx 0,97$, demonstrando ser mais seletivo para ambos os gases $\mathrm{H}_{2}$ e $\mathrm{CO}$, vide Figura 60. Pelos resultados obtidos pela reforma seca, concluiu-se que os catalisadores $\mathrm{a} 750^{\circ} \mathrm{C}$ apresentaram maiores conversões. Logo, foram realizadas as análises de difração de raios $\mathrm{X}$ in situ durante a reação de reforma seca.

$\mathrm{CO}_{2}+\mathrm{H}_{2} \rightleftharpoons \mathrm{CO}+\mathrm{H}_{2} \mathrm{O}$

Reação 28

$\mathrm{CO}_{2}+\mathrm{C} \rightleftharpoons 2 \mathrm{CO}$

Reação 29 
Figura 60 - Resultados dos testes catalíticos na reação de reforma seca do metano utilizando os catalisadores tratados termicamente $750{ }^{\circ} \mathrm{C}$.
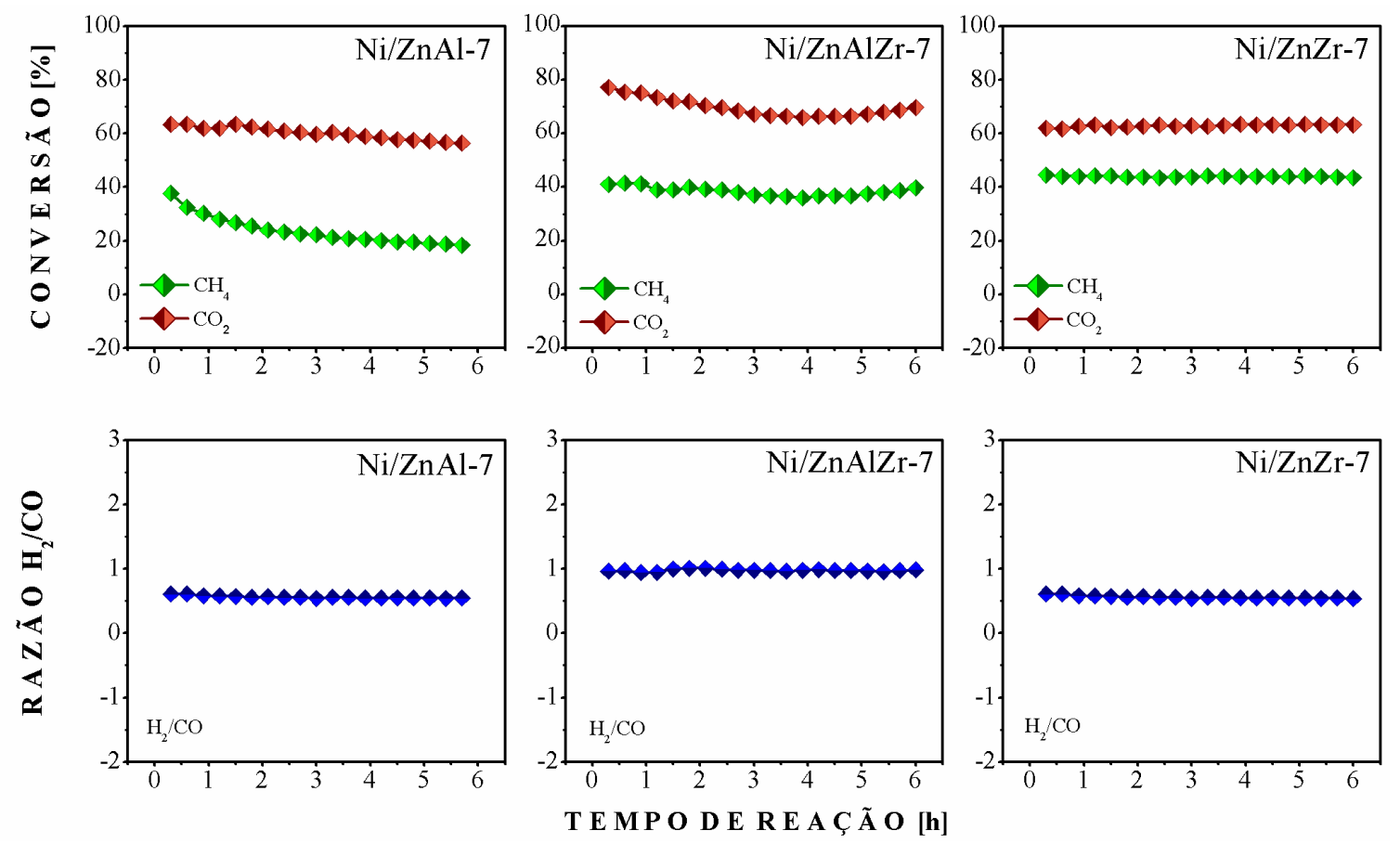

Fonte: Autoria própria.

Com intuito de investigar a formação do carbono e verificar a presença do $\mathrm{Ni}^{0}$, realizou-se a difração de raios $\mathrm{X}$ in situ durante a reação de reforma seca. Na Figura 61(a), reportou-se a etapa de redução do catalisador Ni/ZnAl-7, onde se percebeu a diminuição dos picos referentes à fase $\mathrm{ZnO}\left(2 \theta \sim 32^{\circ}, 34^{\circ}, 36^{\circ}, 48^{\circ}, 57^{\circ}, 66^{\circ}, 68^{\circ}\right.$ e $\left.69^{\circ}\right)$ e um pequeno aumento da intensidade dos picos referentes as fases de espinélios $\left(\mathrm{ZnAl}_{2} \mathrm{O}_{4}\right.$ e $\left.\mathrm{NiAl}_{2} \mathrm{O}_{4}\right)$. Simultaneamente, iniciou-se o aparecimento do $\mathrm{Ni}^{0}$ em $2 \theta \sim 44^{\circ}$ e $51^{\circ}$. Ao elevar para a temperatura de reação de $750^{\circ} \mathrm{C}$, notou-se o aumento de intensidade do pico da fase de espinélio $\left(\mathrm{ZnAl}_{2} \mathrm{O}_{4}\right)$ e a diminuição do pico referente a fase de $\mathrm{ZnO}$. Além disso, ocorreu um aumento da intensidade da fase de $\mathrm{Ni}^{0}$. Após 30 min de reação há um comportamento diferente daquele em relação ao início da reação. Constatou-se a formação de carbono (coque) em $2 \theta \sim 25^{\circ}$, além do aparecimento de um pico de alta intensidade em $2 \theta \sim 42^{\circ}$ referente a um óxido contendo $\mathrm{Zn}$ e $\mathrm{Ni}$, o qual foi identificado pela ficha JCPDS \# 01-075-0273. Enquanto isso, verificou-se uma diminuição do pico referente ao $\mathrm{Ni}^{0}$ em torno de $2 \theta \sim 44^{\circ}$ e $52^{\circ}$, sendo consequência da oxidação parcial do $\mathrm{Ni}^{0}$. A 60 min de reação, ocorreu uma diminuição da intensidade do pico referente à fase de $\mathrm{ZnO}$ em $2 \theta \sim 42^{\circ}$. Por fim, o processo de redução do $\mathrm{NiO}$ é novamente constatado. Foi possível observar um pico em $2 \theta \sim 46^{\circ}$ que está relacionado a fase de $\mathrm{Al}_{2} \mathrm{O}_{3}$, o qual permaneceu durante toda a reação. Após 90 min de reação ocorreu uma mudança pouco percep- 
tível. No final da reação (120 min), notou-se claramente a presença do carbono. Além disso, no decorrer da reação o pico em $2 \theta \sim 42^{\circ}$ diminui a intensidade, enquanto que aumenta a intensidade da fase de $\mathrm{Ni}^{0}$. As outras fases identificadas no final da reação foram $\mathrm{ZnO} \mathrm{Al}_{2} \mathrm{NiO}_{4}$, $\mathrm{Al}_{2} \mathrm{ZnO}_{4}$ e fase óxido contendo $\mathrm{Ni}$ e $\mathrm{Zn}$. Para verificar com mais detalhes o comportamento das fases na reação, foi feito o mapa ilustrado na Figura 62, onde constatou-se a formação do carbono em 30 min de reação. Além disso, um aumento e diminuição de intesidades foram observadas para as fases de $\mathrm{Ni}^{0}$ e $\mathrm{ZnO}$, respectivamente.

Figura 61 - Padrão de difração de raios $\mathrm{X}$ in situ do catalisador Ni/ZnAl-7 durante a atividade catalítica. Os símbolos $\alpha, \beta, \lambda, \delta, \gamma, \mathrm{o}, \mathrm{Ni}^{0}$ e $\mathrm{C}$ denotam a ocorrência das fases de $\mathrm{ZnO}, \mathrm{NiO}, \mathrm{ZrO}_{2}, \mathrm{Al}_{2} \mathrm{NiO}_{4}, \mathrm{Al}_{2} \mathrm{ZnO}_{4}$, fase óxida contendo Ni e Zn, Ni metálico e carbono nos catalisadores, respectivamente.

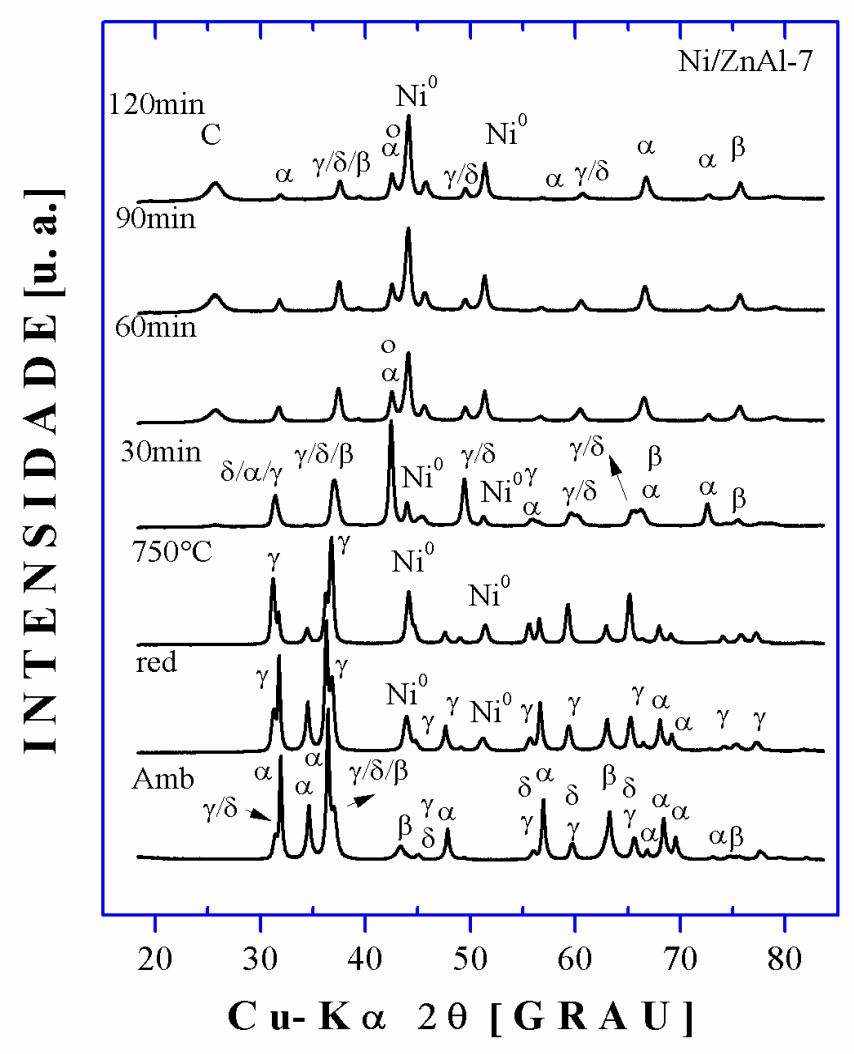

Fonte: Autoria própria 
Figura 62 - Mapa das intensidades dos padrões difração de raios X in situ durante o processo catalítico referente ao Ni/ZnAl-7.

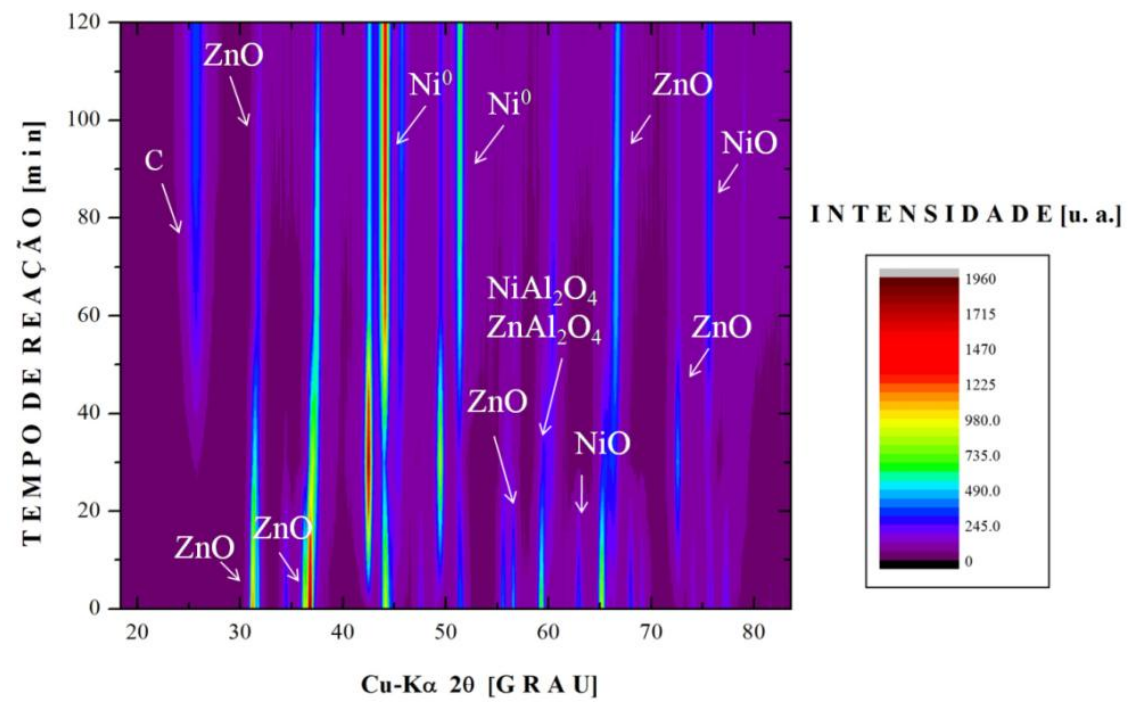

Fonte: Autoria própria.

O difratograma para o catalisador $\mathrm{Ni} / \mathrm{ZnAlZr}-7$ obtido na temperatura ambiente está aludido na Figura 63. A presença da fase de $\mathrm{ZnO}$ pode ser observada em torno de $2 \theta \sim 28^{\circ}$, $34^{\circ}, 36^{\circ}, 47^{\circ}, 54^{\circ}, 56^{\circ}, 63^{\circ}, 65^{\circ}, 66^{\circ}, 68^{\circ}, 69^{\circ}, 73^{\circ}, 77^{\circ}$ e $82^{\circ}$. Enquanto que as fases referentes ao $\mathrm{NiO}$ estão reportados em $2 \theta \sim 31^{\circ}, 36^{\circ}, 43^{\circ}$ e $63^{\circ}$. A presença das fases de espinélios (. $\mathrm{ZnAl}_{2} \mathrm{O}_{4}$ e $\mathrm{NiAl}_{2} \mathrm{O}_{4}$ ) aparecem em torno de $2 \theta \sim 45^{\circ}, 56^{\circ}, 59^{\circ}$ e $65^{\circ}$. E, por último, verificou-se as fases referentes ao $\mathrm{ZrO}_{2}$ em $2 \theta \sim 24^{\circ}, 28^{\circ}, 34^{\circ}, 49^{\circ}, 50^{\circ}$ e $56^{\circ}$. Durante a etapa de redução, claramente, notou-se o aumento referente a fase de $\mathrm{ZrO}_{2}\left(2 \theta \sim 28^{\circ}, 34^{\circ}, 36^{\circ}\right.$ e $\left.57^{\circ}\right)$ e o aparecimento de novos picos também associados ao $\mathrm{ZrO}_{2}$ em $2 \theta \sim 24^{\circ}, 41^{\circ}, 50^{\circ}, 52^{\circ}$ e $54^{\circ}$. Ao passo que o pico referente ao $\mathrm{Ni}^{0}$ foi observado em $2 \theta \sim 44^{\circ}$. Após a redução (na temperatura de $750^{\circ} \mathrm{C}$ ), uma pequena diminuição da intensidade e o desaparecimento dos picos atribuídos ao $\mathrm{ZnO}\left(2 \theta \sim 31,82^{\circ} ; 36,32^{\circ} ; 47,69^{\circ} ; 56,68^{\circ} ; 66,48^{\circ} ; 68,10^{\circ}\right.$ e $\left.69,21^{\circ}\right)$ foram verificados. Já na temperatura de reação ocorreu pouca mudança no comportamento do difratograma. No período de 30 a 90 min de reação, ocorreu um aumento nas intensidades dos picos associados ao $\mathrm{ZrO}_{2}$, que estão relacionados as fases cristalinas monoclínica e tetragonal . A 90 min de reação ocorreu a diminuição do pico relacionado a fase de $\mathrm{NiO}$ em $2 \theta \sim 36^{\circ}$, além do deslocamento do pico assinalado ao $\mathrm{Ni}^{0}$. Neste período, foi possível observar o aparecimento de carbono com baixa intensidade $\left(2 \theta \sim 25^{\circ}\right)$. Finalmente, a 120 min de reação, o comportamento é praticamente o mesmo, somente ocorre um deslocamento do pico referente ao $\mathrm{Ni}^{0}$. A Figura 64 ilustra um mapa das intensidades obtido da difração de raios X in situ para o catalisa- 
dor Ni/ZnAlZr-7. A formação do coque começa em 80 min de reação. O comportamento do NiO também pode ser verificado, onde se averigua sua redução.

Figura 63 - Padrão de difração de raios X in situ do catalisador Ni/ZnAlZr-7 durante a atividade catalítica. Os símbolos $\alpha, \beta, \lambda, \delta, \gamma, \mathrm{Ni}^{0}$ e $\mathrm{C}$ denotam a ocorrência das fases de $\mathrm{ZnO}, \mathrm{NiO}, \mathrm{ZrO}_{2}, \mathrm{Al}_{2} \mathrm{NiO}_{4}, \mathrm{Al}_{2} \mathrm{ZnO}_{4}, \mathrm{Ni}$ metálico e carbono nos catalisadores, respectivamente.

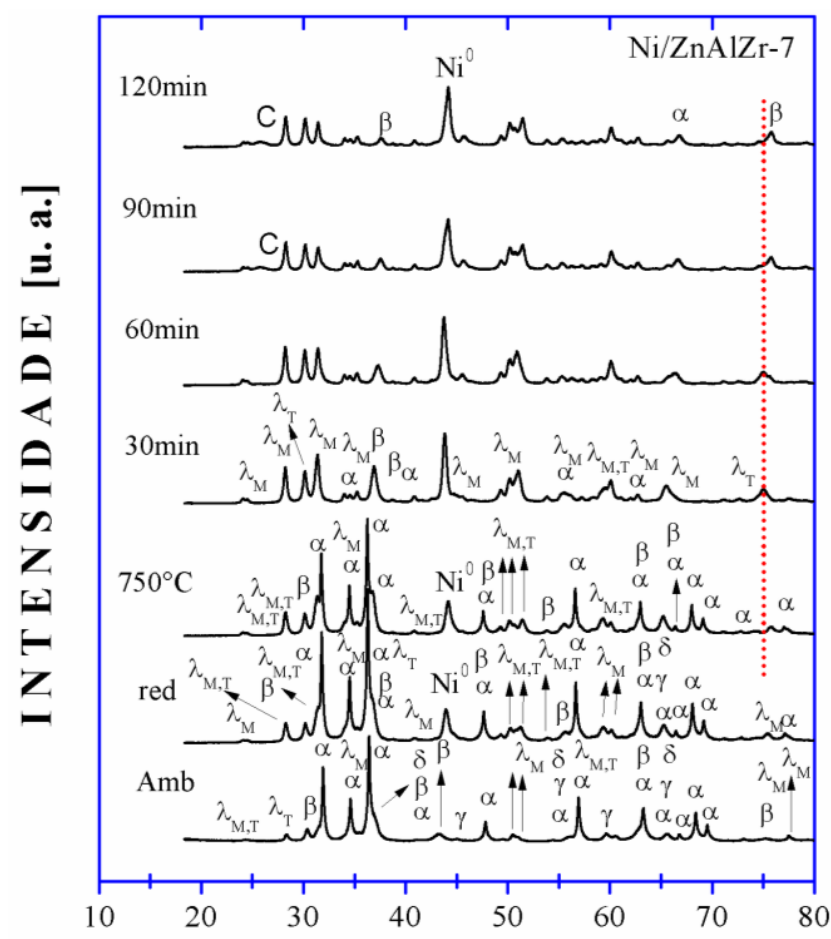

Fonte: Autoria própria.

\section{$\mathbf{C} \mathbf{u}-\mathbf{K} \alpha 2 \theta[\mathbf{G} \mathbf{R} \mathbf{A} \mathbf{U}]$}

Figura 64 - Mapa das intensidades dos padrões difração de raios X in situ durante o processo catalítico referente ao Ni/ZnAlZr-7.

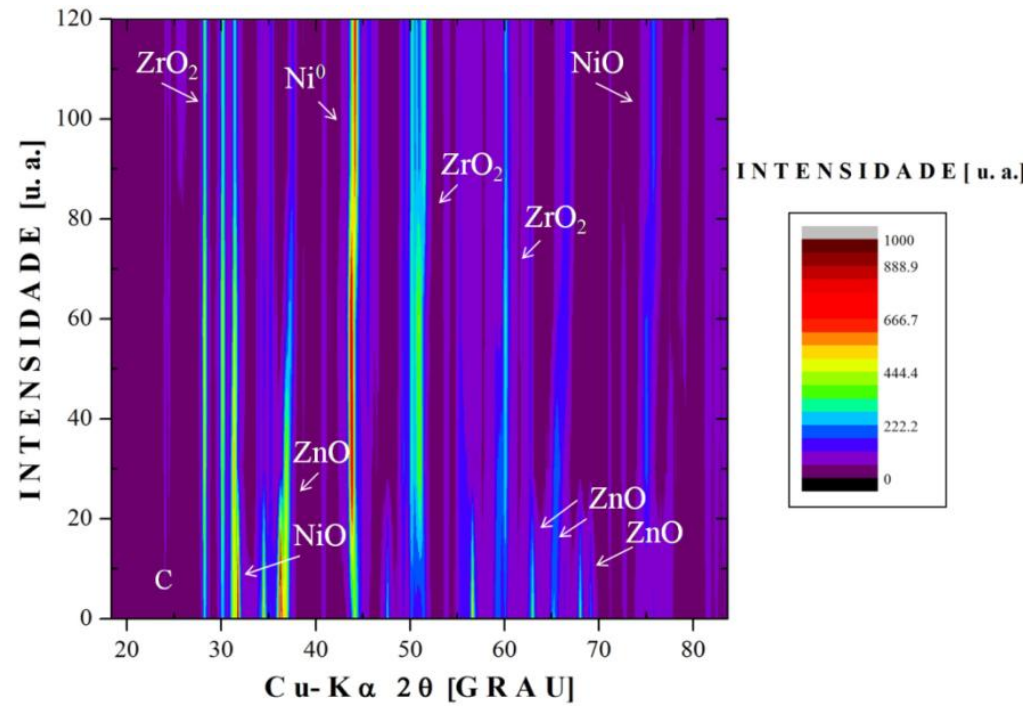

Fonte: Autoria própria. 
O padrão de difração de raios $\mathrm{X}$ do catalisador Ni/ZnZr-7 está reportados na Figura 65. Os resultados mostraram a presença da fase de $\mathrm{ZnO}\left(2 \theta \sim 31^{\circ}, 32^{\circ}, 34^{\circ}, 35^{\circ}, 36^{\circ}, 47^{\circ}, 54^{\circ}\right.$, $57^{\circ}, 58^{\circ}, 62^{\circ}, 63^{\circ}, 66^{\circ}, 67^{\circ}, 68^{\circ}, 69^{\circ}, 76^{\circ}$ e $\left.77^{\circ}\right)$, $\mathrm{NiO}\left(2 \theta \sim 37^{\circ}, 43^{\circ}, 63^{\circ}, 75^{\circ}\right.$ e 79$)$ e $\mathrm{ZrO}(\mathrm{mo}-$ noclínica e tetragonal). Durante a etapa de redução, verificou-se a diminuição e o desaparecimento dos picos referentes ao $\mathrm{NiO}$, paralelamente ocorreu o aparecimento do pico em $2 \theta \sim$ $44^{\circ}$ referente ao $\mathrm{Ni}^{0}$. No período de 30 min de reação, notou-se um pico de alta intensidade em $2 \theta \sim 42$, assinalado como $\mathrm{ZnO}$, ao mesmo tempo, averiguou-se um deslocamento e a diminuição do pico referente ao $\mathrm{Ni}^{0}\left(2 \theta \sim 43,99^{\circ}\right)$, provocada por uma oxidação deste metal. Passando para 60 min de reação, a presença de carbono de baixa intensidade em $2 \theta \sim 25,86^{\circ}$ foi constatada. A 90 min de reação, ocorreu uma diminuição dos picos referentes ao $\mathrm{ZrO}_{2}$ evidenciados em $2 \theta \sim 28,25^{\circ}, 30,14^{\circ}$ e $31,41^{\circ}$, além de um pequeno deslocamento para maiores ângulos do pico referente à fase de $\mathrm{Ni}^{0} \mathrm{em} 2 \theta \sim 44,15^{\circ}$. Finalmente, a 120 min, a mudança do gráfico não foi significativa em relação a 90 min de reação. No mapa da Figura 66, notouse claramente que as fases referentes ao $\mathrm{ZrO}_{2}$ permance durante toda a reação, enquanto que há uma diminuição da fase referente ao $\mathrm{ZnO}$. Por fim, notou-se claramente a presença da fase de carbono.

Figura 65 - Padrões de difração de raios $\mathrm{X}$ in situ do catalisador Ni/ZnZr-7 durante a atividade catalítica. Os símbolos $\alpha, \beta, \lambda, \mathrm{Ni}^{0}$ e $\mathrm{C}$ denotam a ocorrência das fases de $\mathrm{ZnO}, \mathrm{NiO}, \mathrm{ZrO}_{2}$, Ni metálico e carbono nos catalisadores, respectivamente.
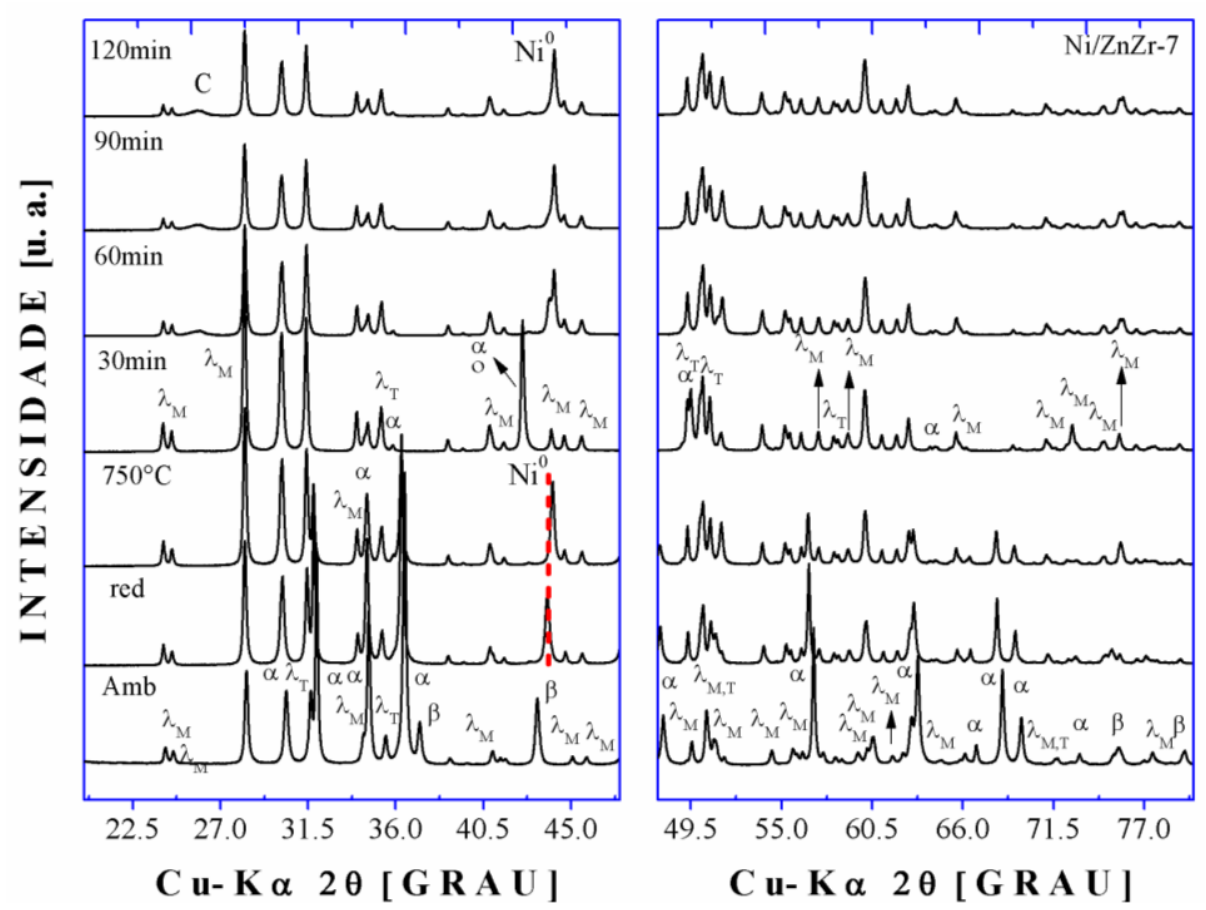

Fonte: Autoria própria 
Figura 66 - Mapa das intensidades dos padrões difração de raios X in situ durante o processo catalítico referente ao $\mathrm{Ni} / \mathrm{ZnZr}-7$.

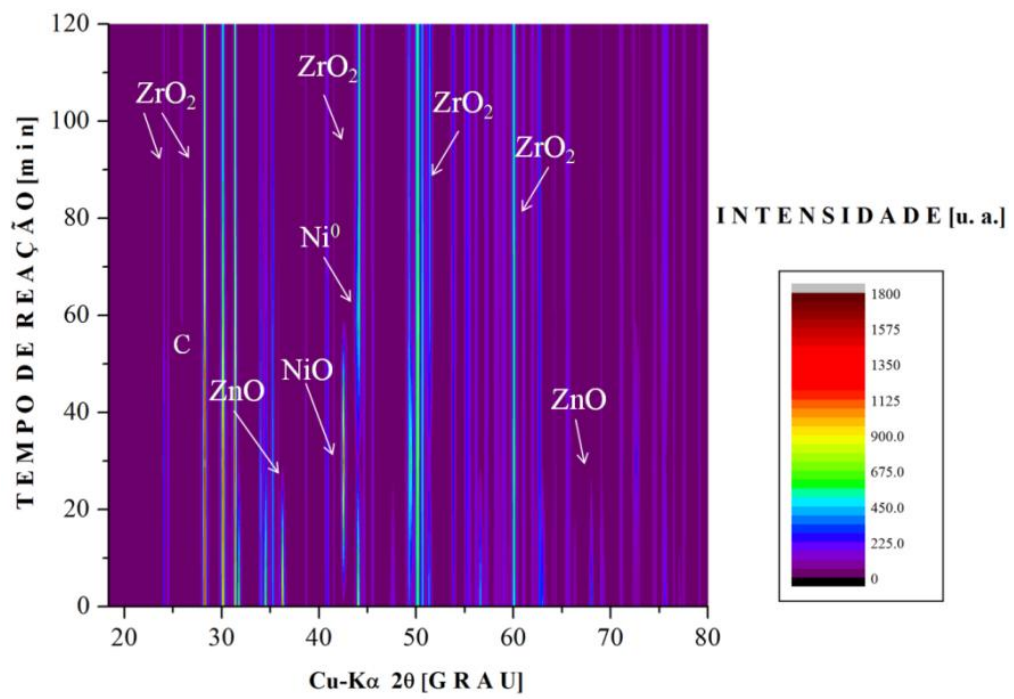

Fonte: Autoria própria.

\subsection{Estudo da formação de carbono dos catalisadores reduzidos a $550^{\circ}, \mathbf{6 5 0}^{\circ}$ e $750^{\circ} \mathrm{C}$.}

Para a analisar a formação e a quantidade do carbono, realizou-se a medida termogravimétrica das amostras após a reação para todos os catalisadores, com intuito de obter a taxa de carbono formado durante a reação (ver Tabela 20 ). Verificou-se que entre as amostras calcinadas a $550^{\circ} \mathrm{C}$, o catalisador $\mathrm{Ni} / \mathrm{ZnAlZr}-5$ apresentou a maior taxa de carbono formado em torno de $1,81 \times 10^{-3} \mathrm{gc} / \mathrm{gcat} \mathrm{h}$. Esse resultado corrobora com o fato do catalisador ter promovido à maior conversão do metano, além de ter sido influenciado pelas reações paralelas, a saber, reação de Boudouard $\left(2 \mathrm{CO} \rightleftarrows \mathrm{CO}_{2}+\mathrm{C}\right)$ e reversa da Shift. O consumo do carbono por outras reações paralelas podem ter influenciado na menor taxa de formação do mesmo no catalisador Ni/ZnAl-5 (3,05 × 10 $0^{-6}$ gc/gcat h) e Ni/ZnZr-5 $\left(3,46 \times 10^{-4}\right.$ gc/gcat h).

Para os catalisadores calcinados a $650^{\circ} \mathrm{C}$, a taxa de formação do carbono foi maior para a amostra Ni/ZnAlZr-6, em torno de 0,1 gc/gcat h. Enquanto que o catalisador Ni/ZnAl-6 apresentou a menor taxa de formação do mesmo, nesse caso, de 5,73 $\times 10^{-7} \mathrm{gc} / \mathrm{gcat} \mathrm{h}$. Esse resultado pode ser um reflexo da baixa decomposição do metano, por outro lado, a pequena quantidade de carbono formado pode ter reagido com o $\mathrm{CO}_{2}\left(\mathrm{CO}_{2}+\mathrm{C} \rightleftarrows 2 \mathrm{CO}\right)$ formando o $\mathrm{CO}$, o que explicaria a maior conversão do $\mathrm{CO}_{2}$, a menor formação de carbono e a contribuição para uma razão $\mathrm{H}_{2} / \mathrm{CO}$ baixa. 
A maior taxa de formação para dos catalisadores calcinados a $750^{\circ} \mathrm{C}$ ocorreu para a amostra Ni/ZnAl-7, em torno de 29,5 × $10^{-2}$ gc/gcat h. Para esse catalisador a reação de decomposição de metano foi baixa, o que leva a concluir que as reações, tal como, reação de Bourdouard pode ter favorecido a maior taxa de carbono. O catalisador Ni/ZnZr-7 apresentou a menor taxa de formação de carbono em torno de $14,1 \times 10^{-3} \mathrm{gc} / \mathrm{gcat}$ h. Os resultados verificados para esse catalisador também podem estar relacionados à reação inversa de desproporcionamento do CO. Em suma, notou-se que ocorreu à formação de carbono em todos os catalisadores, porém em quantidades diferentes. Além disso, nesse catalisadores a formação de carbono também foi influenciada pela reação reversa da shift, esse resultado foi constatado pela presença de $\mathrm{H}_{2} \mathrm{O}$ em pequena quantidade após as reações.

Tabela 20 - Taxa de formação do carbono Rc (gc/gcat h) obtida para os catalisadores a $550{ }^{\circ} \mathrm{C}, 650{ }^{\circ} \mathrm{C}$ e $750{ }^{\circ} \mathrm{C}$ através da análise termogravimétrica.

\begin{tabular}{cc}
\hline Catalisadores & $\begin{array}{c}\text { Taxa de formação do carbono Rc } \\
\text { (gc/gcat h) }\end{array}$ \\
\hline Ni/ZnAl-5 & $3,05 \times 10^{-6}$ \\
Ni/ZnAlZr-5 & $1,81 \times 10^{-3}$ \\
Ni/ZnZr-5 & $3,46 \times 10^{-4}$ \\
Ni/ZnAl-6 & $5,73 \times 10^{-7}$ \\
Ni/ZnAlZr-6 & $1,0 \times 10^{-1}$ \\
Ni/ZnZr-6 & $2,62 \times 10^{-3}$ \\
Ni/ZnAl-7 & $29,5 \times 10^{-2}$ \\
Ni/ZnAlZr-7 & $18,9 \times 10^{-2}$ \\
Ni/ZnZr-7 & $14,1 \times 10^{-3}$ \\
\hline
\end{tabular}

Fonte: Autoria própria.

Com intuito de obter informações sobre a estrutura do carbono, realizou-se a difração de raios X dos catalisadores após a reação de reforma, ver Figura 67(a). Pela difração dos catalisadores calcinados a $550^{\circ} \mathrm{C}$ não foi possível verificar o pico característico do coque. A não verificação do carbono nas amostras pode ser um reflexo da baixa concentração do carbono, isto é, insuficiente para ser detectada pela difração de raios X. Além disso, a não detecção do carbono também pode ser atribuído a presença de carbono amorfo. Deve-se ressaltar, em primeiro lugar, que no carbono amorfo as camadas de planos empilhados são orientados aleatoriamente, enquanto que o carbono grafite as camadas de planos tem uma ordem tri- 
dimensional fixada (AMINGTON, 1995). Para avaliar a formação do mesmo, foram coletados os espectros Raman, conforme ilustrados na Figura 67(b). Pelo método da análise do grupo fator para a cela unitária $\mathrm{P}_{3} / \mathrm{mmc}$ do carbono grafítico, as representações irredutíveis para os modos no centro da 1. ${ }^{\mathrm{a}}$ zona de Brillouin são $\Gamma=2 \mathrm{E}_{2 g} \oplus \mathrm{E}_{u} \oplus 2 \mathrm{~B}_{2 g} \oplus \mathrm{A}_{2 u}$. Logo, são esperados 12 vibrações para o carbono grafítico, sendo 3 acústicas $\left(\mathrm{A}_{2 u} \oplus \mathrm{E}_{1 u}\right), 3$ ativas no infravermelho $\left(\mathrm{A}_{2 u} \oplus \mathrm{E}_{1 u}\right), 4$ ativas no Raman $\left(2 \mathrm{E}_{2 g}\right)$ e 2 silenciosos $\left(2 \mathrm{~B}_{1 g}\right)$ (NEMANICH et al., 1977). Pelos espectros Raman da Figura 67b, verificou-se duas bandas para todos os catalisadores, porém na presença de ruídos, demonstrando a dificuldade de detecção das mesmas devido à baixa quantidade de carbono formado. Logo, uma banda em $\sim 1594 \mathrm{~cm}^{-1}$, atribuída o carbono aromático ou, mais especificamente, às ligações de estiramento de todos os pares de átomos $\mathrm{sp}^{2}$ dos anéis foi observada. Outra banda em $\sim 1350 \mathrm{~cm}^{-1}$, consequiência das vibrações de respiração dos átomos $\mathrm{sp}^{2}$ nos anéis, sendo que estas bandas são conhecidas popularmente por bandas G e D, respectivamente. Ressaltando que esse modo presente em $\sim 1350 \mathrm{~cm}^{-1}$, tem sido atribuído a desordem induzida pelo processo de distorção da rede da estrutura de grafite. Pela presença não definida das bandas há uma dificuldade na identificação da banda D' nesses espectros.

Figura 67 - (a) Difração de raios $X$ dos catalisadores tratados a $550^{\circ} \mathrm{C}$ ( Ni/ZnAl-5, Ni/ZnAlZr-5 e Ni/ZnZr-5) após a reação; (b) Espectros Raman dos catalisadores (Ni/ZnAl-5, Ni/ZnAlZr-5 e Ni/ZnZr-5) após a reação.
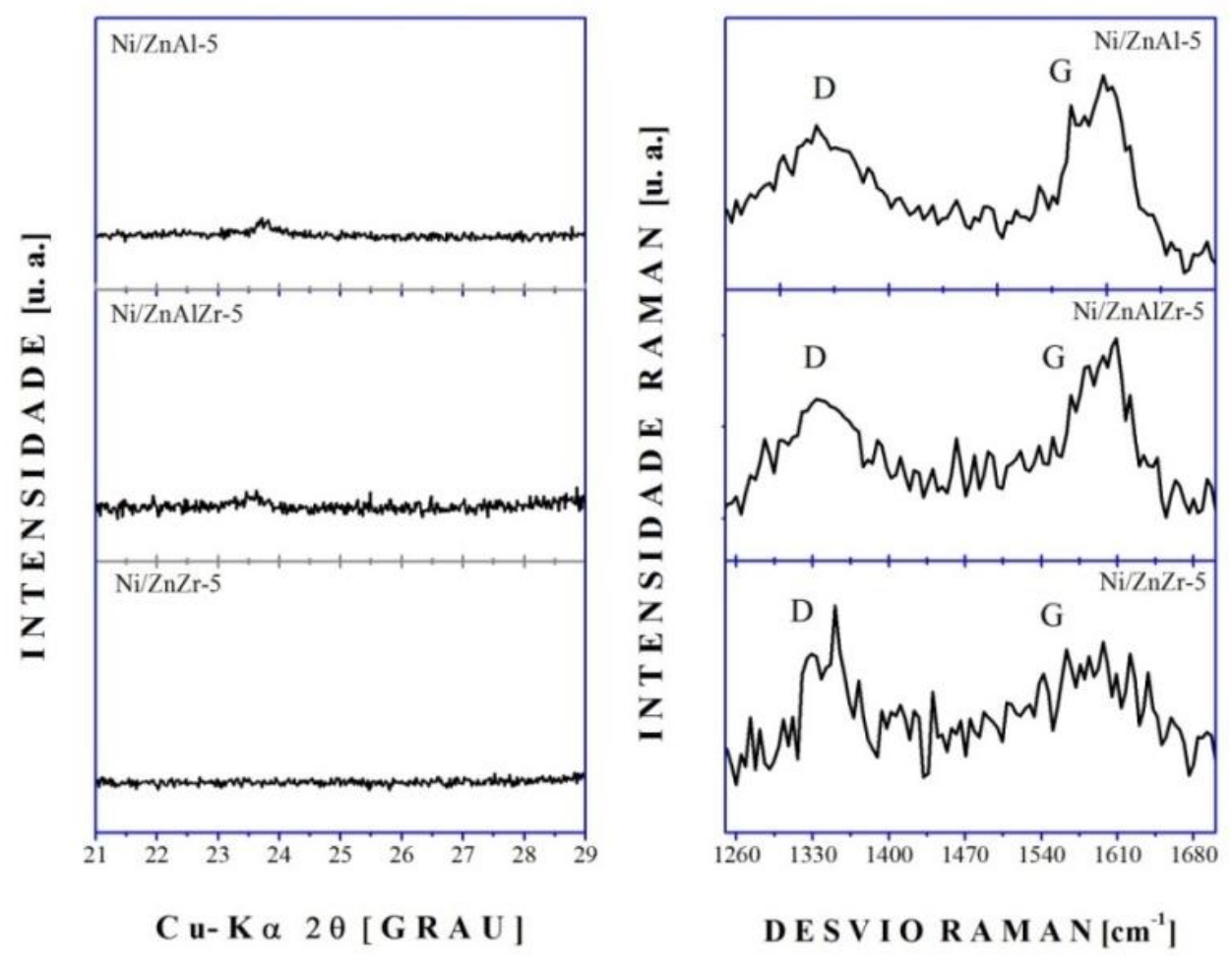

Fonte: Autoria própria. 
Padrões de difração de raios $\mathrm{X}$ dos catalisadores tratados a $650^{\circ} \mathrm{C}$ após a reação de reforma seca do metano estão ilustrados na Figura 68a. Um pico de difração em $2 \theta \sim 26,2$ atribuído ao carbono grafítico com espaçamento basal igual a 3,398 $\AA$ (hkl = 002) foi apenas constatado na amostra Ni/ZnAlZr-6. A não identificação do pico nos outros catalisadores podem estar relacionada à pequena quantidade de carbono formado após reação, como reportado na taxa de carbono formado (ver Tabela 20). Além disso, foi possível verificar somente no catalisador Ni/ZnAlZr-6 um pico de baixa intensidade referente ao $\mathrm{Ni}^{0}$. Na Figura $68 \mathrm{~b}$ estão reportados os espectros Raman à temperatura ambiente do carbono obtido para os catalisadores Ni/ZnAl-6, Ni/ZnAlZr-6 e Ni/ZnZr-6 com respectivos números no topo de cada banda, onde se observa a presença das bandas D (1342, 1347 e 1347 para os catalisadores Ni/ZnAl-6, Ni/ZnAlZr-6 e Ni/ZnZr-6, respectivamente) e G (1580, 1589 e 1576, respectivamente), além de um ombro correspondente a banda D', juntamente com a banda D, correspondem a desordem induzida pelo efeito de distorção da rede e pelo tamanho finito de partículas.

Figura 68 - (a) Difração de raios $X$ dos catalisadores tratados a $650^{\circ} \mathrm{C}(\mathrm{Ni} / \mathrm{ZnAl}-6, \mathrm{Ni} / \mathrm{ZnAlZr}-6$ e Ni/ZnZr-6) após a reação; (b) Espectros Raman dos catalisadores (Ni/ZnAl-6, Ni/ZnAlZr-6 e Ni/ZnZr-6) após a reação.
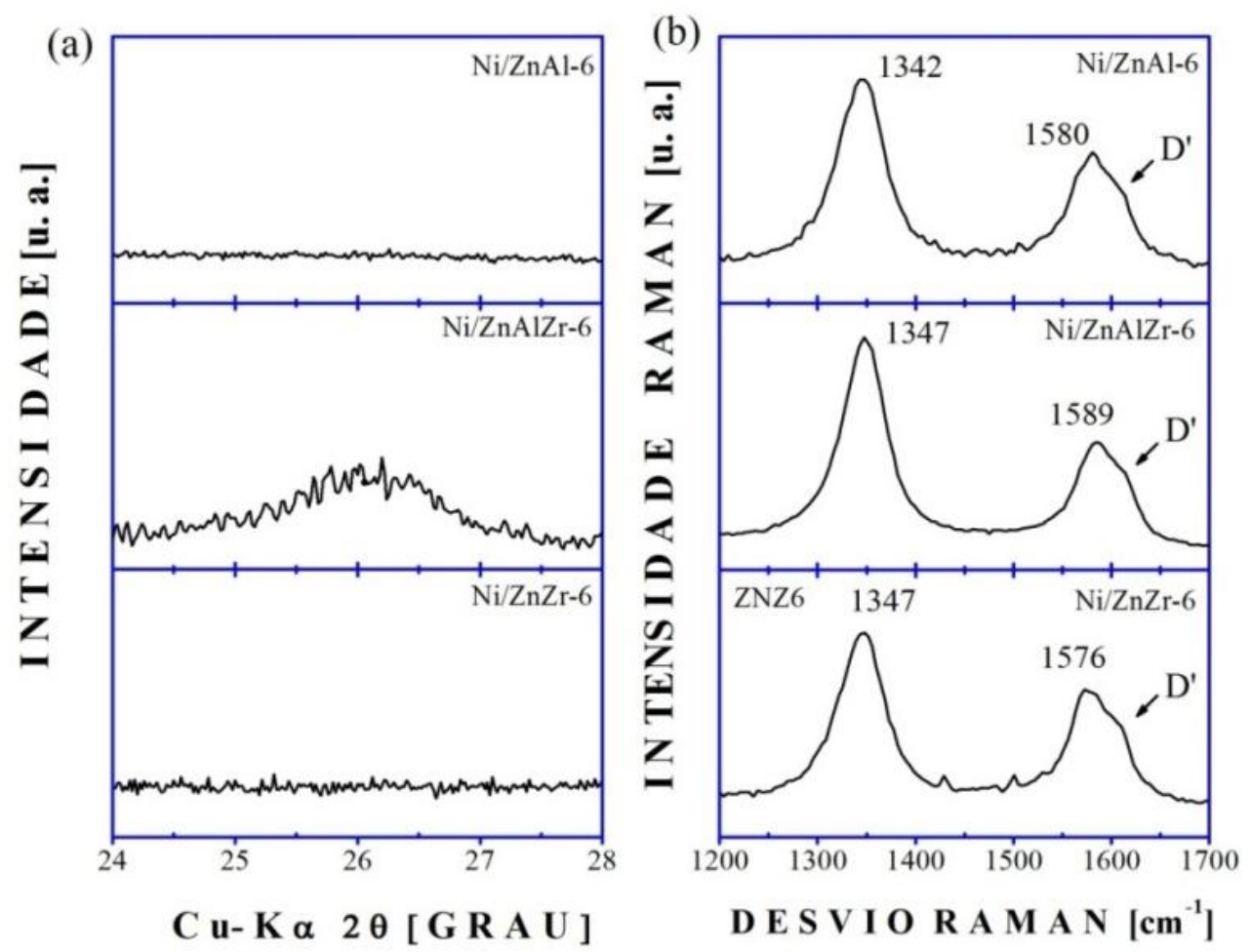

Fonte: Autoria própria.

Pelos resultados de difração de raiosX ilustrado na Figura 69, verificou-se que os catalisadores $\mathrm{Ni} / \mathrm{ZnAl}-7$ e Ni/ZnAlZr-7 apresentaram picos referentes ao carbono com maior in- 
tensidade, enquanto que o mesmo pico aparece no catalisador Ni/ZnZr-7, porém com baixa intensidade. Enquanto que os resultados de espectroscopia Raman (Figura 69b) mostraram as bandas bem definidas referentes ao carbono grafítico, para os catalisadores Ni/ZnAl-7 e $\mathrm{Ni} / \mathrm{ZnAlZr}-7$, no quais aparece mais bem definida, enquanto que no catalisador Ni/ZnZr-7 essas bandas foram obtidas com ruídos. Esse fato pode estar relacionado a menor quantidade de carbono formado, como observado na Tabela 20. Além disso, pode-se observar a presença das fases de $\mathrm{Ni}^{0}$, de alta intensidade, nos catalisadores $\mathrm{Ni} / \mathrm{ZnAl}-7$ e Ni/ZnAlZr-7, por outro lado, o Ni/ZnZr-7 apresentou um pico de carbono de baixa inensidade. Pelos resultados de espectroscopia Raman, notou-se a presença das bandas D (1340, 1348 e $1349 \mathrm{~cm}^{-1}$ para os catalisadores Ni/ZnAl-7, Ni/ZnAlZr-7 e Ni/ZnZr-7, respectivamente) e G (1574,1594 e 1589 $\mathrm{cm}^{-1}$ para os catalisadores $\mathrm{Ni} / \mathrm{ZnAl}-7, \mathrm{Ni} / \mathrm{ZnAlZr}-7$ e Ni/ZnZr-7,respectivamente), além de observar a presença da banda D'.

Figura 69 - (a) Difração de raios $X$ dos catalisadores tratados a $750^{\circ} \mathrm{C}(\mathrm{Ni} / \mathrm{ZnAl}-7, \mathrm{Ni} / \mathrm{ZnAlZr}-7$ e Ni/ZnZr-7) após a reação; (b) Espectros Raman dos catalisadores (Ni/ZnAl-7, Ni/ZnAlZr-7 e Ni/ZnZr-7) após a reação.
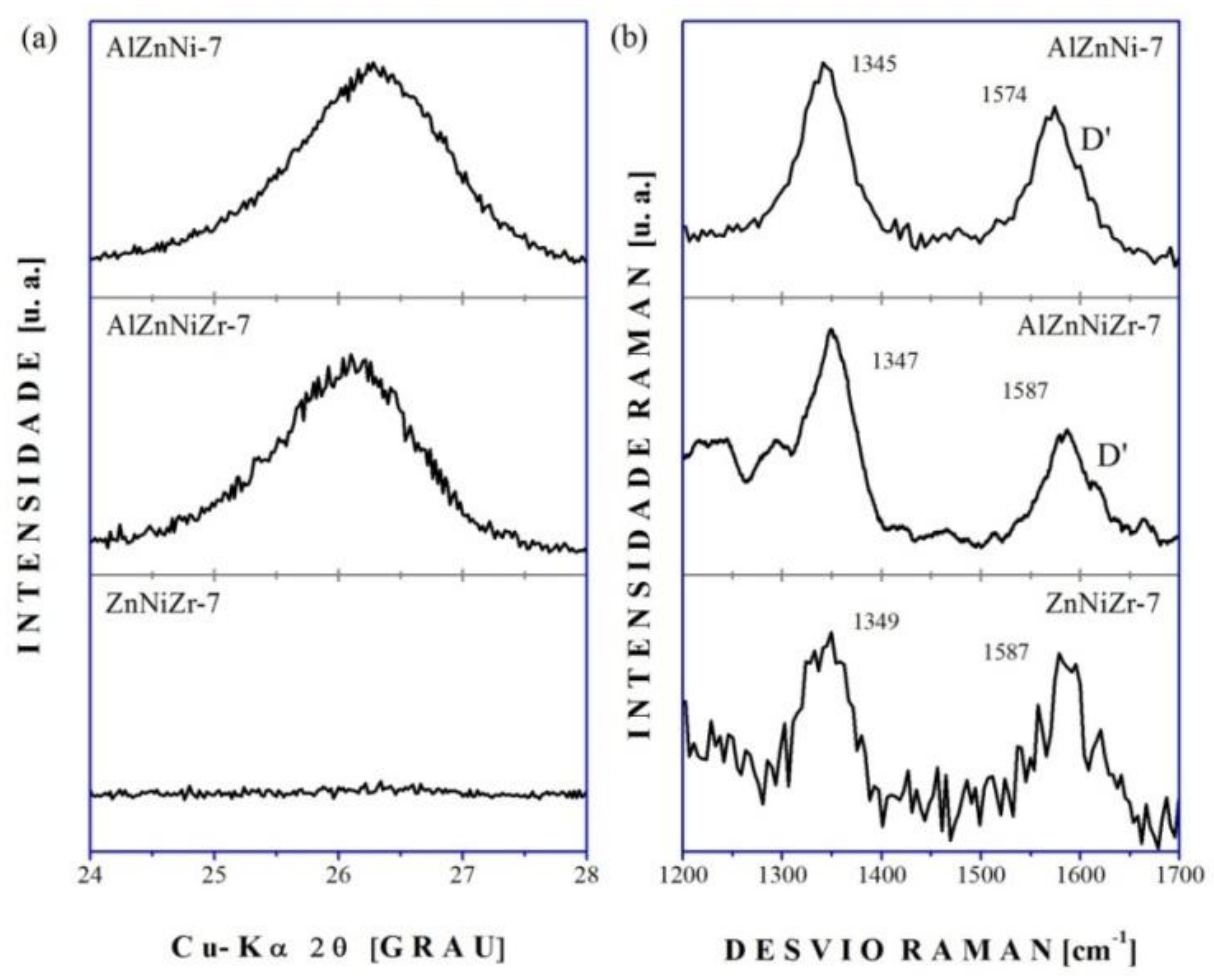

Fonte: Autoria própria.

O efeito da calcinação sobre a morfologia dos catalisadores Ni/ZnAl-5, Ni/ZnAlZr-5e Ni/ZnZr-5 foi investigado pela microscopia eletrônica de varredura, assim como após a reação estão ilustrados na Figura 70. A morfologia para o catalisador a $550^{\circ} \mathrm{C}$ mostrou uma dife- 
rença em relação à morfologia do precursor, além do mais, os catalisadores derivados de hidrotalcitas tiveram uma morfologia mais próxima. Todos os catalisadores apresentaram óxidos aglomerados, além de apresentar formas irregulares e porosidade ( ver Figura 70a/b/ c). Após a reação percebe-se uma morfologia diferenciada em relação ao catalisador antes da reação. $\mathrm{O}$ fato das amostras terem passado pelo processo de redução, e em seguida pela reação, constatou-se um processo maior de aglomeração. Embora tenha sido observado a presença do carbono pela espectroscopia Raman, não foi possível verificar a formação de coque pela microscopia eletrônica de varredura em nenhuma das amostras estudadas ( Figura 70d/e/f).

Figura 70 - Microscopia eletrônica de varredura dos catalisadores calcinados a $550^{\circ} \mathrm{C}$ (a) Ni/ZnAl-5 (b) $\mathrm{Ni} / Z n A l Z r-5$ and (c) Ni/ZnZr-5. Além dos catalisadores após a reação de reforma seca do metano (d) Ni/ZnAl-5 (e) Ni/ZnAlZr-5 e (f) Ni/ZnZr-5.
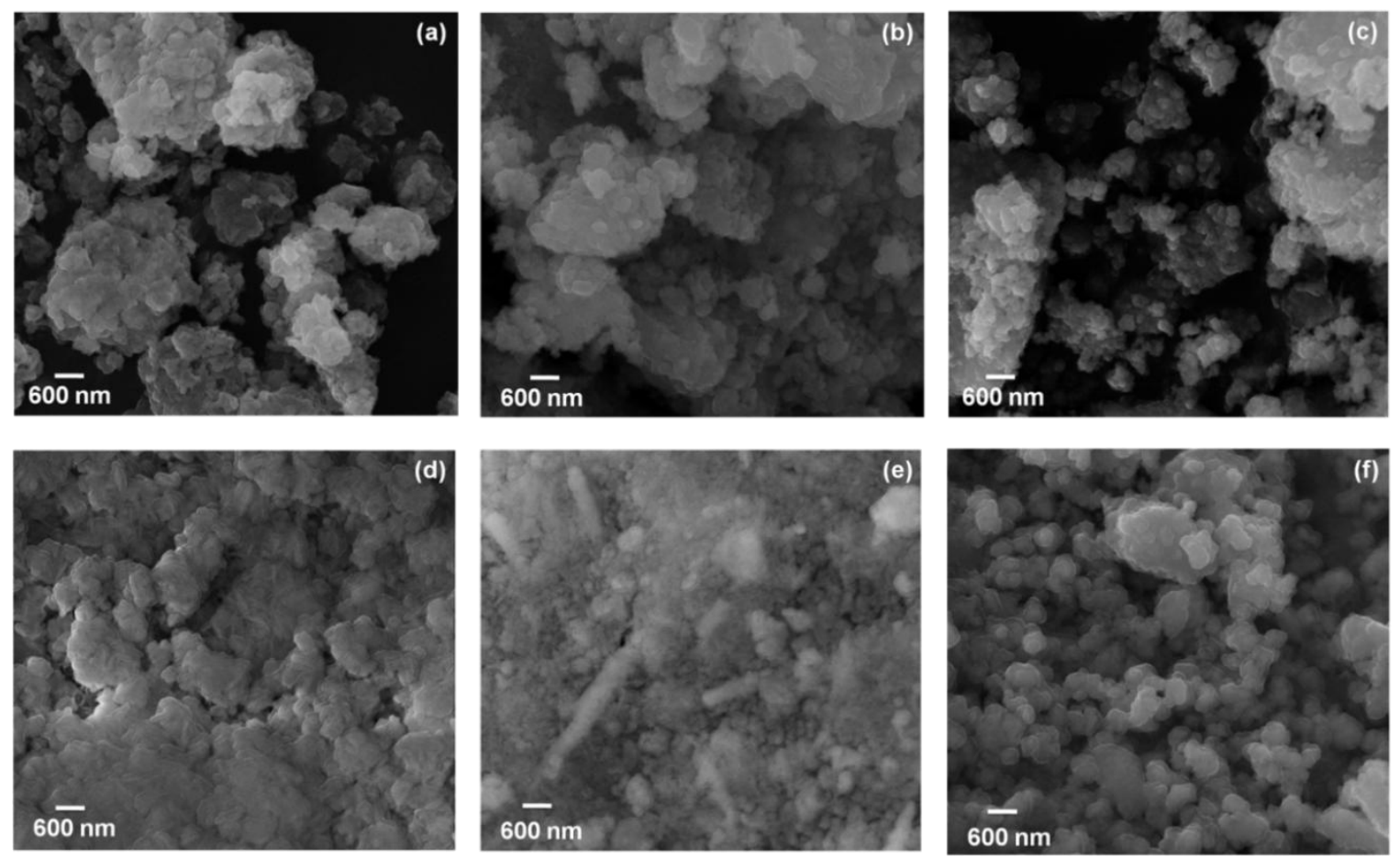

Fonte: Autoria própria.

A Figura $71(\mathrm{a} / \mathrm{b} / \mathrm{c})$ ilustra a microscopia eletrônica de varredura para os catalisadores calcinados a $650^{\circ} \mathrm{C}$. Pelas imagens, constatou-se que o catalisador Ni/ZnAl-6 apresentou um comportamento diferenciado em relação aos catalisadores Ni/ZnAlZr-6 e Ni/ZnZr-6. O catalisador Ni/ZnAl-6 mostrou uma porosidade maior em relação aos outros catalisadores, além de exibir formas mais regulares. O crescimento do cristal com um aumento da temperatura promoveu o processo de aglomeração nos catalisadores. Esse comportamento também foi observado após a reação ( ver Figura 71d/e/f), principalmente no catalisador Ni/ZnZr-6. O carbono 
foi observado somente nos catalisadores Ni/ZnAl-6 e Ni/ZnAlZr-6, neste último, com uma morfologia mais filamentosa, evidenciando que o carbono grafítico foi apresentado na forma de filamento, bem como enfatizado no trabalho de Yang 1989, o qual concluiu pelos estudos de microestrutura que os filamentos equivalem a carbono grafítico com estrutura “fishbone”(YANG, 1989). Não foi possível verificar a formação de carbono no catalisador $\mathrm{Ni} / \mathrm{ZnZr}$-6, embora este tenha apresentado uma quantidade maior de carbono em relação ao catalisador Ni/ZnAl-6.

Figura 71 - Microscopia eletrônica de varredura dos catalisadores calcinados a $650^{\circ} \mathrm{C}$ (a) Ni/ZnAl-6 (b) Ni/ZnAlZr-6 e (c) Ni/ZnZr-5. Além dos catalisadores após a reação de reforma seca do metano (d) Ni/ZnAl-6 (e) Ni/ZnAlZr-6 e (f) Ni/ZnZr-6.
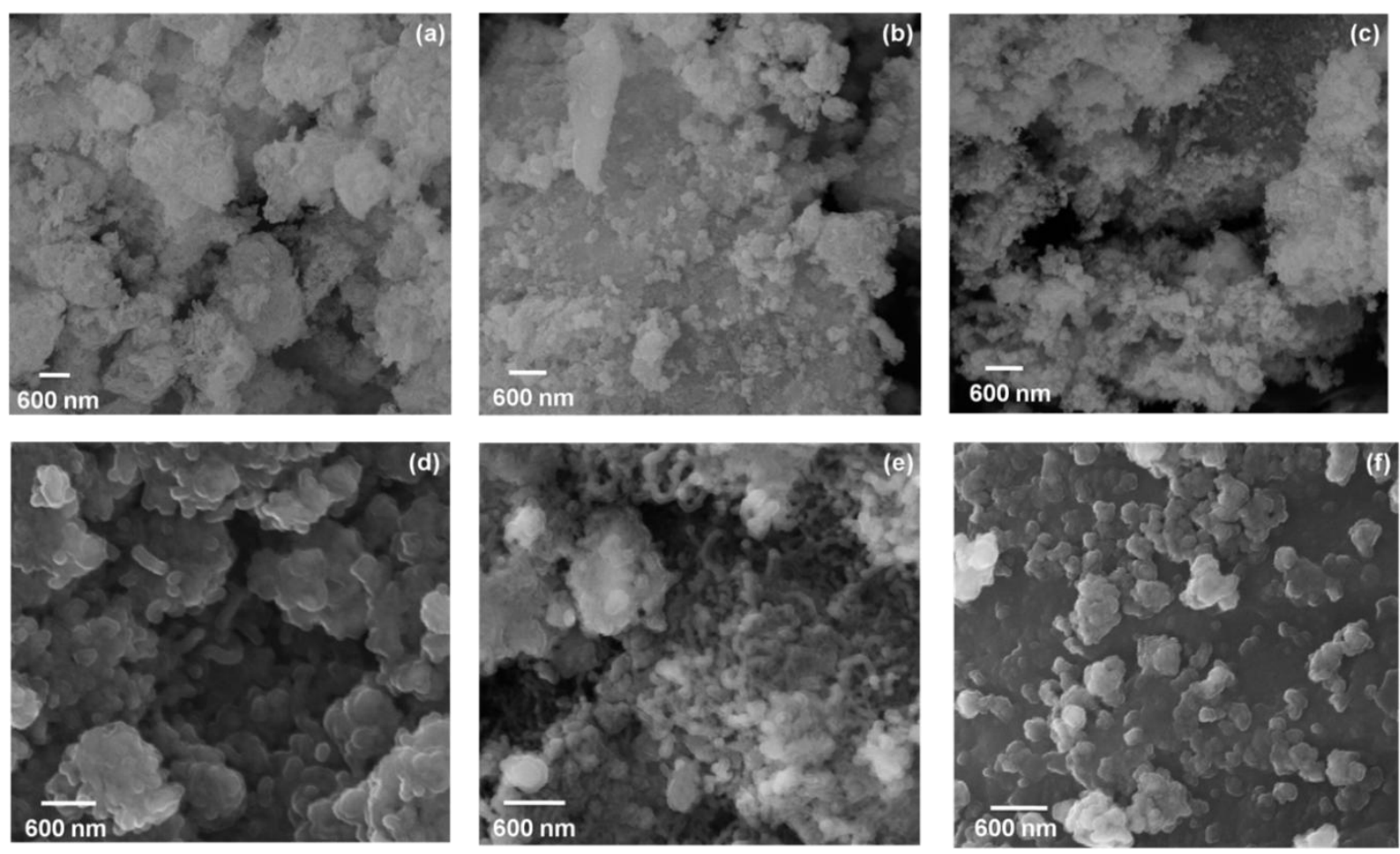

Fonte: Autoria própria

A morfologia dos catalisadores Ni/ZnAl-7, Ni/ZnAlZr-7 e Ni/ZnZr-7 está reportada na Figura $72(\mathrm{a} / \mathrm{b} / \mathrm{c})$. O tratamento térmico feito em alta temperatura promoveu um maior transporte de massa provocando, com isso, o processo de sinterização das amostras. A morfologia referente a formação de carbono para os catalisadores Ni/ZnAl-7, Ni/ZnAlZr-7 e Ni/ZnZr-7 está ilustrado na Figura 72 (d/e/f), respectivamente. Após a etapa de reação, verificou-se a formação de carbono filamentoso misturado com as partículas dos catalisadores em todas as amostras. No entanto, o catalisador Ni/ZnAl-7 apresentou um filamento menor em relação aos outros catalisadores do grupo. 
Figura 72 - Microscopia eletrônica de varredura dos catalisadores calcinados a $750^{\circ} \mathrm{C}$ (a) $\mathrm{Ni} / \mathrm{ZnAl}-7$ (b) $\mathrm{Ni} / Z n A l Z r-7$ e (c) Ni/ZnZr-7. Além dos catalisadores após a reação de reforma seca do metano (d) Ni/ZnAl-7 (e) $\mathrm{Ni} / \mathrm{ZnAlZr-7}$ e (f) Ni/ZnZr-7.
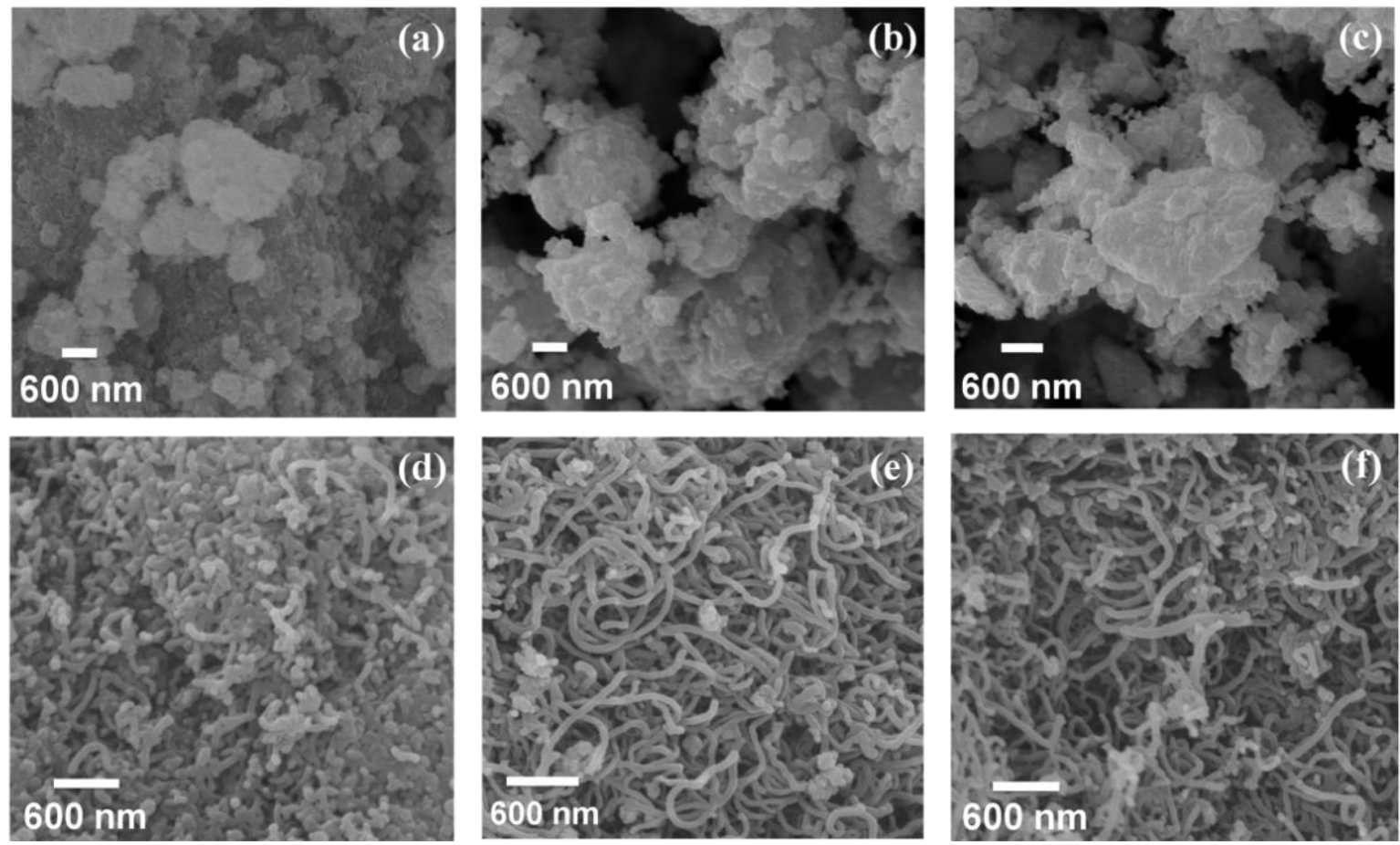

Fonte: Autoria própria.

\subsubsection{Reação com os catalisadores reduzidos a $750^{\circ} \mathrm{C}$}

Os catalisadores reduzidos a $750^{\circ} \mathrm{C}$ apresentaram conversões menores em relação aos catalisadores reportados acima. Na Figura 73 estão reportadas as conversões referentes à conversão dos catalisadores calcinados a $650^{\circ} \mathrm{C}$. Pelos resultados, constatou-se que as conversões para o $\mathrm{CH}_{4}$ e $\mathrm{CO}_{2}$ foram baixas. A conversão para o catalisador Ni/ZnAl-6 foi em torno de $24 \%$ para o $\mathrm{CO}_{2}$, enquanto que para o $\mathrm{CH}_{4}$ foi de $16 \%$. O catalisador Ni/ZnAlZr-6 apresentou uma conversão diferenciada em relação aos demais catalisadores, uma vez que a conversão para o $\mathrm{CH}_{4}$ foi maior em relação ao $\mathrm{CO}_{2}$. A conversão do $\mathrm{CH}_{4}$ foi em torno de $23 \%$, enquanto que a conversão do $\mathrm{CO}_{2}$ iniciou-se com uma conversão de $8 \%$, terminando com $5 \%$ de conversão. E finalmente, o catalisador Ni/ZnZr-6 exibiu um uma conversão inicial de $11 \%$, terminando com uma conversão de $16 \%$ para o $\mathrm{CO}_{2}$. A conversão do $\mathrm{CH}_{4}$ foi menor em relação ao $\mathrm{CO}_{2}$, apresentando um valor em torno de $8 \%$ e terminando com $4 \%$ de conversão. A razão $\mathrm{H}_{2} / \mathrm{CO}$ do Ni/ZnAl-6 e Ni/ZnAlZr-6 foi de 0,47 e 0,44, respectivamente. Para os catalisadores 
Ni/ZnZr-6 a razão $\mathrm{H}_{2} / \mathrm{CO}$ foi em torno de 0,33 . Logo, observou-se que todos os valores para razão $\mathrm{H}_{2} / \mathrm{CO}$ foi menor que 1 , demonstrando maior seletividade para o CO.

A redução feita a $750^{\circ} \mathrm{C}$ promoveu, inicialmente, uma redução completa das fases de níquel. Ao ser reduzido durante 1h, promoveu o processo de aglomeração da fase ativa pela migração das partículas metálicas. Desse modo, gerando uma menor conversão para o $\mathrm{CH}_{4}$ principalmente para os catalisadores Ni/ZnAl-6 e Ni/ZnZr-6. Ainda na Figura 73, notouse que o catalisador Ni/ZnAlZr-6 apresentou um comportamento diferenciado, pois sua conversão foi maior para o $\mathrm{CH}_{4}$ em relação ao $\mathrm{CO}_{2}$. A diminuição da área relativa as outras fases responsáveis pelo processo de adsorção do $\mathrm{CO}_{2}$ explica essa baixa conversão para o mesmo.

Figura 73 - Reações realizadas com os catalisadores calcinados a $650^{\circ} \mathrm{C}$ e reduzidos a $750^{\circ} \mathrm{C}$.
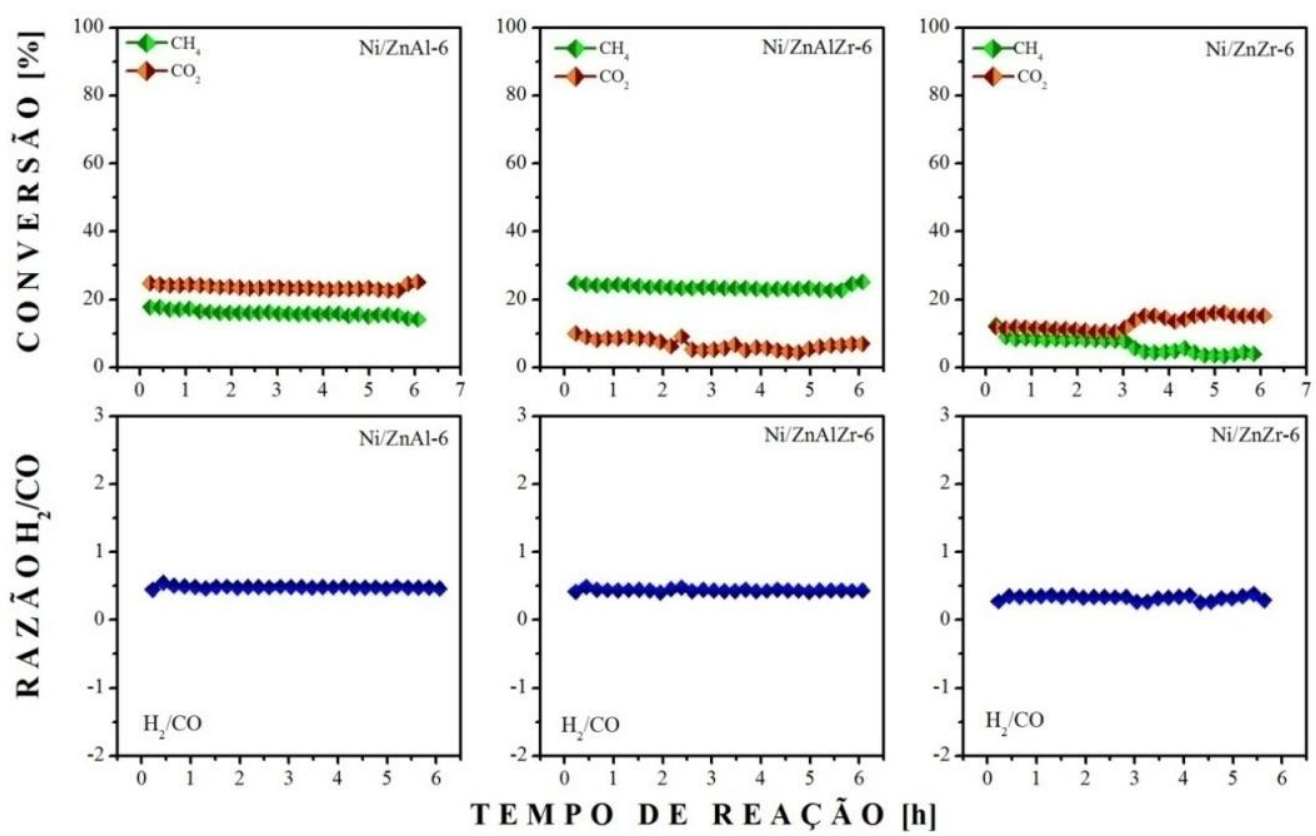

Fonte: Autoria própria.

Analisando o gráfico da Figura 74 referente aos catalisadores reduzidos e calcinados a $750^{\circ} \mathrm{C}$, verificou-se que a diferença na conversão do $\mathrm{CH}_{4}$ é baixa. $\mathrm{O}$ catalisador $\mathrm{Ni} / \mathrm{ZnAl}-7$ obteve uma conversão em torno de $16 \%$ em relação aos catalisadores Ni/ZnAlZr-7 e $\mathrm{Ni} / Z n Z r-7$. Para o catalisador Ni/ZnZr-7, a conversão ficou em torno de $20 \%$ permanecendo constante durante toda a período de reação. Passando para Ni/ZnAlZr-7, notou-se que o mesmo não permaneceu constante durante as 6 h de reação, pois iniciou-se com uma conversão $30 \%$ e após uma e meia de reação ocorreu uma diminuição para de $19 \%$ de conversão. A conversão para a molécula de $\mathrm{CO}_{2}$ ficou em torno de $44 \%$ para o catalisador $\mathrm{Ni} / \mathrm{ZnAl}-7$ e $31 \%$ para o catalisador Ni/ZnZr-7. Para o catalisador Ni/ZnAlZr-7 também ocorreu uma variação 
da conversão no decorrer do tempo, iniciando em com $40 \%$ de reação e obtendo uma pequena diminuição na conversão para $33 \%$. Pelos resultados obtidos pela razão $\mathrm{H}_{2} / \mathrm{CO}$, verificou-se que a variação é pouco perceptível, uma vez que os catalisadores apresentaram razões abaixo de 1, demonstrando uma maior seletividade para a formação de CO. Essa baixa razão é favorecida pela reação reversa gás-água, uma vez que esta ocorreu consumindo o $\mathrm{H}_{2}$ e formando CO. Como já reportado acima, os sítios básicos das amostras promoveram a adsorção da molécula de $\mathrm{CO}_{2}$

Comparando esses resultados com as reações feitas com a redução levando em conta o pico máximo de redução, notou-se que os resultados foram inferiores. Assim como explanado acima, deve ter ocorrido o processo de aglomeração tanto da fase ativa, quanto das outras fases oxidas presentes, com isso diminuindo na conversão do $\mathrm{CH}_{4}$ e $\mathrm{CO}_{2}$. A maior conversão para $\mathrm{o} \mathrm{CO}_{2}$ está relacionada ao processo de aglomeração da fase ativa, prmovendo o transporte de massa. Dessa forma os sítios básicos e ácidos presentes nas outras fases ficaram expostos facilitando a adsorção do $\mathrm{CO}_{2}$. É evidente que não se pode renegar que nessa temperatura as outras reações paralelas são favoráveis, tais como, a reação inversa de desproporcionamento do CO. Para exemplificar melhor esse processo de aglomeração, a Figura 75a ilustra a sinterização tanto da fase ativa, gerando partículas maiores e de baixa área e a Figura 75 b mostra o processo de aglomeração das fases oxidas presentes.

Figura 74 - Reação dos catalisadores calcinados a $750^{\circ} \mathrm{C}$ e reduzidos a $750^{\circ} \mathrm{C}$.

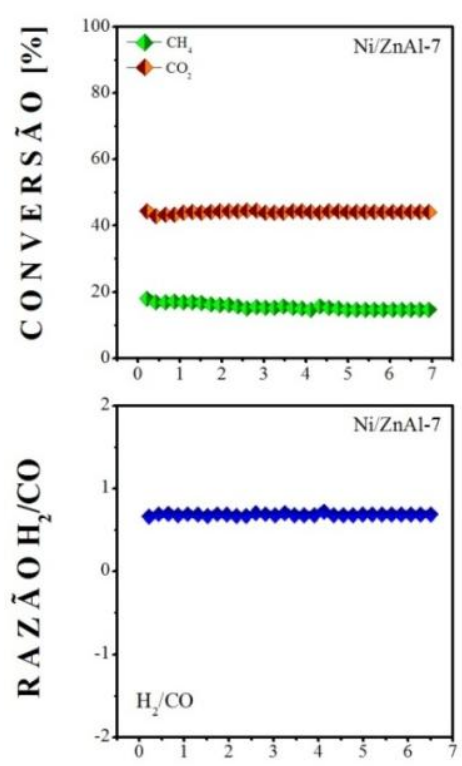

onte: Autoria própria.
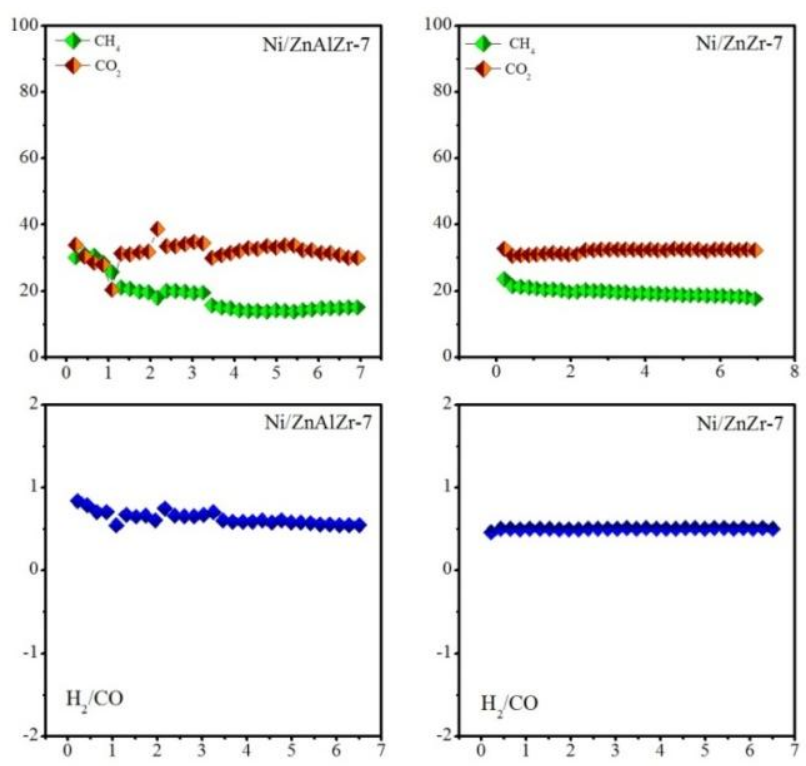

TEMPO DE REACCÃ O [h] 
Figura 75 - Sinterização da fase ativa através da migração dos átomos e cluster para formar partículas maiores : (1) representa a etapa de sinterização e (2) etapa de crescimento da partícula.

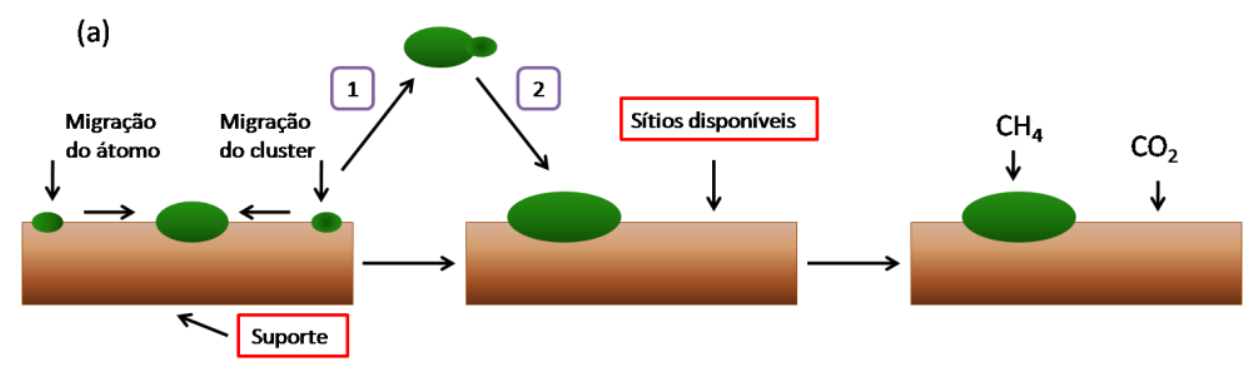

(b)

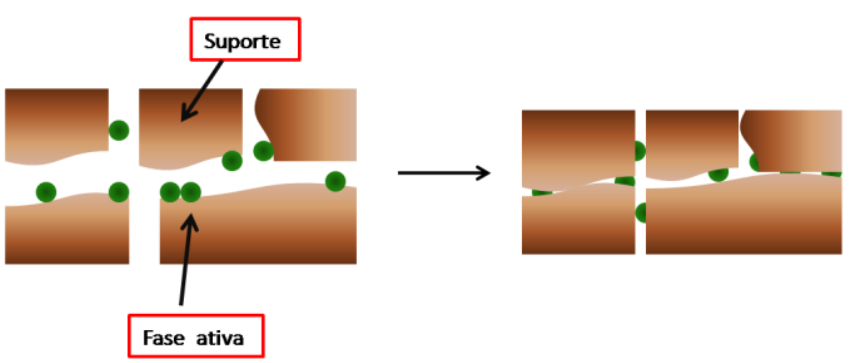

Fonte: Adaptado do trabalho de (NEWNHAM, 2012)

\subsection{Estudo do carbono formado dos catalisadores reduzidos a $750^{\circ} \mathrm{C}$}

A Figura 76 ilustra a difração de raios X e a espectroscopia Raman para os catalisadores calcinados a $650^{\circ} \mathrm{C}$. Pelos resultados de difração não foi possível verificar a formação de carbono para todas as amostras. Pelos resultados de espectroscopia Raman, notou-se a presença das bandas (G e D) referentes ao carbono, porém não intensas, decorrente da baixa quantidade de carbono formado. Esses resultados corrobora com os apresentados na conversão do $\mathrm{CH}_{4}$ e $\mathrm{CO}_{2}$ para esses catalisadores. Como reportado acima, a temperatura utilizada na redução dos catalisadores promoveu aglomeração das fases presentes, e , portanto não favoreceu as reações de decomposição do metano e as reações paralelas.

A difração de raios X e a espectroscopia Raman para os catalisadores calcinados a $750^{\circ} \mathrm{C}$ cuja redução foi realizada a $750^{\circ} \mathrm{C}$ estão ilustrados na Figura 76 , onde não foi possível observar a presença do carbono para os catalisadores pela difração de raios X. Pelos resultados, ocorreu a formação de carbono amorfo ou uma baixa formação do carbono, sendo impossível a identificação do mesmo no difratogram de raio $\mathrm{X}$. Pelo resultado de espectroscopia Raman foi possível verificar somente a banda de carbono grafítico no catalisador Ni/ZnAlZr7, onde foi possível observar todos os modos característicos do carbono ( modo D, D' e G). Nos resultados apresentados para os catalisadores Ni/ZnAl-7 e Ni/ZnZr-7ocorreu uma baixa formação de carbono. 
Figura 76 - (a) Difração de raios $X$ dos catalisadores tratados a $650^{\circ} \mathrm{C}$ ( Ni/ZnAl-7, Ni/ZnAlZr-7 e Ni/ZnZr-7) após a reação; (b) Espectros Raman dos catalisadores ( Ni/ZnAl-7, Ni/ZnAlZr-7 e Ni/ZnZr-7) após a reação.
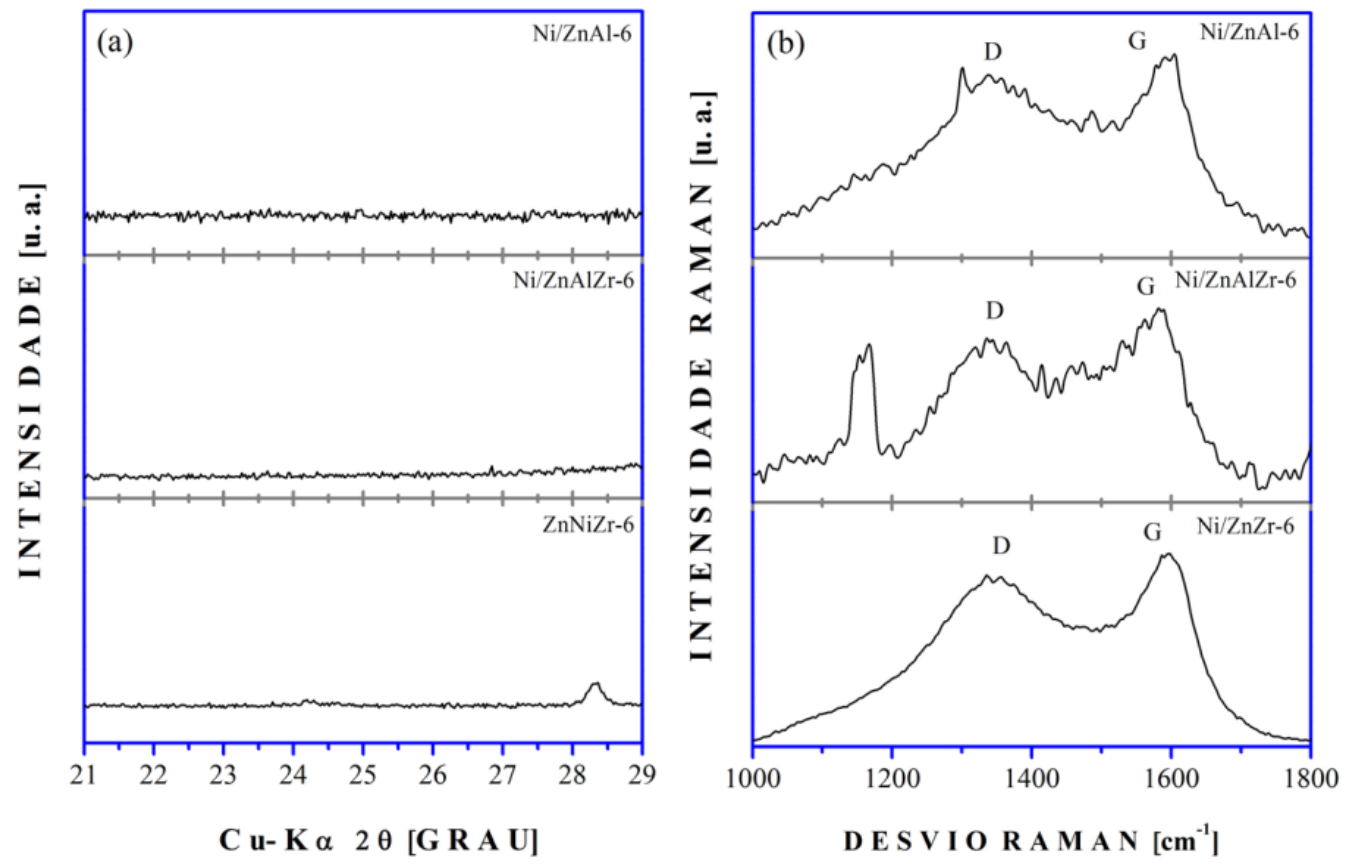

Fonte: Autoria própria.

Figura 77 - (a) Difração de raios $X$ dos catalisadores tratados a $750^{\circ} \mathrm{C}$ ( Ni/ZnAl-7, Ni/ZnAlZr-7 e Ni/ZnZr-7) após a reação; (b) Espectros Raman dos catalisadores ( Ni/ZnAl-7, Ni/ZnAlZr-7 e Ni/ZnZr-7) após a reação.

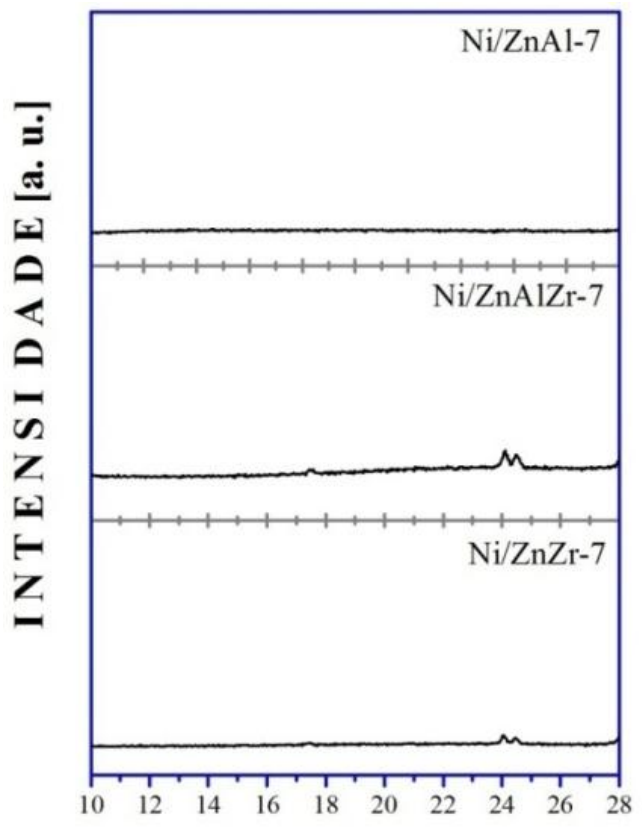

C u-K $\alpha 2 \theta[D$ E G R E E]

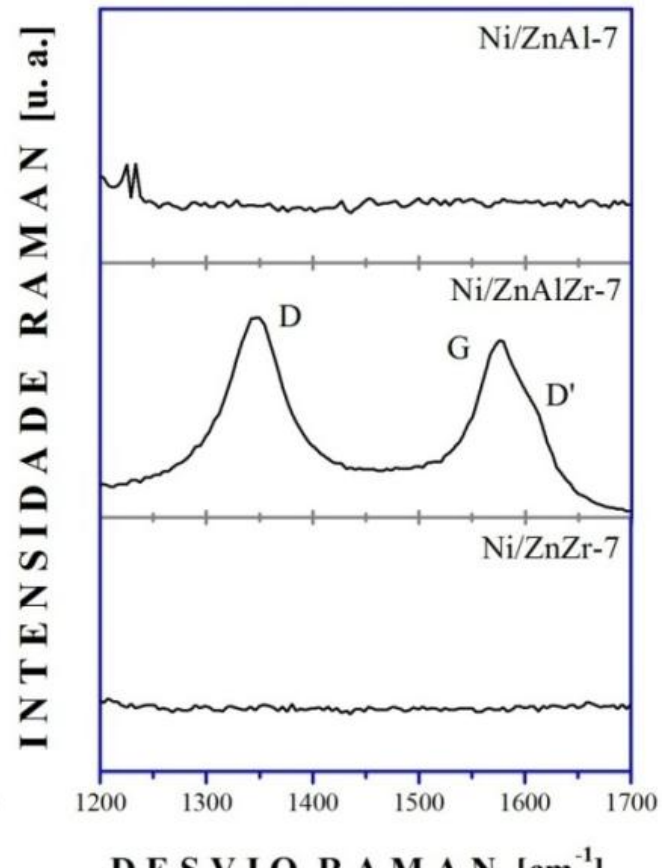

D E S V I O RA M A N $\left[\mathrm{cm}^{-1}\right]$

Fonte: Autoria própria. 


\section{CONSIDERAÇÕES FINAIS}

Tendo em vista os resultados apresentados, concluiu-se que o método de coprecipitação química foi efetivo para a síntese dos precursores do tipo hidrotalcita (NiZn-Al e NiZn-AlZr), como demonstrado pelas análises de difração de raios X de HDL's para essas amostras. Os padrões de difração mostraram o efeito memória das hidrotalcitas, ou seja, os óxidos mistos obtidos a partir desses compostos são capazes de retornar à estrutura em camadas quando em contato com a solução de $\mathrm{Na}_{2} \mathrm{CO}_{3}$. No que concerne aos parâmetros de rede, notou-se que a presença do $\mathrm{Zr}^{4+}$ no precursor (NiZn-AlZr) favoreceu a diminuição do parâmetro $c$, como um resultado do aumento da interação entre os cátions nas intercamadas. Óxidos mistos com propriedades básicas podem ser obtidos pelo processo de calcinação desses precursores, porém tal basicidade tende a diminuir à medida que ocorreu o aumento da temperatura de calcinação.

Em relação aos catalisadores estudados, os resultados de TPR mostraram que os picos de redução foram atribuídos somente a fase de $\mathrm{NiO}$ referente a interações com os suportes presentes. Além disso, não foi possível verificar picos de redução de alta intensidade referente a fase de $\mathrm{NiAl}_{2} \mathrm{O}_{4}$ nos catalisadores onde ocorreu a substiuição paracial e total do $\mathrm{Al}^{3+}$ calcinados a $650^{\circ} \mathrm{C}$ e $750^{\circ} \mathrm{C}$. Particularmente, para os catalisadores calcinados a $550^{\circ} \mathrm{C}$, a presença da fase de $\mathrm{ZrO}_{2}$ contribuiu o para deslocamentos dos picos para menores temperaturas de redução.

A basicidade sofreu a influência da calcinação, ou seja, quanto maior a temperatura de calcinação menor é quantidade de sítios básicos nas amostras. Pelos resultados obtidos, verificou-se que a fase de $\mathrm{ZrO}_{2}$, juntamente com o $\mathrm{Al}_{2} \mathrm{O}_{3}$ favoreceu a presença de sítios básicos nos catalisadores calcinados a $550^{\circ} \mathrm{C}, 650^{\circ} \mathrm{C}$ e $750^{\circ} \mathrm{C}$, contribuindo diretamente na reação de reforma. Outro fator a ser ressaltado é que a variação da composição dos catalisadores não atuou significantemente na formação de sítios básicos fortes, visto que todos os apresentaram sítios fra$\cos$.

Em relação à propriedade catalítica, o desempenho dos catalisadores depende da presença do $\mathrm{Ni}^{0}$, obtido no processo de redução da amostra. Os catalisadores calcinados a $750^{\circ} \mathrm{C}$ apresentaram as maiores conversões. Em particular o catalisador Ni/ZnAlZr-7 que exibiu uma maior conversão $\mathrm{CO}_{2}$, corroborando os resultados da basicidade. A temperatura de reação empregada para esses catalisadores favoreceu a ocorrência de reações paralelas, tais como a reação reversa de shift que contribuiu para a conversão do $\mathrm{CO}_{2}$. No que concerne ao $\mathrm{CH}_{4}$, notou-se que a substi- 
tuição parcial e total do $\mathrm{Al}^{3+}$ nos catalisadores (Ni/ZnAlZr-7 e Ni/ZnZr-7) não afetou a conversão do mesmo. Esses catalisadores apresentaram menor deposição de carbono, fato este atribuído ao consumo do mesmo promovido pelas reações paralelas.

Em geral, o tempo calcinação (15h) para todos os catalisadores e a temperatura de calcinação a $750^{\circ} \mathrm{C}$ induziu a aglomeração das fases presentes. Essa conclusão atesta os resultados obtidos das áreas superficiais de todos os catalisadores estudados nessa tese, cujos valores não ultrapassaram de $69 \mathrm{~m}^{2} / \mathrm{g}$ em. Outro fator a ser ressaltado é a contribuição da redução referente ao $\mathrm{ZnO}$ que não foi possível ser verificada pela difração de raios $\mathrm{X}$ in situ. Finalmente concluiuse que os catalisadores calcinados a $650^{\circ}$ e $750^{\circ} \mathrm{C}$, ambos reduzidos a $650^{\circ} \mathrm{C}$ são adequados para a reforma seca do metano produzindo altos rendimentos de hidrogênio e monóxido de carbono com as conversões de $\mathrm{CH}_{4}$ e $\mathrm{CO}_{2}$. 


\section{REFERÊNCIAS}

AUDIER, M.; OBERLIN, A.; OBERLIN, M.; COULON, M.; BONNETAIN, L. Morphology and crystalline order in catalytic carbons. Carbon, v. 19, n. 3, p. 217-224, 1981.

AUROUX, A.; GERVASINI, A. Microcalorimetric study of the acidity and basicity of metal oxide surfaces. The Journal of Physical Chemistry, v. 94, n. 16, p. 6371-6379, 1990.

CONDON, B. Surface area and porosity determinations bu phisisortion, measurements and theory. Journal of Chemical Information and Modeling, v.53, n.9, p. 1689-1699,2013.

BAKER, R. T. K. Catalytic growth of carbon filaments. Carbon, v. 27, n. 3, p. 315-323, 1989.

BARTHOLOMEW, C. H. Mechanisms of catalyst deactivation. Applied Catalysis A: General, v. 212, n. 1-2, p. 17-60, 2001.

BOND, T.; TEMPLETON, M. R. History and future of domestic biogas plants in the developing world. Energy for Sustainable Development, v. 15, n. 4, p. 347-354, 2011.

BRADFORD, M. C. J.; VANNICE, M. A. $\mathrm{CO}_{2}$ Reforming of $\mathrm{CH}_{4}$. Catalysis Reviews, v. 41, n. 1, p. 1-42, 1999.

BUDIMAN, A. W.; SONG, S.-H.; CHANG, T.-S.; SHIN, C.-H.; CHOI, M.-J. Dry reforming of methane over cobalt catalysts: a literature review of catalyst development. Catalysis Surveys from Asia, v. 16, n. 4, p. 183-197, 2012.

BURRUECO, M. I.; MORA, M.; JIMÉNEZ-SANCHIDRIÁN, C.; RUIZ, J. R. Raman microspectroscopy of hydrotalcite-like compounds modified with sulphate and sulphonate organic anions. Journal of Molecular Structure, v. 1034, p. 38-42], 2013.

BUSCA, G.; COSTANTINO, U.; MONTANARI, T.; RAMIS, G.; RESINI, C.; SISANI, M. Nickel versus cobalt catalysts for hydrogen production by ethanol steam reforming: $\mathrm{Ni}-\mathrm{Co}-\mathrm{Zn}-$ Al catalysts from hydrotalcite-like precursors. International Journal of Hydrogen Energy, v. 35, n. 11, p. 5356-5366, 2010.

BUSETTO, C. Catalysts for low-temperature methanol synthesis. Preparation of mixed oxides via hydrotalcite-like precursors. Journal of Catalysis, v. 85, n. 1, p. 260-266, 1984.

CANTRELL, D. G.; GILLIE, L. J.; LEE, A. F.; WILSON, K. Structure-reactivity correlations in MgAl hydrotalcite catalysts for biodiesel synthesis. Applied Catalysis A: General, v. 287, n. 2, p. 183-190, 2005.

CAVANI, F.; TRIFIRO, F.; VACCARI, A. Hydrotalcite-type anionic clays: preparation, properties, and applications. Chem Inform, v. 23, n. 12, p. 22, 2010. 
CHANDLER, J. A. An introduction to analytical electron microscopy. Micron, v. 3, p. 85-92, 1972.

CHEN, D.; LØDENG, R.; ANUNDSKÅS, A.; OLSVIK, O.; HOLMEN, A. Deactivation during carbon dioxide reforming of methane over $\mathrm{Ni}$ catalyst: microkinetic analysis. Chemical Engineering Science, v. 56, n. 4, p. 1371-1379, 2001.

CHEN, J.; QIAO, Y.; LI, Y. Promoting effects of doping ZnO into coprecipitated Ni-Al2O3 catalyst on methane decomposition to hydrogen and carbon nanofibers. Applied Catalysis A: General, v. 337, n. 2, p. 148-154, 2008.

CHOUDHARY, T. V.; CHOUDHARY, V. R. Energieeffiziente synthesegasproduktion durch katalytische sauerstoff-reformierung von Methan. Angewandte Chemie, v. 120, n. 10, p. 18521872, 22, 2008.

CONCEIÇÃO, L. D.; PERGHER, S. B. C.; MORO, C. C.; OLIVEIRA, L. C. A. Compósitos magnéticos baseados em hidrotalcitas para a remoção de contaminantes aniônicos em água. Química Nova, v. 30, n. 5, p. 1077-1081, 2007.

CORTEZ, G. G.; MEIRA, D. M. Síntese, caracterização e avaliação catalítica de Vo x/Mg yAlo x na reação de decomposição do isopropanol. Química Nova, v. 31, n. 6, p. 1290-1295, 2008.

CREPALDI, E. L.; VALIM, J. B. Hidróxidos duplos lamelares: síntese, estrutura, propriedades e aplicações. Química Nova, v. 21, n. 3, p. 300-311, 1998.

CULLITY, B. D. Elements of X-ray diffraction. Indiana: Addison-Wesley 1956. 664 p.

CUNHA, V. R. R.; MARIA, A.; FERREIRA, C.; FUNDAMENTAL, D. D. Q.; QUÍMICA, I. DE; PAULO, U. D. S.; SP, S. P. Hidróxidos duplos lamelares: nanopartículas inorgânicas para armazenamento e liberação de espécies de interesse biológico e terapêutico. Química Nova, v. 33, n. 1, p. 159-171, 2010.

DELAHAY, P.; MARTI, F. B.; LLUNA, J. A. B. Analisis instrumental: métodos fisicoquímicos del análisis. Madrid: Paraninfo, 1963. 466p.

DENG, X.; SUN, J.; YU, S.; XI, J.; ZHU, W.; QIU, X. Steam reforming of ethanol for hydrogen production over $\mathrm{NiO} / \mathrm{ZnO} / \mathrm{ZrO}_{2}$ catalysts. International Journal of Hydrogen Energyn, v. 33, p. 1008-1013, 7, 2008.

DJAIDJA, A.; LIBS, S.; KIENNEMANN, A.; BARAMA, A. Characterization and activity in dry reforming of methane on $\mathrm{NiMg} / \mathrm{Al}$ and $\mathrm{Ni} / \mathrm{MgO}$ catalysts. Catalysis Today, v. 113, n. 3-4, p. 194-200, 2006.

DUTROW, C. K. B. Manual de ciências dos materiais. 23. ed. Porto Alegre: Bookman, 2012. 274 . 
CAVALHEIRO, E.T.G.; IONASHIRO, M.; BREVIGLIERI, S.T.; MARIANO, G.; CHIERICE, G.A. A Influência de fatores experimentais nos resultados de análises termogravimétricas.

Química Nova, v. 18, n. 3, p. 305-308, 1995.

EGERTON, T. A.; HARDIN, A. H. Catalysis Reviews : Science and engineering the application of raman spectroscopy to surface chemical studies. Advances in Colloid and Interface Science, v. 11, 2012, p. 37-41, 2007.

RUCKENSTEIN, E.; HU, Y. H. Methane partial oxidation over $\mathrm{NiO} / \mathrm{MgO}$ solid solution catalysts. Applied Catalysis A: General, v. 183, n. 1, p. 85-92, 1999.

ERICKSON, K. L.; BOSTROM, T. E.; FROST, R. L. A study of structural memory effects in synthetic hydrotalcites using environmental SEM. Materials Letters, v. 59, n. 2-3, p. 226-229, 2005.

FACHAGENTUR, N. Guia prático do biogás : geração e utilização. Gülzow: Fachagentur Nachwachsende Rohstoffe, 2010. 234p.

FAN, M. S.; ABDULLAH, A. Z.; BHATIA, S. Catalytic technology for carbon dioxide reforming of methane to synthesis gas. Chem Cat Chem, v. 1, n. 2, p. 192-208, 2009a.

FAN, M.-S.; ABDULLAH, A. Z.; BHATIA, S. Catalytic technology for carbon dioxide reforming of methane to synthesis gas. Chem Cat Chem, v. 1, n. 2, p. 192-208, 2009b.

FARIA, D. L. A.; SANTOS, L. G. C.; GONÇALVES, N. S. Uma demonstração sobre espalhamento inelastico da luz. Química Nova, v. 20, n.3, p. 319-323, 1997.

FARRAUTO, R. J.; BARTHOLOMEW, C. H. Fundamentals of industrial catalytic processes. New York: Blackie Academic Profesional, 1997. 336p.

FEITKNECHT, W. Uber die $\alpha$-form der hydroxyde zweiwertiger metalle. Helvetica Chimica Acta, v. 21, n. 1, p. 766-784, 1938.

FIGUEIREDO, J. L.; RIBEIRO, F. R. Catálise heterogênea. Lisboa: Fundação Calouste Gulbenkian, 1989.352p.

FRAILE, J. M.; GARCÍA, N.; MAYORAL, J. A.; PIRES, E.; ROLDÁN, L. The basicity of mixed oxides and the influence of alkaline metals: The case of transesterification reactions. Applied Catalysis A: General, v. 387, n. 1-2, p. 67-74, 2010.

FROST, R. L.; MARTENS, W. N.; ERICKSON, K. L. Thermal decomposition of the hydrotalcite. Journal of Thermal Analysis and Calorimetry, v. 82, n. 3, p. 603-608, 2005. 
GAO, P.; LI, F.; XIAO, F.; ZHAO, N.; WEI, W.; ZHONG, L.; SUN, Y. Effect of hydrotalcitecontaining precursors on the performance of $\mathrm{Cu} / \mathrm{Zn} / \mathrm{Al} / \mathrm{Zr}$ catalysts for $\mathrm{CO}_{2}$ hydrogenation: Introduction of $\mathrm{Cu}^{2+}$ at different formation stages of precursors. Catalysis Today, v. 194, n. 1, p. 9-15, 2012.

GENNEQUIN, C.; SAFARIAMIN, M.; SIFFERT, S.; ABOUKAÏS, A.; ABI-AAD, E. CO 2 reforming of $\mathrm{CH}_{4}$ over $\mathrm{Co}-\mathrm{Mg}-\mathrm{Al}$ mixed oxides prepared via hydrotalcite like precursors. Catalysis Today, v. 176, n. 1, p. 139-143, 2011.

GROEN, J. C.; PEFFER, L. A. A.; JAVIER, P. Pore size determination in modified micro and mesoporous materials . Pitfalls and Limitations in gas adsorption data analysis. v. 60, p. 117, 2003.

HAINES, P. J. Principles of thermal analysis and calorimetry. Journal of Chemical Information and Modeling, v. 53, p. 55-92, 2002.

HICKEY, L.; KLOPROGGE, J. T.; FROST, R. L. The effects of various hydrothermal treatments on magnesium-aluminium hydrotalcites. Journal of Materials Science, v. 5, p. 4347-4355, 2000.

HINES, D. R.; SOLIN, S. A.; COSTANTINO, U.; NOCCHETTI, M. Physical properties of fixed-charge layer double hydroxides. Physical Review B, v. 61, n. 17, p. 11348-11358, 2000.

HURST, N. W.; GENTRY, S. J.; JONES, A.; MCNICOL, B. D. Temperature programmed reduction. Catalysis Reviews, v. 24, n. 2, p. 233-309, 1982.

KLOPROGGE, J.T.; WHARTON, D.; HICKEL,L.; FROST, R.L. Infrared and Raman study of interlayer anions $\mathrm{CO}_{3}{ }^{2-}, \mathrm{NO}_{3}{ }^{-}, \mathrm{SO}_{4}{ }^{2-}$ and $\mathrm{ClO}_{4}{ }^{-}$in $\mathrm{Mg} / \mathrm{Al}$ - hydrotalcite. American Mineralogist, v. 87, n. 0003-004X, p. 623-629, 2002.

KAMBOLIS, A.; MATRALIS, H.; TROVARELLI, A.; PAPADOPOULOU, C. Ni / $\mathrm{CeO}_{2} . \mathrm{ZrO}_{2}$ catalysts for the dry reforming of methane. Applied Catalysis A : General,v. 377, p. 16-26, 2010 .

KARLSSON, T. Manual básico de biogás. Lajeado: Univates, 2014. 69p.

KIRM, I.; MEDINA, F.; RODRÍGUEZ, X.; CESTEROS, Y.; SALAGRE, P.; SUEIRAS, J. Epoxidation of styrene with hydrogen peroxide using hydrotalcites as heterogeneous catalysts. Applied Catalysis A: General, v. 272, n. 1-2, p. 175-185, 2004.

KLOPROGGE, J. T.; HICKEY, L.; FROST, R. L. FT-Raman and FT-IR spectroscopic study of synthetic Mg/Zn/Al-hydrotalcites. Journal of Raman Spectroscopy, v. 35, n. 11, p. 967-974, 2004.

KOHN, M. P. Catalytic reforming of biogas for syngas production. [s.1.]:Columbia University, 2012. 155p. 
KOLBITSCH, P.; PFEIFER, C.; HOFBAUER, H. Catalytic steam reforming of model biogas. Fuel, v. 87, n. 6, p. 701-706, 2008.

KUŚTROWSKI, P.; SUŁKOWSKA, D.; CHMIELARZ, L.; OLSZEWSKI, P.; RAFALSKAŁASOCHA, A.; DZIEMBAJ, R. Effect of rehydration conditions on the catalytic activity of hydrotalcite-derived $\mathrm{Mg}$-Al oxides in aldolization of acetone. Reaction Kinetics and Catalysis Letters, v. 85, n. 2, p. 383-390, 2005.

LARKIN, P. IR and Raman spectroscopy. principles and spectral interpretatiton. Amsterdam: Hardback, 2011. 230p.

LEOFANTI, G.; PADOVAN, M.; TOZZOLA, G.; VENTURELLI, B. Surface area and pore texture of catalysts. Catalysis Today, v. 41, n. 1-3, p. 207-219, 1998.

LI, C.; CHEN, Y.-W. Temperature-programmed-reduction studies of nickel oxide/alumina catalysts: effects of the preparation method. Thermochimica Acta, v. 256, n. 2, p. 457-465, 1995.

LI, Z.; SONG, Y.; WANG, J.; LIU, Q.; YANG, P.; ZHANG, M. Study of structural transformations and phases formation upon calcination of $\mathrm{Zn}-\mathrm{Ni}-\mathrm{Al}$ hydrotalcite nanosheets. Bulletin of Materials Science, v. 34, n. 2, p. 183-189, 2011.

LIMA, S. M. DE. Preparação de aplicação de óxidos tipo perovskita $\mathrm{La}_{1-\mathrm{x}} \mathrm{Ce}_{\mathrm{x}} \mathrm{NiO}_{3}$ e $\mathrm{La}_{1-}$ ${ }_{x} \mathrm{Ca}_{x} \mathrm{NiO}_{3}$ para obtenção de gás de síntese a partir do metano. 2006. 203f. Tese ( Doutorado em Engenharia Química)- Departamento de Engenharia Química, Universidade Federal de São Carlos, São Carlos, 2006.

LOZANO, R. P.; ROSSI, C.; LA IGLESIA, A.; MATESANZ, E. Zaccagnaite-3R, a new Zn-A1 hydrotalcite polytype from El Soplao cave (Cantabria, Spain). American Mineralogist, v. 97, n. 4, p. 513-523, 2012.

LUCRÉDIO, A. F.; ASSAF, J. M.; ASSAF, E. M. Methane conversion reactions on Ni catalysts promoted with Rh: Influence of support. Applied Catalysis A: General, v. 400, n. 1-2, p. 156165, 2011.

MA, W.; ZHAO, N.; YANG, G.; TIAN, L.; WANG, R. Removal of fluoride ions from aqueous solution by the calcination product of $\mathrm{Mg}-\mathrm{Al}-\mathrm{Fe}$ hydrotalcite-like compound. Desalination, $\mathrm{v}$. 268 , n. 1-3, p. 20-26, 2011.

MENG, X.; HUANG, H.; WENG, H.; SHI, L. Ni/ZnO-based Adsorbents Supported on $\mathrm{Al}_{2} \mathrm{O}_{3}$, $\mathrm{SiO}_{2}, \mathrm{TiO}_{2}, \mathrm{ZrO}_{2}$ : A comparison for desulfurization of model gasoline by reactive adsorption. Bulletin of the Korean Chemical Society, v. 33, n. 10, p. 3213-3217, 2012.

MEYER, P. D. T. J.; SAUVAGE, H. W. R. J. Structure and bonding. Berlin: Sringer, 2006. 234p. 
MONNERAT, B.; MINSKER, K. L.; RENKEN, A. Hydrogen production by catalytic cracking of methane over nickel gauze under periodic reactor operation. Chemical Engineering Science, v. 56, n. 2 , p. 633-639, 2001.

MORA, M.; SANCHIDRIÁN, J. C.; RUIZ, R. J. Raman spectroscopy study of layered-double hydroxides containing magnesium and trivalent metals. Materials Letters, v. 120, p. 193-195, 2014.

MORENO, M. J.H.; ULIBARRI, M. A.; REDON, J.L.; SERNA, C.J. IR characteristics of hydrotalcite-like compounds. Physics and Chemistry of Minerals, v. 12, n. 1, p. 34-38, 1985.

MOTHÉ, C. G.; AZEVEDO, A. D. D. Análise térmica de materiais. Rio de Janeiro: Artiliber, 2002. 301p.

NAKAMURA, J.; AIKAWA, K.; SATO, K.; UCHIJIMA, T. Role of support in reforming of CH4 with CO2 over Rh catalysts. Catalysis Letters, v. 25, n. 3-4, p. 265-270, 1994.

NEMANICH, R. J.; LUCOVSKY, G.; SOLIN, S. A. Infrared active optical vibrations of graphite. Solid State Communications, v. 23, n. 2, p. 117-120, 1977.

NEVES, M. D. L. C.; CONVERTI, A.; PENNA, V. T. C. Biogas production: new trends for alternative energy sources in rural and urban zones. Chemical Engineering \& Technology, v. 32, n. 8, p. 1147-1153, 2009.

NEWNHAM, J. Optimisation and characterisation of nickel based nano-catalysts for the dry reforming of methane with carbon dioxide. 2012. 219f. Tese (Doctor of Philosophy)Department of Applied Science, RMIT University, Melbourne, 2012.

NOGUEIRA, F. G. E. Catalisadores de ni promovidos com Mg e $\mathrm{Nb}$ para reforma a vapor do ácido acético como molécula modelo do bio-óleo. 2014. 95f. Tese (Doutorado em FísicoQímica)- Instituo de Química de São Carlos , Universidade de São Paulo, São Carlos, 2014.

OLIVEIRA, G. M. Simetria de moléculas e cristais: fundamentos da espectrocospia vibracional. Porto Alegre: Bookman, 2009.272p.

ONO, Y.; HATTORI, H. Solid base catalysis, Springer Series in Chemical Physics, v. 101, p. 421, 2011.

PAKHARE, D.; SPIVEY, J. A review of dry $\left(\mathrm{CO}_{2}\right)$ reforming of methane over noble metal catalysts. Chemical Society Reviews, v. 43, n. 22, p. 7813-37, 2014.

PAVEL, O. D.; ZĂVOIANU, R.; BÎRJEGA, R.; ANGELESCU, E. The effect of ageing step elimination on the memory effect presented by $\mathrm{Mg} 0.75 \mathrm{Al} 0.25$ hydrotalcites (HT) and their catalytic activity for cyanoethylation reaction. Catalysis Communications, v. 12, n. 10, p. 845$850,2011$. 
PRETTRE, M.; EICHNER, C.; PERRIN, M. Catalytic oxidation of methane to carbon monoxide and hydrogen. Transactions of the Faraday Society, v. 42, p. 335-340, 1946.

RAMOS, A. L. D.; MARQUES, J. J.; SANTOS, V. DOS; FREITAS, L. DOS S.; SANTOS, R. G. V. DE M.; SOUZA, M. DE M. V. M. Atual estágio de desenvolvimento da tecnologia GTL e perspectivas para o Brasil. Química Nova, v. 34, n. 10, p. 1704-1716, 2011.

RAO, K. Activation of Mg-Al Hydrotalcite catalysts for aldol condensation reactions. Journal of Catalysis, v. 173, n. 1, p. 115-121,1998.

REICHLE, W. Synthesis of anionic clay minerals (mixed metal hydroxides, hydrotalcite. Solid State Ionics, v. 22, n. 1, p. 135-141,1986.

RESINI, C.; MONTANARI, T.; BARATTINI, L.; RAMIS, G.; BUSCA, G.; PRESTO, S.; RIANI, P.; MARAZZA, R.; SISANI, M.; MARMOTTINI, F.; COSTANTINO, U. Hydrogen production by ethanol steam reforming over $\mathrm{Ni}$ catalysts derived from hydrotalcite-like precursors: Catalyst characterization, catalytic activity and reaction path. Applied Catalysis A: General, v. 355, n. 1-2, p. 83-93, 2009.

RIVAS, M. E.; FIERRO, J. L. G.; GUIL-LÓPEZ, R.; PEÑA, M. A.; LA PAROLA, V.; GOLDWASSER, M. R. Preparation and characterization of nickel-based mixed-oxides and their performance for catalytic methane decomposition. Catalysis Today, v. 133-135, p. 367-373, 2008.

RIVES, V. Layered double hydroxides: present and future. New York: Nova Science, 2001.499p.

RIVES, V. Characterisation of layered double hydroxides and their decomposition products. Materials Chemistry and Physics, v. 75, n. 1-3, p. 19-25, 2002.

RIVES, V. Synergistic effect in the hydroxylation of phenol over CoNiAl ternary hydrotalcites. Journal of Catalysis, v. 220, n. 1, p. 161-171, 152003.

ROSA, F.; NAVARRO, R. M. Hydrogen production by oxidative reforming of hexadecane over $\mathrm{Ni}$ and Pt catalysts supported on Ce / La-doped $\mathrm{Al}_{2} \mathrm{O}_{3}$. Applied Catalysis A: General 297, v. 297, n. 1, p. 60-72, 2006.

ROSS, J. Evidence for the participation of surface nickel aluminate sites in the steam reforming of methane over nickel/alumina catalysts. Journal of Catalysis, v. 52, n. 2, p. 280-290, 1978.

ROSSI, P. F.; BUSCA, G.; LORENZELLI, V.; WAQIF, M.; SAUR, O.; LAVALLEY, J. C. Surface basicity of mixed oxides: magnesium and zinc aluminates. Langmuir, v. 7, n. 11, p. 2677-2681, 1991. 
NIELSEN, R. J. R. Production of synthesis gas. Catalysis Today, v. 18, n. 4, p. 305-324, 1993.

ROY, A. DE; FORANO, C.; MALKI, K. EL; BESSE, J.-P. Expanded clays and other microporous solids. New York: Springer, 1992. 388p.

RUCKENSTEIN, E.; HU, Y. H. Carbon dioxide reforming of methane over nickel/alkaline earth metal oxide catalysts. Applied Catalysis A: General, v. 133, n. 1, p. 149-161, 1995.

RUEANGJITT, N.; AKARAWITOO, C.; CHAVADEJ, S. Production of hydrogen-rich syngas from biogas reforming with partial oxidation using a multi-stage ac gliding arc system. Plasma Chemistry and Plasma Processing, v. 32, n. 3, p. 583-596, 2012.

SALA, O. Fundamentos da espectroscopia raman e no infravermelho. São Paulo: Editora Unesp, 2008. 208p.

SHANNON, R. D. Revised effective ionic radii and systematic studies of interatomic distances in halides and chalcogenides. Acta Crystallographica Section A, v. 32, p. 751-

767, 1976.

SHISHIDO, T.; SUKENOBU, M.; MORIOKA, H.; FURUKAWA, R.; SHIRAHASE, H. CO 2 reforming of $\mathrm{CH}_{4}$ over $\mathrm{Ni} / \mathrm{Mg}-\mathrm{Al}$ oxide catalysts prepared by solid phase crystallization method from $\mathrm{Mg}-\mathrm{Al}$ hydrotalcite-like precursors. Catalysis Communications. v. 73, n. 1, p. 05, 2001.

SING, K. S. W.; EVERETT, D. H.; HAUL, R. A. W.; MOSCOU, L.; PIEROTTI, R. A.; ROUQUEROL, J.; SIEMIENIEWSKA, T. Reporting physisorption data for gas/solid systems. Pure and Applied Chemistry, v. 57, n. 4, p. 603-619, 1985.

SMART, L. E.; MOORE, E. A. Solid state chemistry: an introduction. Journal of Chemical Information and Modeling. v. 53, n. 9, p. 1689-1699, 2013.

SKOOG, A. D.; HOLLER, F. J.; NIEMAN, T. A. Princípios de análise instrumental. Porto Alegre: Bookman, 2002. 1056 p.

SURYANARAYANA, C., NORTON, M. G. X-ray diffraction: a practical approach. New York: Springer. 2008. 269p.

TANABE, K.; MISONO, M.; ONO, Y.; HATTORI, H. New solid acids and bases. Amsterdam: Elsevier, 1989. 35p. 
TANABE, T.K.; YAMAGUCHI, T. T. Solid bases and their catalytic activity. Journal of the research institute for Catalysis, v. 16, p. 425-447, 1968.

UEMIYA, S.; SATO, N.; ANDO, H.; MATSUDA,T. E. K. Steam reforming of methane in a hydrogen-permeable membrane reactor. Applied Catalysis, v. 67, n. 1, p. 223-230, 1990.

VACCARI, A. Preparation and catalytic properties of cationic and anionic clays. Catalysis Today, v. 41, n. 1-3, p. 53-71, 1998.

VALENTE, J. S.; LIMA, E.; ANTONIO, T. J. A.; JACOME, C. M. A.; ROJAS, L. L.; MONTIEL, R.; PRINCE, J. Comprehending the thermal decomposition and reconstruction process of sol-gel MgAl layered double hydroxides. The Journal of Physical Chemistry C, v. 114, n. 5, p. 2089-2099, 2010.

VALENTINI, A.; PROBST, L. F. D.; CARREÑO, N. L. V; LEITE, E. R.; PONTES, F. M.; LONGO, E.; SCHREINER, W. H.; LISBOA-FILHO, P. N. Estudo microestrutural do catalisador Ni/gama-Al2O3: efeito da adição de $\mathrm{CeO}_{2}$ na reforma do metano com dióxido de carbono. Química Nova, v. 26, n. 5, p. 648-654, 2003.

WALKER, P.L.; RAKSZAWSK, J. F.; ARMINGTON, A.F. Determination of graphitic and amorphous carbon. Philadelphia: American Chemical Society, 1995.p 51-54 ( ASTM Bulletin, n.208).

WANG, S. $\mathrm{CO}_{2}$ reforming of methane on Ni catalysts: Effects of the support phase and preparation technique. Applied Catalysis b: Environmental, v. 16, n. 3, p. 269-277, 1998.

WANG, S.; LU, G. Q. M.; MILLAR, G. J. Carbon dioxide reforming of methane to produce synthesis gas over metal-supported catalysts: state of the art. Energy \& Fuels, v. 10, n. 4, p. 896904, 1996.

WOLF, E. E.; ALFANI, F. Catalysts deactivation by coking. Catalysis Reviews, v. 24, n. 3, p. 329-371, 1982.

XU, J.; ZHOU, W.; LI, Z.; WANG, J.; MA, J. Biogas reforming for hydrogen production over nickel and cobalt bimetallic catalysts. International Journal of Hydrogen Energy, v. 34, n. 16, p. 6646-6654, 2009.

YAMAGUCHI, T. Application of $\mathrm{ZrO}_{2}$ as a catalyst and a catalyst support. Catalysis Today, v. 20, n. 2, p. 199-217, 1994.

YANG, R. Mechanism of carbon filament growth on metal catalysts. Journal of Catalysis, v. 115, n. 1, p. 52-64, 1989.

YI, H.; ZHAO, S.; TANG, X.; NING, P.; WANG, H.; HE, D. Influence of calcination temperature on the hydrolysis of carbonyl sulfide over hydrotalcite-derived $\mathrm{Zn}-\mathrm{Ni}-\mathrm{Al}$ catalyst. Catalysis Communications, v. 12, n. 15, p. 1492-1495, 2011. 
ZHANG, X.; LEE, C. S.; MINGOS, D. M. P.; HAYWARD, D. O. Carbon dioxide reforming of methane with Pt catalysts using microwave dielectric heating. Catalysis Letters, v. 88, p. 129-139, 2003.

ZHAO, S.; YI, H.; TANG, X.; KANG, D.; WANG, H.; LI, K.; DUAN, K. Characterization of $\mathrm{Zn}-\mathrm{Ni}$-Fe hydrotalcite-derived oxides and their application in the hydrolysis of carbonyl sulfide. Applied Clay Science, v. 56, p. 84-89, 2012. 


\section{APÊNDICE A - Resultados}

Para a determinação da taxa de formação de carbono foi determinar foi feita pelas análises termogravimétricas. O resultado de DTG está reportado na Figura 11, verificou-se que os catalisadores $\mathrm{Ni} / \mathrm{ZnAl}-7, \mathrm{Ni} / \mathrm{ZnAlZr-7}$ e Ni/ZnZr-7 apresentaram picos referente ao carbono grafite localizado em torno de $620^{\circ}, 643^{\circ}$ e $643^{\circ} \mathrm{C}$, respectivamente.

Figura 1- DTG dos catalisadores após a reação.
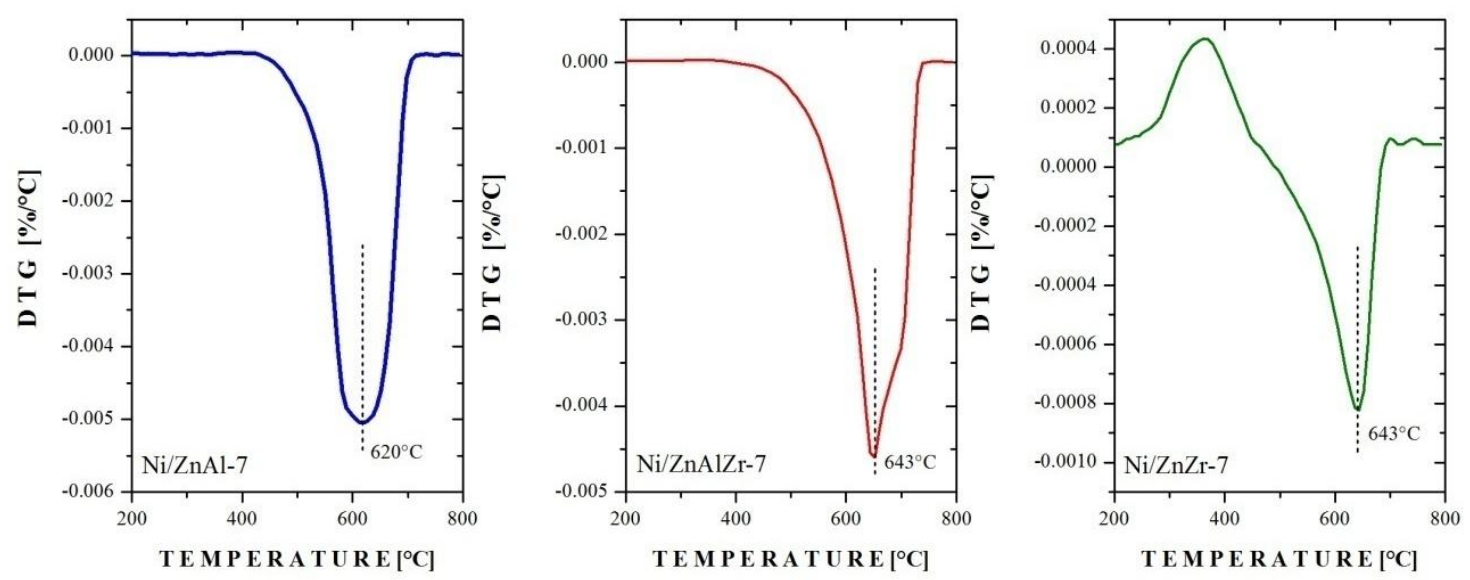

Fonte: Autoria própria.

Figura 2- Padrões de difração de raios X da decomposição térmica do precursor ZnNi-Zr.

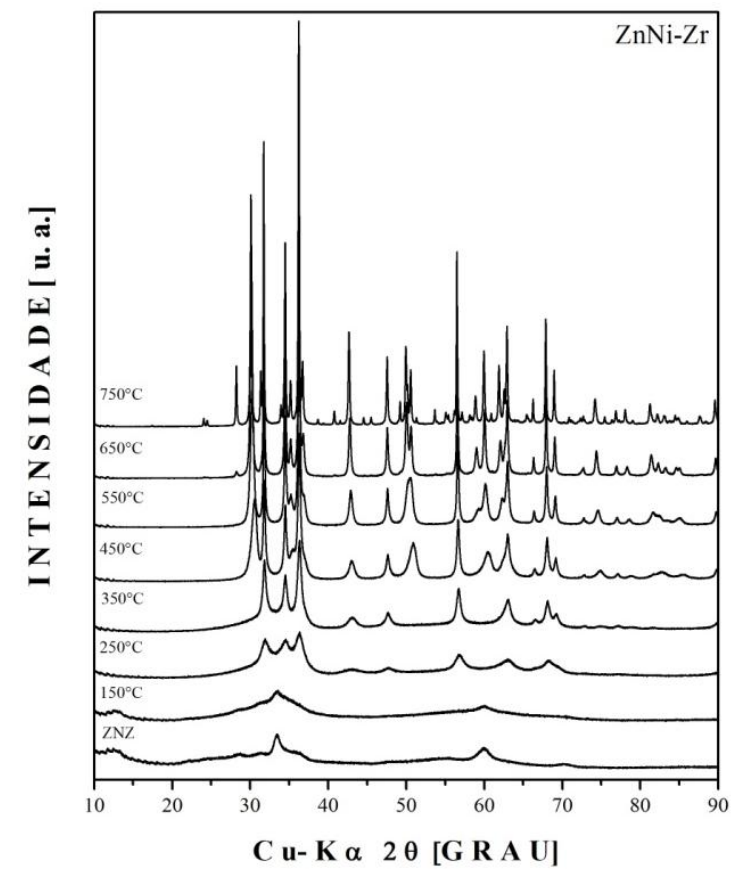

Fonte: Autoria própria. 
Figura 3- (a) Ni K-edge XANES spectra of the patterns ( $\mathrm{NiO}, \mathrm{NiAl}_{2} \mathrm{O}_{4}$ and $\mathrm{ZnAl}_{2} \mathrm{O}_{4}$ ) (b) Ni K-edge XANES spectra of the catalysts $\mathrm{Ni} / \mathrm{ZnAl}, \mathrm{Ni} / \mathrm{ZnAlZr}$ and $\mathrm{Ni} / \mathrm{ZnZr}$. Figure 4 shows the spectrum at the beginning $\left(650^{\circ} \mathrm{C}\right.$ Initial) and at the end of the reduction $\left(650^{\circ} \mathrm{C}\right.$ Final).

(a)

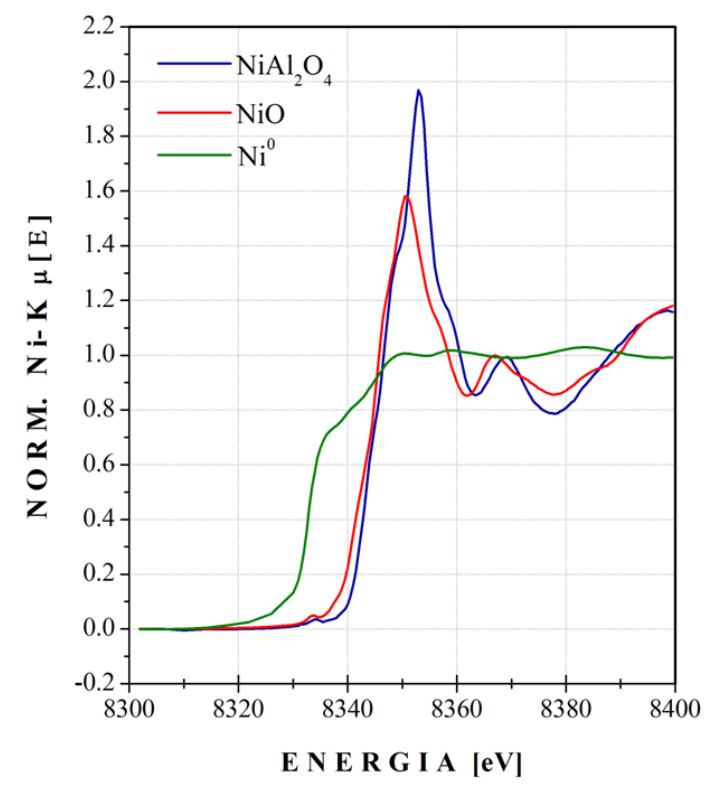

(b)

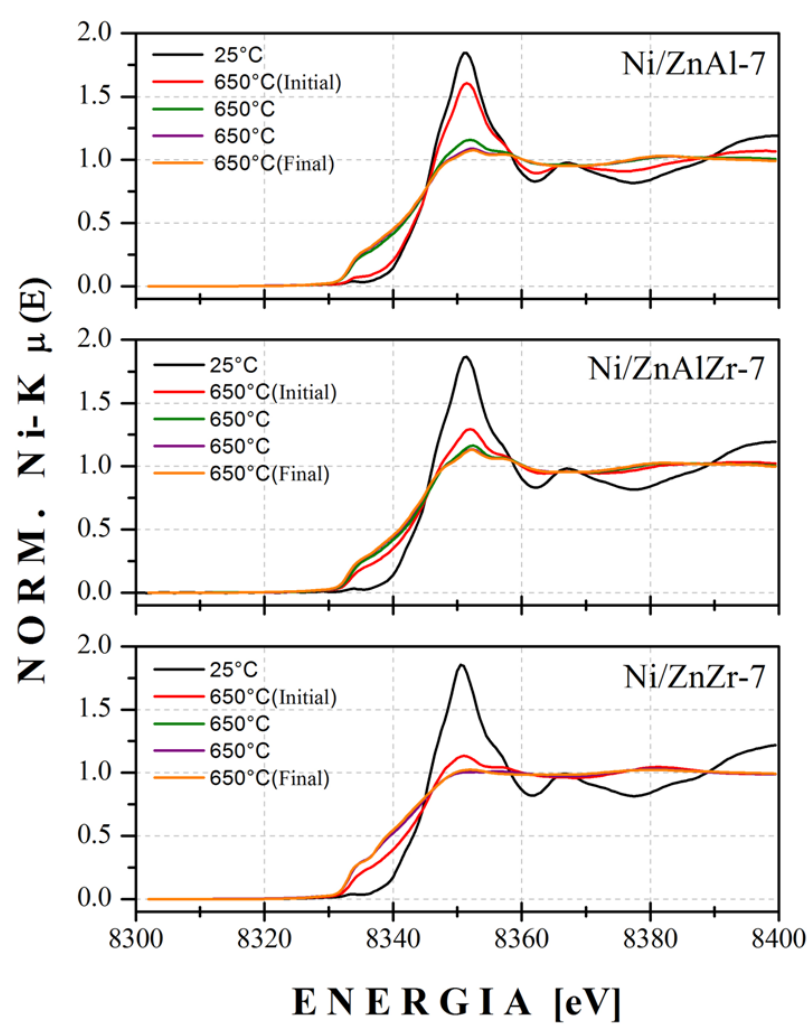

Fonte: Autoria própria.

Figura 4 - Resultados dos testes catalíticos na reação de reforma seca do metano utilizando os catalisadores tratados termicamente $550^{\circ} \mathrm{C}, 650^{\circ} \mathrm{C}$ e $750^{\circ} \mathrm{C}$.

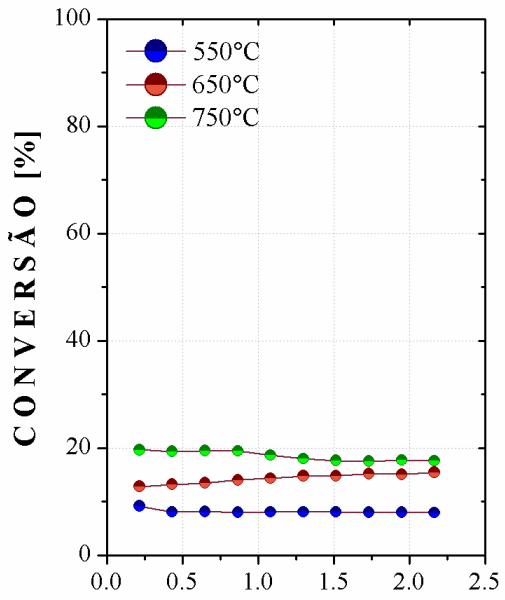

T E M P O D E REAÇÃ O [h]

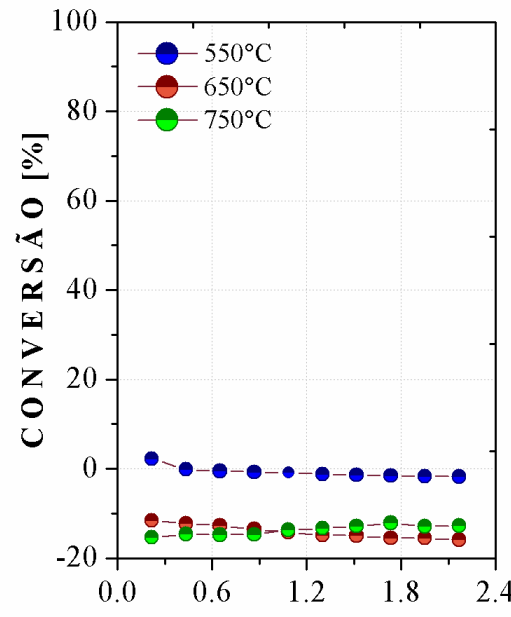

T E MP O D E RE A Ç Ã O [h]

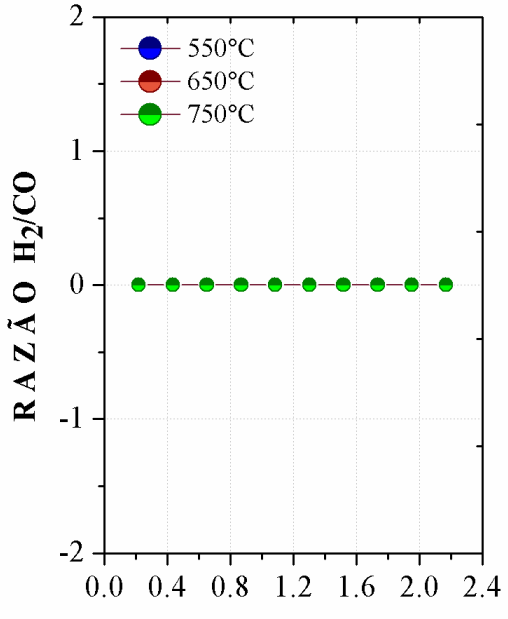

T EMPO DE REAÇ̃̃ O [h]

Fonte: Autoria própria. 
Figura 5- Espectros de transmitância na região do infravermelho para os catalisadores a tratados a $550^{\circ} \mathrm{C}$ por 15 h. (a) Catalisadores a $550{ }^{\circ} \mathrm{C}$, (b) $650{ }^{\circ} \mathrm{C}$ e (C) $750{ }^{\circ} \mathrm{C}$. O número abaixo de cada banda indica a posição desta em unidades de número de onda $\left(\mathrm{cm}^{-1}\right)$

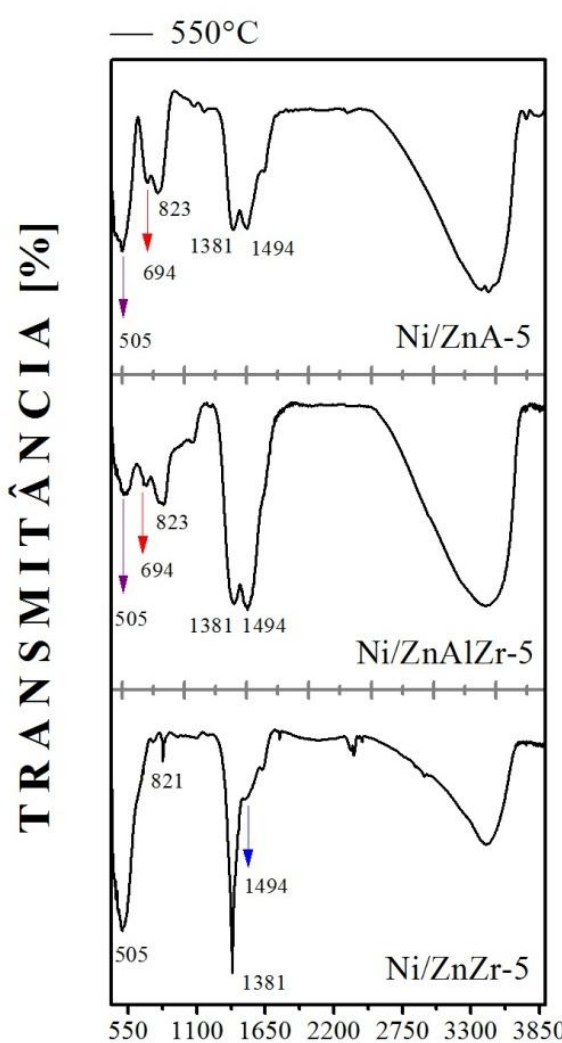

$\begin{array}{lllllllll}550 & 1100 & 1650 & 2200 & 2750 & 3300 & 3850\end{array}$

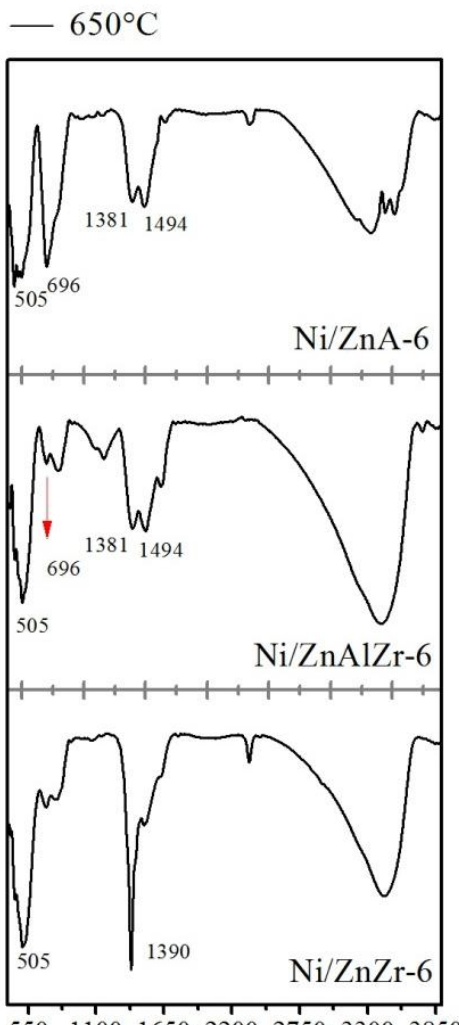

$\begin{array}{lllllllllll}550 & 1100 & 1650 & 2200 & 2750 & 3300 & 3850\end{array}$ $-750^{\circ} \mathrm{C}$

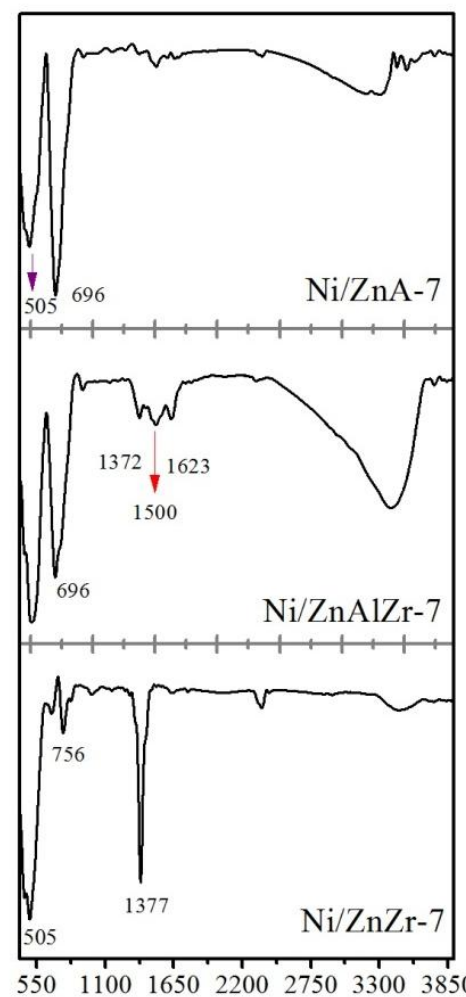

$-1$

Fonte: Autoria própria. 


\section{APÊNDICE B - Cálculos}

Cálculo para determinar o valor de n presente na fórmula molecular das hidrotalcitas.

Considerando a fórmula molecular temos:

$$
\left[\mathrm{M}_{1-x}^{2+} \mathbf{M}_{x}^{3+}(\mathrm{OH})_{2}\right]\left[A^{-m}\right]_{x / m} . n H_{2} \mathrm{O}
$$

Onde n é o número de moléculas de água de hidratação na fórmula molecular.

$$
\begin{aligned}
& {[H T]_{i}=([B]+(O H)) N=\langle H T\rangle N} \\
& {[H T]_{f}-[H T]_{i}=N(O H)=N \times \Delta_{m i f}(\mathrm{~g} / \mathrm{mol})} \\
& \frac{N \times(O H)}{N \times\langle H T\rangle_{i}}=\frac{N \times \Delta_{\text {mif }}(\mathrm{g} / \mathrm{mol})}{N \times\langle H T\rangle_{i}}=\Delta_{\text {mif }}(\%) \\
& \frac{(\mathrm{OH})}{[B]+(\mathrm{OH})}=\Delta_{\text {mif }}(\%)
\end{aligned}
$$

, onde $\mathrm{OH}=n \mathrm{H}_{2} \mathrm{O}$

$$
\begin{aligned}
& \Delta_{m i f}(\%)\left([B]+n H_{2} O\right)=n H_{2} O \\
& {[B] \Delta_{m i f}(\%)=n H_{2} \mathrm{O}-n H_{2} O \times \Delta_{m i f}(\%)} \\
& {[B] \Delta_{m i f}(\%)=n H_{2} O\left(1-\Delta_{m i f}(\%)\right)} \\
& n=\frac{[B]}{H_{2} O} \times \frac{\Delta_{m i f}(\%)}{1-\Delta_{m i f}(\%)}
\end{aligned}
$$




\section{$\checkmark \quad$ Cálculo para determinar o erro da basicidade}

Para determinar a basicidade é necessário somente a massa pesada da amostra e número de mols do titulante.

$$
\mathrm{B}=\frac{\mathrm{C} \times \mathrm{V}}{\mathrm{m}_{\mathrm{a}}}
$$

Considerando que o volume e a massa vai depender da média e desvio padrão, logo teremos:

$$
v=\langle v\rangle+\delta v
$$

e

$$
m=\left\langle m_{a}\right\rangle+\delta m_{a}
$$

Fazendo a substituição de fórmula temos:

$$
b=\frac{d}{M_{t}\left\langle m_{a}\right\rangle} \frac{\langle v\rangle+\delta v}{1+\frac{\delta m_{a}}{\left\langle m_{a}\right\rangle}}
$$

Logo podemos escrever da seguinte forma:

$$
\begin{aligned}
& b=\frac{d}{M_{t}\left\langle m_{a}\right\rangle} \frac{\langle v\rangle+\delta v}{1+\frac{\delta m_{a}}{\left\langle m_{a}\right\rangle}} \\
& b=\frac{d}{M_{t}\left\langle m_{a}\right\rangle}\left[(\langle v\rangle+\delta v)\left(1-\frac{\delta m_{a}}{\left\langle m_{a}\right\rangle}\right)\right] \\
& b=\frac{d}{M_{t}\left\langle m_{a}\right\rangle}\left(\langle v\rangle-\frac{\langle v\rangle \delta m_{a}}{\left\langle m_{a}\right\rangle}+\delta v-\frac{\delta v \delta m_{a}}{\left\langle m_{a}\right\rangle}\right) \\
& \delta v \delta m_{a} \rightarrow 0(\text { segunda ordem })
\end{aligned}
$$




$$
b=\frac{d\langle v\rangle}{M_{t}\left\langle m_{a}\right\rangle}-\frac{d\langle v\rangle \delta m_{a}}{M_{t}\left\langle m_{a}\right\rangle^{2}}+\frac{d \delta v}{M_{t}\left\langle m_{a}\right\rangle}
$$

Logo teremos:

$$
\mathrm{b}=\langle\mathrm{b}\rangle+\delta \mathrm{b}
$$

